\begin{abstract}
Title of dissertation:

TERRORISM, CIVIL WAR, ONE-SIDED VIOLENCE AND GLOBAL BURDEN OF DISEASE

Bradley Townsend Kerridge, Doctor of Philosophy, 2013

Dissertation directed by: $\quad$ Professor Amir Sapkota

Maryland Institute for Applied Environmental Health

Department of Epidemiology and Biostatistics

Professor Maria R. Khan

Department of Epidemiology
\end{abstract}

The purpose of this dissertation was to examine relationships between terrorism, civil war and one-sided violence from 1994-2000 and morbidity and mortality in 2002, as measured by disability-adjusted life years (DALYs), attributable to: (1) major communicable and noncommunicable diseases; (2) diarrheal and related diseases; and (3) substance use disorders among World Health Organization Member States. Multivariable linear regression analyses controlled for economic factors shown to affect public health (Papers 1-3) and pre-existing vulnerability factors: percentage of the population using improved water resources/sanitation facilities (Paper 2); and per capita alcohol consumption and prevalence of illicit drug use (Paper 3). Deaths due to terrorism, war and one-sided violence from 1994-2000 were, with few exceptions, significantly related to DALYs lost to major communicable and noncommunicable diseases, diarrheal and related diseases and substance use disorders in 2002 across the majority of sex-age subgroups of the populace. 
This dissertation research highlighted the need to expand the traditional focus of intervention for communicable diseases among conflict-affected populations to include a variety of noncommunicable diseases (Paper 1). Results underscore the need for international government and nongovernment organizations to prioritize high risk areas for diarrheal and related disease control to include conflict-affected populations with particular attention to young children who are most vulnerable to these diseases (Paper 2). That terrorism and related violence influence diarrheal and related diseases in the longer-term suggests that control strategies should move beyond short-term provisions for safe water and adequate sanitation to seek solutions through health systems infrastructure development. Greater attention should also be given to the prevention and treatment of substance use disorders in conflict-affected populations including brief interventions targeted at high risk substance users, provisions for needles and syringes and management of withdrawal and other acute substance-related conditions (Paper 3).

Strengthening substance abuse treatment systems among conflict-affected populations will be critical in identifying and treating of a variety of physical and psychiatric disorders that are often comorbid with substance use disorders. Taken together, this research has served to highlight the full health costs of terrorism, civil war and one-sided violence will ultimately contribute to forging a stronger rationale for promoting peace. 


\title{
TERRORISM, CIVIL WAR, ONE-SIDED VIOLENCE AND GLOBAL BURDEN OF DISEASE
}

\author{
by
}

Bradley Townsend Kerridge

Dissertation submitted to the Faculty of the Graduate School of the University of Maryland, College Park in partial fulfillment of the requirements for the degree of

Doctor of Philosophy

2013

Advisory Commitee:

Professor Amir Sapkota, Co-Chair

Professor Maria Khan, Co-Chair

Professor Hongjie Liu

Professor Emeritus George Quester

Professor Jürgen Rehm

Professor Deborah Young 
(C) Copyright by

Bradley Townsend Kerridge

2013 


\section{Forward}

The three papers of this dissertation research include Bradley T. Kerridge as first author with Professors Maria Khan and Amir Sapkota as co-authors on three papers and Professor Jürgen Rehm as co-author on two papers. These papers are entitled "Terrorism, Civil War, One-Sided Violence and Global Burden of Disease," "Terrorism, Civil War, One-Sided Violence and Global Burden of Diarrheal and Related Diseases" and "Terrorism, Civil War, One-Sided Violence and Global Burden of Substance Use Disorders." Mr. Kerridge substantially contributed to these three papers by designing and conceptualizing the studies, conducting all statistical analyses, writing the first draft of each paper and serving as corresponding author. Professors Khan, Sapkota and Rehm contributed to refining the conceptualization and providing input to subsequent revisions of each of the papers on which they appear as co-authors. All co-authors and the Chair of the Department of Epidemiology, Dr. Mei-Ling Ting Lee, approved the inclusion of the aforementioned papers in this dissertation. 


\section{Dedication}

I would like to dedicate my dissertation research to my family, who have supported, encouraged and inspired me throughout my graduate scientific career. I would also like to dedicate this dissertation to my wife, Pranisa. Behind many great authors is a cat whose job it is to knock important papers off the table. I therefore thank my cat for her hard work during this dissertation process. I would also like to thank my many mentors who have helped develop my skills as a researcher and exposed me to new methods and ways of thinking about public health. 


\section{Acknowledgements}

Funding for this dissertation work from the National Institutes of Health, National Institute on Drug Abuse, National Research Service Award Individual Predoctoral Fellowship, Number 5F31DA025377, is gratefully acknowledged. The support and encouragement from my Dissertation Committee, including Professors Maria Khan, Amir Sapkota, Jürgen Rehm, Deborah Young, George Quester and Hongjie Liu is also gratefully acknowledged. 


\section{TABLE OF CONTENTS}

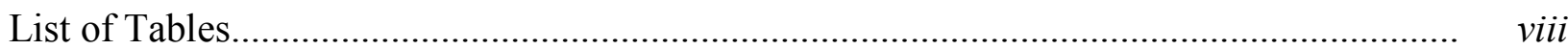

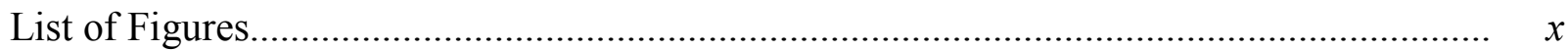

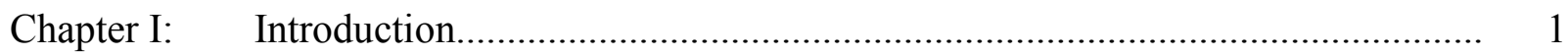

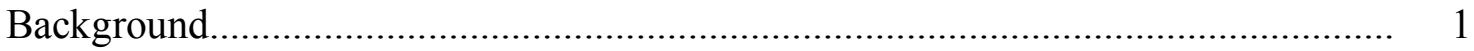

Specific Aims, Theoretical Framework and Hypotheses............................................ 2

Specific Aims....................................................................................... 2

Theoretical Framework............................................................................ 2

Hypotheses....................................................................................... 5

Chapter II: $\quad$ Literature Review............................................................................... 13

Outcome Variables: Disability-Adjusted Life Years................................................. 13

Importance and Definition of Disability-Adjusted Life Years............... 13

Sample Size: WHO Member States............................................................ 23

2002 Global Burden of Disease Study Cause Categories.......................... 24

Major Communicable and Noncommunicable Disease DALYs: Paper 1..... $\quad 24$

Diarrheal and Related Disease DALYs: Paper 2........................................... $\quad 29$

Substance Use Disorder DALYs: Paper 3 ……………………………..... 32

Linking Terrorism, Civil War and One-sided Violence with Morbidity and

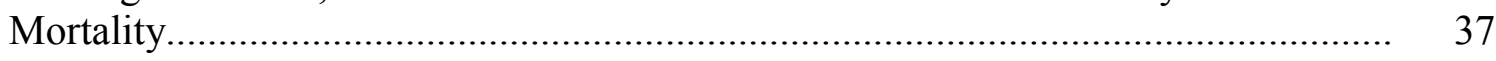

Exposure Variable: Deaths Resulting From Terrorism, Civil War and One-sided Violence.

Deaths Resulting from Terrorist Actions......................................................... 41

Deaths Resulting from Civil War................................................................... 42

Deaths Resulting from One-Sided Violence........................................................ 44 


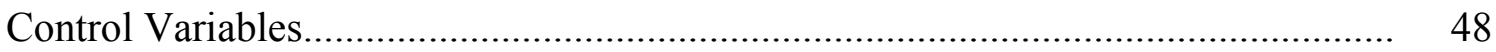

Economic and Related Variables............................................................ 48

Refugees, Asylum Seekers and Displaced Persons............................... $\quad 48$

Number of Deaths, Homeless and Affected by Natural Disasters........... $\quad 54$

General Government Expenditures on Health as Percentage of General Government Expenditure.................................................................... 58

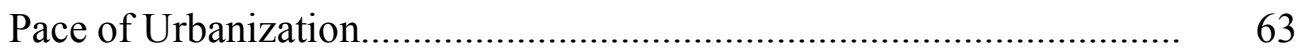

Tropical Country Status.......................................................... $\quad 70$

Ethnic Heterogeneity......................................................................

Life Expectancy at Birth.................................................................. 77

Pre-existing Vulnerability Variables................................................................ $\quad 80$

Unsafe Drinking Water Resources and Inadequate Sanitation Facilities:

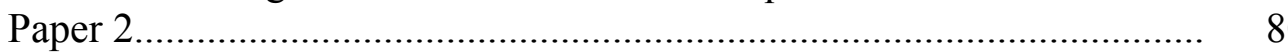

Adult Per Capita Alcohol Consumption: Paper 3 3..................................... 83

Prevalence of Illicit Drug Use: Paper 3.................................................. 84

Chapter III: Paper 1. Terrorism, Civil War, One-Sided Violence and Global Burden of Disease.......................................................................................... 90

Title Page

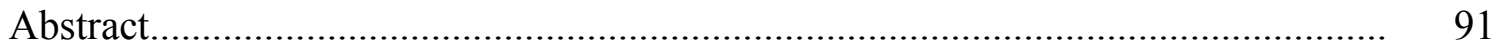

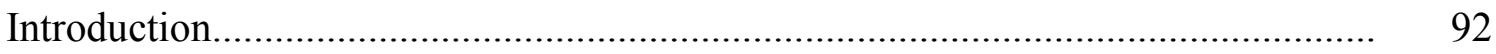

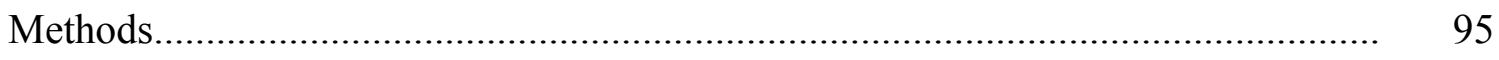

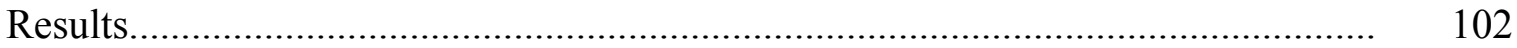

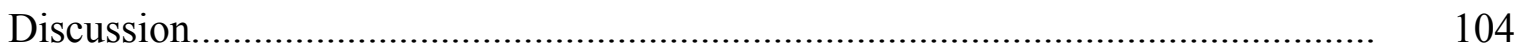

Chapter IV: Paper 2. Terrorism, Civil War, One-Sided Violence and Global Burden of Diarrheal and Related Diseases.................................................................... 112 
Title Page

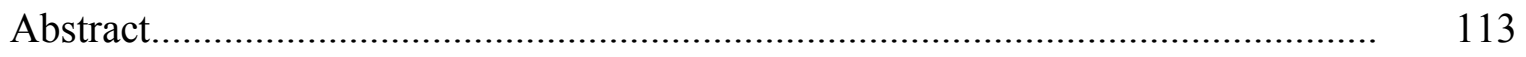

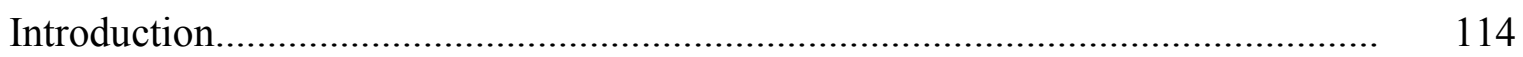

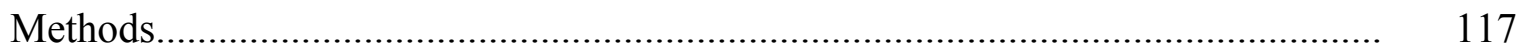

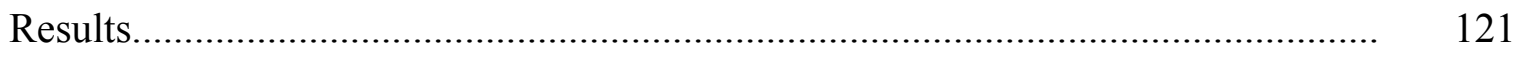

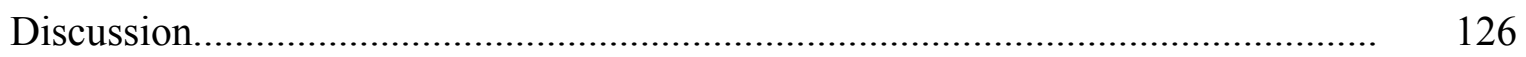

Chapter V: $\quad$ Paper 3. Terrorism, Civil War, One-Sided Violence and Global Burden of Substance Use Disorders............................................................................... 131

Title Page

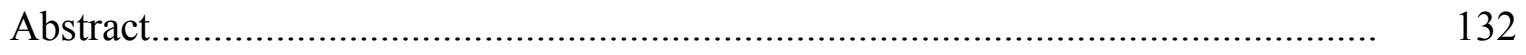

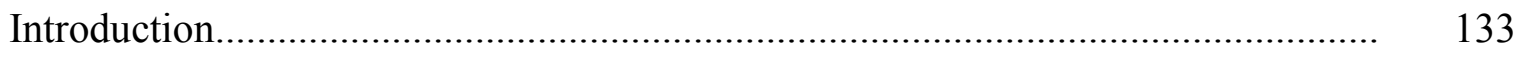

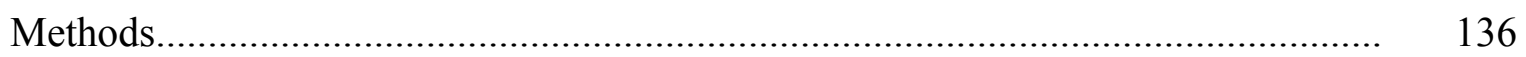

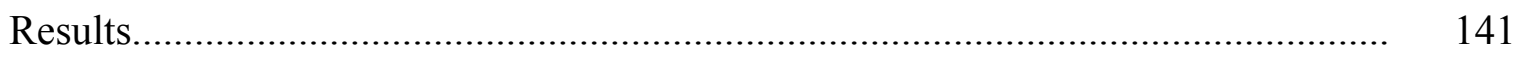

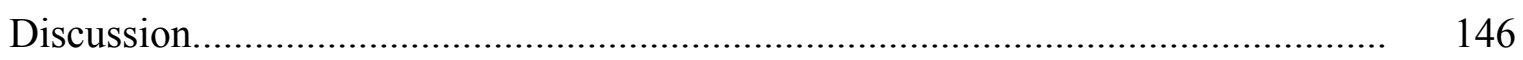

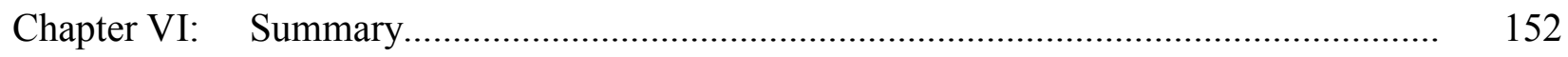

Appendix A: Disability-Adjusted Life Years, 2002: Data Quality........................................ 157

Appendix B: Global Burden of Disease Study, 2002: Cause Categories.................. 164

Appendix C: Methodological Supplement........................................... 169

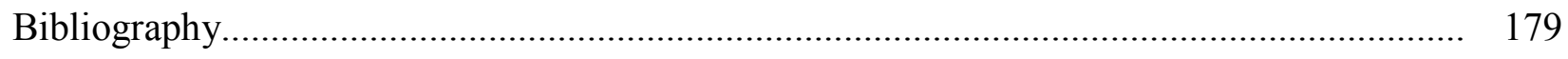




\section{LIST OF TABLES}

Table 1 - World Health Organization Member States by Region, 2002................................ 14

Table 2 - World Health Organization Member States by Subregion and Mortality Stratum, 2002

Table 3 - World Health Organization Residual Micro-States and Non-Member States.......

Table 4 - Nine Leading Causes of Burden of Disease, Global Estimates, 2002

Table 5 - Ten Leading Causes of Burden of Disease by Sex, Global Estimates, 2002...........

Table 6 - Diarrheal and Related Diseases and Attributable Fractions Due to Unsafe Water Resources and Inadequate Sanitation.

Table 7 - Examples of Improved and Unimproved and Drinking Water Resources and Sanitation Facilities.

Table 8 - Multivariable Linear Regression Analysis Between Terrorism, Civil War and One-Sided Violence Deaths from 1994-2000 and All Cause DALYs in 2002 .

Table 9 - Multivariable Linear Regression Analyses Between Terrorism, Civil War and One-Sided Violence Deaths From 1994-2000 and DALYs Attributable to Major Communicable and Noncommunicable Diseases in 2002 by Age Among Males.

Table 10 - Multivariable Linear Regression Analyses Between Terrorism, Civil War and One-Sided Violence Deaths From 1994-2000 and DALYs Attributable to Major Communicable and Noncommunicable Diseases in 2002 by Age Among Females.

Table 11 - Multivariable Linear Regression Analyses Between Terrorism, War and OneSided Violence Deaths From 1994-2000 and DALYs Attributable to Diarrheal and Related Diseases in 2002 by Sex.

Table 12 - Multivariable Linear Regression Analyses Between Terrorism, Civil War and One-Sided Violence Deaths From 1994-2000 and DALYs Attributable to Diarrheal and Related Diseases in 2002 by Age Among Males. 
Table 13 - Multivariable Linear Regression Analyses Between Terrorism, Civil War and

One-Sided Violence Deaths From 1994-2000 and DALYs Attributable to

Diarrheal and Related Diseases in 2002 by Age Among Females.

Table 14 - Multivariable Linear Regression Analyses Between Terrorism, Civil War and One-Sided Violence Deaths From 1994-2000 and DALYs Attributable to Alcohol, Drug and Substance Use Disorders in 2002 by Sex

Table 15 - Multivariable Linear Regression Analyses Between Terrorism, Civil War and One-Sided Violence Deaths From 1994-2000 and DALYs Attributable to Alcohol Use Disorders in 2002 by Sex and Age.

Table 16 - Multivariable Linear Regression Analyses Between Terrorism, Civil War and One-Sided Violence Deaths From 1994-2000 and DALYs Attributable to Drug Use Disorders in 2002 by Sex and Age.

Table 17 - Total Deaths and 95\% Uncertainty Ranges for All Cause Mortality by Region, 2000 (in Thousands)......

Table 18 - Estimates and 95\% Uncertainty Ranges for YLD and DALYs Arising from Uncertainty in Disability Weights for Selected Causes in Low and Middle Income Countries, 2002 (in Thousands)

Table 19 - Additional Descriptive Statistics for Outcome, Exposure and Control Variables. 170

Table 20 - Summary of Stepwise Linear Regression Analysis of Terrorism, Civil War, One-Sided Violence Deaths from 1994-2000 and Diarrheal and Related Disease

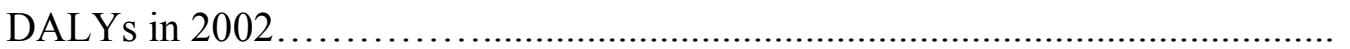

Table 21 - Summary of Poisson Regression Analysis of Terrorism, Civil War and OneSided Violence Deaths from 1994-2000 and All Cause DALY Rates in 2000.... 


\section{LIST OF FIGURES}

Figure 1 - Theoretical Framework: Relationship Between Terrorism, Civil War and OneSided Violence Deaths and Morbidity and Mortality Due to Major

Communicable and Noncommunicable Diseases, Paper 1

Figure 2 - Theoretical Framework: Relationship Between Terrorism, Civil War and OneSided Violence and Morbidity and Mortality Due to Diarrheal and Related Diseases, Paper 2

Figure 3 - Theoretical Framework: Relationship Between Terrorism, Civil War and OneSided Violence and Morbidity and Mortality Due to Substance Use Disorders, Paper 3.

Figure 4 - World Health Organization Regions.

Figure 5 - World Health Organization Regions by Mortality Stratum

Figure 6 - Distribution of Disease Burden by Age Group and Region, 2002.

Figure 7 - Total All Cause DALYs, 2002

Figure 8 - Diarrheal and Related Disease DALYs, 2002.

Figure 9 - Alcohol Use Disorder DALYs, 2002

Figure 10 - Drug Use Disorder DALYs, 2002. 36

Figure 11- Substance Use Disorder DALYs, 2002. 38

Figure 12 - Deaths from Terrorist Actions, 1994-2000.

Figure 13 - Civil War Deaths, 1994-2000.

Figure 14 - One-Sided Violence Deaths, 1994-2000.

Figure 15 - Terrorism, War and One-Sided Violence Deaths, 1994-2000.

Figure 16 - Number of Refugees/Asylum Seekers/Displaced Persons, $1994 .$.

Figure 17 - Deaths/Homeless/Affected by Natural Disasters, 1994-2000.

Figure 18 - Health Expenditures as Percentage of Total Government Expenditure, 1994......

Figure 19 - Percent Change in Urbanization, 1990 to 1995 
Figure 20 - Tropical and Nontropical Countries..........................................................

Figure 21 - Ethnic Heterogeneity Score, 1994-1996............................................... 78

Figure 22 - Life Expectancy at Birth, 1994......................................................... 79

Figure 23 - Improved Drinking Water Resources/Sanitation Facilities, 1994.................... 82

Figure 24 - Per Capital Alcohol Consumption, 1994_................................................ 85

Figure 25 - Annual Prevalence of Drug Use, 1993-1997.............................................. 89 


\section{Chapter I: Introduction}

\section{Background}

Armed conflict has been a major determinant of morbidity and mortality for most of human history (Krug et al., 2002). The nature and scope of armed contest taking place over the years has changed to increasingly include deaths resulting from terrorist actions and one-sided violence such as genocide (Eck and Hultman, 2007; Ericksson et al., 2003; LaFree et al., 2009). The impact of terrorism, civil war and one-sided violence on populations arises both from the immediate (direct) effects of combat (i.e. battle deaths) and from their longer-term (indirect) consequences, namely the breakdown of water, sanitation, agricultural, transportation, health care, safety and regulatory infrastructures which results in lack of shelter, food shortages, depressed economic performance, environmental degradation and heightened risk of disease and premature mortality (Betsi et al., 2006; Colombatti et al., 2009; Dodge, 1990; Guha-Sapir and van Panhuis, 2002a; 2002b; 2003; 2004; Levy and Sidel, 2003; 2007; Sidel and Levy, 2003; 2009). Little data are available about the longer-term effects of terrorism, and related violence on public health and even less is known about their longer-term effects on many specific diseases such as diarrheal and related conditions and substance use disorders (i.e. harmful use and dependence).

Historically, terrorism, war and one-sided violence have not received the attention from public health researchers as have other causes of morbidity and mortality and political scientists have been more interested in the economic and political causes of terrorism, war and one-sided violence than on their impact on public health (Perrin, 1996). This is surprising given that the immediate impact of war and related violence on populations does not begin to account for the longer-term consequences of war resulting from breakdown of the social fabric, lack of shelter, food shortages, depressed economic performance, breakdown of health and human services, 
environmental degradation and the heightened risk of transmission of infectious diseases (Betsi et al., 2006; Colombatti et al., 2009; Dodge, 1990; Guha-Sapir and van Panhuis, 2002; Levy and Sidel; 2003; 2007). The ratio of the longer-term consequences of terrorism and related violence to their direct effects has been reported to be 9:1 (Murray et al., 2002 Sidel and Levy, 2003; 2009). Accordingly, this dissertation research is premised on the conceptualization that terrorism, war and one-sided violence adversely affect morbidity and mortality long after the fighting and bombings are over and that health costs of such violence extend into the postconflict period.

\section{Specific Aims, Theoretical Framework and Hypotheses}

\section{Specific Aims}

The specific aims of this dissertation research are to examine the influence of one exposure variable, combined deaths due to terrorism, civil war and one-sided violence from 1994-2000 on morbidity and mortality attributable to: (1) major communicable and noncommunicable diseases (Paper 1); (2) diarrheal and related diseases (Paper 2); and substance use disorders (Paper 3) in 2002, as measured by disability-adjusted life years (DALYs) among WHO Member States. Analyses control for economic and related factors (Papers 1-3) and disease-specific vulnerability factors (Papers 2 and 3).

\section{Theoretical Framework}

The theoretical framework underlying this research is drawn from a general model used to study factors affecting public health. Several theoretically postulated mechanisms link terrorism, civil war and one-sided violence to increased population exposure to morbidity and mortality attributable to: (1) major communicable and noncommunicable diseases; (2) diarrheal and related diseases; and (3) substance use disorders. These mechanisms can be summarized as: (1) damages to economic and health infrastructures; (2) demographic impacts; (3) economic 
impacts; and (4) psychological reactions. Taken together, these mechanisms, in turn, lead to exposure of the population to conditions that increase risk of death, disease and disability.

First, conflict damages economic and health infrastructures vital to prevention of morbidity and premature mortality (Betsi et al., 2006; Colombatti et al., 2009; Dodge, 1990; Levy and Sidel, 2003; 2007; World Health Organization, 2002c; 2006b). Water and sanitation systems are also frequently damaged as a result of terrorism, war and one-sided violence and that damage has both direct and longer-term adverse effects on health. Agricultural systems are also impacted, resulting in food shortages (de Jong et al., 2007; Payne, 1998). Terrorism, war and one-sided violence adversely impact health care services in the longer-term through damage to infrastructure (i.e. damage to water supplies, electricity and sewage disposal necessary for health services to operate) coupled with injury, death and disappearance of health care workers (Gayer et al., 2007; Hansch and Burkholder, 1996). Damage to the infrastructure exerts a lingering effect on morbidity and mortality because such damage is expensive and time consuming to repair (Doocy and Burnham, 2006). Destruction of water and sanitation infrastructure also results in increased infectious disease transmission that leads to increased disability and shortened life expectancy.

Second, other longer-term consequences of terrorism, civil war and one-sided violence on public health are demographic, that is, the displacement and forced resettlement of large numbers of persons resulting in reduced access to health resources, food, and safe water and sanitation (Asgary and Segar, 2011; Atuyambe et al., 2011; Shultz et al., 2009).

Third, the longer-term economic impacts of terrorism, war and one-sided violence can be profound, including decreased public expenditures on education, transportation, agriculture as well as health sectors (Guha-Sapir et al., 2002a; 2002b; Perrin, 1996; WHO, 2006b). 
Lastly, terrorism, war and one-sided violence result in psychological reactions, including stress, fear, depression, helplessness, and impairment in daily functioning, that serve to increase morbidity and mortality from a number of mental illnesses (Krippner and McIntyre, 2003). Armed conflict around the world has been increasingly characterized by terrorist actions and one-sided violence (e.g., genocide), and, unlike war, these actions are targeted toward civilians and not combatants on the battlefield (Levy and Sidel, 2003; Mueller, 2009). The aims of terrorists and governments perpetrating one-sided violence are to coerce, intimidate, and convey their message to a larger audience beyond their immediate victims, impacting many more persons far removed from where the terrorist acts and associated violence occurred. These actions have a strong effect on public health through longer-term and widespread anxiety, fear, panic, helplessness, hopelessness, demoralization, depression and disrupted sleep (Bonger et al., 2007; DiMaggio and Galea, 2006; Dudley, 2005; Krippner and McIntyre, 2003; Stout, 2002; Van der Kolk et al., 1996; Whalley, 2007). All of these effects, in turn, weaken assumptions about personal security, highlighting the inability of authorities to protect their citizens and their environment (Iqbal, 2006).

The extreme stress resulting from terrorism, war and one-sided violence also substantially contributes to the development of an array of physical as well as mental illnesses (Holman et al., 2008; Qureshi et al., 2003; Schnurr and Green, 2004). Research in this area underscores the need to recognize: (1) physical health along with mental health problems as longer-term outcomes of terrorist actions and related violence; (2) that the strain on the body produced by persistent chronic stress reactions alters metabolism and triggers physiological changes that eventually manifest in damage to a number of organs and tissues (the so-called allostatic load); and (3) the persistent physiological and psychological responses associated with 
acute and chronic stress exposure trigger processes through which terrorism, war and one-sided violence affects public health.

The theoretical frameworks underlying Papers 1-3 of this dissertation are shown in Figures 1-3.

\section{Hypotheses}

Paper 1. It is hypothesized that increasing numbers of deaths due to terrorism, civil war and one-sided violence from 1994-2000 will be associated with increasing levels of morbidity and mortality due to major communicable and noncommunicable diseases in 2002 , as measured by DALYs. This relationship will be examined using multivariable linear regression analyses in the total sample and among subgroups of the population defined by sex and age. Analyses will also control for important economic factors that may be correlated with levels of terrorism, civil war and one-sided violence and that have been linked to a variety of communicable and noncommunicable diseases. The statistical model associated with Paper 1 can be expressed as follows (some variables were transformed using natural logarithms as a result of skew):

DALYs due to a specific communicable or noncommunicable disease $=\beta_{0}+\beta_{1} \log$ (terrorism, war and one-sided violence deaths) $+\beta_{2}$ (ethnic heterogeneity) $+\beta_{3}$ (health expenditures $)+\beta_{4} \log$ (number affected by natural disasters) $+\beta_{5} \log$ (number of refugees/asylum seekers/displaced) $+\beta_{6}$ (pace of urbanization) $+\beta_{7}$ (life expectancy at birth) $+\mathrm{C}$

For models in which infectious and parasitic disease DALYs serve as outcome variables, tropical country status will also be controlled.

Paper 2. It is hypothesized that increasing numbers of deaths due to terrorism, civil war and one-sided violence from 1994-2000 will be associated with increasing levels of morbidity and mortality due to diarrheal and related diseases in 2002, as measured by DALYs. This 
Figure 1: Theoretical Framework: Relationship between Terrorism, Civil War and One-Sided Violence and Morbidity and Mortality Due to Major Communicable and Noncommunicable Diseases, Paper 1

Independent Variables

\section{Exposure Variable}

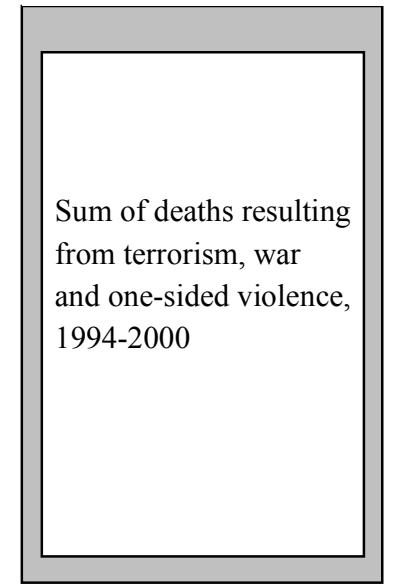

\section{Economic and Related Control Variables}

\begin{tabular}{|c|c|}
\hline Ethnic heterogeneity, 1994- & \multirow{3}{*}{$\begin{array}{l}\text { Tropical country status for } \\
\text { communicable diseases } \\
\text { only }\end{array}$} \\
\hline & \\
\hline $\begin{array}{l}\text { Government health } \\
\text { exnenditures as }\end{array}$ & \\
\hline $\begin{array}{l}\text { government expenditure, } \\
1994\end{array}$ & \multirow{2}{*}{$\begin{array}{l}\text { Number of } \\
\text { deaths/homeless/affected } \\
\text { by natural disasters, 1994- } \\
2000\end{array}$} \\
\hline $\begin{array}{l}\text { Life expectancy at birth, } \\
1994\end{array}$ & \\
\hline $\begin{array}{l}\text { Number of refugees/ } \\
\text { asylum seekers/displaced } \\
\text { persons, } 1994\end{array}$ & $\begin{array}{l}\text { Pace of urbanization, } 1990 \\
\text { to } 1995\end{array}$ \\
\hline
\end{tabular}

Theoretically Postulated Dependent Variables $\underline{\text { Mechanisms }}$

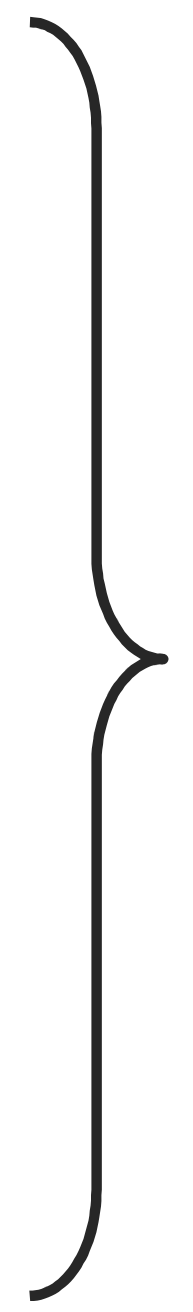

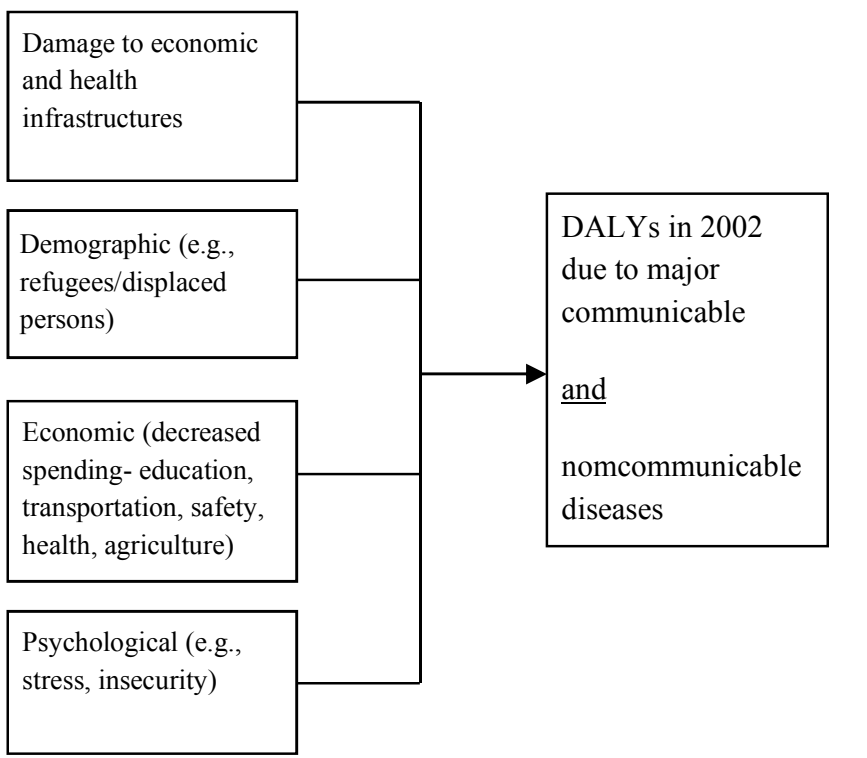

Damage to economic

and health

infrastructures

Demographic (e.g.

persons)

Economic (decrease

spending- education,

transportation, safety,

ealth, agriculture)

DALYs in 2002

due to majo

communicable

$\underline{\text { and }}$

omcommunicable

diseases refugees/displaced 
Figure 2: Theoretical Framework: Relationship between Terrorism, Civil War and One-Sided Violence and Morbidity and Mortality Due to Diarrheal and Related Diseases, Paper 2

\section{$\underline{\text { Independent Variables }}$}

\section{Exposure Variable}

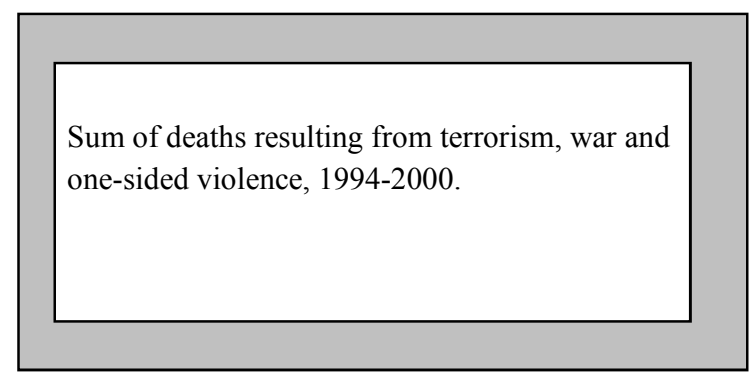

\section{Theoretically Postulated Dependent Variable Mechanisms}

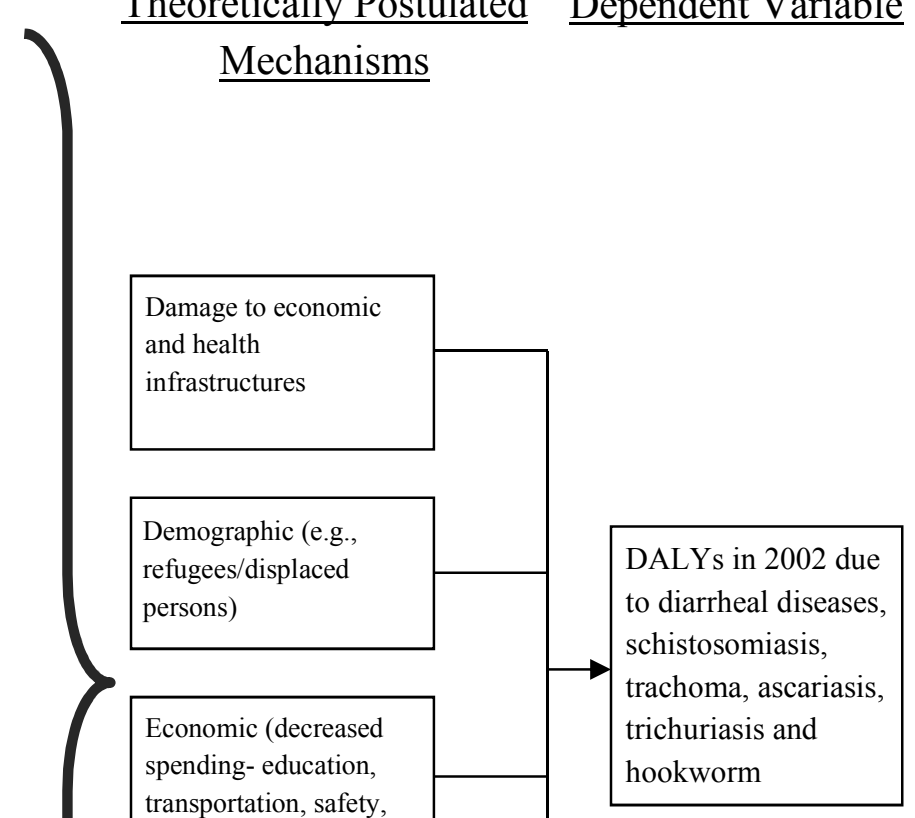

Percentage of population with

improved water resources/sanitation

facilities, 1994

Disease-Specific

Pace of urbanization,

Life expectancy at

Vulnerability Control

Variable

Government health expenditures as $\%$ of

total government

Number of

expenditure, 1994

Tropical Country Status

Ethnic heterogeneity,

$1994-1996$

affected by natural

disasters, 1994-2000

Number of

refugees/asylum-

seekers/displaced

persons, 1994 to diarrheal diseases,

omiasis,

trichuriasis and

transportation, safety,

health, agriculture)

Psychological (e.g.,

stress, insecurity) hookworm 
Figure 3: Theoretical Framework: Relationship between Terrorism, Civil War and One-Sided Violence and Morbidity and Mortality Due to Substance Use Disorders, Paper 3

$\underline{\text { Independent Variables }}$

\section{Exposure Variable}

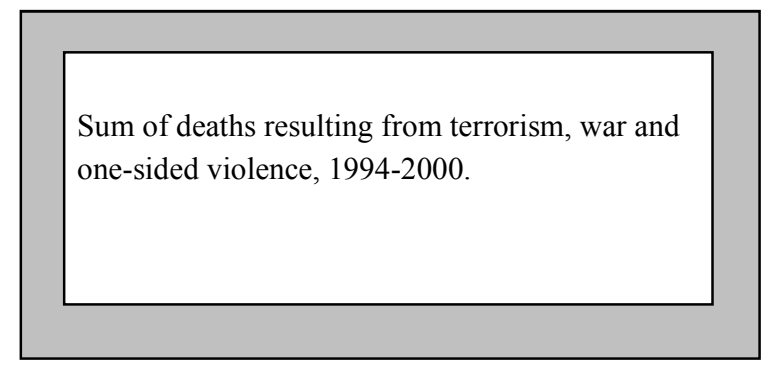

$\infty$

\section{Economic and Related Control Variables}

\begin{tabular}{|c|c|}
\hline $\begin{array}{l}\text { Pace of urbanization } \\
1990-1995\end{array}$ & $\begin{array}{l}\text { Life expectancy at } \\
\text { birth, } 1994\end{array}$ \\
\hline \multirow{3}{*}{$\begin{array}{l}\text { Government health } \\
\text { expenditures as \% of } \\
\text { total government } \\
\text { expenditure, } 1994\end{array}$} & Number of \\
\hline & $\begin{array}{l}\text { deaths/homeless/ } \\
\text { affected by natural } \\
\text { disasters, 1994-2000 }\end{array}$ \\
\hline & Number of \\
\hline $\begin{array}{l}\text { Ethnic heterogeneity, } \\
\text { 1994-1996 }\end{array}$ & $\begin{array}{l}\text { refugees/asylum- } \\
\text { seekers/displaced } \\
\text { persons, } 1994\end{array}$ \\
\hline
\end{tabular}

Disease-Specific Vulnerability Control Variables

Prevalence of illicit drug use, 19931997

Per capita adult alcohol consumption (liters), 1994
DALYs in 2002 due to alcohol and/or

drug dependence and harmful use

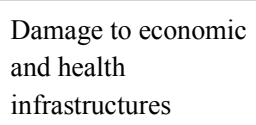

Demographic (e.g., refugees/displaced

persons)

Economic (decreased spending- education, transportation, safety,

health, agriculture)

Psychological (e.g., stress, insecurity)
Dependent Variables 
relationship will be examined using multivariable linear regression analyses in the total sample, and among subgroups of the population defined by sex and age.

Analyses will also control for economic and related factors and disease-specific preexisting vulnerability factors (i.e. unsafe water resources inadequate sanitation facilities) that may be associated with terrorism, war and one-sided violence and that have been linked to morbidity and mortality attributable to diarrheal and related diseases. The statistical model associated with Paper 2 can be expressed as follows:

DALYs due to diarrheal and related diseases $=\beta_{0}+\beta_{1} \log$ (terrorism, war and one-sided violence deaths) $+\beta_{2}$ (ethnic heterogeneity) $+\beta_{3}$ (health expenditures) $+\beta_{4} \log$ (number affected by natural disasters) $+\beta_{5} \log$ (number of refugees/asylum seekers/displaced) $+\beta_{6}$ (pace of urbanization $)+\beta_{7}$ (access to improved water/sanitation $)+\beta_{8}($ tropical climate $)+$ $\epsilon$

Life expectancy at birth was not included in these models because of its high correlation $(r>0.84)$ with improved water resources and sanitation facilities.

Paper 3. It is hypothesized that increasing numbers of deaths due to terrorism, civil war and one-sided violence from 1994-2000, will be associated with increasing levels of morbidity and mortality due to substance use disorders in 2002, as measured by DALYs. This relationship will be examined using multivariable linear regression analyses in the total sample and among subgroups of the population defined by sex and age. Analyses will also control for economic and related factors and pre-existing vulnerability factors (i.e. adult per capita alcohol consumption and prevalence of illicit drug use) that may be associated with terrorism, war and one-sided violence and that have been linked to morbidity and mortality attributable to substance use disorders. 
Analyses will also control for economic and related factors and disease-specific preexisting vulnerability factors (i.e. unsafe water resources/inadequate sanitation facilities) that may be associated with terrorism, war and one-sided violence and that have been linked to morbidity and mortality attributable to diarrheal and related diseases. The statistical model associated with Paper 2 can be expressed as follows:

DALYs due to diarrheal and related diseases $=\beta_{0}+\beta_{1} \log$ (terrorism, war and one-sided violence deaths $)+\beta_{2}$ (ethnic heterogeneity) $+\beta_{3}$ (health expenditures) $+\beta_{4} \log$ (number affected by natural disasters) $+\beta_{5} \log$ (number of refugees/asylum seekers/displaced $)+\beta_{6}$ (pace of urbanization $)+\beta_{7}$ (access to improved water/sanitation $)+\beta_{8}($ tropical climate $)+$ $\epsilon$

Life expectancy at birth was not included in these models because of its high correlation $(r>0.84)$ with improved water resources and sanitation facilities).

Paper 3. It is hypothesized that increasing numbers of deaths due to terrorism, civil war and one-sided violence from 1994-2000, will be associated with increasing levels of morbidity and mortality due to substance use disorders in 2002, as measured by DALYs. This relationship will be examined using multivariable linear regression analyses in the total sample and among subgroups of the population defined by sex and age. Analyses will also control for economic and related factors and pre-existing vulnerability factors (i.e. adult per capita alcohol consumption and prevalence of illicit drug use) that may be associated with terrorism, war and one-sided violence and that have been linked to morbidity and mortality attributable to substance use disorders. The statistical model associated with Paper 3 can be expressed as follows:

DALYs due to substance use disorders $=\beta_{0}+\beta_{1} \log$ (terrorism, war and one-sided violence deaths $)+\beta_{2}$ (ethnic heterogeneity) $+\beta_{3}$ (health expenditures) $+\beta_{4} \log$ (number affected by natural disasters $)+\beta_{5} \log ($ number of refugees/asylum seekers/displaced $)+\beta_{6}$ (pace of 
urbanization $)+\beta_{7}($ life expectancy at birth $)+\beta_{8}($ per capita alcohol consumption $)+\beta_{9} \log$ (prevalence of illicit drug use) $+€$

For analyses in which alcohol use disorder DALYs served as outcome measures, adult per capita consumption, and not prevalence if illicit drug use, served as a control variable. Similarly, for those analyses in which drug use disorder DALYs served as outcome variables, prevalence of illicit drug use, and not per capita alcohol consumption, served as a control variable.

While the primary focus of this research is on terrorism, civil war and one-sided violence as the exposure variable, economic and related factors that have been empirically shown to affect cross-national variation in morbidity and mortality need to be controlled in all three papers. These include general health expenditures as a percentage of total government expenditure, pace of urbanization, life expectancy at birth (Papers 1 and 3), ethnic/linguistic/religious heterogeneity, number refugees/ asylum seekers/internally displaced persons within a country, and the number of deaths/homeless/affected by natural disasters. For Paper 2, two additional covariates, unsafe water resources and inadequate sanitation facilities and tropical country status, will be included. Tropical country status will also be controlled in those analyses in which infectious diseases serve as outcome measures in Paper 1. For Paper 3, two additional covariates will be included: adult per capita alcohol consumption and annual prevalence of illicit drug use.

Results from this study can be used by peace building missions, national governments and non-governmental agencies to suggest interventions to protect conflict-affected populations from the disease consequences of terrorism, war and related violence and to establish priorities in rebuilding public health care systems and infrastructure (Banatvala and Zwi, 2000; Doocy and Burnham, 2006). Understanding the nature and magnitude of morbidity and mortality in conflict- 
affected populations is critical to addressing the public health needs of these populations necessary to enhance social capital, promote human development and reduce pain and suffering worldwide. Understanding the deleterious longer-term impact of terrorism, war and one-sided violence on population health will also help underscore the hidden costs of conflict that may ultimately inform decisions not to use force. 


\section{Chapter II: Literature Review}

\section{Outcome Variables: Disability-Adjusted Life Years}

\section{Importance and Definition of Disability-Adjusted Life Years}

The outcome variables in this dissertation research are DALYs attributable to major communicable and noncommunicable diseases and conditions among the 192 WHO Member States in 2002 , by sex and age $(0-4,5-14,15-44,45-59,60+)$. WHO Member States are shown in Table 1 and Figure 4 by region and in Table 2 and Figure 5 by subregion and mortality stratum. Table 3 lists WHO residual Micro-States along with WHO Non-Member States.

A DALY is an indicator that combines information on morbidity and mortality. This summary measure was first used in the 1990 Global Burden of Disease (GBD) Study conducted by the WHO and the World Bank (Murray and Lopez, 1996a). The significance of combining the proportionate burden of disease attributable to health conditions and causes of mortality at the global population level cannot be overstated. The DALY methodology offered a distinct advantage over using mortality statistics alone to express global disease burden as these statistics substantially underestimate burden due to nonfatal disorders such as many noncommunicable and chronic diseases and conditions.

One DALY can be viewed as one lost year of life. The DALY is calculated as the sum of years of life lost (YLL) due to premature mortality and years of productive life lost due to disability (YLD) in a population.

\section{DALY $=$ YLL + YLD}


Table 1. World Health Organization Member States by Region, 2002

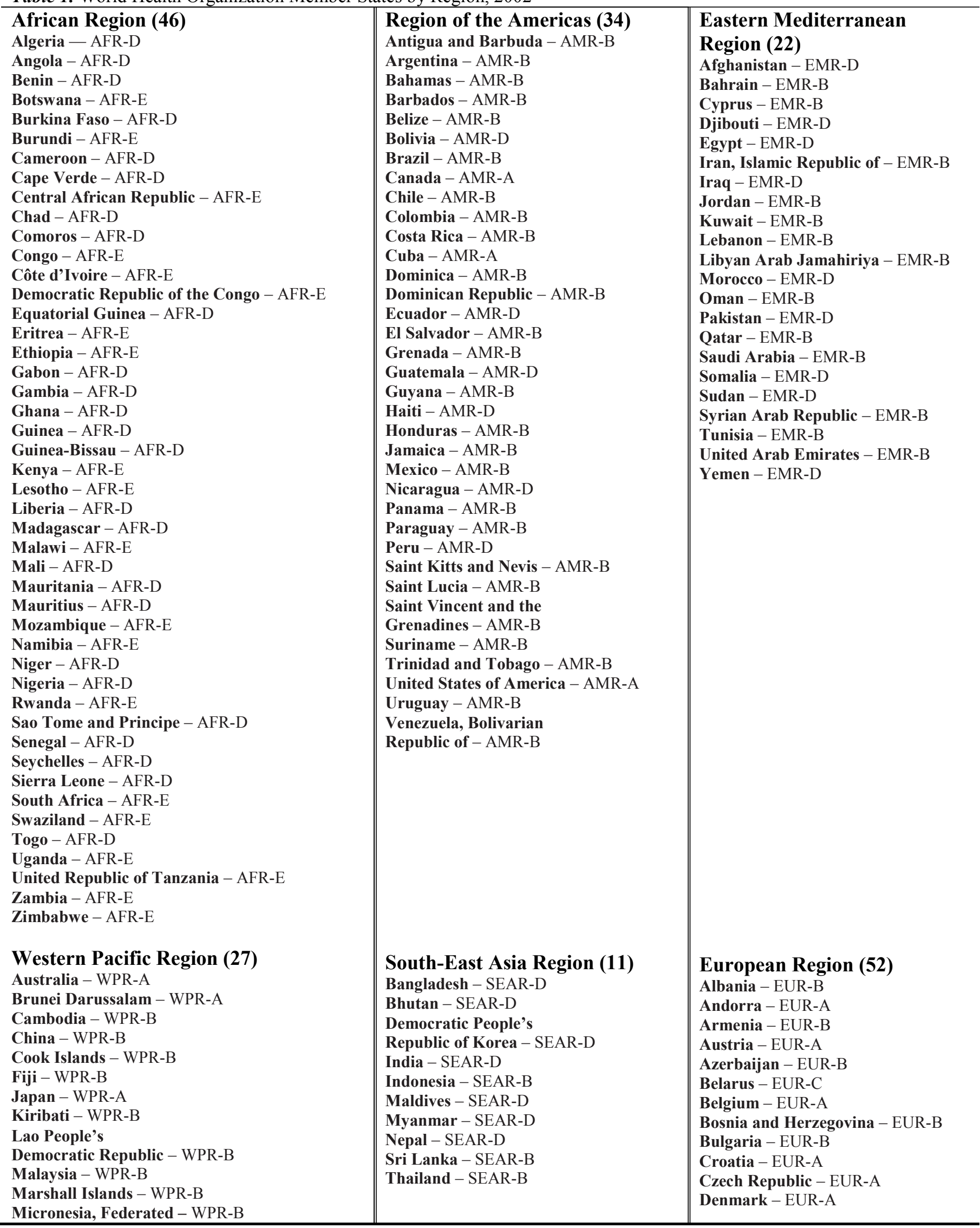




\begin{tabular}{|c|c|}
\hline $\begin{array}{l}\text { States of - WPR-B } \\
\text { Mongolia - WPR-B } \\
\text { Nauru - WPR-B } \\
\text { New Zealand - WPR-A } \\
\text { Niue - WPR-B } \\
\text { Palau - WPR-B } \\
\text { Papua New Guinea - WPR-B } \\
\text { Philippines - WPR-B } \\
\text { Republic of Korea - WPR-B } \\
\text { Samoa - WPR-B } \\
\text { Singapore - WPR-A } \\
\text { Solomon Islands - WPR-B } \\
\text { Tonga - WPR-B } \\
\text { Tuvalu - WPR-B } \\
\text { Vanuatu - WPR-B } \\
\text { Viet Nam - WPR-B }\end{array}$ & $\begin{array}{l}\text { Estonia - EUR-C } \\
\text { Finland - EUR-A } \\
\text { France - EUR-A } \\
\text { Georgia - EUR-B } \\
\text { Germany - EUR-A } \\
\text { Greece - EUR-A } \\
\text { Hungary - EUR-C } \\
\text { Iceland - EUR-A } \\
\text { Ireland - EUR-A } \\
\text { Israel - EUR-A } \\
\text { Italy - EUR-A } \\
\text { Kazakhstan - EUR-C } \\
\text { Kyrgyzstan - EUR-B } \\
\text { Latvia - EUR-C } \\
\text { Lithuania - EUR-C } \\
\text { Luxembourg - EUR-A } \\
\text { Malta - EUR-A } \\
\text { Monaco - EUR-A } \\
\text { Netherlands - EUR-A } \\
\text { Norway - EUR-A } \\
\text { Poland - EUR-B } \\
\text { Portugal - EUR-A } \\
\text { Republic of Moldova - EUR-C } \\
\text { Romania - EUR-B } \\
\text { Russian Federation - EUR-C } \\
\text { San Marino - EUR-A } \\
\text { Serbia and Montenegro - EUR-B } \\
\text { Slovakia - EUR-B } \\
\text { Slovenia - EUR-A } \\
\text { Spain - EUR-A } \\
\text { Sweden - EUR-A } \\
\text { Switzerland - EUR-A } \\
\text { Tajikistan - EUR-B } \\
\text { The Former Yugoslav } \\
\text { Republic of Macedonia - EUR-B } \\
\text { Turkey - EUR-B } \\
\text { Turkmenistan - EUR-B } \\
\text { Ukraine - EUR-C } \\
\text { United Kingdom - EUR-A } \\
\text { Uzbekistan - EUR-B } \\
\text { Yugoslavia - EUR-B }\end{array}$ \\
\hline
\end{tabular}


Table 2. World Health Organization Member States by Subregion and Mortality Stratum, 2002.

\begin{tabular}{|c|c|c|c|}
\hline $\begin{array}{c}\text { Subregion and } \\
\text { Mortality Stratum }\end{array}$ & Description & Broad Grouping & Member States \\
\hline \multicolumn{4}{|l|}{ African } \\
\hline AFR-D & $\begin{array}{l}\text { Africa with high child and } \\
\text { high adult mortality }\end{array}$ & $\begin{array}{l}\text { High-mortality } \\
\text { developing }\end{array}$ & $\begin{array}{l}\text { Algeria, Angola, Benin, Burkina Faso, Cameroon, } \\
\text { Cape Verde, Chad, Comoros, Equatorial Guinea, } \\
\text { Gabon, Ghana, Guinea, Guinea-Bissau, Liberia, } \\
\text { Madagascar, Mali, Mauritania,Mauritalius, Niger, } \\
\text { Nigeria, Sao Tome and Principe, Senegal, Seychelles, } \\
\text { Sierra Leone, Togo }\end{array}$ \\
\hline AFR-E & $\begin{array}{l}\text { Africa with high child and } \\
\text { very high adult mortality }\end{array}$ & $\begin{array}{l}\text { High mortality } \\
\text { developing }\end{array}$ & $\begin{array}{l}\text { Botswana, Burundi, Central African Republic, Congo, } \\
\text { Cote d'Ivoire, Democratic Republic of the Cong, } \\
\text { Eritrea, Ethiopia, Kenya, Lesotho, Malawi, } \\
\text { Mozambique, Namibia, Rwanda, South Africa, } \\
\text { Swaziland, Uganda, United Republic of Tanzania, } \\
\text { Zambia, Zimbabwe }\end{array}$ \\
\hline
\end{tabular}

\section{Americas}

\begin{tabular}{|c|c|c|c|}
\hline AMR-A & $\begin{array}{l}\text { Americas with very low } \\
\text { child and very low adult } \\
\text { mortality }\end{array}$ & Developed & Canada, Cuba, United States of America \\
\hline AMR-B & $\begin{array}{l}\text { Americas with low child } \\
\text { and low adult mortality }\end{array}$ & $\begin{array}{l}\text { Low-mortality } \\
\text { developing }\end{array}$ & $\begin{array}{l}\text { Antigua and Barbuda, Argentina, Bahamas, Barbados, } \\
\text { Belize, Brazil, Chile, Colombia, Costa Rica, Dominica, } \\
\text { Dominican Republic, El Salvador, Grenada, Guyana, } \\
\text { Honduras, Jamaica, Mexico, Panama, Paraguay, Saint } \\
\text { Kitts and Nevis, Saint Lucia, Saint Vincent and the } \\
\text { Grenadines, Suriname, Trinidad and Tobago, Uruguay, } \\
\text { Venezuela }\end{array}$ \\
\hline AMR-D & $\begin{array}{l}\text { Americas with high child } \\
\text { and high adult mortality }\end{array}$ & $\begin{array}{l}\text { High-mortality } \\
\text { developing }\end{array}$ & Bolivia, Ecuador, Guatemala, Haiti, Nicaragua, Peru \\
\hline
\end{tabular}

\section{South-East Asia}

\begin{tabular}{|c|c|c|c|}
\hline SEAR-B & $\begin{array}{l}\text { South-East Asia with low } \\
\text { child and low adult } \\
\text { mortality }\end{array}$ & $\begin{array}{l}\text { Low-mortality } \\
\text { developing }\end{array}$ & Indonesia, Sri Lanka, Thailand \\
\hline SEAR-D & $\begin{array}{l}\text { South-East Asia with high } \\
\text { child and high adult } \\
\text { mortality }\end{array}$ & $\begin{array}{l}\text { High mortality- } \\
\text { developing }\end{array}$ & $\begin{array}{l}\text { Bangladesh, Bhutan, Democratic People's Republic of } \\
\text { Korea, India, Maldives, Myanmar, Nepal, Timor-Leste }\end{array}$ \\
\hline
\end{tabular}

\section{European}

\begin{tabular}{|c|c|c|c|}
\hline EUR-A & $\begin{array}{l}\text { Europe with very low child } \\
\text { and very low adult } \\
\text { mortality }\end{array}$ & Developed & $\begin{array}{l}\text { Andorra, Austria, Belgium, Croatia, Cyprus, Czech } \\
\text { Republic, Denmark, Finland, France, Germany, } \\
\text { Greece, Iceland, Ireland, Israel, Italy, Luxemburg, } \\
\text { Malta, Monaco, Netherlands, Norway, Portugal, San } \\
\text { Marino, Slovenia, Spain, Sweden, Switzerland, United } \\
\text { Kingdom }\end{array}$ \\
\hline EUR-B & $\begin{array}{l}\text { Europe with low child and } \\
\text { low adult mortality }\end{array}$ & Developed & $\begin{array}{l}\text { Albania, Armenia, Azerbaijan, Bosnia and } \\
\text { Herzegovina, Bulgaria, Georgia, Kyrgyzstan, Poland, } \\
\text { Romania, Serbia and Montenegro, Slovakia, Tajikistan, } \\
\text { The Former Yugoslav Republic of Macedonia, Turkey, } \\
\text { Turkmenistan, Uzbekistan }\end{array}$ \\
\hline
\end{tabular}




\begin{tabular}{|c|c|c|c|}
\hline EUR-C & $\begin{array}{l}\text { Europe with low child and } \\
\text { high adult mortality }\end{array}$ & Developed & $\begin{array}{l}\text { Belarus, Estonia, Hungary, Kazakhstan, Latvia, } \\
\text { Lithuania, Republic of Moldova, Russian Federation, } \\
\text { Ukraine }\end{array}$ \\
\hline \multicolumn{4}{|c|}{ Eastern Mediterranean } \\
\hline EMR-B & $\begin{array}{l}\text { Eastern Mediterranean with } \\
\text { low child and low adult } \\
\text { mortality }\end{array}$ & $\begin{array}{l}\text { Low-mortality } \\
\text { developing }\end{array}$ & $\begin{array}{l}\text { Bahrain, Iran, Jordan, Kuwait, Lebanon, Libyan Arab } \\
\text { Jamahiriya, Oman, Qatar, Saudi Arabia, Saudi Arabia, } \\
\text { Syrian Arab Republic, Tunisia, United Arab Emirates }\end{array}$ \\
\hline EMR-D & $\begin{array}{l}\text { Eastern Mediterranean with } \\
\text { high child and high adult } \\
\text { mortality }\end{array}$ & $\begin{array}{l}\text { High-mortality } \\
\text { developing }\end{array}$ & $\begin{array}{l}\text { Afghanistan, Djibouti, Egypt, Iraq, Morocco, Pakistan, } \\
\text { Somalia, Sudan, Yemen }\end{array}$ \\
\hline WPR-A & $\begin{array}{l}\text { Western Pacific with very } \\
\text { low child and very low } \\
\text { adult mortality }\end{array}$ & Developed & $\begin{array}{l}\text { Austalia, Brunei Darussalam, Japan, New Zealand, } \\
\text { Singapore }\end{array}$ \\
\hline WPR-B & $\begin{array}{l}\text { Western pacific with low } \\
\text { child and low adult } \\
\text { mortality }\end{array}$ & $\begin{array}{l}\text { Low-mortality } \\
\text { developing }\end{array}$ & $\begin{array}{l}\text { Cambodia, China, Cook Islands, Fiji, Kiribati, Lao } \\
\text { People's Democratic Republic, Malaysia, Marshall } \\
\text { Islands, Micronesia, Mongolia, Nauru, Niue, Palau, } \\
\text { Papua New Guinea, Philippines, Republic of Korea, } \\
\text { Samoa, Solomon Islands, Tonga, Tuvalu, Vanuatu, } \\
\text { Vietnam }\end{array}$ \\
\hline
\end{tabular}

The YLL measure corresponds to the number of deaths multiplied by the standard life expectancy at the age at which death occurs. The basic formula for YLL for a given cause, age and sex is:

\section{$\mathbf{Y L L}=\mathbf{N} \mathbf{X} \mathbf{L}$}

where:

- $\mathrm{N}=$ Number of deaths

- $\mathrm{L}=$ Standard life expectancy at age of death in years. The ideal life expectancy is applied to all countries: 82.5 years for women and 80 years for men using Japan as the standard. 


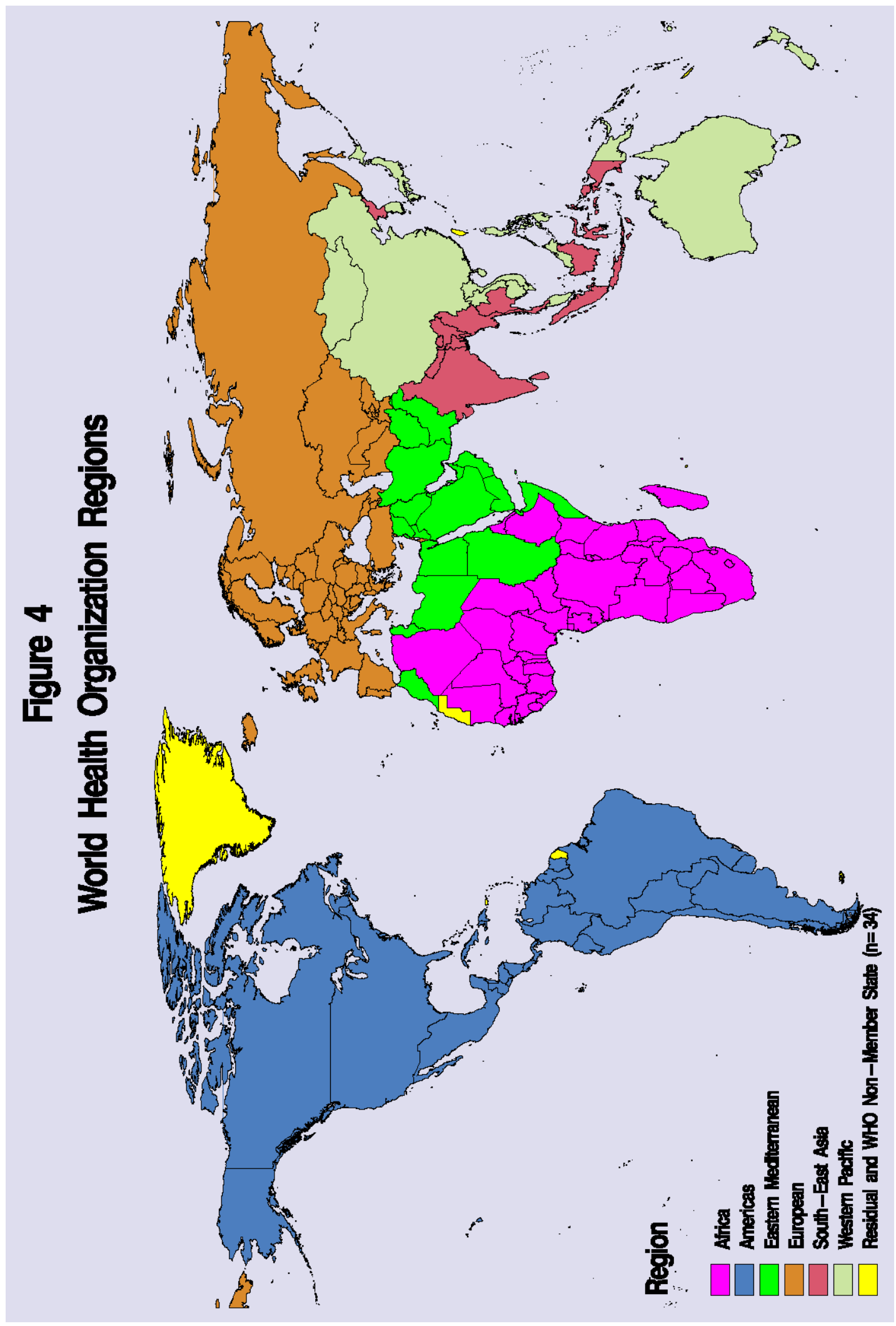




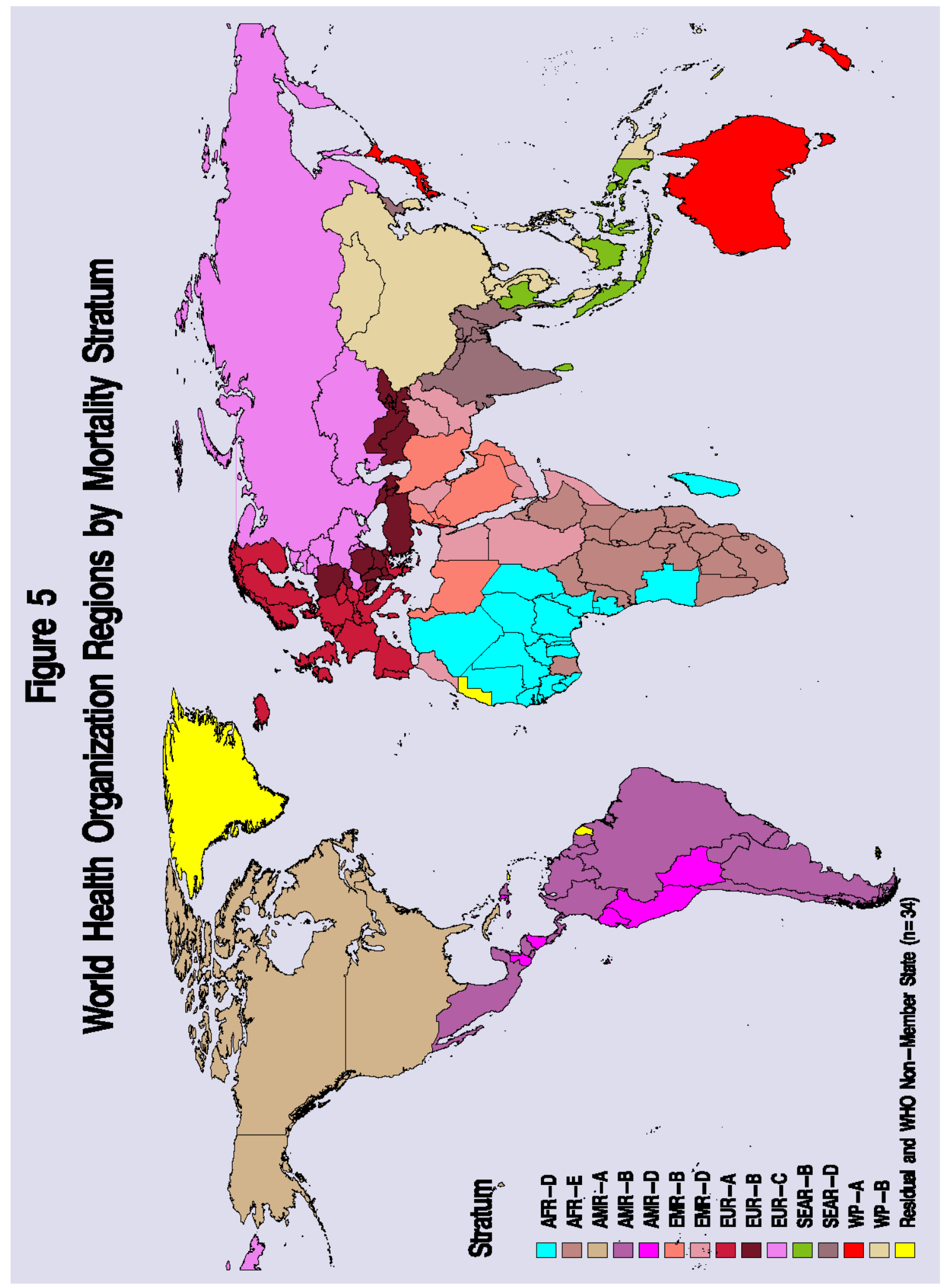


Table 3. World Health Organization Residual Micro-States and Non-Member States

\section{Residual Micro-States}

\begin{tabular}{|c|c|}
\hline 1. American Samoa & 15. Isle of Man \\
\hline 2. Anguilla & 16. Liechtenstein \\
\hline 3. Aruba & 17. Martinique \\
\hline 4. Bermuda & 18. Montserrat \\
\hline 5. British Virgin Islands & 19. Netherlands Antilles \\
\hline 6. Cayman Islands & 20. New Caledonia \\
\hline 7. Channel Islands & 21. Northern Mariana Islands \\
\hline 8. Falkland Islands (Malvinas) & 22. Occupied Palestinian Territories \\
\hline 9. Faroe Islands & 23. Puerto Rico \\
\hline 10. French Guiana & 24. Reunion Island \\
\hline 11. French Polynesia & 25. Saint Helena \\
\hline 12. Gibraltar & 26. Turks and Caicos Islands \\
\hline 13. Guadeloupe & 27. United States Virgin Islands \\
\hline 14. Guam & 28. Western Sahara \\
\hline
\end{tabular}

\section{Non-Member States}

1. Azores

2. Canary Islands

3. China Macao SAR

4. Greenland

5. Hong Kong

6. Taiwan

Note: WHO generally reports estimated DALYs for all 28 residual microstates and Greenland, but data on many control variables used in this dissertation research were generally not available for these microstates; no data on DALYs and very sparse information on control variables used in this dissertation research were collected for WHO Non-Member States, excluding Greenland. 
To estimate YLD for a particular disease in a particular time period, the number of incident cases in that period is multiplied by the average duration of the disease until remission or death and a weight factor that reflects the severity of the disease on a scale from 0 (perfect health) to 1 (death). The basic formula for YLD is as follows:

\section{YLD $=\mathbf{I} \times \mathbf{D W} \times \mathbf{L}$}

where:

- $\quad I=$ Number of incident cases

- $\mathrm{DW}=$ Disability weight

- $\mathrm{L}=$ Average duration of the case until remission or death (in years)

Calculation of the YLD requires estimates of incidence, remission and case fatality or relative risk. In addition, a disability weight is needed that reflects the severity of the disability or health state on a scale of 0 (equivalent to perfect health) to 1 (equivalent to death). The disability weight assigns a value to time spent in different health states worse than perfect health in the YLD calculation (Murray and Lopez., 1994; Reidpath et al., 2003; Williams, 1999). These weights are analogues to time lost to premature mortality in YLLs. Accordingly, these weights provide a critical link between morbidity and mortality and allow them to be combined in the DALY summary health measure. Although numerous methods have been used to estimate disability weights, including econometric methods such as person trade-offs (PTO) and various rating or visual analogue scale methodologies (WHO, 1999b), the WHO relied on PTO methods to develop disability weights for the 2002 estimates of YLD (Murray and Lopez, 1996a).

The 2002 DALYs used in this dissertation research have been discounted. Discounting reflects a social preference of a healthy year now, rather than in the future (Anand and Hanson, 1997; Lyttkens, 2003). Discounting is accomplished by decreasing annually the value of a year of life by a fixed percentage, in the case of 2002 DALYs, by 3\% (Murray and Acharya, 1997). 
Discounting thus implies that one life saved today will be worth more than 5 lives in 55 years. All DALY outcome measures examined in this research were log transformed as the result of skew. Data quality associated with various components of the DALY measure is discussed in Appendix A. DALYs used as outcome variables in this dissertation research reflect the years of life lost due to deaths from a particular condition contracted during 2002 plus the expected disability to be experienced by people who suffered from the same condition in 2002 . Thus, these are not deaths or disabilities incurred from conditions experienced in the earlier years during the time the terrorism, war and one-sided violence was active. Accordingly, this gives us a 2-year lag between deaths resulting from terrorism, war and one-sided violence from 19942000 and DALYs in 2002. For communicable diseases, a two-year lag between exposure and DALYs would appear reasonable. For more chronic conditions, the adverse environmental, demographic, social and economic impacts resulting from terrorism, war and one-sided violence from 1994-2000 are likely to create conditions conducive to greater premature mortality and increased morbidity (incidence) in 2002 than would have been expected had the terrorism and related violence not occurred.

Very few of the 192 WHO Member States shown in Table 1 were excluded from Papers 1-3 analyses due to missing data for control measures. Rwanda experienced approximately 500,000 deaths resulting from one-sided violence (i.e. genocide) in 1994 necessitating it's removal from all analyses as an extreme outlier. The following additional Member States were eliminated from Papers 1-3 analyses due to insufficient data on control variables, as follows: Paper 1 - Communicable and Noncommunicable Diseases (Cook Islands, Nauru, San Marino, San Marino, Seychelles, Timor Leste, Tuvalu, and Western Sahara); Paper 2 - Diarrheal and Related Diseases (same countries as Paper 1, in addition to Niue); Paper 3 - Drug Use Disorders (same countries as Paper 1, but not including Western Sahara and including Palau); Paper 3 - 
Alcohol Use Disorders (same counties as Paper 1 except for Western Sahara and also including Palau). Therefore, Paper 1 had a total of 8 missing Member States, Paper 2 had a total of 9 missing member states and Paper 3 had a total of 8 and 10 missing Member States when drug use disorder or alcohol use disorder DALYs served as outcome variables, respectively. It is important to note that with the exception of Rwanda, all other WHO Member States excluded from the analysis were small islands or microstates.

\section{Sample Size: WHO Member States}

Sample sizes of 182 to 184 WHO Member States included in analyses for Papers 1-3 are more than adequate statistically as determined using sample size formulations designed for multivariable linear regression models. Minimum adequate sample size for the multivariable linear regression design was estimated herein using a method based on the t-statistic (Milton, 1986). The sample size formula is given by:

$$
n=k+1+\frac{t^{2}(1-R)^{2}}{\Delta r j^{2}}
$$

where $\mathrm{k}=$ the number of independent variables in models associated with Papers 1-3 $(\mathrm{k}=7-9)$; the anticipated overall $\mathrm{R}=$ the variance explained by the full model estimated from previous research, $(\mathrm{R}=0.60)$; and $\mathrm{t}=$ the desired $\mathrm{t}$-level $(1.66$ for 1 -sided $\mathrm{t}$-statistic at $\mathrm{p}<0.05)$. The term $\Delta \mathrm{rj}^{2}$ was selected to be 0.01 in order to arrive at a sample size large enough to ensure that any independent variable constituting an additional $1.0 \%$ of explained variance in the model (if entered last) would be significant at the $\mathrm{p}<0.05$ level. Using these paramaters, the estimated sample size would be 116 for $\mathrm{p}<0.05$ and $\mathrm{k}=7$. For $\mathrm{p}<0.05$ and $\mathrm{k}=9$, the estimated sample size would be 118. Both sample size estimates remain lower than the number of WHO Member States $(n=182$ to 184$)$ included in analyses associated with Papers $1-3$, indicating that sample 
sizes used in this dissertation research were more than adequate for the multivariable regression analyses conducted herein.

\section{Global Burden of Disease Study Cause Categories}

The major outcome variables in this dissertation research are the number of DALYs (in thousands) due to major communicable and noncommunicable diseases. The cause list used in the 2002 GBD study has four levels of aggregation (Mathers et al., 2002). Paper 1 will examine the impact of terrorism, war and one-sided violence on DALYs due to diseases and conditions defined by the top three levels of aggregation shown in Appendix B along with the associated International Statistical Classification of Diseases - Ninth Revision (ICD-9: WHO, 1977) and International Statistical Classification of Diseases and Related Health Problems - Tenth Revision (ICD-10) codes (WHO, 1992). At the first level, all causes are combined. At the second level, causes are divided into two groups consisting of Group I, communicable diseases, maternal and perinatal conditions and nutritional deficiencies and Group II comprising noncommunicable diseases. The third level of the cause classification defines major Group I (e.g. infectious and parasitic diseases, maternal conditions, nutritional deficiencies) and Group II (e.g. malignant neoplasms, neuro-psychiatric conditions, cardiovascular diseases) causes prefaced by capital letters in Appendix B. For Papers 2 and 3, diarrheal and related disease and alcohol and drug use disorder DALYs, classified at the fourth level of the cause list, will serve as outcome variables, respectively. Injuries classified as Group III conditions in the GBD cause list will not be examined in this dissertation research.

\section{Major Communicable and Noncommunicable Disease DALYs: Paper 1}

In $2002,41.0 \%$ of global DALYs were attributable to communicable diseases, including maternal and perinatal conditions and nutritional deficiencies, while $46.7 \%$ were due to noncommunicable conditions for the total world population (WHO, 2002a). Tables 4 and 5 
show the nine leading causes of global burden of disease in 2002 attributable to communicable and noncommunicable diseases for the world and by sex, respectively (WHO, 2002a). Perinatal conditions were the leading cause of burden worldwide, accounting for $6.5 \%$ of the burden of disease, followed by lower respiratory conditions (5.8\%) and acquired immunodeficiency virus/acquired immune deficiency syndrome (HIV/AIDS: 5.8\%). The greatest contributors to noncommunicable disease burden were unipolar depressive disorders $(4.5 \%)$ ischemic heart disease $(3.9 \%)$ and cerebrovascular disease $(3.3 \%)$.

Communicable and noncommunicable diseases accounted for $38.7 \%$ and $45.8 \%$ of total DALYs among males while the corresponding figures were $43.7 \%$ and $47.7 \%$ among females. The 10 leading causes of global disease burden among males and females are shown in Table 6 (WHO, 2002a). Among males and females, the three leading causes of disease burden were perinatal conditions, HIV/AIDs and lower respiratory infections, accounting for between 5.7\% to $6.9 \%$ of total DALYs.

Table 4. Nine Leading Causes of Burden of Disease, Global Estimates, 2002

Disease $\quad \%$ of Total DALYs

1. Perinatal conditions $\quad 6.5 \%$

2. Lower respiratory conditions $\quad 5.8 \%$

3. HIV/AIDs $\quad 5.8 \%$

4. Unipolar depressive disorders $\quad 4.5 \%$

5. Diarrheal diseases $\quad 4.1 \%$

6. Ischemic heart disease $\quad 3.9 \%$

7. Cerebrovascular disease $\quad 3.3 \%$

8. Malaria $\quad 3.0 \%$

9. Tuberculosis $\quad 2.4 \%$


Table 5. Ten Leading Causes of Burden of Disease by Sex, Global Estimates, 2002

$\begin{array}{llll}\text { Males } & \begin{array}{l}\text { \% of Total } \\ \text { DALYs }\end{array} & \text { Females } & \begin{array}{l}\text { \% of To } \\ \text { DALYs }\end{array} \\ & & & \\ \text { 1. Perinatal conditions } & 6.9 \% & \begin{array}{l}\text { 1. Perinatal conditions } \\ \text { infections }\end{array} & 6.2 \% \\ \text { 2. HIV/AIDs } & 5.8 \% & \text { 3. HIV/AIDs } & 6.0 \% \\ \text { 3. Lower respiratory infections } & 5.7 \% & \text { 4. Unipolar depressive } & 5.7 \% \\ \text { 4. Ischemic heart disease } & 4.4 \% & \text { disorders } & 5.7 \% \\ \text { 5. Diarrheal diseases } & & \text { 5. Maternal conditions } & 4.7 \% \\ \text { 6. Unipolar depressive disorders } & 3.4 \% & \text { 6. Diarrheal diseases } & 4.1 \% \\ \text { 7. Cerebrovascular disease } & 3.3 \% & \text { 7. Ischemic heart disease } & 3.4 \% \\ \text { 8. Tuberculosis } & 2.9 \% & \text { 8. Cerebrovascular disease } & 3.3 \% \\ \text { 9. Malaria } & 2.8 \% & \text { 9. Malaria } & 3.2 \% \\ \text { 10. Alcohol use disorders } & 2.2 \% & \text { 10. Cataracts } & 2.0 \%\end{array}$

Diarrheal diseases were the fifth and sixth leading causes of burden worldwide among males and females, respectively, accounting for $4.1 \%$ of total DALYs for each sex. Ischemic heart disease, unipolar depressive disorder and cerebrovascular disease were also leading causes of communicable disease burden constituting $4.4 \%, 3.4 \%$ and $3.3 \%$ of total DALYs among men. For females, unipolar depressive disorders, maternal conditions, ischemic heart disease and cardiovascular disease were leading causes of noncommunicable disease burden accounting for $17.1 \%$ of total DALYs.

With respect to age, $36 \%$ of the global burden of disease in 2002 was experienced by children aged less than 15 years, primarily among children aged 0-4 years (29\%) (Figure 6). Disease burden among children aged 0-to-4 years among developed world regions (6.0\%) stands in marked contrast to burden observed in high mortality developing regions (40\%) (WHO, 2002a). The majority of global disease burden lies among 15-to-59 year-olds, accounting for $43 \%$ to $57 \%$ of total disease burden among developed and developing regions.

In 2002, there were approximately 1.5 billion DALYs lost worldwide from all causes, with 772.9 million and 717.2 million lost for males and females, respectively (Figure 7). 
Figure 6. Distribution of Disease Burden By Age Group and Region, 2002

\section{High-mortality developing regions}

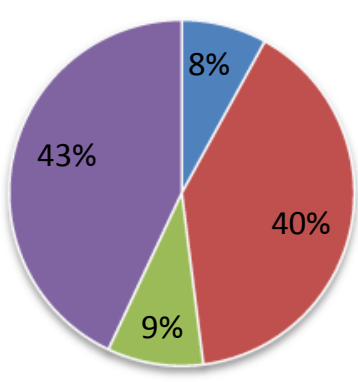

- 60+ years old

0-4 years old

5-14 years old

15-59 years old

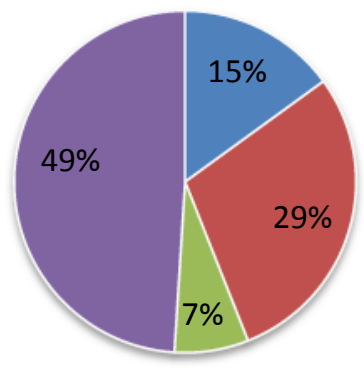

60+ years old

- 0-4 years old

- 5-14 years old

-15-59 years old

\section{High-mortality developing regions}

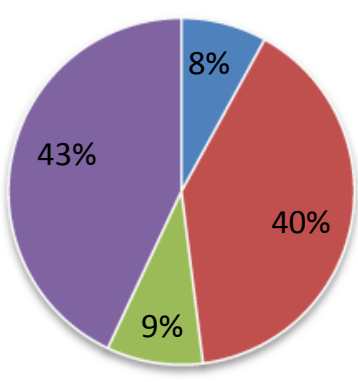

- 60+ years old

0-4 years old

5-14 years old

-15-59 years old

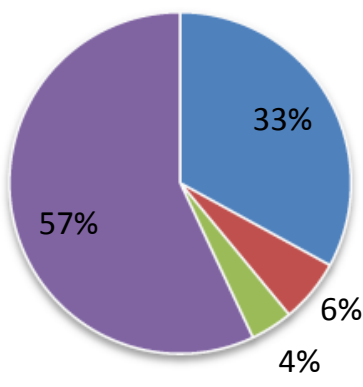

- 60+ years old

0-4 years old

5-14 years old

15-59 years old

DALYs lost from all causes were greatest among 15 -to-44 year-olds ( $\mathrm{n}=552.0$ million), followed by 0 -to- 4 year-olds ( $\mathrm{n}=433.8$ million), those 60 years or older ( $\mathrm{n}=217.6$ million), 45 -to-59 yearolds ( $\mathrm{n}=205.9$ million) and 5-to-15 year-olds $(\mathrm{n}=110.7$ million). With regard to region, the greatest number of DALYs were lost in the South-East Asia Region ( $\mathrm{n}=426.6$ million), with India being the largest contributor ( $\mathrm{n}=299.4$ million). The African region experienced the next largest number of DALYs lost ( $\mathrm{n}=361.4$ million), followed by the South-East Asia ( $\mathrm{n}=264.9$ million), European ( $\mathrm{n}=150.3$ million $)$, The Americas $(\mathrm{n}=145.6$ million $)$ and the Eastern Mediterranean ( $\mathrm{n}=139.1$ million) Regions. 


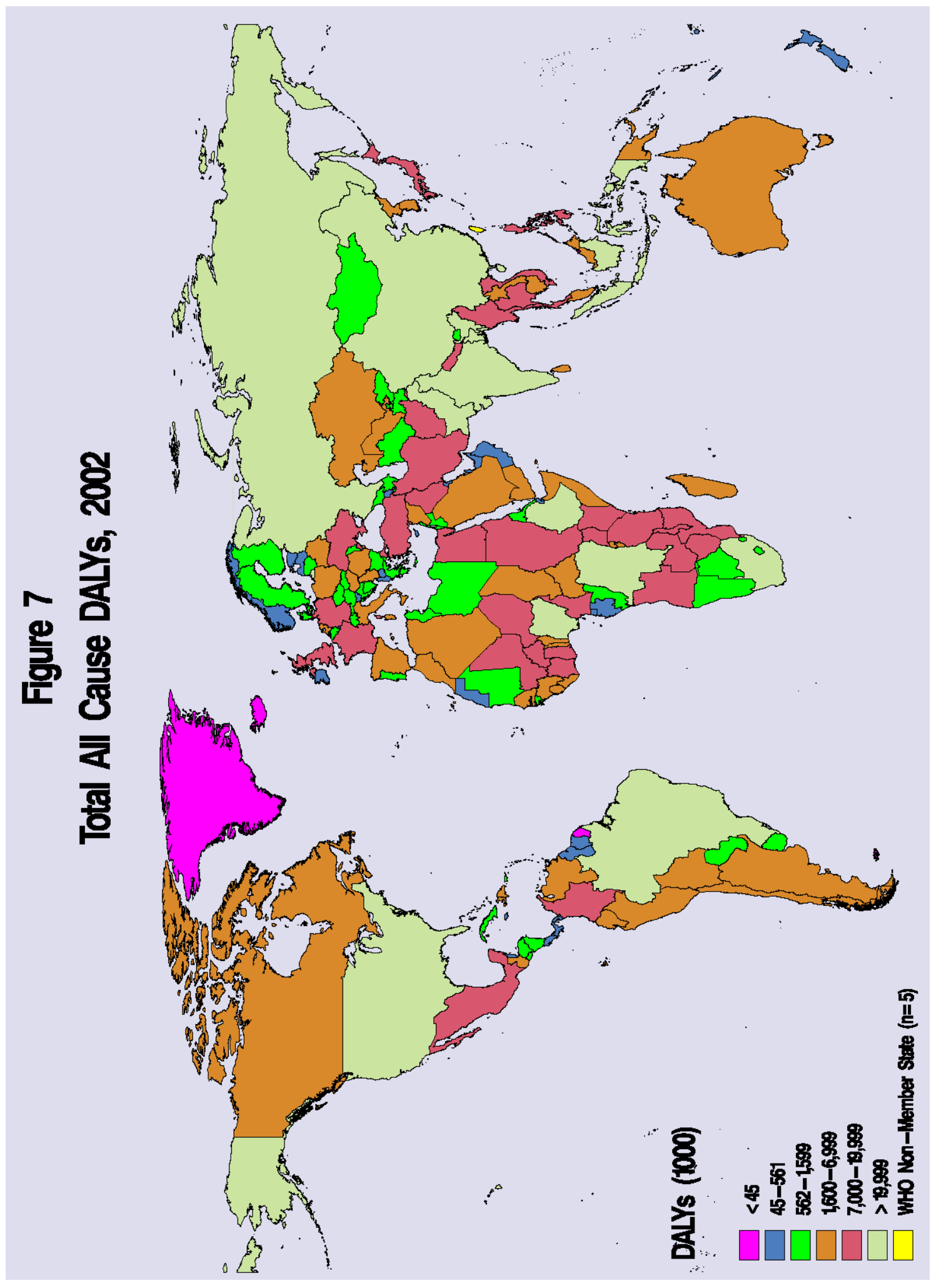


Countries with the greatest number of DALYs lost in 2002 included China ( $n=200.4$

million), Nigeria ( $n=67.3$ million), Indonesia ( $n=46.2$ million), Pakistan $(n=44.9$ million), the United States of America ( $\mathrm{n}=41.6$ million) and the Russian Federation ( $\mathrm{n}=39.5$ million), results, in part, attributable to the population size of these countries. All of the 47 countries with less than 46,000 DALYs lost in 2002 were microstates, small islands or residual states (e.g. Aruba, Andorra, Sao Tome and Principe, Northern Marina Islands).

\section{Diarrheal and Related Disease DAL Ys: Paper 2}

Diarrheal and related diseases DALY outcome variables (in thousands) examined in this dissertation included: (1) infectious diarrheal and the related conditions of cholera, salmonellosis, shigellosis, amoebiasis, and other bacterial, protozoal and viral intestinal diseases; (2) schistosomiasis; (3) trachoma; (4) ascariasis; (5) trichuriasis; and (6) hookworm. These specific diarrheal and related diseases are estimated to be $90-100 \%$ attributable to unsafe water resources and inadequate sanitation facilities (Table 6) (Prüss-üstün et al., 2002; 2004; WHO, 2006a). Accordingly, unimproved water resources and inadequate sanitation facilities were combined as baseline vulnerability control variable in Paper 2 of this dissertation.

Table 6. Diarrheal and Related Diseases and Attributable Fractions Due to Unsafe Water Resources and Inadequate Sanitation Facilities

\begin{tabular}{|c|c|c|c|}
\hline Disease & $\begin{array}{l}\text { Fraction of Disease } \\
\text { Attributable to WSH }\end{array}$ & $\begin{array}{l}\text { ICD-10 } \\
\text { Code }\end{array}$ & Description \\
\hline Infectious Diarrhea & $90 \%-94 \%$ & $\begin{array}{l}A 00, A 01 \\
A 02, A 03 \\
A 04, A 06-A 09\end{array}$ & $\begin{array}{l}\text { Cholera, Salmonellosis, Shigellosis, } \\
\text { Amoebiasis and Other Bacterial, Protozoal } \\
\text { and Viral Intestinal Diseases. }\end{array}$ \\
\hline Schistosomiasis & $100 \%$ & B65 & $\begin{array}{l}\text { Parasitic disease caused by exposure to } \\
\text { Shisoma trematodes larvae. }\end{array}$ \\
\hline Trachoma & $100 \%$ & A71 & $\begin{array}{l}\text { Chronic contagious disease of ocular } \\
\text { surface by Chlamydia Trachomatis. }\end{array}$ \\
\hline Ascariasis & $100 \%$ & B77 & $\begin{array}{l}\text { Helminthic infection caused by eggs of } \\
\text { round worm. }\end{array}$ \\
\hline Trichuriasis & $100 \%$ & B79 & $\begin{array}{l}\text { Caused by ingestion of whipworm Trichuris } \\
\text { Trichura. }\end{array}$ \\
\hline Hookworm & $100 \%$ & B76 & Caused by exposure to hookworm larvae. \\
\hline
\end{tabular}


Diarrheal and its related diseases of cholera, salmonellosis, shigellosis, amoebiasis and other bacterial, protozoal and viral intestinal diseases are caused by several pathogens, including retrovirus, E.Coli, Shigella, Campylobacter, Salmonella, V.Cholerae and Cryptosporidium (WHO, 2006a). Most of these pathogens share a common mode of transmission- from the stool of one person to the mouth of another- known as fecal-oral transmission (Grimwood and Forbes, 2007). Diarrheal and related diseases are the second leading cause of death among children under five years old, killing 1.5 million children each year (WHO, 2009). In 2002, these diseases accounted for $4.1 \%$ of total global DALYs, affecting males and females equally. Water constitutes a greater proportion of body weight in children than adults, making them more vulnerable to life-threatening dehydration from these conditions. Susceptibility to these conditions also increases among children with poor nutritional status and those exposed to poor environmental conditions (WHO, 2009).

Schistosomiasis is a chronic parasitic disease caused by blood flukes or trematode worms (schistosoma) that leads to chronic ill health (WHO, 2010b). People become infected when the larval forms of the parasite, released by freshwater snails, penetrate their skin during contact with contaminated water. Once penetration has occurred, the larvae develop into adult schistosomes that live in blood vessels where females release their eggs. Although some eggs are passed through the body in feces or urine, others become trapped in body tissues, causing immune reactions and progressive damage to organs. More than 207 million people are infected worldwide with schistosomiasis, while an estimated 700 million people worldwide are at risk of infection as a result of exposure to unsafe water and sanitation (Steinmann et al., 2006).

Trachoma is an infection of the eye that may result in blindness and is caused by Chlamydia Trachomatis (WHO, 2006a). All transmission routes are hygiene-related and occur in overcrowded conditions with limited access to improved water resources and sanitation 
facilities. Transmission occurs from person to person and is passed on by hands, clothing or flies exposed to eye discharge. Trachoma is responsible for approximately $3.0 \%$ of the world's blindness (Resnikoff et al., 2008). Repeated infection causes the eyelashes to rub against the eyeball, a condition called triciasis, that causes eye scarring. Overall, Africa is the most affected continent with 27.8 million cases of active trachoma representing $68.5 \%$ of all cases globally and 3.8 million cases of trachiasis or $46.6 \%$ of all cases globally. In this most affected region, active trachoma is common in pre-school children, but it becomes less prevalent with increasing age (Bailey, 1999). Trachoma is more prevalent among females than males, a difference attributable to closer contact of mothers and other female caregivers with children, a major source of the infection.

Ascariasis, trichuriasis and hookworm disease, the nematode infections, are all transmitted via soil or other media that are contaminated with excreta. Infection occurs when the infective larvae are ingested or in the case of hookworm disease, when the eggs penetrate the skin. Larvae then grow into adult worms in the intestines and can grow to over $30 \mathrm{~cm}$ long. As a result, intestinal blockage, difficulty breathing and coughing can cause severe abdominal pain and even death. Among the nematode infections, ascariasis is the most common parasitic infection and occurs most frequently in tropical and subtropical regions and in areas with inadequate sanitation facilities. Approximately 10 percent of the population in developing countries is infected with intestinal worms with a large percentage caused by ascariasis. Globally, ascariasis infections cause about 60,000 deaths per year, mainly in children under eight years old (WHO, 2010b).

In 2002, there were approximately 68.8 million DALYs attributable to these diarrheal and related diseases worldwide. There was a slightly greater number of DALYs lost to these diarrheal and related diseases among males $(n=35.4$ million) than females ( $n=33.5$ million). The 
majority of these DALYs were lost among the 0 -to-4 year-olds ( $\mathrm{n}=56.6$ million) relative to all older age groups combined ( $\mathrm{n}=12.3$ million). As can be seen in Figure 8 , most DALYs attributable to diarrheal and related diseases were concentrated in the African ( $\mathrm{n}=26.9$ million) and South-East Asia ( $\mathrm{n}=21.3$ million) Regions, followed by the Eastern Mediterranean $(\mathrm{n}=9.5$ million), Western Pacific ( $\mathrm{n}=7.7$ million) and The Americas ( $\mathrm{n}=2.7$ million) Regions. Countries experiencing the greatest number of DALYs lost to these diseases ( $>2.0$ million) were India,

China, Nigeria, Pakistan, Democratic Republic of the Congo, Bangladesh and Ethiopia. The majority of the 61 countries experiencing less than 20,000 DALYs attributable to diarrheal and related diseases in 2002 were islands (e.g. Fiji, Netherlands Antilles, Faroe Islands) or small countries in terms of land mass (e.g. Qatar, Western Sahara, Bahrain).

\section{Substance Use Disorder DALYs: Paper 3}

The dependent variable in Paper 3 is the number of DALYs (in thousands) in 2002 attributable to substance use disorders, defined in the GBD Study as alcohol dependence and/or harmful use (ICD-10, F10.1, F10.2) and drug dependence and harmful use (ICD-10: F11.1, F11.2, F14.1, F14.2) (WHO, 1993). Within the GBD Study framework, alcohol and drug use disorders are considered $100 \%$ attributable to alcohol use and drug use, respectively (Degenhardt et al., 2004; Rehm et al., 2004). This feature required that adult per capita alcohol consumption and prevalence of illicit drug use be controlled at baseline (i.e. 1994) in analyses in which alcohol and drug use disorder DALYs (both separately and combined into substance use disorders) served as outcome variables. 


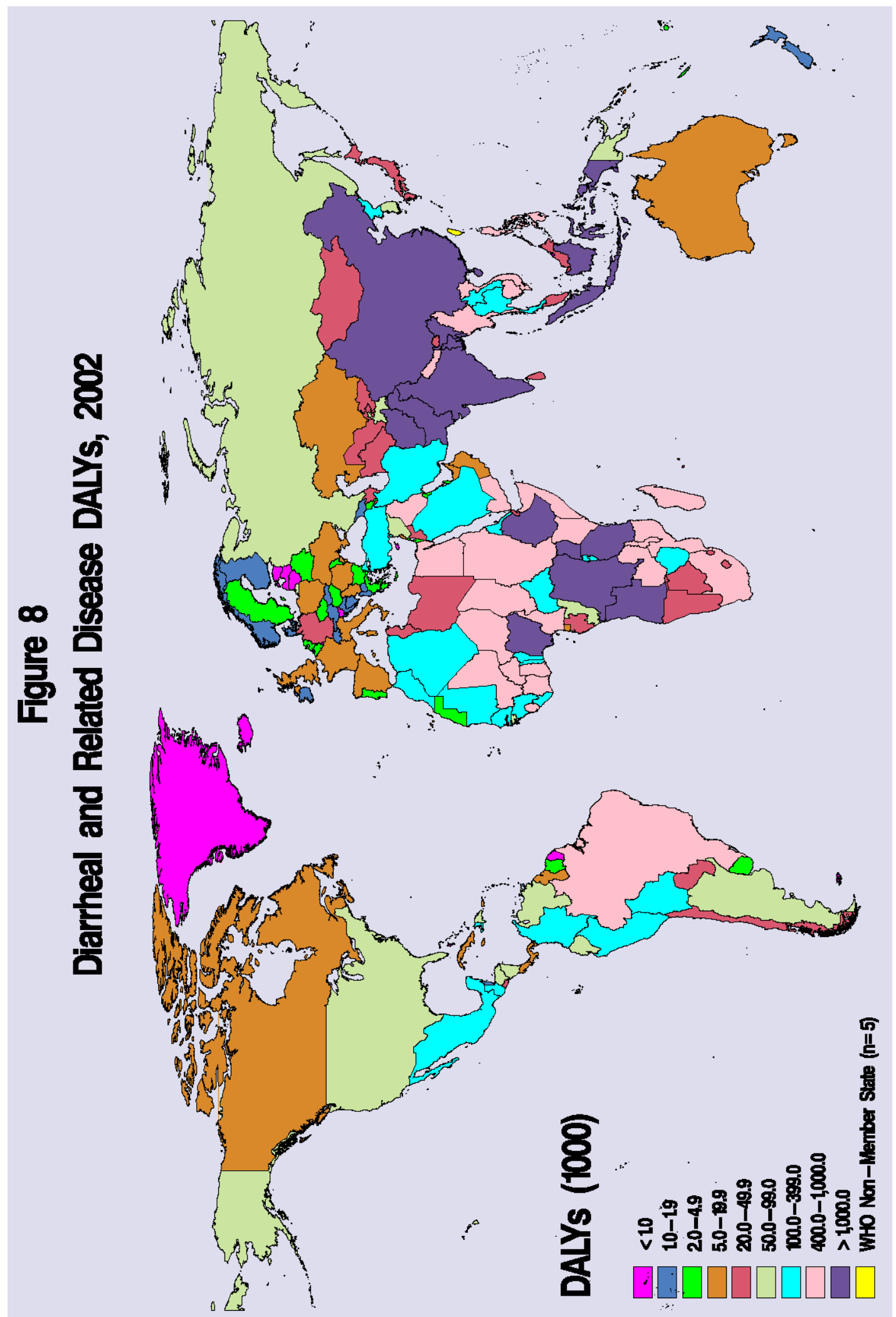


Alcohol use disorders are major contributors to morbidity and mortality worldwide. In 2002, alcohol use disorders accounted for $1.4 \%$ of worldwide DALYs, figures that were much greater among males (2.2\%) than females (0.4\%) (WHO, 2002a). Globally, alcohol use disorders were the twelfth leading cause of DALYs among males and the third leading cause of DALYs in high-income countries (4.6\%) (WHO, 2003). With respect to region, alcohol use disorders were the fourth leading cause of DALYs in the region of The Americas (4.4\%), accounting for $6.4 \%$ and $1.9 \%$ of total DALYs among males and females, respectively. Alcohol use disorders were also substantial contributors to DALYs experienced in the European (3.1\%) and Western Pacific (2.4\%) Regions.

In 2002, there were approximately 20.3 million DALYs attributed to alcohol use disorders worldwide. The majority of these DALYs lost were among males (17.2 million) compared with females (3.1 million) and among 15-to-44 year-olds ( $\mathrm{n}=16.9$ million) and 45-to59 year-olds ( $\mathrm{n}=2.7$ million). As can be seen in Figure 9, the largest number of DALYs lost to alcohol use disorders were in The Americas ( $\mathrm{n}=6.4$ million), Western Pacific ( $\mathrm{n}=6.3$ million) and European ( $n=4.7$ million) Regions, with the United States of America ( $n=2.2$ million) and the Russian Federation ( $\mathrm{n}=1.3$ million) being the largest contributors. DALYs lost to alcohol use disorders were also large in China ( $\mathrm{n}=4.8$ million) and India ( $\mathrm{n}=1.4$ million). Relatively speaking, fewer DALYs attributable to alcohol use disorders were lost in the South-East Asia $(\mathrm{n}=1.9$ million $)$, African $(\mathrm{n}=912,810)$ and Eastern Mediterranean $(\mathrm{n}=98,470)$ Regions.

Globally, illicit drug use disorders were responsible for approximately 7.4 million DALYs lost in 2002; substantially less than alcoholic use disorders (Figure 10). During this time, drug use disorders accounted for $0.5 \%$ of total global DALYs, figures that were greater for males ( $\mathrm{n}=0.7 \%$ or 5.8 million DALYs) compared with females $(0.2 \%$ or 1.6 million DALYs). Similar to alcohol use disorders, drug use disorder morbidity and mortality was greatest among 


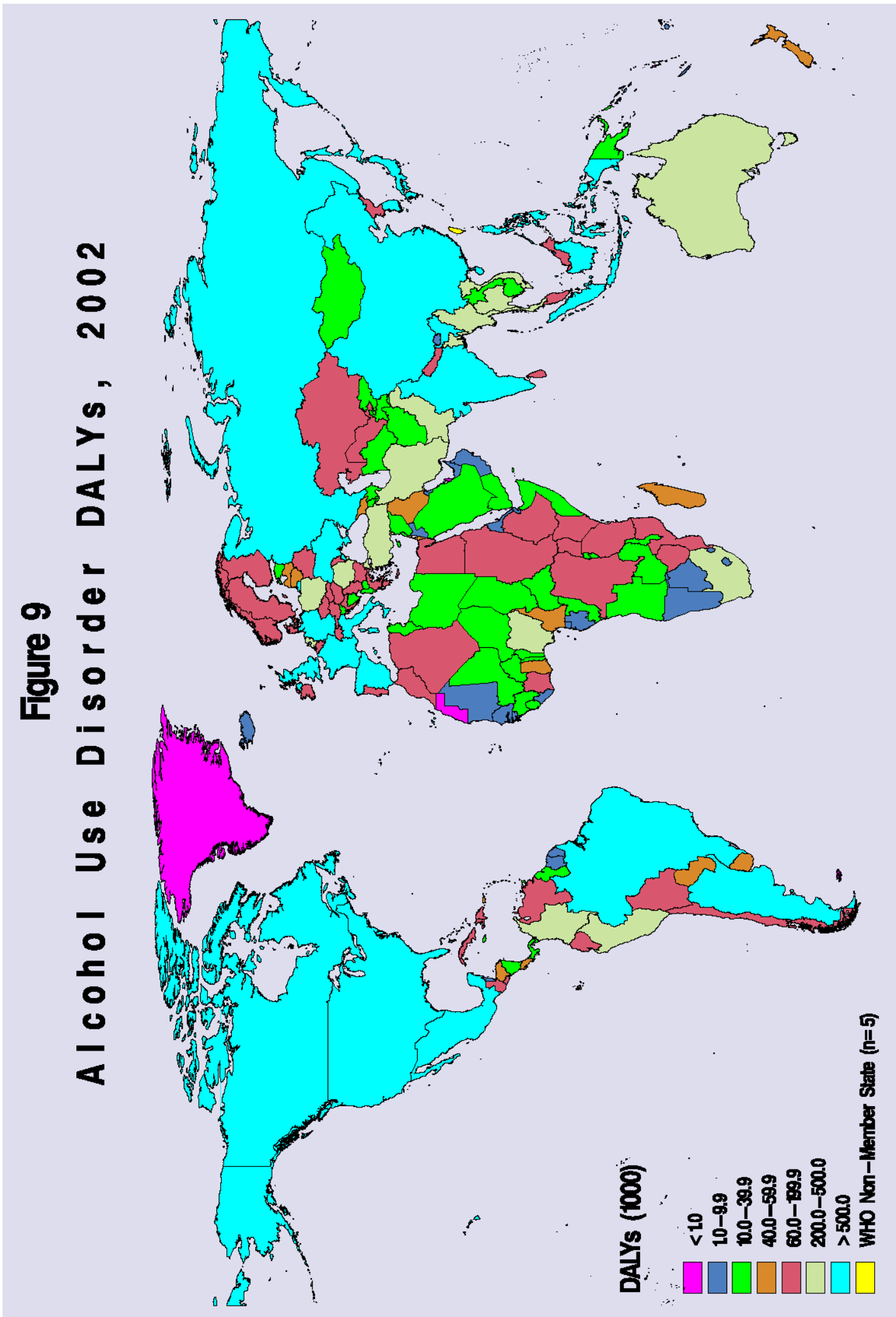




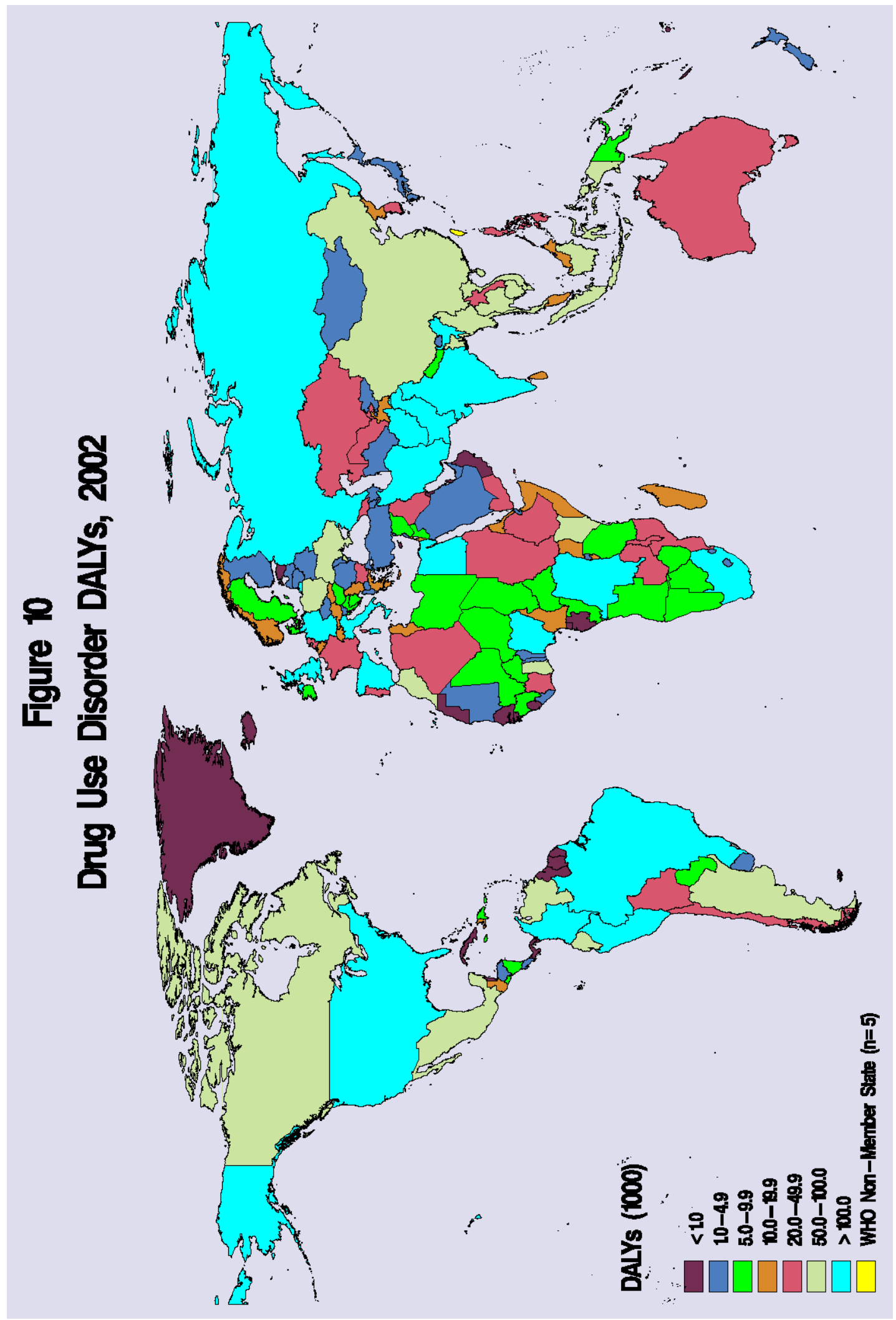


15-to-44 year-olds ( $\mathrm{n}=6.5$ million) relative to the younger and older subgroups of the population. The number of DALYs attributable to drug use disorders was large in the Eastern Mediterranean ( $\mathrm{n}=1.4$ million) and African ( $\mathrm{n}=1.3$ million) Regions, including those countries with the world's greatest coca and poppy production (Iran, Afghanistan, Pakistan and Nigeria), and in The Americas ( $\mathrm{n}=1.9$ million) and European ( $\mathrm{n}=1.5$ million) Regions, those regions with countries that have the largest number of consumers of illicit drugs worldwide. Countries with the greatest number of DALYs lost to drug use disorders included the United States of America $(\mathrm{n}=734,611)$ and India ( $\mathrm{n}=612,867$ million). DALYs lost to illicit drug use disorders were much lower in the South-East Asia $(\mathrm{n}=986,640)$ and Western Pacific $(\mathrm{n}=379,150)$ Regions.

The global distribution of substance use disorder DALYs (i.e. alcohol and illicit drug use DALYs combined) mirrored the demographic patterns observed for each type of substance examined separately (Figure 11). [For additional descriptive statistics related to DALY outcome variables, see Appendix C].

\section{Linking Terrorism, Civil War and One-Sided Violence with Morbidity and Mortality}

Although research has examined the short-term and longer-term impact of war and related violence on mortality across countries (Guha-Sapir and van Panhuis, 2002a; 2002b; 2004; Li and Wen, 2005), these studies ignore the effect of terrorism, war and one-sided violence on non-fatal diseases and conditions and associated disability and quality of life worldwide. Ghobarah et al. (2003) were the first to attempt to bridge the gap in the literature on the impact of conflict on civilian populations. Employing a theoretical model in which public health outcomes reflected variations in resource and investment decisions in the level and distribution of health services; they hypothesized that civil wars should produce damage to public health that extends beyond periods of direct military conflict. Ghobarah and colleagues (2003) examined the impact of civil war deaths from 1991-1997 on DALYs in 1999 for a variety 


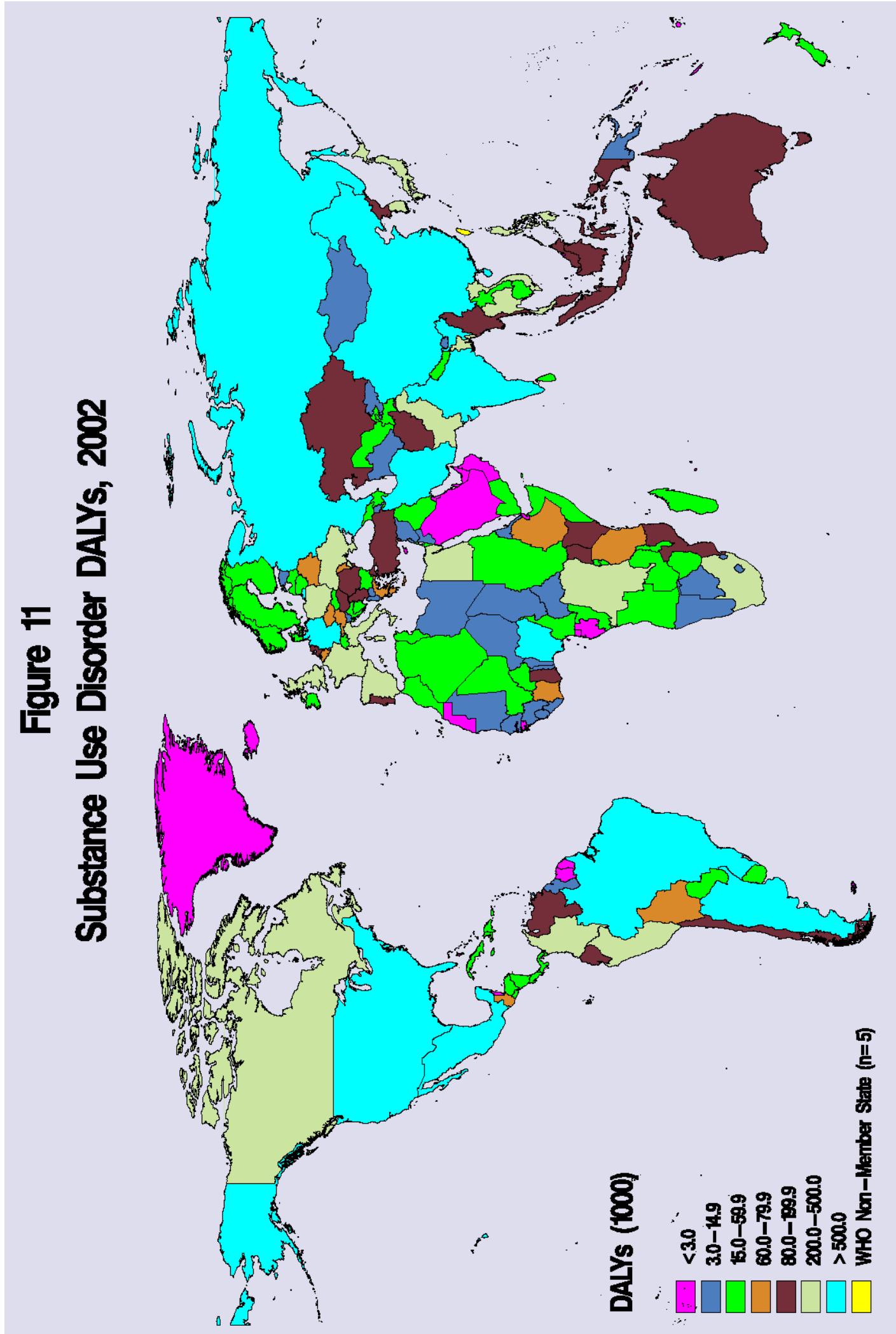


of infectious diseases, several types of cancer, transportation accidents, homicide, unintentional injuries, and respiratory and digestive diseases, controlling for economic variables.

Interestingly, civil war deaths were not significantly associated with all cause DALYs for the majority of the youngest and oldest subgroups of the populace. Further, longer-term effects of war were found for only $48(23 \%)$ of the 210 diseases and conditions examined by age and sex. In a later article (Ghobarah et al., 2004b), in which both political regime type and ethnic division were eliminated as control variables, their initial results were confirmed. The authors found that civil war deaths from 1991-1997 raised the risk of death and disability in 1999 for only 63 $(30 \%)$ of the 210 disease categories examined by sex and age. Neither diarrheal or related diseases nor substance use disorders were associated with civil war deaths, and no diseasespecific vulnerability factors were controlled for in the analyses.

There was also an issue related to a critical control variable, the contiguous civil war deaths by border permeability measure used in this study. This measure was used as a proxy for the number of refugees, asylum seekers and displaced persons in each host country. A more direct measure of the increased risk of disease resulting from a large number of refugee, asylum seekers and displaced persons on an already weakened health services infrastructure of the host country is the actual number of refugees, asylum seekers and displaced persons in the country of asylum.

Most recently, Ghobarah et al. (2004a) examined the effect of civil wars on healthy life expectancy (HALE), or the average number of years a person can be expected to live to full health by taking into account years of life lived in disability or illness (Mathers et al., 2000). The results of their analyses showed that civil wars had a lingering effect on health even after the fighting had concluded. The most destructive civil wars were found to reduce HALEs by 10 
years. In addition, the destructive nature of civil wars had an additional impact, depressing healthy life expectancy in contiguous countries by 3 years.

In another study, the relationship between civil war deaths and deaths resulting from genocide/politicide occurring during 1991-1997 and all cause morbidity and mortality in 1999 as measured by DALYs, was examined separately and simultaneously, controlling for economic variables (Hoddie and Smith, 2009). When only war deaths were examined, there were no longer-term effects of war deaths on all cause morbidity and mortality. However, when war deaths and deaths from genocide/politicide were examined simultaneously, deaths from genocide/politicide, but not war deaths, were significantly related to all cause DALYs, but only among the youngest (4 years or less) and older (45 years and older) subgroups of the population. Limitations of this study included a focus on all-cause morbidity and mortality as the outcome variable, rather than specific diseases, and the use of an ordinal, rather than a continuous measure of the number of deaths resulting from genocide/politicide. Moreover, data used to measure deaths from genocide/politicide included both deaths due to genocide/politicide when the government was a major actor and those deaths that are more appropriately defined as deaths attributable to terrorism perpetuated by subnational actors.

Another limitation shared by this prior research is largely the result of rapid advances in data quality of key outcome variables. Foremost, the DALY measures used in these studies were preliminary unpublished WHO figures. The first official DALYs for Member States was published by WHO in 2006 for the year 2002. These estimates benefited from WHO Version 3.0 GBD Study methodology, including increased reliability of morbidity and mortality reporting and provision for dependent comorbidity factors for selected disorders that adjust DALYs to account for the probability of having two or more diseases or conditions (Mathers et al., 2003). Another limitation of this work was the failure to assess the longer-term effects of deaths from 
terrorist actions, an increasingly important component of armed conflict (Eck and Hultmann, 2007; Ericksson et al., 2003). All of these prior studies also failed to transform the DALY measures, variables that are skewed.

Difficulties in measurement of major control and outcome variables in the Ghobarah et al. (2004a) and Hoddie and Smith (2009) studies may also have led to the premature abandonment of extremely important factors that should be controlled in any study of the longer-term impact of war and related violence on public health, that is, ethnic/religious/linguistic heterogeneity, number of deaths, homeless and affected by natural disasters, number of refugees, asylum seekers and displaced persons and life expectancy at birth. More critically, the one-size-fits-all approach taken in prior studies assumes that the same factors influence all diseases and conditions in similar ways. Although this assumption may be correct for important economic factors in these studies (e.g. health expenditures), it does not account for specific vulnerability factors that relate differently to different diseases. Accordingly, it will be necessary in the present research to control for unimproved water resources and inadequate sanitation facilities at baseline in 1994 when examining the influence of terrorism, war and one-sided violence from 1994-2000 on DALYs attributable to diarrheal and related diseases in 2002 (Paper 2). Diarrheal and related diseases are $90 \%$ to $100 \%$ attributable to these factors within the context of the GBD study. Similarly, prevalence of illicit drug use from 1993-1997 and adult per capita alcohol consumption in 1994 will be controlled when examining the influence of terrorism, war and one-sided violence from 1994-2000 on DALYs attributable to substance use disorders in 2002 (Paper 3), as these disorders are 100\% attributable to these factors within the GBD Study framework.

Exposure Variable: Deaths Resulting From Terrorism, Civil War and One-sided Violence Deaths Resulting From Terrorist Actions 
Terrorist acts are intended to produce effects beyond immediate human and property damage and to have long-term psychological repercussions on a particular audience. Data on the number of deaths resulting from terrorist actions from 1994-2000 were derived from the 2010 update of the Global Terrorism Database (GTD) constructed by National Consortium for the Study of Terrorism and the Responses to Terrorism (NCSTRT) at the University of Maryland (2010), a Department of Homeland Security National Center for Excellence. The definition of a terrorist incident in this database includes terrorist incidents that are intentional, that achieve some level of violence or threat of violence and that are perpetrated by sub-national, non-state actors. In addition, to qualify as a terrorist incident, at least two of the following three criteria must be met: (1) the act must be aimed at attaining a political, economic, religious or social goal; (2) there is evidence of an intention to coerce, intimidate, or convey some other message to a larger audience than the immediate victims; and/or (3) the action must be outside the context of legitimate warfare activities (NCSTRT, 2010).

During the years 1994-2000 there were 43,269 deaths resulting from terrorist actions worldwide. As can be seen in Figure 12, the majority of these deaths occurred in the African $(\mathrm{n}=19,534)$ and South-East Asia $(\mathrm{n}=8,277)$ Regions. There were between 3,977 and 5,364 fatalities from terrorist actions in The Americas, Eastern Mediterranean and European Regions, while the Western Pacific Region $(\mathrm{n}=1,527)$ experienced far fewer fatalities related to terrorist actions.

\section{Deaths Resulting From Civil War}

Civil war is defined as armed conflict between the government of a state and one or more internal opposition groups with or without intervention from other states. War (armed conflict) is defined as a contested incompatibility that concerns governments and/or territory where the use of armed force between two parties, of which at least one is the government of the state, 


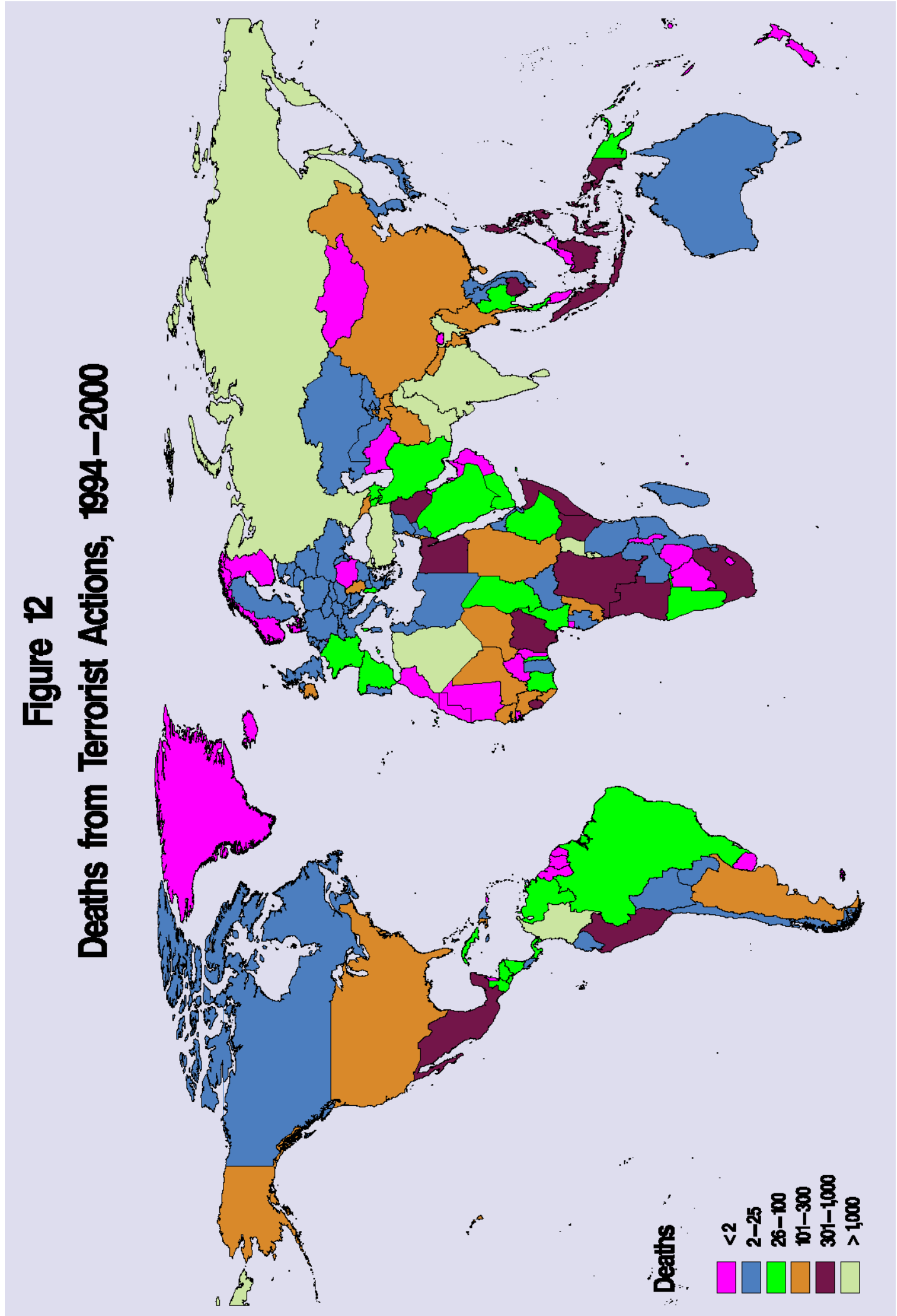


results in at least 25 battle-related deaths (Lacina, 2009; Lacina and Gleditsch, 2005). The present analyses will use the sum of the number of civil war deaths between 1994-2000 in each country (combined with deaths from terrorist actions and one-sided violence), providing for a measure of the scale and magnitude of current day armed conflict (Lacina, 2009). Battle deaths are deaths among the military and civilians during conflict or from wounds received during conflict resulting directly from violence inflicted through the use of armed force by a party to an armed conflict during contested conflict (Lacina and Gleditsch, 2005).

The number of deaths in civil wars from 1994-2000 were derived from the Battle Deaths Dataset 1946-2008 constructed by the Center for the Study of Civil Wars, International Peace Research Institute in Oslo, Sweden (Lacina, 2009; Lacina and Gleditsch, 2005). Between 1994 and 2000, there were 632,851 deaths from civil conflict worldwide (Figure 13). The majority of these deaths were in the African $(n=318,175)$ and European $(n=132,696)$ Regions, followed by the Eastern Mediterranean ( $\mathrm{n}=88,017)$, South-East Asia $(\mathrm{n}=81,099)$, The Americas $(\mathrm{n}=10,203)$ and Western Pacific $(\mathrm{n}=2,661)$ Regions. Many countries experiencing between 201 and 1,000 civil war deaths during this period were the African countries, including Somalia, Nigeria, The Democratic Republic of the Congo, Kenya, Egypt, Sierra Leone, South Africa and Angola. Other countries substantially contributing to this death toll, with deaths exceeding 1,000 , included Uganda, Turkey, Pakistan, India, Rwanda, Sri Lanka, Burundi, Columbia and Algeria.

\section{Deaths Resulting From One-Sided Violence}

In the past, the war literature has relied upon datasets with limited information on the deaths of civilians, including those due to genocide or mass killing (Azam and Hoeffler, 2002; Harff, 2003). New data on one-sided violence have recently become available through the Uppsala Conflict Data Program and the Department of Peace and Conflict Research, Uppsala University for the years 1989-2010 (Kreutz and Eck., 2011). One-sided violence is defined as 


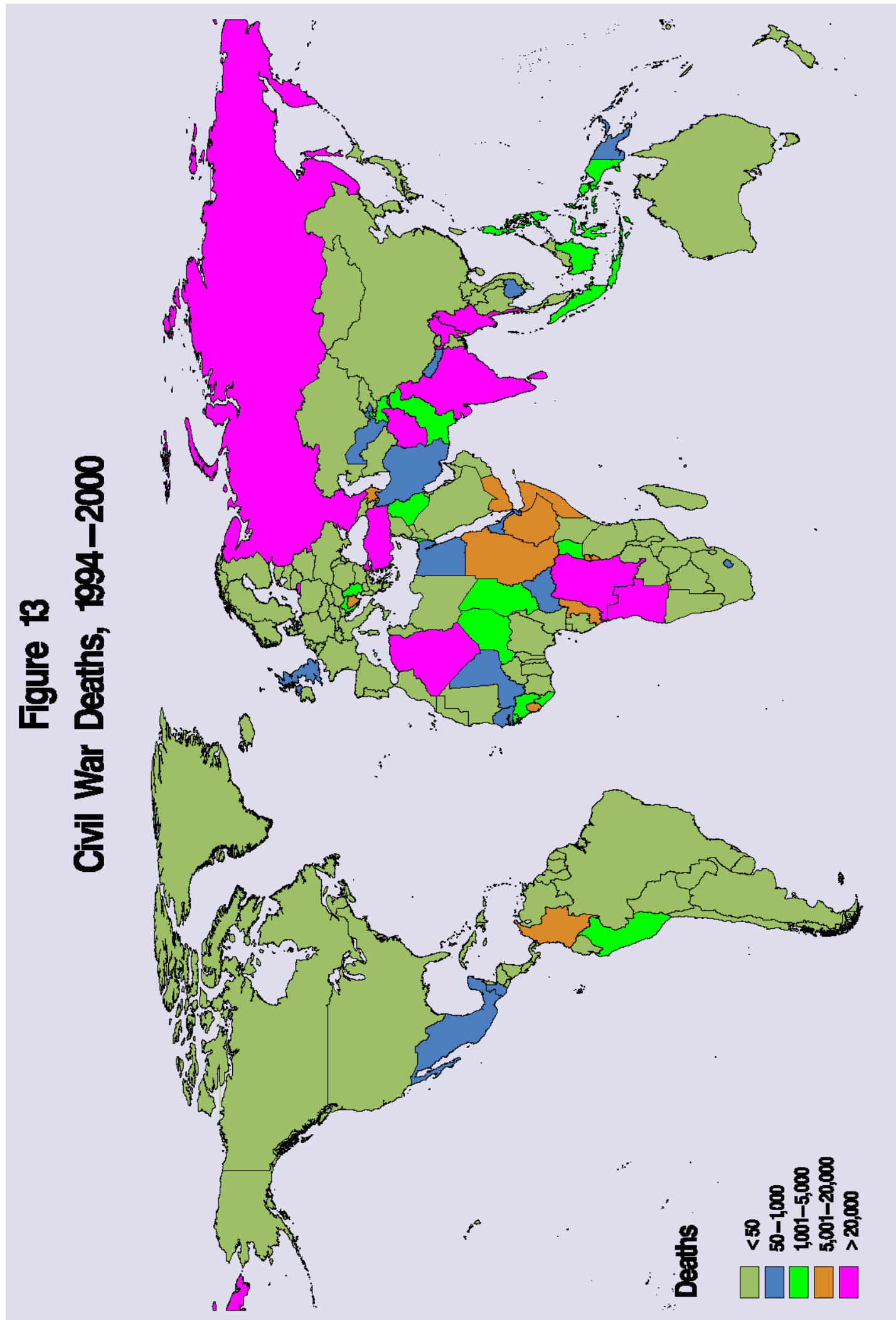


the use of armed force by the government of the state or by a formally organized group against civilians which results in at least 25 deaths and includes genocide and summary execution of prisoners (Kreutz and Eck, 2011; Kreutz et al., 2011). Unintentional killings, such as civilians caught in the crossfire, and indirect deaths, such as civilian deaths due to disease, are not counted. Because data on formally organized terrorist groups in this database overlaps with acts by non-state actors appearing in the GTD, only deaths resulting from one-sided violence occurring between 1994 and 2000 perpetrated by governments will be used.

In 1994, Rwanda experienced approximately 500,000 deaths resulting from genocide, an extraordinary number relative to the number of one-sided violence deaths occurring worldwide in other countries during 1994-2000, that is 27,895. Because the number of one-sided violence deaths occurring in Rwanda represented an extreme outlier, Rwanda was removed from all multivariable analyses conducted in this dissertation research. However, all descriptive statistics reported in this chapter include Rwanda.

During the years 1994-2000, there were 27,895 deaths worldwide resulting from onesided violence, excluding Rwanda (535,603 including Rwanda). As can be seen in Figure 14, those countries experiencing the greatest number of one-sided violence deaths from 1994-2000 perpetrated by government actors were Rwanda $(n=507,708)$; the Democratic Republic of Congo ( $\mathrm{n}=7,744)$; Afghanistan $(\mathrm{n}=6,454)$; Burundi $(\mathrm{n}=3,787)$; The Russian Federation $(\mathrm{n}=2,091)$; Sudan $(\mathrm{n}=1,479)$; Indonesia $(\mathrm{n}=1,056)$; and Myanmar $(\mathrm{n}=999)$.

Between 1989 and 2004, the vast majority of fatalities from one-sided violence have been shown to take place in countries experiencing both armed conflict and terrorism (Eck and Hultmann, 2007). Less than $1.0 \%$ of the total fatalities took place in countries that did not experience armed conflict and terrorism (Ericksson et al., 2003). These results strongly suggest that one-sided violence is closely related to the dynamics of armed conflict and terrorism and 


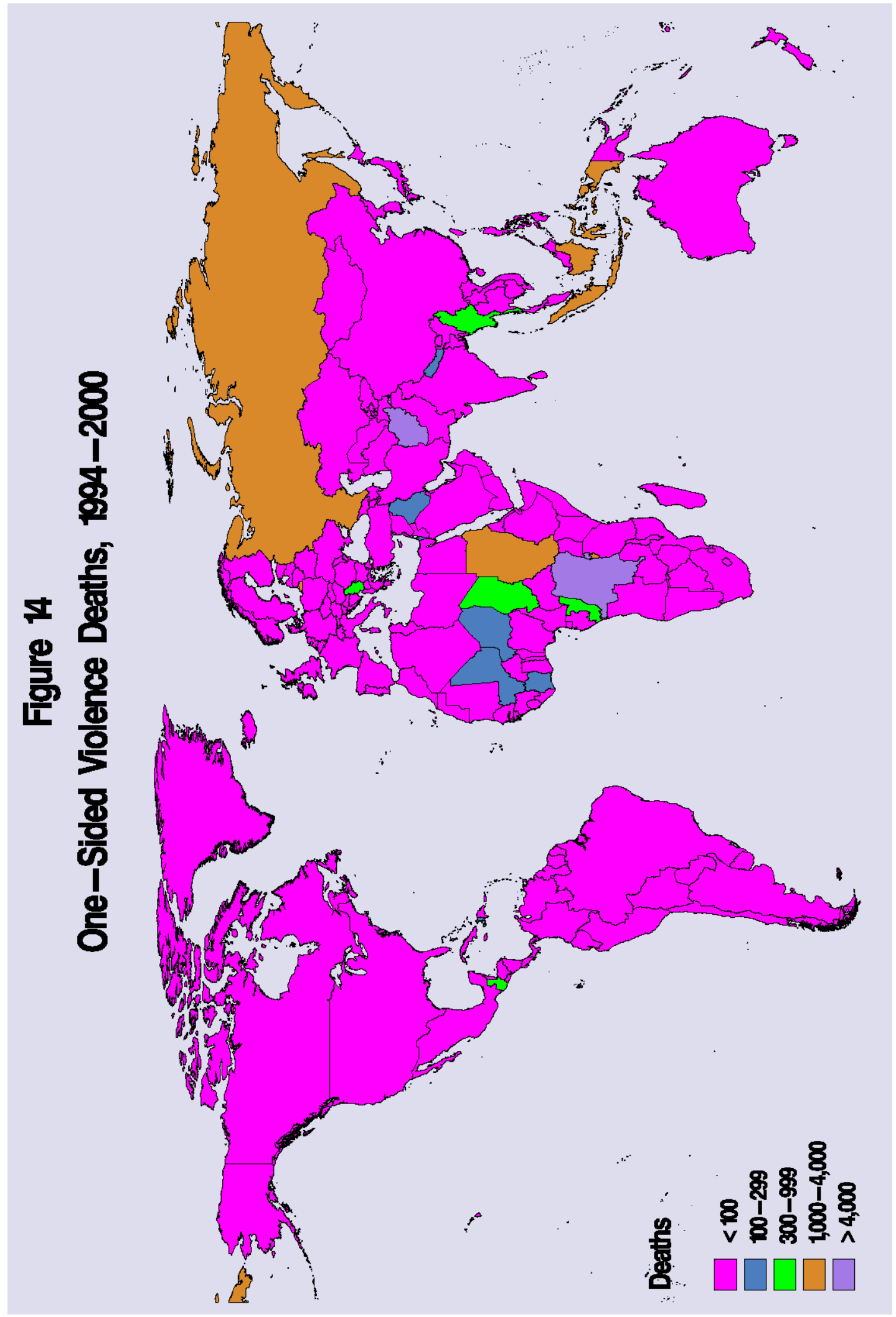


rarely occurs alone. For these reasons, deaths resulting from one-sided violence perpetrated by government actors were combined with those deaths occurring as the result of civil war and terrorist actions in this dissertation research. This aggregate continuous exposure variable (in thousands) was log transformed as the result of skew. Figure 15 shows the distribution of this combined exposure variable across countries which closely parallels those distributions observed for each form of violence when examined separately. [For additional descriptive statistics related to the terrorism, civil-war and one-sided violence exposure variable, see Appendix C].

\section{Control Variables}

\section{Economic and Related Variables}

Refugees, Asylum Seekers and Displaced Persons. Refugees are defined as people who, owing to a well-founded fear of being persecuted for reasons of race, religion, nationality or membership of a particular social group or political opinion, is outside of their country of nationality and is unable or, owing to such fear, unwilling to avail themselves of the protection of that country; or who, not having a nationality and being outside the country of his/her former habitual residence as a result of such events, is unable or, owing to such fear, is unwilling to return to it (United Nations High Commissioner for Refugees [UNHCR], 1995a; 1995b). Immigrants, on the other hand, move on their own free will for various economic and social reasons (Fagan, 1990). Thus, what differentiates refugees from immigrants is the threat of force. While mobile populations all face hardships resulting from exposure to foreign cultures and subsequent changes in personal identity, refugees are unique in that they experience trauma as a direct result of stress caused by conflict, isolation as well as the danger associated with their forced exile (Keyes, 2000; Stein, 1986). Internally displaced persons are an important subpopulation of those forced to leave their homes as a result of complex emergencies but have 


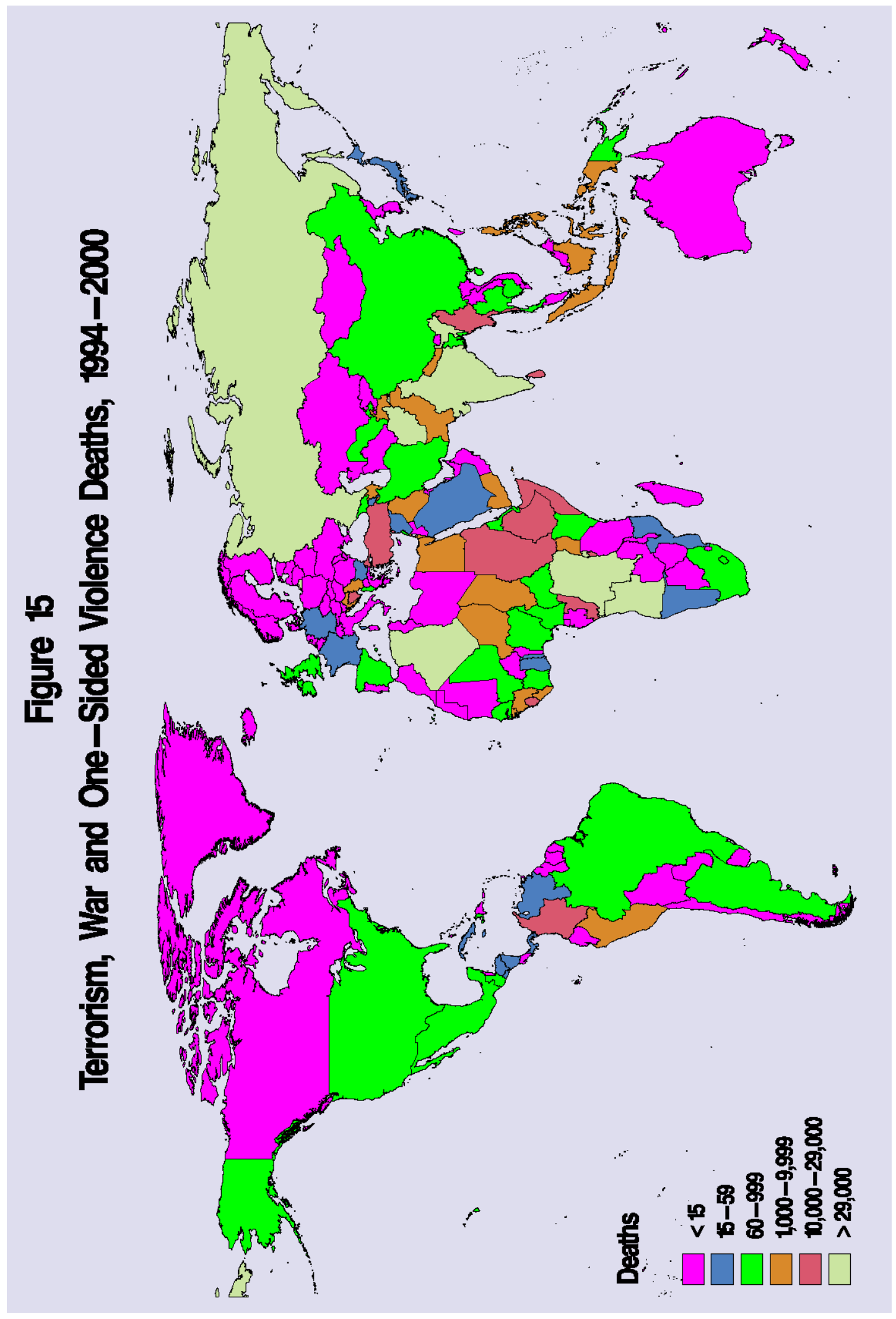


not crossed an international border. Asylum seekers are those individuals who seek international protection but whose claims have not yet been validated. These groups are collectively referred to as "persons of concern" by the UNHCR and are especially vulnerable to disease and disability, relative to the general population from which they derive as a consequence of their exposure to complex emergencies (Toole, 1997).

The experience of refugees has typically been broken down into two fundamental stagespre-migration and post-migration (Keyes, 2000). During the first stage, refugees directly experience trauma, including torture, imprisonment, loss of family members and fear of personal safety (Mollica, 1987). This is typically followed by brief period of emotional euphoria as a result of freedom from the threat of force. However, the post-migration period is typically marked by a number of additional stressors and threats to health. For externally displaced refugees not in refugee camps, the experience is defined by the need to adapt to new cultures, the inability to acquire employment within their new place of residence and the destruction of social support networks that can protect individuals from the psychological and economic challenges they may face (Beiser and Hyman, 1997; World Bank, 2009). Internally displaced and externally placed refugees in camps experience a different and frequently more unstable set of circumstances. Conditions of settlements, exposure of women and children to sexual and other assault and inadequate access to proper nutrition, safe water sources and the adequate sanitation facilities increases refugee's risk of mental and physical illness or even death. Premature mortality is also a major concern among refugees newly arriving at settlements or in neighboring countries. In the 1980s, death rates among newly arriving refugees in Somalia, Sudan and Thailand were between 20-to-30 times higher than baseline death rates in the refugees' country of origin (Toole, 1997; Toole and Wadlman, 1993). Improvements in the response and funding of international and regional organizations have helped to reduce 
premature mortality among newly arriving refugees, but crude death rates remain high. In the 1990s, newly arriving refugees in Ethiopia, Kenya, Malawai and Nepal suffered death rates 3.5to-13 times higher than baseline in their country of origin (Toole and Waldman, 1993). Following the crisis in Rwanda, refugees displaced in Zaire suffered death rates 40-to-60 times higher than the normal rate in Rwanda. In Somalia, death rates of internally displaced persons ranged from 2-to-5 times greater than the baseline death rates of Somali people (Moore et al., 1993). Among internally displaced populations, the risk of premature death is more difficult to quantify as the environment is often so volatile that surveys are impossible to conduct.

Mortality at refugee camps at the earliest phases of displacement is largely a consequence of preventable diarrheal diseases, malaria, acute respiratory infections or malnutrition (Toole, 1997). Resources are often scarce, especially with regard to the provision of proper nutrition. The immediate displacement phase is typically characterized by extremely high malnutrition. In the Sudan, malnutrition rates exceeded $60 \%$, while even higher rates were recorded in Somalia, as much as $80 \%$ (Moore et al., 1993). Additionally, many studies of civilian refugee populations in settlement camps have observed extremely poor sanitary conditions as well as significant crowding, which in turn increases the risk of disease transmission (Ahoua et al., 2006). Among Kurdish refugees in 1991, nearly $70 \%$ of all deaths were associated with outbreaks of cholera and other diarrheal diseases. Typically, countries experiencing mass population migrations due to complex emergencies also suffer high prevalence rates of HIV infection (Toole, 1997). It has been hypothesized that certain characteristics of displacement, such as changes in risky sexual behavior, scarcity of sex and sexual violence could lead to increased transmission of HIV across borders, throughout refugee settlements and among sex workers (Hanson et al., 2010; Khaw et al., 2000). 
Refugees, asylum seekers and displaced persons also suffer increased risk of mental illness as a result of significant trauma. However, each complex event brings with it a unique set of traumatic exposures, including torture (Carlson and Rosser-Hogan, 1991), sexual violence (Amanda et al., 2010), mutilation and machete wounds (Mitike and Deressa, 2009), loss of property (Carballo et al., 2004), detention (Steel et al., 2006) and threats or violence inflicted upon loved ones (Marshall et al., 2005). Variation in exposures during complex events, and the potential for multiple exposures, has in turn resulted in wide variation in symptom prevalence (Hollifield et al., 2002). However, almost all studies of refugees have found increased risk of many mental disorders, including depression, anxiety disorders, post-traumatic stress disorder, drug and alcohol abuse, schizophrenia, disassociation and psychosis (Allodi, 1991; Boyd and Nihart, 2007; Buchwald et al., 1991; Carlson and Rosser-Hogan, 1991; Ebata and Miyake, 1989; Turnip et al., 2010).

For the purposes of this dissertation research, the number of refugees, asylum seekers and displaced persons (in thousands) served as an important baseline control variable. This continuous variable was log transformed as a result of skew. Data were available from the UNHCR (1995a) and reflect the number of refugees, asylum seekers and displaced persons in each host country at the end of the year 1994.

At the end of 1994, approximately 24.2 million people were classified as refugees, asylum seekers and displaced persons by the UNHCR. With respect to the WHO regions, the largest number of refugees, asylum seekers and displaced persons were located in the African ( $\mathrm{n}=8.4$ million) and European ( $\mathrm{n}=8.1$ million) Regions. Nearly half ( $\mathrm{n}=10.6$ million) of the refugees, asylum seekers and displaced persons were located in seven developed or developing countries (Figure 16). These developing countries included: Mozambique ( $\mathrm{n}=1.7$ million); Islamic Republic of Iran ( $\mathrm{n}=1.7$ million); Bosnia and Herzegovina ( $\mathrm{n}=1.7$ million); the Russian 


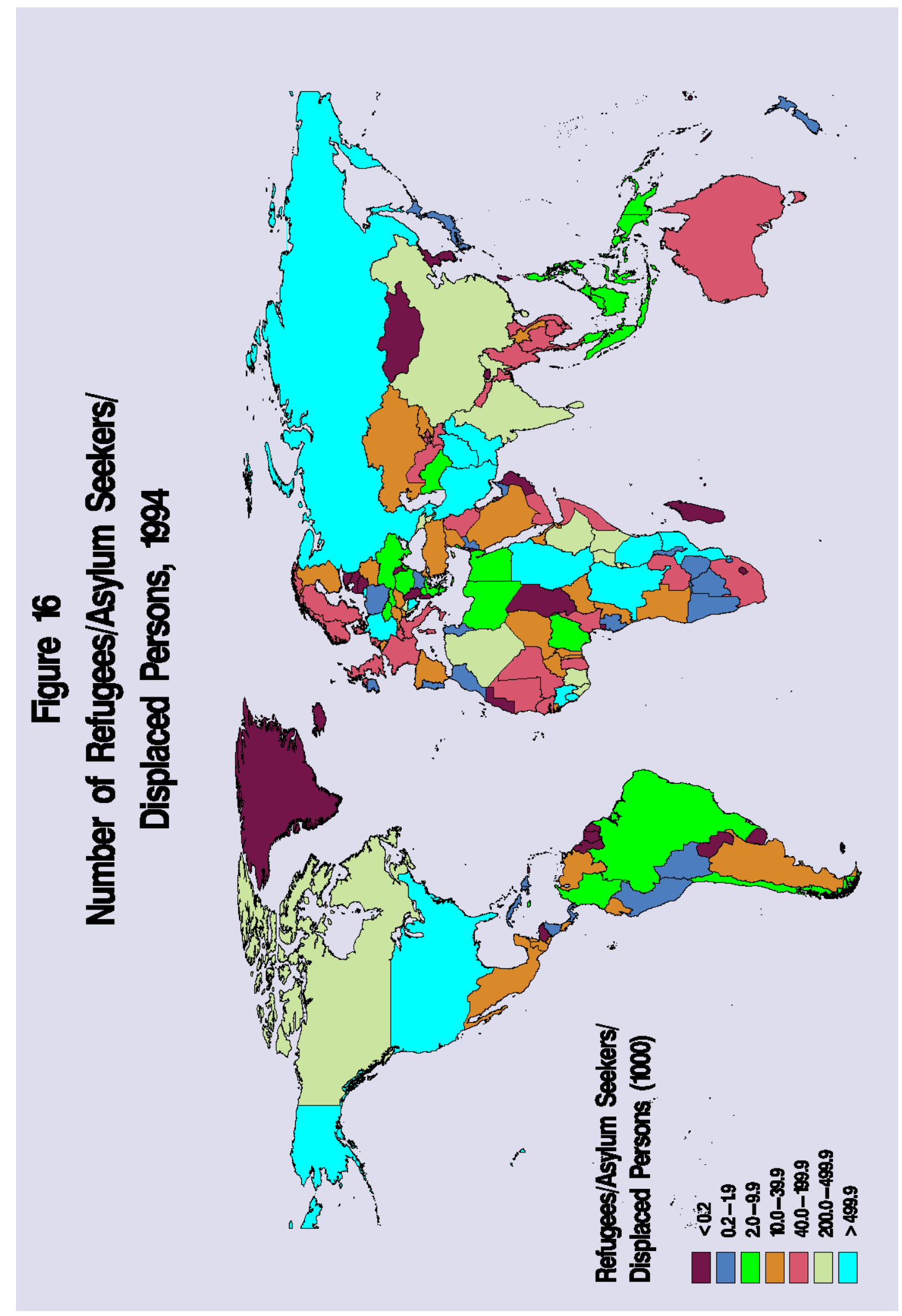


Federation ( $\mathrm{n}=1.4$ million); and the Democratic Republic of Congo ( $\mathrm{n}=1.3$ million). Two developed countries also hosted a large number of refugees, asylum seekers and displaced persons: Germany ( $\mathrm{n}=1.6$ million) and the United States of America $(\mathrm{n}=1.1$ million).

Number of Deaths, Homeless and Affected by Natural Disasters. Natural disasters are events in which a trigger is a natural phenomenon or hazard (biological, geological or climactic). They are large scale stressful events that affect a large number of people (Briere and Elliott, 2000). Natural disasters are fairly common in developed and developing countries (Green and Solomon, 1995). It is estimated that at least one natural disaster occurs somewhere in the world every day (McCoy, 2008; Norris et al., 2002). A defining characteristic of natural disasters is that health and economic losses disproportionately affect developing countries and primarily affect the poor within those countries (Fogarty International, 2007). While total economic losses due to natural disasters in developed countries exceed those in developing countries, the percentage of losses relative to gross national product in developing countries greatly exceeds that of developed countries. Further, people in developing countries are four times as likely to die from extreme natural events as those in developed countries (WHO, 2002a).

The immediate health impacts of natural disasters include illness, disability and death, direct losses in infrastructure and loss or disruption in health care services. As a result, natural disasters are typically associated with the spread of infectious diseases. For example, three times in the past thirty years, Bangladesh has experienced severe flooding, in which at least $25 \%$ and as much as $50 \%$ of the country was submerged (Schwartz, 2006). In each flood, critical infrastructure was destroyed, water was contaminated and epidemics of diarrheal diseases occurred (Rashid, 2000). While disruption of purification systems and the leaking of sewage systems into drinking water were primarily responsible for the spread of disease, secondary 
effects including crowding also played a vital role in the development of diarrheal outbreaks in India and other developing countries such as Mozambique (Aghababian and Teuscher, 1992; Kondo et al., 2002).

However, while the spread of infectious diarrheal diseases are most typically associated with the immediate aftermath of natural disasters, respiratory infections, adverse psychosocial outcomes and chronic diseases can linger long after the disaster has occurred. Nearly all disasters, whether a volcano, earthquake, hurricane or flood, release high concentrations of aerosolized particulate matter. Inhalation exposures of chemicals and particulate matter are frequently complicated by exposure and inhalation of the incomplete particles of combustion released during explosions, collapses and fires (Prezant et al., 2008). Following a disaster, bronchial hyperactivity may occur quickly, within 3 hours, and persist for considerably longer than a year (Baxter et al., 1983; Chia et al., 1990; Kinsella et al., 1991). Further, exposure to aerosolized building materials in earthquake collapse zones following fires, earthquakes and other disasters have been associated with chronic inflammatory syndromes involving the respiratory system (Lockey et al., 2007). Natural disasters frequently mimic those of man-made disasters, cause widespread destruction of infrastructure and thus provide crucial insights into the relationship between natural disasters and respiratory health outcomes. A number of studies among rescue workers and construction workers in New York City following the September 11, 2001 terrorist attacks found increased chronic upper and lower respiratory symptoms as a result of exposure to dioxins, volatile organic compounds, asbestos, silica and other contaminants (Centers for Disease Control and Prevention, 2004; Fireman et al., 2004; Herbstmann and Frank, 2005; Salzman et al., 2004).

The association between exposure to natural disasters and mental health is also well established in the literature and has been examined in the context of earthquakes (Carr et al., 
1997; Xu and Liao, 2011), floods (Norris et al., 1994), hurricanes (Burnett et al., 2011; Fussell and Elliott, 2009; Wagner et al., 2009), tornados (Greenbough et al., 2001) and fires (McFarlane, 1994). This association has been found for many psychological syndromes including substance abuse (McFarlane, 1994), depression (Green and Solomon, 1995), anxiety disorders (Fan et al., 2011; Phifer and Norris, 1989) and especially posttraumatic stress disorder (Adams and Boscarino, 2011; McMillen et al., 1997; Tracy et al., 2011; Xu and Liao, 2011). In general, the prevalence of certain mental illnesses are more likely to increase as a result of exposure to natural disasters but generally decline over time, often to pre-exposure levels (Holen, 1993; Johnsen et al., 1997). However, the severe nature of many natural disasters frequently leave victims feeling pain, distress and discomfort for years after the event has occurred. Variations in mental health outcomes are likely due to differences in severity characteristics of the disasters and the populations affected (Green and Solomon, 1995). These characteristics typically involve direct physical injury to oneself or witnessing the injury of others and personal property loss (Bravo et al., 1990).

The longer-term impacts of natural disasters include losses in the production of goods and services and reduced income (Guha-Sapir et al., 2011). Damage to water, sewage, channels of communications, schools, industry and health infrastructures have the biggest impact on health. Women and children are particularly vulnerable populations to the effects of natural disasters. While there exists a paucity of research on the differential impact of disasters by gender, most evidence suggests that women face different and unique consequences as a result of biological, social, cultural and reproductive differences. During earthquakes in India and cyclones in Bangladesh, women frequently relied upon male evacuation decisions before leaving the home. As a result, thousands of women perished. Women also face increasing violence in the aftermath of disasters which result in short and longer-term health consequences, such as 
depression and disfigurement (Thornton and Voight, 2007). Further, access to contraceptive and prenatal care and prevention of sexually transmitted diseases is greatly diminished in the event of natural disasters (Al Gasseer et al., 2004).

There is also significant evidence to suggest that natural disasters are associated with increased risks of civil conflict and related violence. Specifically, when examining 187 countries, Nel and Righarts (2008) found that rapid onset natural disasters (such as earthquakes) increased the risk of civil conflict. Typically, these findings were restricted to developing countries, with high inequality and mixed-regime types (Olson and Drury, 1997). In short, disasters magnify the economic and political problems facing a population and generate new problems, including the distribution of food and medical supplies. In some cases, such as Guatemala and Nicaragua in 1976 following an earthquake, the government was removed as a result of inadequately responding to the disaster. Other times, rebel or terrorist organizations have attempted to gain political advantage by highlighting unequal distribution of resources following disasters or by providing resources themselves (Hoffman and Oliver-Smith, 2002).

The control variable used in this dissertation research combines the number of deaths (persons confirmed as dead or missing), number of homeless (persons needing immediate shelter), and number of affected (i.e. people requiring immediate assistance in basic survival needs such a food, water and sanitation) by natural disasters (in thousands) occurring at the country level for the years 1994-2000. This continuous variable was log transformed as the result of skew. Data were available from the Emergency Events Database (EM-DAT) maintained by the WHO Collaborating Center for Research on the Epidemiology of Disasters (CRED) (Guha-Sapir et al., 2004). A disaster event is defined by CRED if it meets one or more of the following criteria: there are 10 or more people reported killed; there are at least 100 
people reported affected; or the disaster leads to the declaration of a state of emergency or leads to calls for international assistance.

During the years 1994-2000, approximately 1.1 billion persons were left dead, homeless or seriously affected by natural disasters. As can be seen from Figure 17, natural disasters were fairly common in most countries during 1994 and 2000. However, the majority of the loss resulting from disasters disproportionately impacted developing countries. By far, the Western Pacific Region had experienced the largest number of deaths, homeless and affected by natural disasters between 1994 and 2000 or about 565.9 million, followed by the South-East Asia Region with 303.1 million deaths, homeless and affected. Corresponding figures for the African, Eastern Mediterranean, The Americas and European Regions were approximately 65.2 million, 57.6 million, 33.7 million and 20.5 million, respectively.

Countries most affected by disasters in the Western Pacific Region included China, the Philippines, South Vietnam, the Democratic People's Republic of Korea and Cambodia with about 500.0 million, 21.1 million, 20.9 million, 18.8 million and 11.4 million persons left dead, homeless and affected by natural disasters, respectively. Among the South-East Asian countries, India, Bangladesh and Thailand were most seriously impacted by natural disasters with approximately 213.2 million, 47.8 million, and 13.5 million deaths, homeless and affected. Significant numbers of people in the Islamic Republic of Iran ( $n=37.5$ million), Kenya ( $n=33.6$ million) and Brazil ( $\mathrm{n}=10.8$ million) were also impacted by natural disasters during the years 1994 to 2000.

\section{General Government Expenditures on Health as Percentage of Total Government}

Expenditure. It is a longstanding and generally accepted economic principle that morbidity and mortality are reduced through public and private investments in health, sanitation and nutrition. Health economists have continually observed that 'wealthier is healthier' (Organization for 


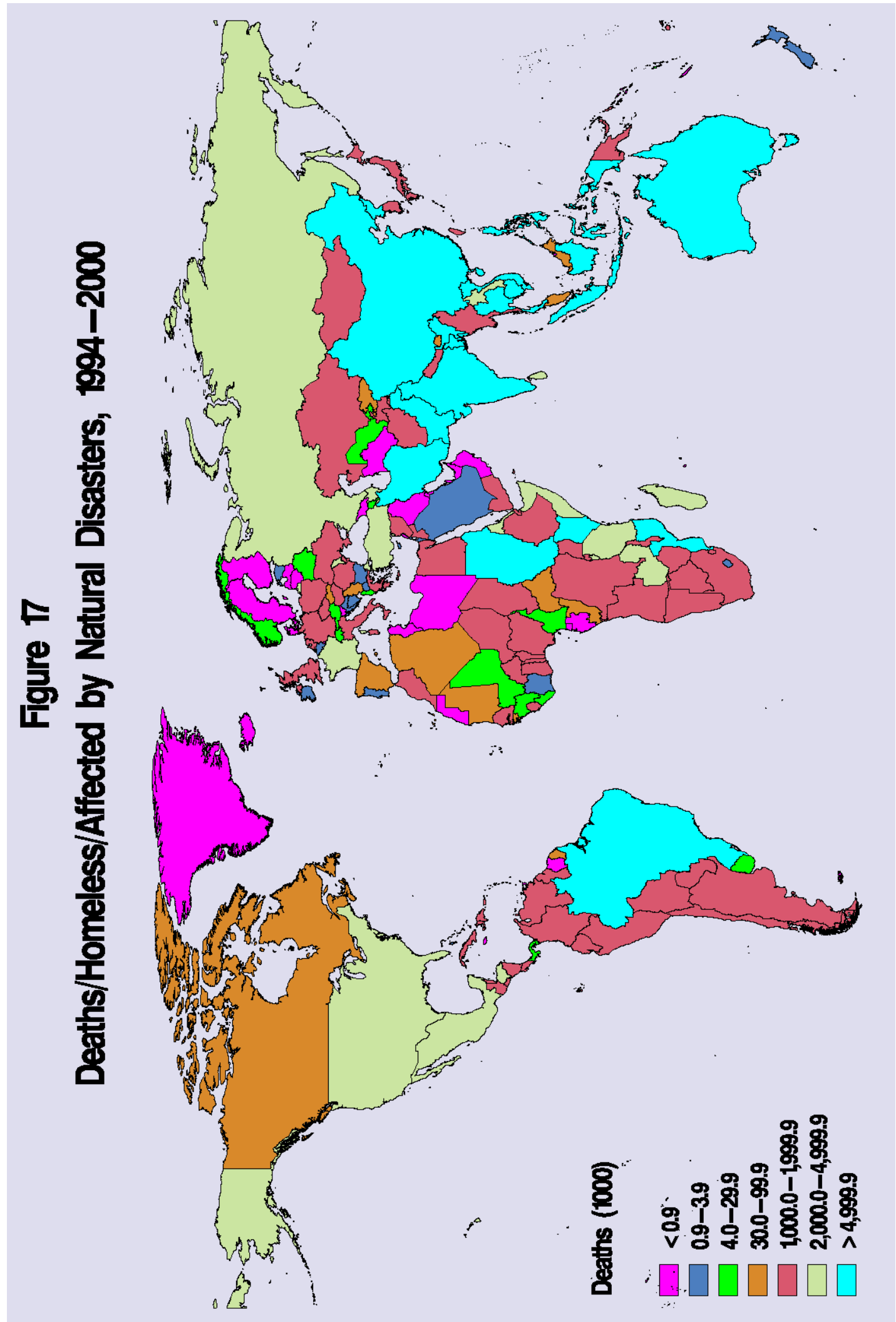


Economic Co-Operation and Development ((OECD), 2000; Theo, 1992). That is, since high per capita income has been observed to be associated with high levels of health expenditures, it is predicted that countries with higher per capita income (and thus higher health expenditures) would have better health. That these health expenditures reduce morbidity and mortality was also observed in patterns of life expectancy and infant mortality in Europe. As total health expenditures in the European Union (EU) rose from 3.4\% to 7.7\% between 1960 to 1995, infant mortality declined, life expectancy at birth for males and females rose, and other health outcomes also improved (OECD/CREDES, 2000).

However, with few exceptions, the early literature on comparative health expenditures did not find relationships between health expenditures and health status. This initial finding, that health expenditures and health were not associated, rested on the now erroneous assumption that medical care expenditures were a luxury good with a marginal effect on health. Another limitation of this earlier research was that it was typically restricted to the use of relatively small samples of cross-sectional data. One author remarked that 'it seems to us surprising that the results of this approach have passed so quickly and uncritically into the assimilative knowledge of health economics, when they are based on such unsophisticated econometric modeling of such small data sets' (Pierre-Yves et al., 1999; Theo and Posnett, 1992). Additionally, these studies failed to account for individual decisions regarding nutrition and lifestyle, sociodemographic, and other characteristics such as the physical and natural environment within each country (Roberts, 1999).

A more contemporary review paper concluded that health expenditures were significantly associated with improved health outcomes in over $80 \%$ of the studies under review (Nixon and Ulmann, 2006). The authors further conducted an independent econometric analysis of 15 OECD states to determine the association between health expenditures and health 
outcomes between the years 1980-1995. They found that health expenditures were significantly associated with decreasing infant mortality and increasing life expectancy at birth for both men and women. These observations are consistent with other contemporary research of health macroeconomists of OECD countries (Majnoni and Ulmann, 1999).

Although previous analyses were restricted to developed countries, there is considerable evidence to suggest that even small changes in health expenditure in developing or intermediate countries would have a larger impact on health outcomes than in developed countries. Over the last decade, researchers have observed a reduction in public spending per capita in health across low-income countries since 1990 (Jowett, 1999). As expected, various health outcomes have worsened. However, developing countries were more sensitive to changes in health expenditures than previously anticipated. In developing countries, the highest fraction of deaths are due to infectious and parasitic diseases (e.g. malaria, tuberculosis, etc.). Among the most deadly diseases for children under the age of 5 years are diarrheal diseases and acute respiratory infections.

Health expenditures, unlike income, are influenced by political processes that determine the level and allocation of health expenditures that impact actual health outcomes such as DALYs due various diseases and conditions. This indicator contributes to our understanding of the weight of public health spending on government budgets and expenditures on health by extrabudgetary entities, notably compulsory health insurance (Deaton, 2002). Terrorism, war and one-sided violence reduce the pool of human and financial resources available for public health care expenditures, constrain the level of resources allocated to the public health care system and reduce the efficient use of resources allocated to public health, and these effects extend to the post-conflict period (Chanda et al., 2011). 
This dissertation research uses the WHO health financing indicator general government health expenditures as a percentage of total government expenditure (GGHE as a percentage of TGE) in 1994, as a critical economic control varriable. This core indicator of health financing systems contributes to the understanding of the weight of public spending on health within public sector operations (WHO, 2011c). This indicator includes resources channeled through government budgets (e.g. Ministries of Health) in addition to expenditures on health by parastatal organizations or social security agencies, and notably compulsory health insurance. All of these resources are collected and pooled by public agencies, including revenue modalities. Data on GGHE as a percentage of TGE for 1994 was available from the WHO Global Health Observatory Database (WHO, 2011a).

Globally, the average GGHE as a percentage of TGE was $10.1 \%$ in 1994 . Among those 20 countries with the lowest $(<5.0 \%)$ GGHE as a percentage of TGE, eleven were among those within high child and/or high to very high adult mortality strata (Figure 18). These included Afghanistan, Iraq and Zimbabwe, where GGHE as a percentage of TGE was close to $0.0 \%$ and several countries in the WHO African Region with corresponding percentages between 3.8\% and 4.9\%, including Eritrea, Guinea, Liberia, Côte d'Ivoire and Gabon. Eastern Mediterranean countries also had some of the lowest GGHE as a percentage of TGE: Pakistan (2.6\%); Somalia (4.0\%) and Cyprus (4.6\%). Similarly, India (4.1\%) and Myanmar (1.5\%) were the two SouthEast Asian countries with very low GGHE as a percentage of TGE that also have high child and adult mortality status. Interestingly, several countries classified within the low or very low child and adult mortality strata had relatively low GGHE as a percentage of TGE including Georgia (2.3\%), Morocco (3.8\%), Indonesia (4.1\%), Brunei Darussalam (4.2\%), and the Lao People's Democratic Republic (4.6\%). 
As can be seen in Figure 18, those countries with the greatest GGHE as a percentage of TGE (> 15.0\%) were located primarily in The Americas (15.0\%-to-27.6\%), as well as in Germany (15.0\%), France (15.2\%), Serbia and Montenegro (15.2\%), Japan (15.7\%), Marshall Islands (15.9\%), Iceland (16.1\%), San Marino (17.8\%), Bulgaria (19.8\%), Democratic People's Republic of Korea (20.0\%) and Andorra (23.6\%).

Pace of Urbanization. The world has experienced dramatic and unprecedented urban growth over the last two centuries. By the $18^{\text {th }}$ Century, only $3 \%$ of the total population lived in urban areas (Caracci, 2008). By 1900, the percentage of people living in urban areas had tripled, and by 2007, for the first time in world history, over half of the world's population was concentrated in urban areas (Patel and Burke, 2009; UN, 2005). Currently, there are about 50,000 cities with a population greater than a million people (UN Human Settlements Programs, 2001).

Dramatic new trends in urban growth affect both developed and developing nations alike. While most countries in Europe, North America and Oceania experienced rapid urbanization during the $19^{\text {th }}$ Century, and currently show high rates of urbanization, they continue to experience slow urban growth (Alirol et al., 2010). In developing countries, especially tropical countries, the processes of urbanization work at a more chaotic pace. In less than a decade, more than 870 million people in China alone will be living in urban areas and in Botswana, urban areas are expected to triple (Patel and Burke, 2009). This 'chaotic urbanization' may account for nearly all population growth in the coming decades. Urban growth is problematic for developing countries since between $30 \%$ and $60 \%$ of people who reside in large urban cities live in abject poverty and slums (Population Reference Bureau, 2002).

There is no universally accepted definition of what constitutes 'urban' (UN, 2005). The term urbanization refers to "the process whereby a society changes from a rural to an urban way 


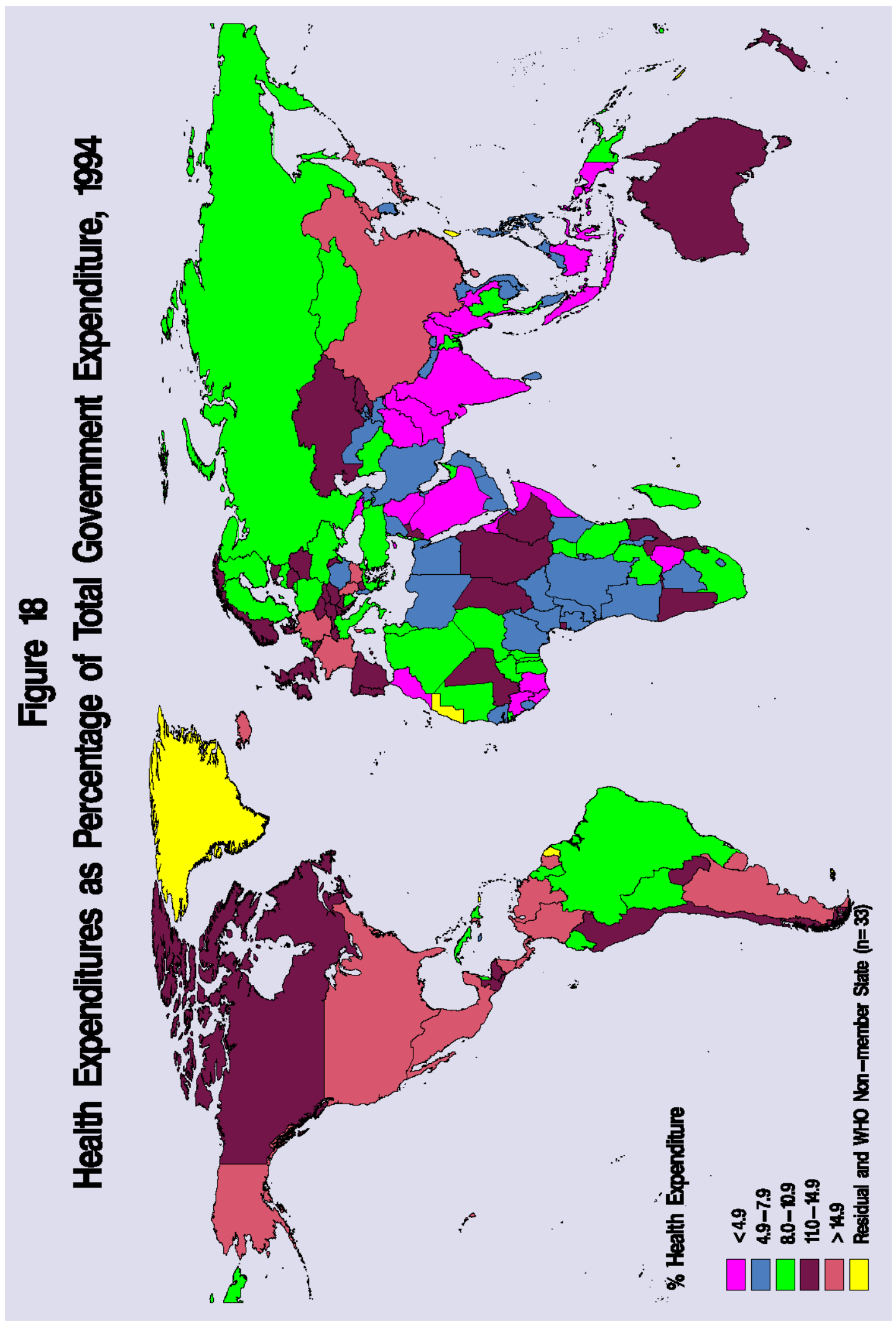


of life" and also refers to "the gradual increase in the proportion of people living in urban areas" (Flourney, 2004).

In general, urbanization is conceptualized through a set of common characteristics of urban settings. These features include: changes in size; heterogeneity and distance from other urban centers; density; population mobility; industrialization; increasing proximity between the wealthy and the poor, and economic activity (Marsella, 1998; Vlahov and Galea, 2002). When collecting data on urbanicity, the UN accepts each country's definition of 'urban' and has set no international standard. Vhalov and Galea (2002) show that among 228 countries from which the United Nations collect data, roughly $25 \%$ define urbanicity using basic administrative criteria (e.g. size and density) and nearly 1 in 8 use functional characteristics. Accordingly, there exists some degree of variation in this measure between countries at a given time as well as within the same country over time.

A contentious debate has emerged around what factors of the urban context most critically influence health outcomes (Flourney and Yen, 2004; Vhalov and Galea, 2002). At the forefront of the debate was the aggregation of several groups of studies under the rubric of "urban studies." Much of this work suggests that urban residents have worse health than nonurban residents, a disparity labeled the "urban health penalty" (American College of Physicians, 1997). Proponents of the urban health penalty posit that cities are areas highly concentrated with poor and disenfranchised people. Urban settings are expected to expose residents to unhealthy environments which in turn lead to disproportionately poor health (American College of Physicians, 1997; Galea and Vhalov, 2002). This approach has been criticized for equating 'urbaness' with class and race, equating urban health with conditions among the minority and poor in cities, failing to address that urban characteristics can improve health for some, and failing to describe the specific characteristics that are associated with ill-health (American 
College of Physicians, 1997). A number of authors propose a more robust framework for understanding the relationship between urbanicity and negative health outcomes in which multiple levels of influence shape population health. Specifically, health outcomes are influenced by municipal factors, civil society and national and global trends (Allender et al., 2008; Mendez and Popkin, 2004).

Among those characteristics of the physical urban environment that have been empirically shown to increase morbidity and mortality is the built environment. These factors included the density of development, mixed land use, scale of streets, aesthetic qualities of place, connectivity of streets and maintenance of public spaces (Harphan and Tanner, 1995; Mohan et al., 2008). Urban infrastructure, water and sanitation also play a vital role in the transmission of infectious diseases as municipalities increasingly struggle to provide services for growing populations. Inadequate provision for solid waste collection frequently leads to contamination of water bodies and has been shown to present substantial risk for spreading epidemics rapidly (Alexander and Ehrlich, 2000; Handy et al., 2002). Urban climate has been shown to be as much as $5^{\circ} \mathrm{F}$ warmer than surrounding areas, an effect known as the urban heat island effect. Heat related deaths and injuries often become epidemic in urban areas, especially among impoverished and older groups (Chanthikul et al., 2004).

Pollution also plays a critical role in the development of disease. Cities contribute more than $80 \%$ of global carbon dioxide emissions. During the 1990 s, pollution contributed nearly 60,000 deaths per year in the United States alone, and nearly 1 billion individuals worldwide in urban areas were affected by atmospheric pollution (Cohen et al., 2003; Mackenbach et al., 1997). Other factors of the physical urban environment may also have important relationships with human health. Noise exposure has been associated with hearing impairment, hypertension and ischemic heart disease (Dockery et al., 1993). Other threats to health include proximity to 
hazardous waste landfills, a factor that has been associated with low birth weight, birth defects and some cancers. Lastly, a substantial literature supports the association between the availability of green spaces and parks with specific health outcomes. Living areas with green spaces are associated with decreased cardiovascular risk, improved health of the elderly and increased physical activity (Passchier-Vermeer and Passchier, 2000; Vrijheid, 2000).

The urban social environment or occupational structure, labor markets, social and economic processes, wealth, social, human and health services, power relations, government, race relations, social inequality, cultural practices, the arts, religious institutions and practices, and beliefs about place and community also influences morbidity and mortality (Takano et al., 1996). Among the fundamental characteristics of the social environment are social disorganization and social strain. Contemporary anomie/strain theories suggest that strain in modern urban living are associated with deviant behavior and poor health (e.g. crime) (Agnew, 1992; Galea et al., 2002). Disease can also be spread through processes of social contagion. Contagion theories of social organization predict that group practices and social norms will influence the transmission of certain infectious diseases such as HIV (Pick and Obermeyer, 1996). Urban populations, by virtue of population density, are also assumed to present higher risks for transmission of biological organisms. Lastly, spatial segregation may also be an important determinant of health. Segregated communities frequently face disproportionate access to health care services, the quality of health care and the political power to redistribute resources (Mayberry et al., 2000).

However, while many researchers argue that urbanicity is associated with increasing levels of morbidity and mortality, others argue that urban environments may be healthier than their rural counterparts (Montgomery et al., 2003). Some evidence supports the 'urban health' hypothesis, and this can be explained by better access to health care and education. However, it 
should be noted that while urban populations have become healthier, they have also experienced a dramatic shift from infectious to chronic illness. This movement toward chronic illness has often been called the "epidemiological transition or health transition" (Alirol et al., 2011; Lopez and Mathers, 2006a; 2006b; Lopez et al., 2006).

Urbanization could, thus, result in either an overall global increase or decrease in morbidity and mortality. During the period of observation in this study (i.e. 1990 to 1995) most urbanization was occurring in less developed tropical regions while urban growth among developed countries was relatively stable (Alirol et al., 2003). The epidemiologic transition was well established in developed countries but well beyond the reach of developing countries. Although chronic diseases were becoming increasingly important in developing countries, infectious diseases remained the leading causes of morbidity and mortality. Ultimately, individual characteristics of each country experiencing significant urban growth (i.e. ability of health care system to manage growth; income disparity, heterogeneity of populations within the city space) will determine the nature of the relationship.

The measure of urbanization used as a control variable in this dissertation research was the average percentage change in the urban population between 1990 and 1995 . These data are collected routinely by the UN Department of Economic and Social Affairs and available on the UN Millennium Goals Database (UN, 2011b).

The majority of urban growth occurring between 1990 and 1995 was clearly among developing countries (Figure 19). These countries were located largely in the African and Eastern Mediterranean Regions in which urban growth equaled or exceeded 2.0\%: Botswana (3.1\%); Sudan (3.3\%); Burundi (3.2\%); Angola (3.5\%); Rwanda (4.2\%) and Mozambique (4.4\%). Similar urban growth was observed in Indonesia (3.0\%) and Nepal (4.2\%). Over the 


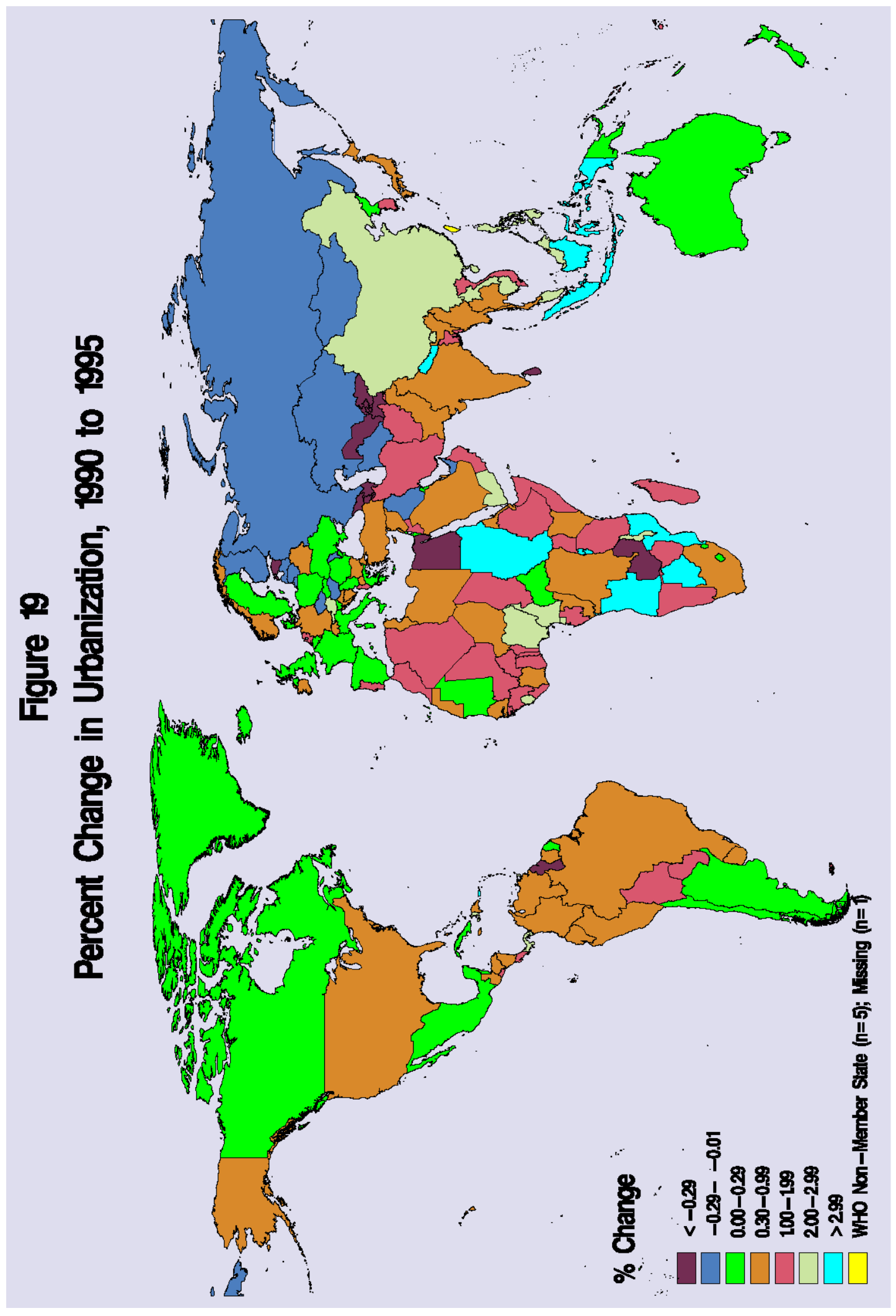


last 20 years, several countries have seen such rapid growth in their economies that in 2011 they were classified as newly industrialized countries (NIC) by the International Monetary Fund (2011). NICs are nations with economies more advanced and developed than those in the developing world, but not yet with the full signs of a developed country. Consistent with their newly classified economic status, NIC countries such as the Philippines (2.0\%), Malaysia (2.2\%) and China (2.7\%) showed high urban growth between 1990 and 1995 . With few exceptions, The Americas and the European Regions, most of the Eastern Mediterranean and Western Pacific Regions and India experienced less than a 1.0\% change in urbanization between 1990 and 1995.

Tropical Country Status. Tropical climate is considered a critical determinant for the development of infectious and parasitic diseases and must be controlled in models in which diarrheal and related conditions (Paper 2) and other communicable disease DALYs (Paper 1) serve as the major outcome variables. Tropical diseases are defined as those diseases found predominantly in the Tropics where the ecological and socioeconomic conditions allow for the propagation of disease. Vector borne diseases account for roughly $16 \%$ of global communicable disease burden and make up the majority of tropical diseases (WHO, 2008a).

The 17 neglected tropical diseases profiled in the first WHO report on tropical diseases are held in common through several distinct features (Remme et al., 2002). Foremost, they are frequently a proxy for disadvantage. Developing countries bear the greatest burden associated with diminished quality of life, productivity loss, high costs of care and mortality. These diseases are most commonly associated with the most politically marginalized populations least capable of soliciting resources for the reduction of disease in their communities. These diseases are not known to travel widely and thus the threat to developed countries is small (Bradley, 1998). These diseases disproportionately affect girls and women and frequently cause 
permanent dysfunction and disfigurement, leading to persistent and debilitating social discrimination (WHO, 2010b). Assumptions continue to exist about the impact of these diseases on different populations. Most importantly, it has been erroneously assumed that many of these diseases have low rates of mortality. This assumption has largely been refuted in a growing literature, but lingers in the policy realm, where those most capable of providing resources to fight disease operate (Gwatkin et al., 1999).

The costs associated with reducing or eliminating these diseases are extremely low and are easily implemented even in the most troubled economic and social environments. Several economic analyses of de-worming campaigns in Cambodia, Myanmar, Egypt, Ghana and Tanzania estimated a cost of U.S. $\$ 0.07$ per round of drug administered (Montresor et al., 2010). Astoundingly, these calculations include the costs of training, monitoring, health education and the distribution of medicines. Cost-effectiveness studies have also found other disease interventions to be similarly inexpensive. The cost associated with averting a single schistosomiasis DALY range between U.S. \$10-23 dollars; averting a single leishmaniasis DALY costs U.S. \$11-22 and averting a single human African trypnosomiasis DALY costs less than U.S. \$12 per day (Conteh et al., 2010).

The economic consequences of tropical diseases are significant, and serve to reduce the overall pool of resources available for the development of modern infrastructures and health services. While a considerable amount of tropical disease burden is unquantifiable, efforts have been made to estimate the overall economic impact of tropical disease on populations (Momson and Kinnard, 1993). For example, the average global expenditures for rabies prevention and control exceeds U.S. \$1 billion per year and the productivity loss associated with lymphatic filariasis exceeds U.S. \$1 billion per year (Ramaiah, 2000). 
Climate change is also increasingly implicated as a factor influencing the range and spread of vector and reservoir species for infectious disease. The Intergovernmental Panel on Climate Change (IPCC, 2001) has predicted that the global temperature is likely to increase by between $1.4^{\circ} \mathrm{C}$ and $5.8^{\circ} \mathrm{C}$ between 1990 and 2100 . These changes in global temperature are expected to exceed any natural change in world climate in the last 10,000 years. While the overall impact of these climactic changes on human health is unknown, several global and regional models of disease transmission have been developed for malaria, dengue fever, schistosomiasis and viral encephalitides (McMichael et al., 1996; Patz et al., 1996). The IPCC concluded that: 'In areas with limited or deteriorating public health infrastructure, and where temperatures are now or in the future permissive of disease transmission, an increase in temperatures (along with adequate rainfall) will cause certain vector-borne diseases (including malaria, dengue and leishmaniasis) to extend to higher altitude" (IPCC, 2001). Malaria, like many vector borne tropical diseases, are limited by climactic tolerance of mosquito vectors and increasing temperature is expected to increase the distribution by extending the months of transmission (Kovats et al., 2001; Lieshout et al., 2004; Sutherst, 1998).

For this dissertation research, tropical country status will be operationalized as a dichotomous variable $(1=$ at least one-half of land mass in the tropics and $0=$ less than one-half of land mass in the tropics). The tropics include countries in part or entirely located between the Tropics of Cancer and Capricorn. Data on tropical country status is collected by the International Union for the Conservation of Nature (2000). Figure 20 shows countries with less than or greater than or equal to one-half of their land mass in the tropics along with those countries with no land mass in the tropics. 


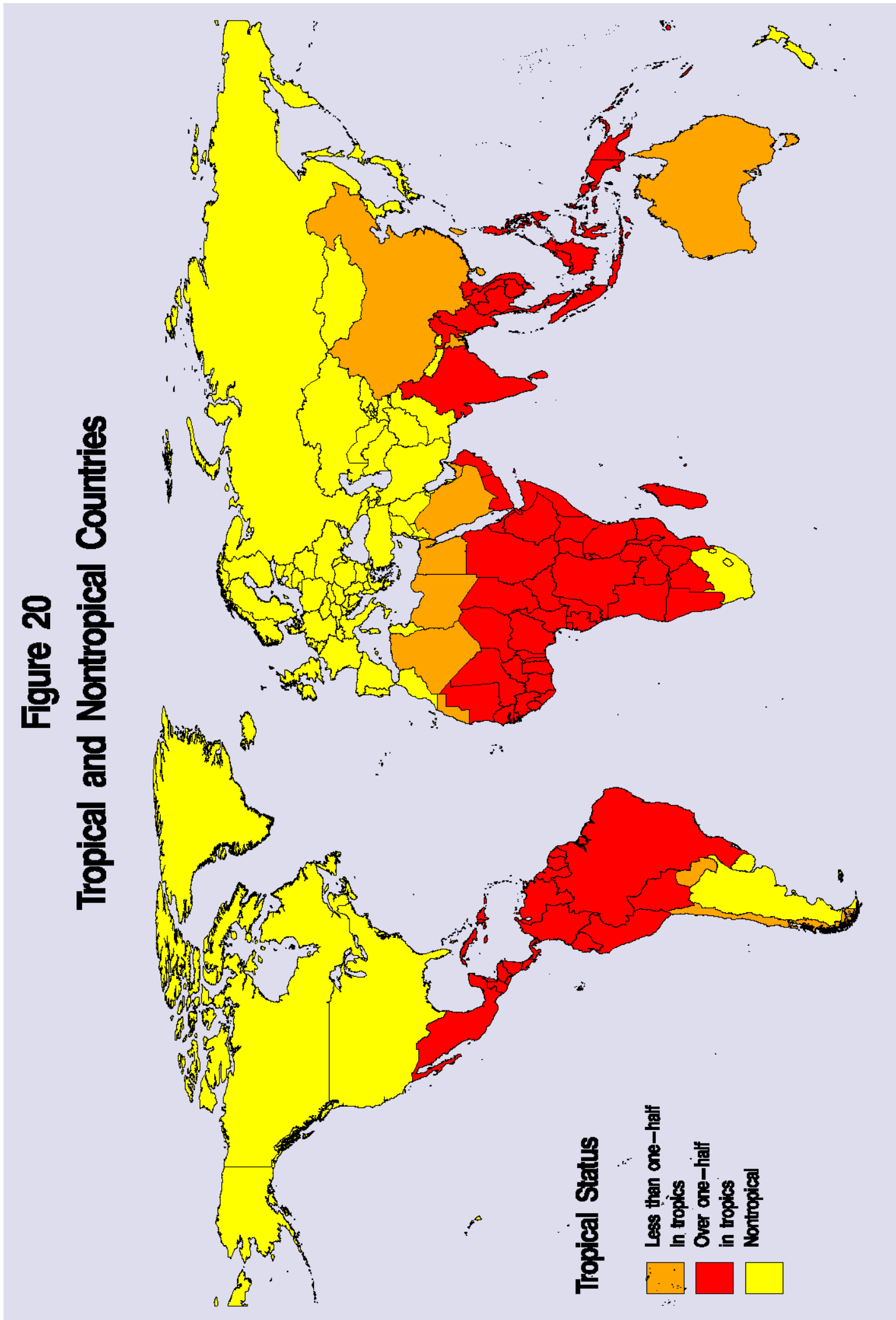


Ethnic Heterogeneity. The underlying causes of terrorism, war and related violence have often been interpreted as ancient ethnic grudges that make living peacefully intractable, especially in ethnically diverse societies (Fearon and Laitin, 2003; Sambanis, 2001; Stewart, 2002). Older literatures frequently assumed that ethnic identity is constant and that such identities are biologically determined (Bergh, 1981; Fearon, 2002). However, 'identity' is a complex issue, and culture is inherited, constructed and at times chosen by many people. Moreover, many people have multiple overlapping identities (Wallenstein and Sollenberg, 2001). The African case has been frequently cited in support of the 'ancient grudge' hypothesis, but most ethnic identities in Africa were constructed by colonial powers in the 20th Century (Ranger, 1983). Contemporary African ethnic identity constructions have only weak origins in pre-Colonial times. Similarly, in the United States, defining ethnic categories is also complicated. For example, the classical racial categorization of Hispanic could be broken down into Mexican Americans, Cuban Americans, Puerto Rican Americans and others. Census categories within the United States themselves have changed over time considerably (Nobles 2000). Constructing and defining ethnicity is thus a perpetual process involving many actors and is amenable to change over time. However, careful consideration of ethnic identity provides useful insights into the nature of human health and conflict.

Over time the number of domestic conflicts has changed, but one underlying cause has largely remained the same: differential access to critical resources results in disputes over identity, which in turn has led to problems of state-building and the maintenance of peace (Pederson, 2002). As some authors have hypothesized, ethnic diversity has been associated with economic growth rates as well as the provision of public goods (Alesina et al., 1999; Easterly and Levine, 1997). Access to healthcare is also defined by political processes in which minority ethnic groups are often excluded. Central to the association between ethnic heterogeneity and 
health is the concept of ethnic nepotism. This concept emerged from sociobiological theory of the 1960's in which Hamilton (1964) and Smith (1964) developed the theory of 'kin selection' to predict human behavior. In sum, the logic of evolution presupposes individual selfishness and favoritism toward relatives. Individuals struggle for resources and power that protects and advances those close to them (Bergh, 1981; Vanhanen, 1999).

Differences in ethnic, linguistic and/or religious composition, can be a major source of political contention within a country. This often produces discrimination and unequal access to political power that translates into inequality in access to health care (Ghobarah et al., 2003). Dominant groups defined by ethnicity, language, and/or religion shift public health expenditures away from minorities into government programs that would provide a greater benefit to them. The greater the ethnic, linguistic and religious heterogeneity within the population, the greater the adverse impact on access to health care by those discriminated against. In one study by Ostby and Urdal (2011), countries with high levels of social and economic polarization between ethnic groups from 1986-2004 were more than twice as likely to suffer internal conflict as those without such economic and social polarizations. Proponents of the 'grievance perspective' of conflict have shown that perceptions of injustice have played a critical role in creating the conditions in which conflict emerges.

While some studies have found evidence to support the association between ethnic heterogeneity and economic growth and the distribution of resources and health outcomes, they have failed to establish a relationship between religious or ethnic heterogeneity and armed conflict (Fearon and Laitin, 2002). However, the failure to find quantitative associations between ethnic heterogeneity and conflict stemmed from the conceptualization of ethnic diversity itself. Until Vanhanen (1999), there existed only two sources of information on ethnolinquistic diversity across countries- the World Christian Encyclopedia and the 
Encyclopedia Britannica (Montalvo and Reynal-Querol, 2005). However, each of these data sources suffer from considerable weaknesses. For example, empirical evidence suggests that when measured as the sum of all ethnic groups comprising $1 \%$ or more of the population, ethnic heterogeneity does not predict potential conflict (Fearon, 2003). Instead, the qualitative literature suggests that it is specific forms of ethnic heterogeneity that are more important in predicting conflict. For example, specific religious and linguistic cleavages within societies make them prone to conflict (Montalvo and Reynal-Querol, 2005). Other studies have found that different aspects of multiethnicity matter, such as the size of the largest minority group, the physical space the groups occupy, ethnic affinities and the level of inclusiveness in political systems (Elbadwi, 1999).

Vanhanen (1999) developed what is considered to be one of the best measures of ethnic division since the emergence of this literature. Specifically, his measure of ethnic heterogeneity takes into account only 'the most important and conspicuous ethnic divisions' rather than all possible ethnic differences among groups. In other words, ethnic groups are associated by 'genetic distance' rather than simple cultural differences (Vanhanen, 1999). Vanhanen's measure of ethnic homogeneity combines racial, linguistic and religious division, each measured as the percentage of the largest respective group of a country's total population for the years 19941996. Aggregated, the inverse of these three percentages measures the degree of ethnic heterogeneity. The larger the sum of these three percentages, the greater the ethnic heterogeneity within a country.

As can be seen in Figure 21, the greatest ethnic heterogeneity scores exist in African countries where civil war has occurred over the past 30 years. Ethnic heterogeneity in these countries exceeds 90.0\% and includes Bhutan (90.0\%); Nigeria (95.0\%); Cote d'Ivoire (96.0\%); Eritrea (100.0\%); Ethiopia (100.0\%); South Africa (107.0\%); Sudan (124.0\%); Guyana 
(140.0\%); and Chad (144.0\%). Other ethnically heterogeneous countries during 1994-1996 included Afghanistan (90.0\%); Latvia (90.0\%); Khazakhstan (102.0\%); Malaysia (110.0\%); Bosnia and Herzegovina (112.0\%); India (128.0\%); and Suriname (147.0\%), countries that have all experienced civil conflict and related violence episodically over the past three decades.

Life Expectancy at Birth. Life expectancy at birth is defined as the average number of years that a newborn is expected to live if current mortality rates continue to apply (WHO, 2011c). Life expectancy at birth reflects the overall mortality experience in a population by summarizing mortality patterns across age groups. As an indicator of health and social development, life expectancy at birth reflects the effects of environmental degradation, exposure to harmful substances, access to health care and political power and living standards. Life expectancy at birth is strongly associated with morbidity as well as mortality and is an integral component of the UN Statistical Commission's Human Development Index (UN, 2010) and a basic WHO health indicator (WHO, 2011c).

The average global life expectancy at birth in 1994 was 64.8 years. As can be seen in Figure 22, the country with the lowest life expectancy was Sierra Leone (38.4 years) and there were 25 countries with life expectancies less than 51 years. With the exception of Afghanistan and Timor-Leste where life expectancy was 41.7 and 48.6 years, respectively, all 23 remaining countries with life expectancies less than 50 years were located in the African Region. There was no country in the African region in which life expectancy at birth exceeded 64.2 years. Other countries such as India, Bangladesh and Haiti, that suffer severe income disparities 


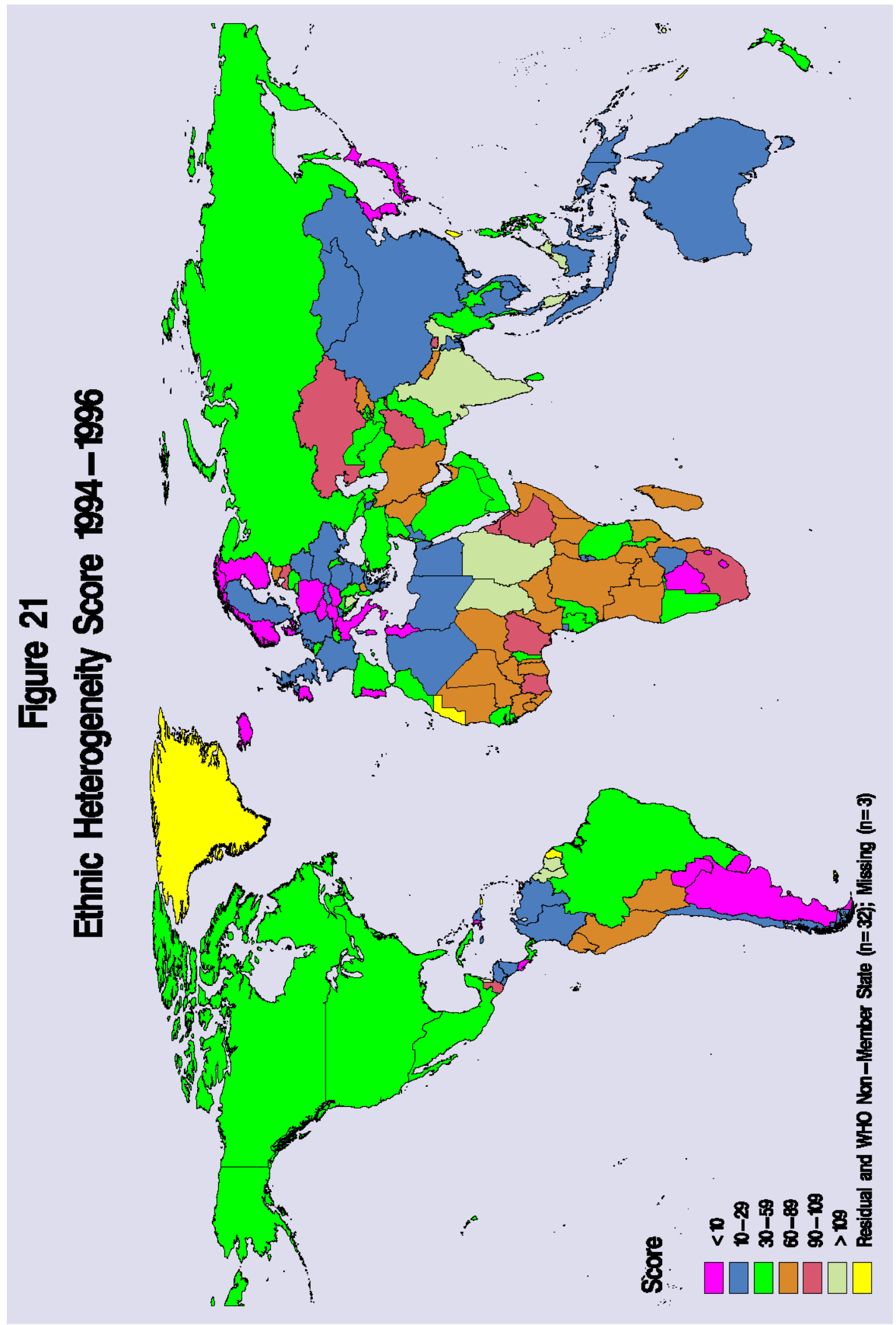




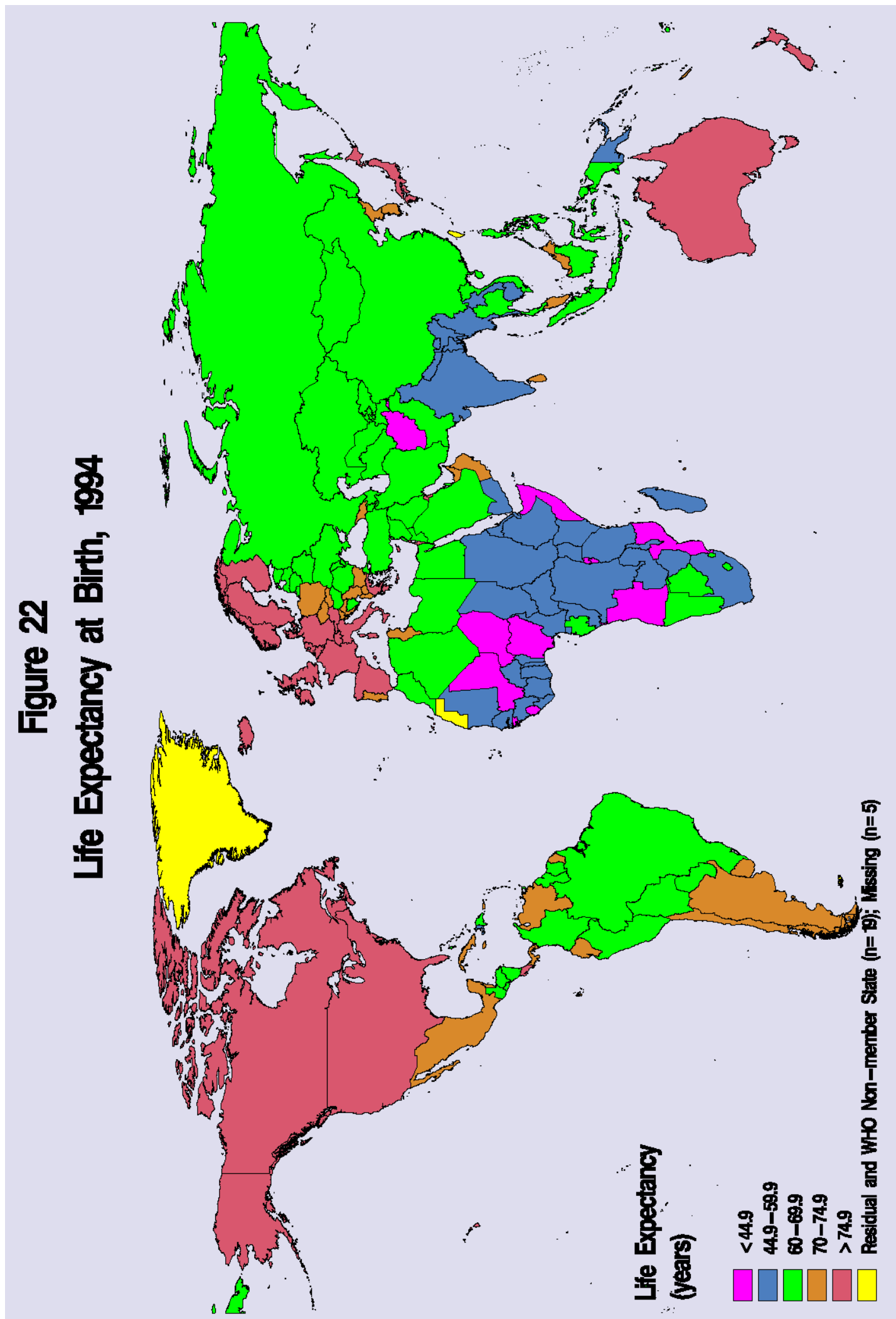


between upper class neighborhoods and slums, also experienced low life expectancies (55.7-58.8 years).

In contrast to developing countries, those countries that benefit from well-educated workforces, high savings and investment rates, well organized medical care and public services and political stability all share life expectancy at birth exceeding 70 years (Masaki and Koizumi, 1987). In 1994, Iceland and Japan had the greatest life expectancies, 78.6 and 80.9 years. Many of the countries with life expectancies exceeding 70 years were located in the European Region (e.g. Germany, United Kingdom, France, Netherlands, Ireland and Denmark) and in The Americas, including the United States of America and Canada. [For additional descriptive statistics related to economic control variables, see Appendix C].

\section{Pre-existing Vulnerability Variables}

\section{Unsafe Drinking Water Resources and Inadequate Sanitation Facilities: Paper 2.}

Diarrheal and related diseases (including shigellosis, amoebiasis and other bacterial, protozoal and viral intestinal diseases), schistosomiasis, trachoma, ascariasis, tricuriasis and hookworm, are almost entirely attributable to unsafe drinking water and inadequate sanitation (WHO, 2008a). This strong relationship highlights the need to control for these factors in analyses of the impact of terrorism, war and one-sided violence on diarrheal and related disease DALYs in Paper 2 of this dissertation.

The WHO (2011c) defines two indicators to measure access to safe drinking water and basic sanitation: (1) percentage of the population using an improved drinking water source; and (2) percentage of the population using an improved sanitation facility. An improved drinking water source is one that by nature of its construction adequately protects the source from contamination, in particular from fecal matter. An improved sanitation facility is one that 
hygienically separates human excreta from human contact. Examples of improved and unimproved drinking water sources and sanitation facilities are shown in Table 7 (WHO, 2000).

For the purposes of this dissertation research, the percentages of improved water resources and improved sanitation facilities were combined for the year 1994. In 1994, approximately $20 \%$ and $45 \%$ of the world's population did not have access to improved drinking water resources and improved sanitation facilities, respectively (WHO, 2006a) (Figure 23). Nearly every country on the African continent had a combined improved water resources and sanitation facilities percentages of $120.0 \%$ or lower with the exception of the Libyan Arab Jamahiriya (151.0\%), South Africa (155.0\%), and Egypt (172.0\%).

Table 7. Examples of Improved and Unimproved Drinking Water Resources and Sanitation Facilities

\begin{tabular}{|c|c|c|c|}
\hline $\begin{array}{l}\text { Improved } \\
\text { Sanitation } \\
\text { Facilities }\end{array}$ & $\begin{array}{l}\text { Use of the following facilities: } \\
\text { - Flush or pour-flush to: } \\
\text { - piped sewer } \\
\text { - } \quad \text { septic tank } \\
\text { - Ventilated improved pit } \\
\text { - Pit latrine with slab } \\
\text { - Composting toilet }\end{array}$ & $\begin{array}{l}\text { Use of the following facilities: } \\
\text { - Flush or pour to elsewhere } \\
\text { (not piped to sewer system, } \\
\text { septic tank or pit latrine) } \\
\text { - Our latrine without slab/open } \\
\text { pit } \\
\text { - Bucket } \\
\text { - Hanging toilet or hanging } \\
\text { - latrine } \\
\text { - Shared facilities of any type } \\
\text { No facilities, bush or field }\end{array}$ & $\begin{array}{c}\text { Unimproved Sanitation } \\
\text { Facilities }\end{array}$ \\
\hline $\begin{array}{c}\text { Improved } \\
\text { Drinking-Water } \\
\text { Sources }\end{array}$ & $\begin{array}{l}\text { - Piped water into dwelling, yard or } \\
\text { plot } \\
\text { - Tubewell or borehole } \\
\text { - Protected dug well } \\
\text { - Protected Spring } \\
\text { - Rainwater collection }\end{array}$ & $\begin{array}{l}\text { - Unprotected dug well } \\
\text { - Unprotected spring } \\
\text { - } \text { Cart with small tank or drum } \\
\text { - Tanker truck } \\
\text { - Surface water } \\
\text { - } \quad \text { Bottled water }\end{array}$ & $\begin{array}{c}\text { Unimproved Drinking } \\
\text { Water } \\
\text { Sources }\end{array}$ \\
\hline
\end{tabular}

Other countries with notably low percentages of improved water resources and sanitation facilities included Afghanistan (32.0\%), Cambodia (48.0\%), Haiti (72.0\%), Yemen (95.0\%), Nepal (96.0\%), India (97.0\%), Mongolia (108.0\%), Vietnam (115.0\%), and China (119\%). The 


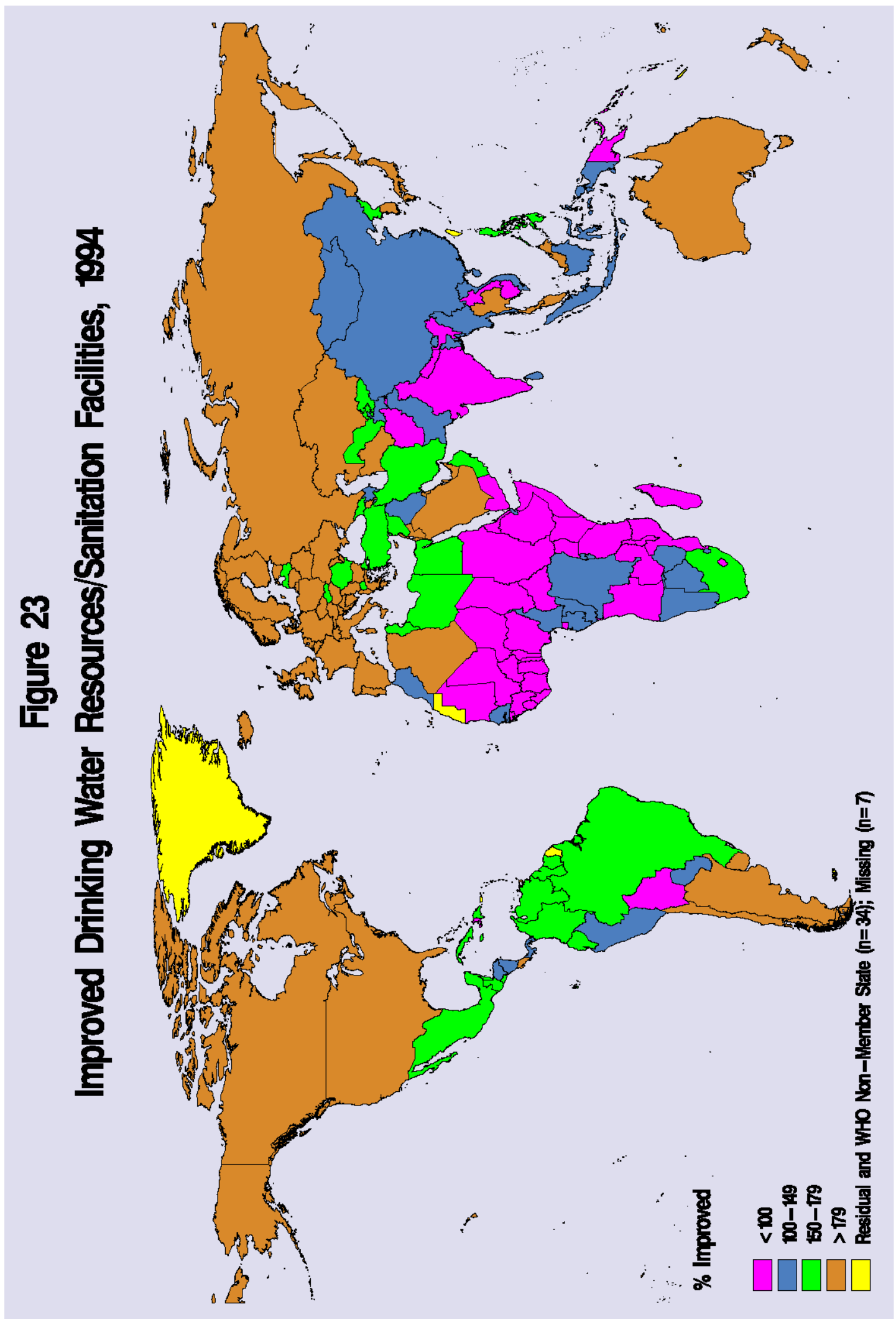


Russian Federation and most countries in the European and The Americas Regions were characterized with relatively higher combined improved water resource and sanitation facility percentages $(>150.0 \%)$.

Adult Per Capita Alcohol Consumption: Paper 3. Alcohol use is related to a wide range of physical and mental harms including liver cirrhosis, cardiovascular diseases, neuropsychiatric conditions, and cancers of the mouth, pharynx, oesophagus, liver, stomach and colon and injuries (Rehm et al., 2003; 2004; WHO, 1994; 2002b; 2004b). Among these conditions, only alcohol dependence and harmful use of alcohol (i.e. alcohol use disorders) are considered within the GBD Study framework to be almost entirely attributable to alcohol use. This relationship between alcohol use and alcohol use disorders highlights the importance of including alcohol consumption as a baseline vulnerability factor in Paper 3 in which alcohol use disorder DALYs served as the major outcome variable.

The WHO uses adult (persons 15 years and older) per capita consumption to measure alcohol consumption (WHO, 1999a). This variable does not use per capita consumption for the whole population because population distributions in developing countries differ from those of developed countries, having a much greater proportion of children and young people. Using a per capita indicator would, therefore, underestimate consumption of adults in countries with many young people under the assumption that most young people under 15 do not consume large amounts of alcohol (WHO, 2011b).

Estimates of adult per capita consumption are derived for total recorded consumption expressed as liters of pure alcohol, computed as the sum of alcohol production and imports, less alcohol exports, divided by the adult population (aged 15 years and older). Adult per capita consumption estimates are based on either the Food and Agricultural Organization (FAO) (United Nations, 2008) or World Drink Trends (WDT: Produkschap voor Gedistill Dranken, 
2006) data, with the exception of a few countries in Europe where data comes directly from governments. The FAOSTAT - United Nations Food and Agricultural Statistical Database $(\mathrm{FAO}, 2008)$ is the most complete and comprehensive international source on per capita alcohol consumption while WDT is the best source of industry data (Rehm et al., 2003).

In the European region, WDT is used for 25 countries, FAO for 19 countries and government data for four countries. Outside Europe, most of the remaining countries of the world use FAO data to estimate consumption, while only seven use WDT data. Country-level data on per capita alcohol consumption is compiled from both these sources and is available within the WHO Global Health Observatory Database (WHO, 2004b; 2011a).

Globally, alcohol consumption is much greater among males than females and is most prevalent among people aged 15-to-59 years (WHO, 1994). In 1994, worldwide recorded adult per capita alcohol consumption was about 4.9 liters of pure alcohol. Average per capita alcohol consumption in 1994 was greatest among developed countries (9.9 liters), relative to developing countries (3.2 liters) and those countries in transition (7.4 liters) (Jernigan et al., 2000; WHO 2011b). During this time, average per capita consumption was also greatest in the European (8.3 liters) and The Americas (5.9 liters) Regions, followed by the Western Pacific Region (3.2 liters). The lowest average per capita alcohol consumption was observed in the South-East Asia (1.4 liters) and Eastern Mediterranean (0.8 liters) Regions (Figure 24).

Prevalence of Illicit Drug Use: Paper 3. Illicit drug use is defined as the non-medical use of a variety of drugs that are prohibited by international law (WHO, 2011c). Illicit drug use is associated with several adverse health consequences including HIV/AIDs, Hepatitis B virus, Hepatitis C virus, suicide, drug dependence and harmful use (i.e. drug use disorders) and other neuro-psychiatric disorders, and a variety of social harms and consequences (United Nations 


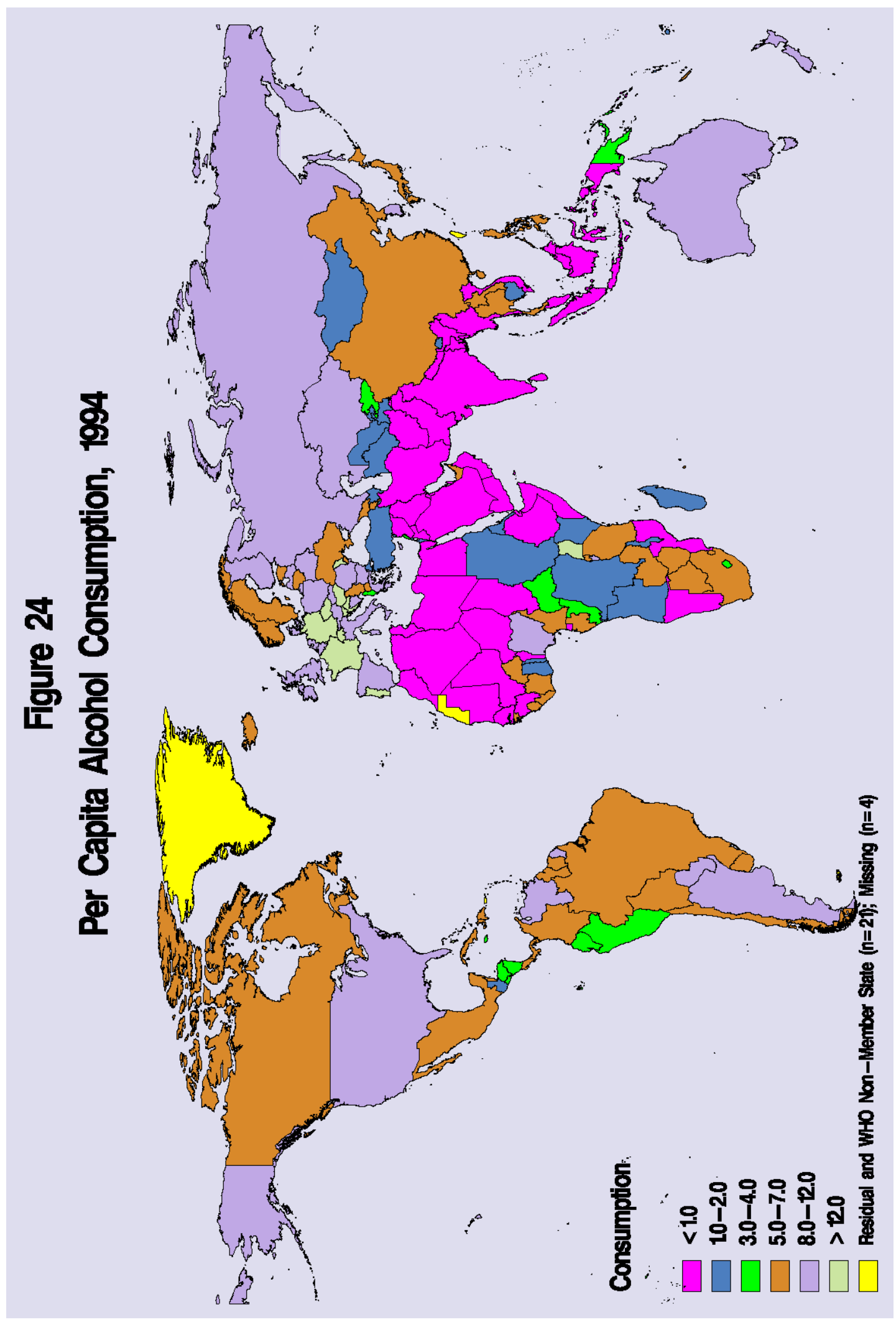


International Drug Control Programme [UNIDCP], 1997). Among these disorders and consequences, only drug use disorders are considered almost entirely attributable to illicit drug use within the GBD Study framework. This relationship establishes illicit drug use as a critical control vulnerability factor in analyses in which drug use or substance use disorder DALYs served as outcome variables (Paper 3).

Data on illicit drug use has been collected routinely since 1991 by the United Nations Office of Drug Control (UNODC, 1999). This information is provided by governments through the Annual Reports Questionnaire (ARQ), which is completed and submitted by governments in response to reporting obligations imposed by three international drug control conventions. Governments also sometimes submit results of national surveys and other reports along with information requested in the ARQ. Of relevance to this dissertation are the key indicators of the extent of drug use: the annual prevalences of illicit drug use related to cannabis, amphetaminetype stimulants, cocaine-type substances and opiates. The annual prevalence of each of these illicit drugs is defined as the number of people who have consumed the illicit drug at least once prior to the survey year. These prevalence figures are expressed as percentages of the population above the age of 15 years. Annual prevalences of cannabis, amphetamine-type stimulants, cocaine-type substances and opiates were combined in this dissertation research to yield an aggregate measure of illicit drug use. This continuous variable was log transformed as the result of skew. Data for these indicators were collected between 1993 and 1997 and appear in the Global Illicit Drug Trends Report for 1999 prepared by the UNODC.

There is good evidence that illicit drug use is also related to terrorism, civil war and related violence. With the end of the Cold War, state financing for terrorism and insurgent movements was drastically reduced and the cultivation, transport and sale of psychotropic substances became a lucrative source of alternative financing. This is particularly true regarding 
coca, opium and cannabis, the most profitable psychotropic substances. Between 1990 and 2000 , the majority of cultivation of these crops was taking place in countries experiencing terrorism and civil war (Bjornehed, 2004; Cornell, 2005). Recent comparative research has suggested that cultivation of these psychotropic drugs relates to the duration of civil war and terrorist actions, but not their initiation (Fearon, 2002), results that are highly consistent with case studies done in this area (Ross, 2004a; 2004b).

Unlike most natural resources like oil, timber, gold, copper and diamonds, illicit drugs are lootable and unobstructable: they are easily appropriated and transported and not easily obstructable due to their high value-to-size ratio. Illicit drugs are also illegal which makes them benefit insurgents and terrorists, who are less influenced by international prohibitions against the cultivation, transport and sale of psychotropic substances than governments. The lootability, unobstructability and illegality of psychotropic substances as natural resources define their enormous potential to provide a financial base to strengthen insurgents and terrorist organizations, aid insurgents in avoiding government onslaught and deny governments control over significant parts of their territories for extended periods of time. Although psychotropic substances seem to be linked to the duration of terrorism, civil war and related violence, future research is needed to elucidate the exact mechanisms that define the association.

Between 1993 and 1997, the global annual prevalence rate of illicit drug use was about $4.0 \%$ or 185 million people of the total world's population (UNIDCP, 1997). Cannabis was the most prevalent illicit drug used worldwide, accounting for approximately $2.5 \%$ (141.2 million persons) of the world's population. Other illicit drugs were far less prevalent including amphetamine-type stimulants $(0.52 \%)$, cocaine-type substances $(0.23 \%)$ and opiates $(0.14 \%)$, accounting for 30.2, 13.3 and 8.0 million persons worldwide, respectively. As can be seen in Figure 25, the average prevalence of illicit drug use was clearly greatest in The Americas 
(2.6\%), Western Pacific (2.1\%) and European (1.9\%) Regions, with Australia (16.5\%), the United Kingdom (12.8\%), the United States of America (12.2\%) and Papua New Guinea $(10.0 \%)$ being the largest contributors. Figure 25 also shows the rise of illicit drug use occurring during this time in the African Region with annual prevalences of illicit drug use exceeding $10.0 \%$ in Nigeria, Ghana and Sierra Leone. [For additional descriptive statistics related to preexisting vulnerability variables, see Appendix C].

In the next three chapters, three papers examining the relationship between deaths due to terrorism, civil war and one-sided violence and major communicable and noncommunicable disease DALYs, diarrheal and related diseaase DALYs and substance use disorder DALYs, controlling for economic and/or pre-existing vulnerability variables are examined using ordinary least square (OLS) regression analyses. Statistical models that might be used in related applications are described in Appendix C. 


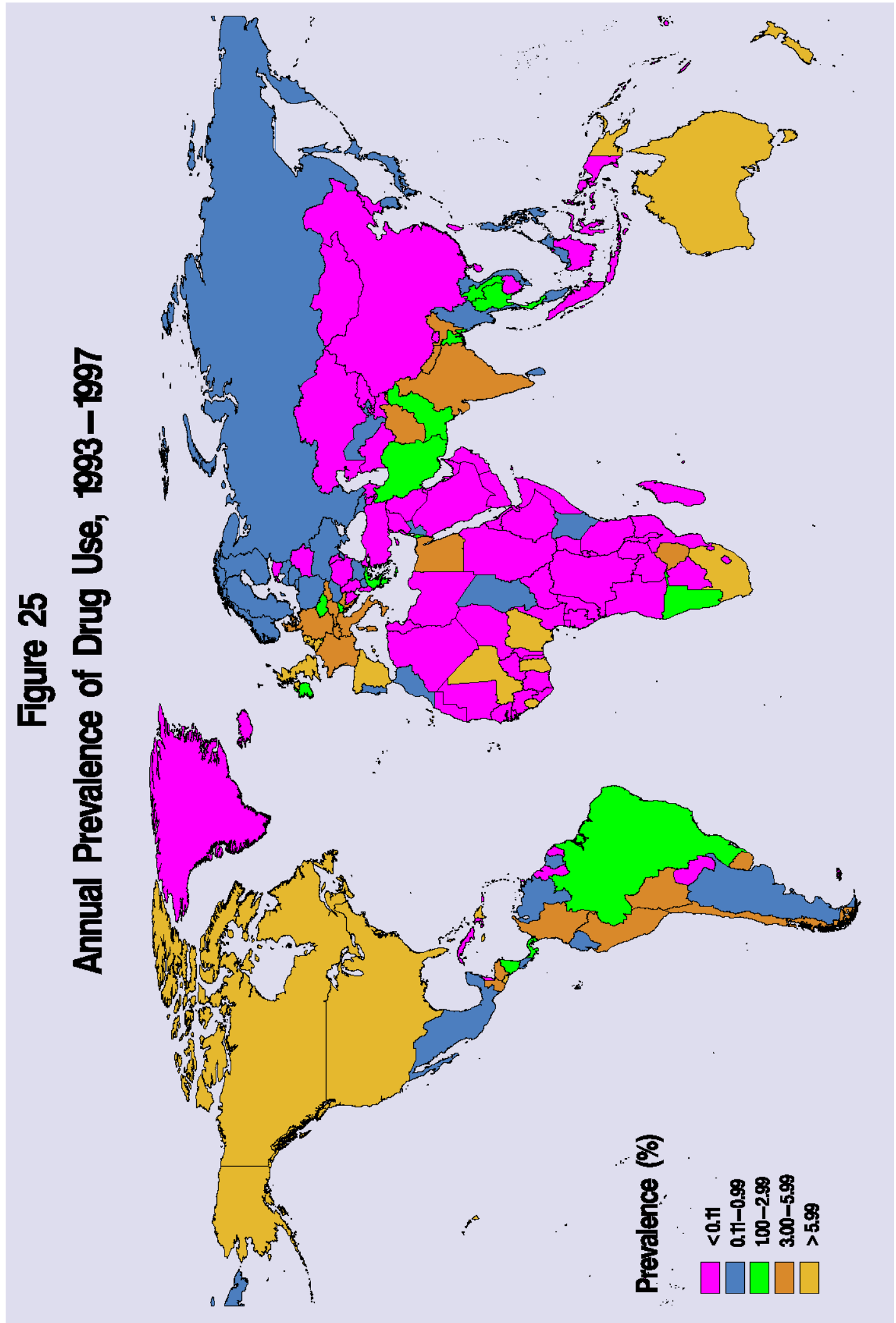


Chapter III: Paper 1. Terrorism, Civil War, One-Sided Violence and Global Burden of Disease

\author{
Bradley T. Kerridge ${ }^{\mathrm{a}}$, Maria R. Khan ${ }^{\mathrm{b}}$, Amir Sapkota $^{\mathrm{c}}$
}

${ }^{\text {a }}$ Bradley T. Kerridge

Department of Epidemiology and Biostatistics

School of Public Health

University of Maryland, College Park

College Park, Maryland, 20742

${ }^{\mathrm{b}}$ Department of Epidemiology

College of Public Health and Health Professions

School of Medicine

University of Florida Health Sciences Center

University of Florida

Gainesville, Florida, 32610

${ }^{\mathrm{c}}$ Maryland Institute for Applied Environmental Health

Department of Epidemiology and Biostatistics

School of Public Health

University of Maryland, College Park

College Park, Maryland, 20742 


\begin{abstract}
Armed conflict and related violence, including terrorism and one-sided violence, has profound effects on people's health and lives. The purpose of this study was to determine the relationship between deaths due to terrorism, civil war and one-sided violence from 1994-2000 and disability-adjusted life years (DALYs) occurring in 2002 attributable to all causes and specific communicable and noncommunicable diseases. Deaths resulting from terrorism, war and one-sided violence were positively associated with all cause as well as a number of communicable and noncommunicable disease-specific DALYs across the majority of sex and age subgroups of the populace, controlling for an array of economic factors empirically shown to affect public health. Overall, a 1.0\% increase in deaths due to terrorism, civil war, and onesided violence from 1994-2000 was associated with a $0.16 \%$ increase in DALYs lost to all causes in 2002 in the total world population. There was little variation in the magnitude of these associations between males and females and between communicable and noncommunicable diseases. The results of the present study can begin to guide post-conflict recovery by focusing on interventions targeting both noncommunicable as well as communicable diseases, thereby highlighting the full health costs of war and ultimately providing a strong rationale for promoting peace.
\end{abstract}




\section{Introduction}

Armed conflict and related violence, including terrorism and one-sided violence, has profound effects on health and an enormous and tragic impact on people's lives. In 2002, Murray and his colleagues argued that armed conflict should be recognized as a major public health problem (Murray et al., 2002). They underscored the adverse impact of war on population health resulting from the immediate direct effects of armed conflict (i.e. battle deaths) and from the even more substantial indirect or longer-term effects. The longer-term consequences of war arise from displacement of large numbers of people, traumatic stress, and breakdown of water, sanitation, agricultural, transportation, safety and regulatory infrastructures and health and social services resulting in depressed economic performance and heightened risk of disease and death (Dodge, 1990, Levy and Sidel, 2007; 2009). Despite the toll of death and disability that defines war, the longer-term effects of conflict as a major determinant of morbidity and mortality has received little attention by public health researchers.

Although research has found support for the longer-term impact of war on life expectancy and mortality, these studies did not account for the burden of conflict associated with disability and non-fatal outcomes (Guha-Sapir and van Panhuis, 2004; Li and Wen, 2005). To date, a very limited number of studies have addressed the broader health consequences of armed conflict using summary measures of health that combine information on both morbidity and mortality (Ghobarah et al., 2003; 2004a; 2004b; Hoddie and Smith, 2009). The first measure is healthy life expectancy (HALE) at birth. Unlike the conventional life expectancy measure that considers only mortality, the HALE deducts time lost to being in ill health (Mathers et al., 2000). The second measure is the disability-adjusted life year (DALY), that is derived as the sum of years of life lost to premature mortality and years of life lost due to disability in a population. 
Ghobarah et al. (2004a) examined the impact of civil war deaths occurring from 19911997 on HALEs in 1999. Civil war deaths were shown to have an adverse effect on health, with the most devastating wars reducing HALEs by 10 years. In two earlier studies, these authors also examined the relationship between civil war deaths from 1991-1997 and DALYs in 1999 attributable to all causes and specific diseases and injuries (Ghobarah et al.; 2003; 2004b). These studies controlled for an array of economic and related factors (e.g. health expenditures, urban growth) and a civil war deaths occurring in contiguous countries by border permeability interaction measure to operationalize burden to health systems resulting from the influx of refugees into the host country. In these studies, civil war deaths were significantly related to all cause DALYs among four and seven of the 10 sex-age groups of the population: 0 -to-4 year-old males, 5-to-14 year-olds and 45-to-59 year-old females, but not among 0-to-4 year-old females or those 60 years or older. When specific diseases and injuries were examined, civil war deaths were significantly related to between $23 \%$ and $30 \%$ of the 210 disease/injury-specific DALYs examined by sex and age, largely among 5-to-59 year-olds. Taken together, the age results of these two studies were surprising since approximately $40 \%$ of the world's disease burden in 1999 occurred among 0-to-4 year-olds and people aged 60 years or older (WHO, 1999b).

Prior research discussed above defined civil war deaths to include all fatalities among combatants, that is, regular armed forces of the state and armed insurgents or non-state actors and civilians targeted by either. Among these fatalities are one-sided violence deaths resulting from security forces firing on unarmed protestors, genocide, and summary execution of prisoners. Hoddie and Smith (2009) separated deaths resulting from civil war from those resulting from one-sided violence occurring during 1991-1997 and examined their differential effects on all cause DALYs in 1999. When only war deaths were entered into the statistical model, there was no significant effect of deaths on all cause DALYs. However, when war and 
one-sided violence deaths were examined simultaneously, fatalities resulting from one-sided violence, but not war deaths, were significantly associated with all cause DALYs, among younger (0-to-4 year-olds) and older (45 year olds and older) subgroups of the world populace.

Although the studies by Hoddie and Smith (2009) and Ghobarah et al. (2003; 2004b) have significantly increased our knowledge of the relationship between civil war and longerterm morbidity and mortality, some limitations are noted. The Hoddie and Smith (2009) study focused on all cause DALYs rather than disease-specific DALYs and used an ordinal, rather than a continuous, measure of the number of fatalities due to one-sided violence. Previous research in this area has also controlled for war deaths in contiguous countries by border permeability, a measure best operationalized directly as the number of refugees and displaced persons in the host country (Ghobarah et al., 2003; 2004b). In addition, each of these studies failed to control for a major determinant of global morbidity and mortality, that is, the number of persons affected by natural disasters. The absence of associations between civil war deaths and DALYs for a majority of specific diseases among the very young and old examined in the Ghobarah et al. $(2003 ; 2004 b)$ studies may have been the result of neglecting to transform the DALY outcome measures that are skewed. Linear regression models used in prior studies, and indeed in the present study, require such transformed data to satisfy underlying model assumptions of linearity and homogeneity of variances of the residuals. Importantly, all studies in this area did not assess the impact of terrorist actions on longer-term morbidity and mortality. Between 1989 and 2004, the vast majority (about 99\%) of fatalities from terrorist actions has taken place in countries experiencing both war and one-sided violence (Eck and Hultmann, 2007; Ericksson et al., 2003).

The present study addresses the limitations of and expands upon prior seminal work on the relationship between civil war deaths and morbidity and mortality. Since the severity and 
scope of civil war has changed over the last three decades to increasingly include fatalities arising from terrorist actions and one-sided violence, the major exposure variable in this study will be the sum of deaths resulting from terrorist actions, civil war and one-sided violence (Eck and Hultman, 2007; Ericksson et al., 2003; Lacina and Gleditsch, 2005). Data were derived from three new, mutually exclusive, databases: Battle Deaths Dataset constructed by the Center for the Study of Civil Wars, in Oslo (Lacina, 2009; Lacina and Gleditsch, 2005). One-sided Violence Deaths Dataset available from the Department of Peace and Conflict Research, Uppsala University (Kreutz and Eck, 2011); and the Global Terrorism Database (GTD) constructed by the National Consortium for the Study of Terrorism and the Responses to Terrorism (NCSTRT), University of Maryland (NCSTRT, 2010).

It is hypothesized that increasing numbers of deaths attributable to terrorism, civil war and one-sided violence from 1994-2000 will be associated with increasing levels of morbidity and mortality as measured by DALYs in 2002 attributable to major communicable and noncommunicable disease, controlling for a wide array of economic and related factors that have been empirically linked to morbidity and mortality. Given the widespread devastation and misery that defines civil war and related violence and the numerous mechanisms through which it exerts its toll on death and disability (i.e. displacement, destruction of health and a variety of other infrastructure, psychological stress), it is predicted that the impact of such violence on longer-term public heath will be pervasive. That is, terrorism, war and one-sided violence will adversely impact morbidity and mortality in the longer-term associated with communicable and mental and physical noncommunicable diseases across the majority of the sex-age subgroups of the populace.

\section{Methods}

\section{Outcome Measures: Disability-Adjusted Life Years}


The outcome variables were the number of DALYs (in thousands) due to major communicable and noncommunicable diseases for 2002 in 184 of the 192 WHO member states. Seven small islands and countries were excluded from the analyses due to insufficient data. Rwanda also was eliminated from the analyses because the country experienced 500,000 deaths due to genocide in 1994, rendering it an extreme outlier. Diseases and conditions examined included infectious and parasitic diseases, maternal and perinatal conditions, respiratory infections, nutritional deficiencies, malignant neoplasms, other neoplasms, diabetes mellitus, endocrine disorders, neuro-psychiatric disorders, and sense organ, cardiovascular, respiratory, digestive, genito-urinary, skin, and musuloskeletal diseases, congenital anomalies and oral conditions.

\section{Exposure Measure: Deaths from Terrorism, Civil War and One-sided Violence}

Terrorist acts are intended to produce effects beyond immediate human and property damage and to have long-term physical repercussions on a particular audience. Data on the number of deaths among victims and perpetrators resulting from terrorist actions from 19942000 were derived from the 2010 update of the Global Terrorism Database (NCSTRT, 2010). The definition of a terrorist incident in this database includes terrorist incidents that are intentional, that achieve some level of violence or threat of violence and that are perpetrated by sub-national, non-state actors. In addition, to qualify as a terrorist incident, at least two of the following three criteria must be met: (1) the act must be aimed at attaining a political, economic, religious or social goal; (2) there is evidence of an intention to coerce, intimidate, or convey some other message to a larger audience than the immediate victims; and (3) the action must be outside the context of legitimate warfare activities (NCSTRT, 2010). 
Data for civil war deaths occurring between 1994-2000 were derived from the Battle Deaths Database (Lacina, 2009; Lacina and Gleditsch, 2005). Civil wars are defined as internal armed conflict occurring between the government of a state and one or more internal opposition groups without intervention from other states, and internationalized internal armed conflict between the government of a state and one or more internal opposition groups with intervention from other states on one or both sides. Civil war conflict is further defined as a contested incompatibility that concerns governments and/or territory where the use of armed force between two parties (of which at least one is the government of the state) results in at least 25 battle deaths (Lacina and Gleditsch, 2005). War deaths result directly from violence inflicted through the use of armed force by a party to armed conflict. In the present study, interstate wars were not included in the analyses for several reasons. Foremost, during the period of observation for this study, only four wars representing nine war-years or 3\% of the 290 waryears fought were interstate wars. Further, information on the number of deaths on each side (i.e. for each country) necessary for inclusion of these war deaths in the present analyses was not available.

Information on deaths resulting from one-sided violence for the years 1994-2000 were available from the One-sided Violence Database (Kreutz and Eck, 2011). One-sided violence is defined as the use of armed force by the government of the state or by a formally-organized group against civilians which results in at least 25 deaths. Only one-sided deaths perpetrated by government actors were included in the present analyses since those perpetrated by formallyorganized groups overlapped with those included in the GTD. These deaths include genocide and summary execution of prisoners. This database was also specifically designed not to overlap with the Battle Deaths Dataset with respect to incidents and deaths classified. 
The number of deaths resulting from terrorist actions, civil war and one-sided violence (in thousands) between 1994-2000 were summed to form the major exposure variable, thereby providing for a measure of the scale and intensity of current day armed conflict and associated violence (Eck and Hultmann, 2007; Ericksson et al., 2003; Lacina and Gleditsch, 2005).

Using deaths from terrorism, war and one-sided violence for the years 1994-2000 produces a 2-year lag to the DALY outcome measures in 2002. DALYs in 2002 reflect years of life lost due to deaths from a particular condition during 2002 plus the disability incurred by people suffering from the same condition in 2002. Thus, these are not deaths or disabilities experienced in earlier years during which the terrorism and related violence was active.

\section{Control Measures}

Refugees/Asylum Seekers/Displaced Persons. Civil wars and related violence displace large populations either internally (i.e. internally displaced persons) or as refugees, including asylum seekers, or people owing to a well-founded fear of prosecution for reasons of race, religion, nationality or membership of a particular social group or political opinion, is outside their country of origin (UNHCR, 1995a). Refugees/asylum seekers/displaced persons are at increased risk of disease and premature mortality from a variety of communicable and noncommunicable diseases and malnutrition (CDC, 2004).

The number of refugees/asylum seekers/displaced persons (in thousands) residing in each host country at the end of the year 1994 served as an important control measure. These data were available from the United Nations Refugee Agency (UNHCR) Statistical Yearbook Annex Tables (1995b). Similar to all control variables used in the present analyses, except the number of deaths/homeless/affected by natural disasters (summed for the years 1994-2000), the number of refugees/asylum seekers/displaced persons were measured at baseline, that is, as close to the year 1994 as the available data would allow. 
Number of Deaths/Homeless/Affected by Natural Disasters. Although immediate health impacts of natural disasters include illness, disability and death typically associated with the spread of infectious diarrheal diseases, longer-term effects including respiratory and other chronic conditions and mental illnesses can be substantial (Fogarty International, 2007).

The natural disaster measure in this study combined the number of deaths (persons confirmed as dead or missing), number of homeless (persons needing shelter) and number affected (i.e. people requiring immediate assistance in basic survival needs such as food, water and sanitation), in thousands, occurring at the country level for the years 1994-2000. Data were available from the Emergency Events Database (EM-DAT) maintained by the WHO Collaborating Center for Research on Epidemiology and Disasters (CRED) (Guha-Sapir et al., 2004). A disaster event is defined by CRED if it met one or more of the following criteria: (1) there were 10 or more people killed; (2) there were at least 100 people reportedly affected; or (3) the disaster led to the declaration of a state of emergency or calls for international assistance.

\section{General Government Expenditures on Health as Percentage of Total Government}

Expenditure. It is a longstanding and generally accepted principle that morbidity and mortality are reduced through public and private investments in health, sanitation and nutrition. Health economists have continually observed that 'wealthier is healthier' (Nixon and Ulmann, 2006; Theo and Posnett, 1992). This study uses total general government health expenditures as a percentage of total government expenditure (GGHE as a percentage of TGE) as a critical economic control measure. This core indicator of health financing systems contributes to our understanding of the weight of public spending on health within public sector operations (WHO, 2011). Data on GGHE as a percentage of TGE for 1994 were available from the WHO Global Health Observatory Database (WHO, 2011a). 
Urban Growth. Numerous characteristics of the physical urban environment, including density of development, provisions for safe water and adequate sanitation infrastructure, and maintenance of public spaces are all predicted to adversely influence health outcomes (Mohan et al., 2008). This would be particularly true during the period of observation in the present study (i.e., between 1990 and 1995) when urban growth was occurring chaotically in less developed regions but had essentially stabilized among most developed countries (Alirol et al., 2010). The measure of urbanization used as a control measure in this study is the average percentage change in the urban population between 1990 and 1995. These data are collected routinely by the UN Department of Economic and Social Affairs and available on the UN Millennium Goals Database (UN, 2011b).

Ethnic Heterogeneity. Differences within a country in ethnic, linguistic and/or religious composition can be a major source of political contention and conflict. In turn, this produces discrimination and unequal access to political power that translates into inequality in access to health care (Ghobarah et al., 2003). Dominant groups defined by ethnicity, language, and/or religion often deflect public health expenditures away from minorities, just as the wealthy shift resources away from the disadvantaged into government programs that would provide a greater benefit to them.

The measurement of ethnic heterogeneity in this study is derived from Vanhanen (1999) that operationalizes ethnic groups based on: (1) racial differences; (2) linguistic, national or tribal differences; and (3) stabilized old religious communities. The measure combines racial, linguistic and religious division, each measured as the percentage of the largest group of a country's population for the years 1994-1996. The inverse of these three percentages are summed to measure the degree of ethnic heterogeneity. 
Life Expectancy at Birth. Life expectancy at birth is defined as the average number of years that a newborn is expected to live if current mortality rates continue to apply, data routinely collected by the WHO (WHO, 2011a). In the present study, life expectancy at birth serves as a critical control measure, reflecting the effects of environmental degradation, exposure to harmful substances, access to health care and political power and living standards in 1994 or at baseline.

Tropical Country Status. Tropical climate is a critical determinant for the development of infectious and parasitic diseases and tropical country status is included in models in which communicable disease DALYs serve as outcome variables in this study (Remme et al., 2002; WHO, 2008a). Tropical country status is operationalized as a dichotomous variable $(1=$ at least one-half of land mass in the tropics and $0=$ less than one-half of land mass in the tropics). Data on tropical country status are collected by the International Union for the Conservation of Nature (2000).

\section{Statistical Analyses}

Multivariable linear regression analyses were conducted to examine the relationships between deaths from terrorism, war and one-sided violence from 1994-2000 and DALYs due to all causes and major communicable and noncommunicable diseases in 2002, controlling for economic and related factors. These selected diseases and conditions constitute the second level of aggregation in the 2002 WHO cause list ensuring sufficient number of DALYs for analytic purposes (Mathers et al., 2003). DALY outcome measures, the war and related violence exposure measure and two control factors (number of deaths/homeless/affected by natural disasters, number of refugees/asylum seekers/displaced persons) were log transformed as the result of skew associated with their distributions. 


\section{Results}

Table 8 shows the results of the multivariable linear regression analyses examining the relationships between deaths due to terrorism, war and one-sided violence from 1994-2000 and all cause DALYs in 2002, controlling for critical economic and related factors. Deaths due to terrorism, war and one-sided violence were significantly related with all cause DALYs examined in the world populace and among the 10 sex-age subgroups. Overall, the beta coefficient associated with all cause DALYs was 0.16 indicating that a $1.0 \%$ increase in deaths from terrorism, war and one-sided violence from 1994-2000 was associated with a $0.16 \%$ increase in DALYs lost to all causes in 2002 in the total world population. Alternatively, an increase of $10(1.0 \%$ of 1000$)$ deaths due to terrorism, war and one-sided violence was associated with an increase of $1.6(0.0016 \times 1000)$ DALYs lost to all causes. There was little variation in the magnitude of corresponding associations across sex-age subgroups of the populace $(b=0.14-0.16)$.

Although not the focus of attention in this study, the number of refugees/asylum seekers/displaced persons in 1994 and the number of deaths/homeless/affected by natural disasters from 1994-2000 were also significantly associated with all cause DALYs in 2002. An increase of 10 refugees/asylum seekers/displaced persons was associated with increases of between 1.3 and 2.5 DALYs lost to all causes across sex-age subgroups. Corresponding increases in all cause DALYs lost associated with an increase of 10 deaths/homeless/affected by natural disasters were between 3.2 and 3.6.

Associations between health expenditures in 1994 and urban growth between 1990 and 1995 and all cause DALYs in 2002 were largely concentrated among children less than 15 years of age. A $1.0 \%$ increase in health expenditures resulted in decreases of between 40 and 50 DALYs lost in 2002 from all causes while a 1.0\% increase in the urban population between 


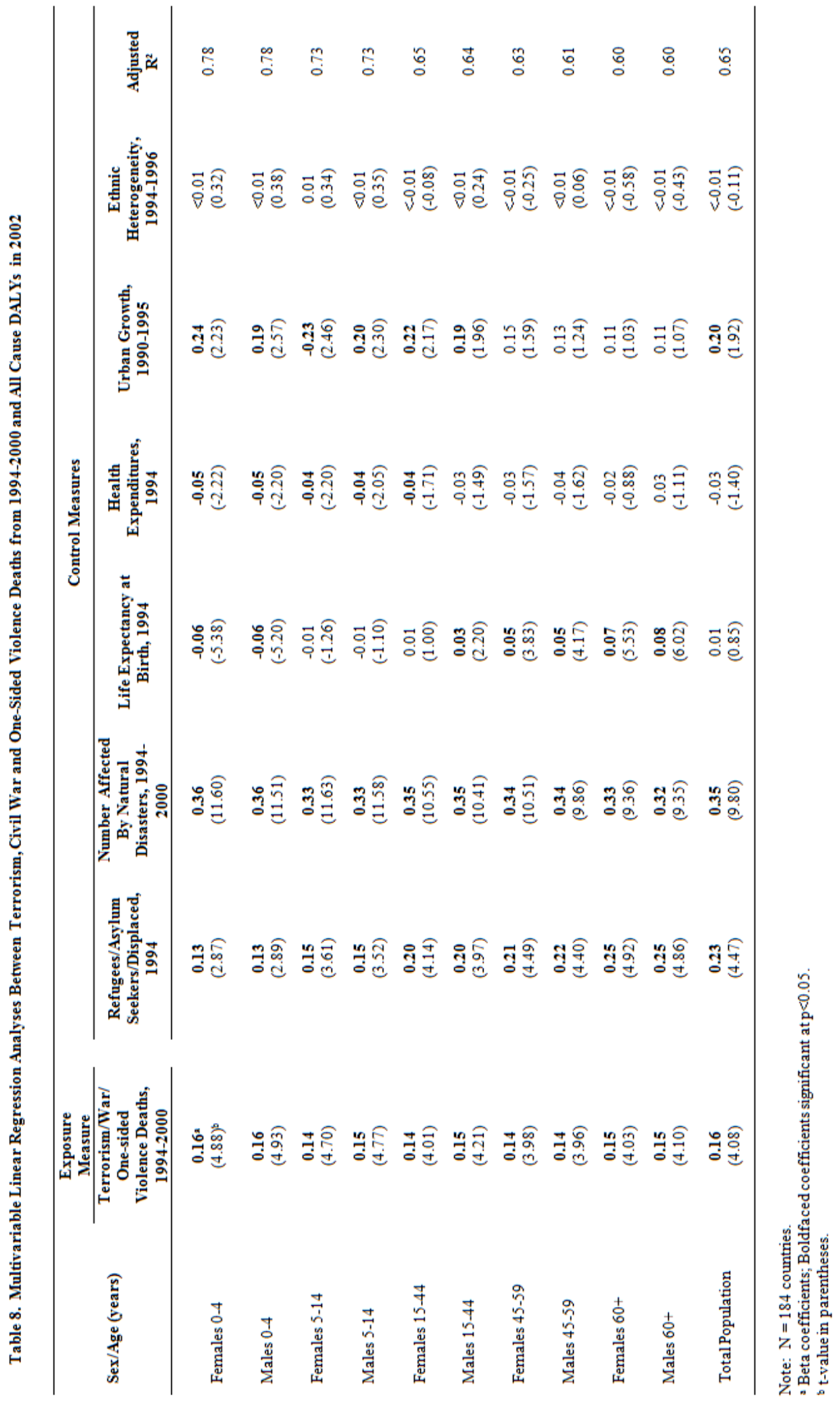


1990 and 1995 resulted in an increase of 20.9\% in DALYs lost in 2002. Interestingly, life expectancy at birth was negatively associated with all cause DALYs among the youngest age group (ages 0-to-4 years-olds), but positively associated for older males (aged 15 years and older) and females (aged 45 years and older). For parasitic and infectious diseases, being located in a tropical region was positively associated with DALYs lost in 2002.

Tables 9 and 10 show the relationship between deaths resulting from terrorism, war and one-sided violence from 1994-2000 and disease-specific DALYs attributable to major communicable and noncommunicable diseases in 2002 by age group among males and females, respectively. There was little variation in the magnitude of associations between males and females and between communicable and noncommunicable diseases. On average, a 1.0\% increase in deaths due to terrorism, civil war and one-sided violence was associated with an increase of $0.16 \%$ in DALYs lost. With very few exceptions, associations between deaths due to terrorism, war and one-sided violence and DALYs attributable to specific communicable and noncommunicable diseases were overwhelmingly positive and significant across the majority of sex-age subgroups. In general, a 1.0\% increase in deaths due to terrorism, war and one-sided violence from 1994-2000 resulted in increases of between $0.02 \%$ and $0.16 \%$ in DALYs lost in 2002 to the specific diseases examined in this study.

\section{Discussion}

This study found that the impact of terrorism, civil war and one-sided violence on morbidity and mortality extends well into the post-conflict period. Deaths from terrorist actions, civil war and one-sided violence from 1994-2000 were positively and significantly related to all cause DALYs occurring in 2002, even after controlling for a variety of economic variables empirically shown to affect public health. In contrast with prior studies (Ghobarah et al., 2003; 


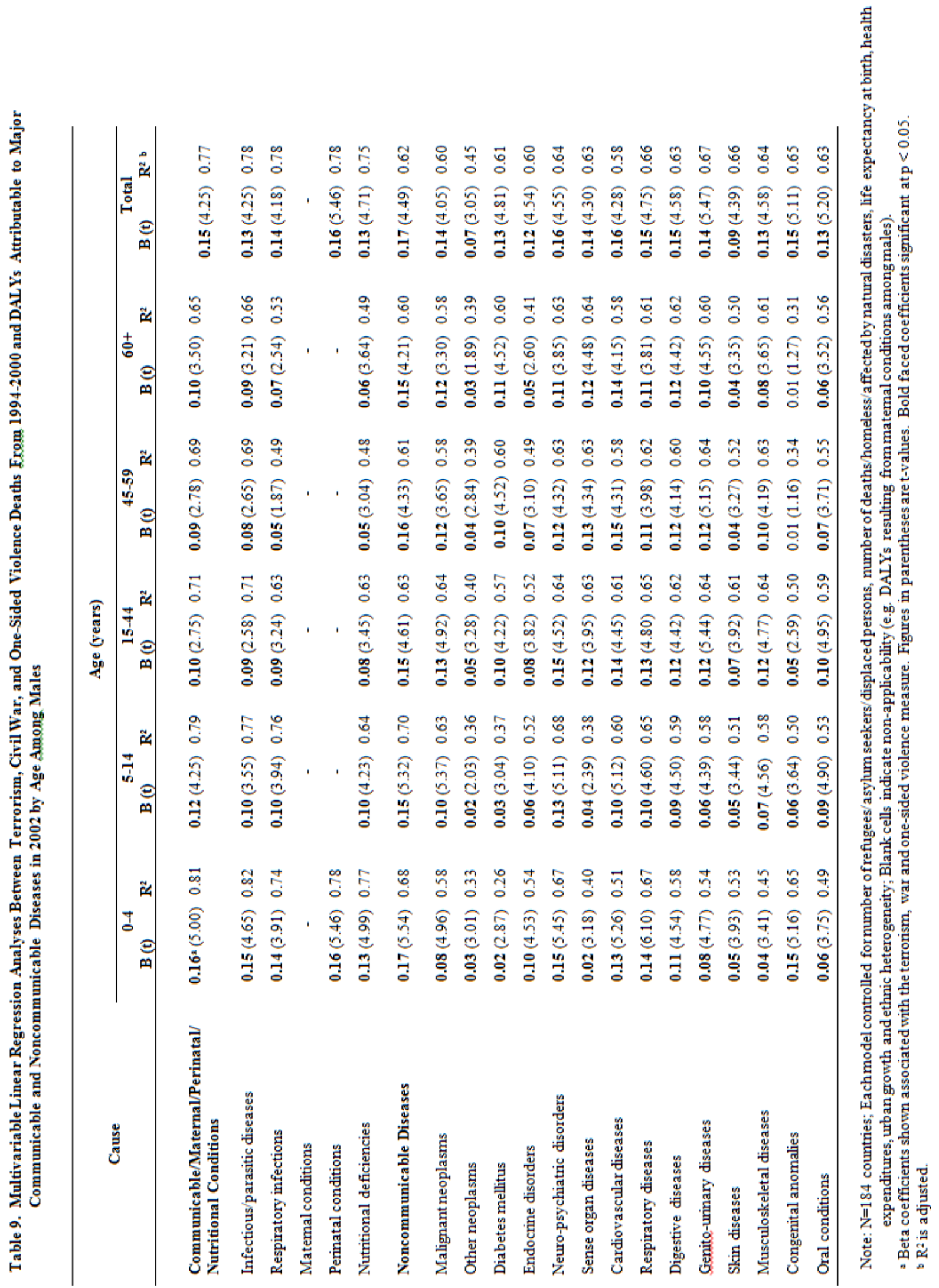




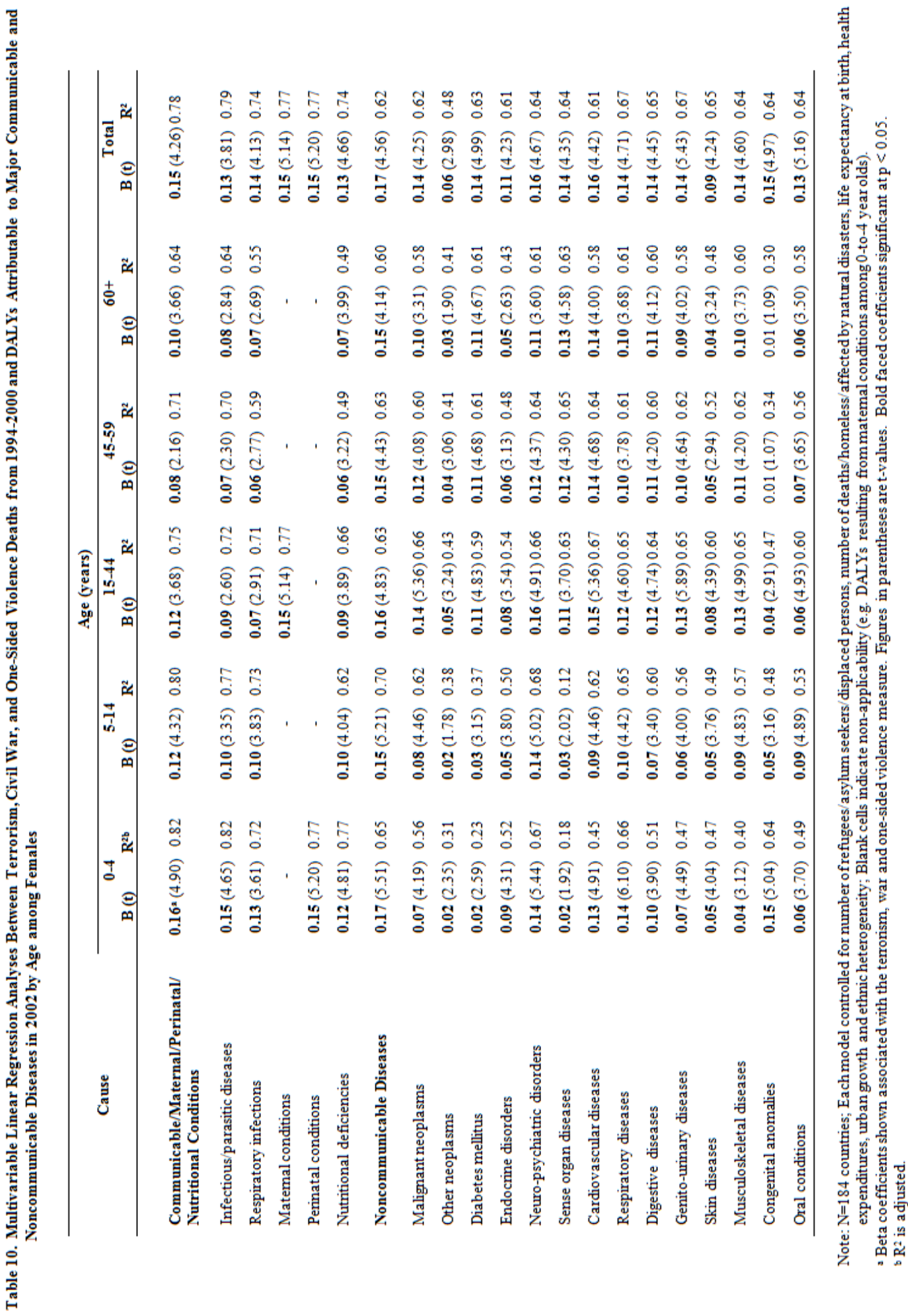


2004b), the adverse impact of terrorism, civil war and one-sided violence on DALYs was found across sex-age subgroups of the populace and across a variety of communicable and noncommunicable conditions and diseases: infectious and parasitic diseases, respiratory infections, maternal and perinatal conditions, nutritional deficiencies, malignant neoplasms, diabetes mellitus, endocrine disorders, neuro-psychiatric disorders, sense-organ, cardiovascular, respiratory, digestive, genito-urinary, skin and musculoskeletal diseases, congenital anomalies and oral conditions. These discrepancies between the results of prior research and the present study may, in part, be due to broadening the major exposure variable to reflect the nature and scope of conflict to include deaths due to terrorist actions and one-sided violence and applying appropriate transformations to outcome measures necessary to render the data suitable for linear regression analyses. These results underscore the need to expand the traditional focus of postconflict interventions on communicable, maternal and perinatal, and nutritional diseases to a variety of noncommunicable diseases shown in this study to be strongly associated with terrorism, war and one-sided violence in the longer-term (Banatvala and Zwi, 2000; Thoms and Ron, 2007; Toole and Waldman, 1993).

Although not the focus of attention in the present study, the number of refugees/asylum seekers/displaced persons in 1994 consistently and significantly increased DALYs lost to all causes and specific communicable and noncommunicable diseases. This result was expected since many studies of refugee populations in settlement or makeshift camps have observed the extremely poor water resources and sanitation conditions as well as significant overcrowding, which substantially contributes to the risk of disease transmission (Ahoua et al., 2006). Refugees/asylum seekers/displaced persons also suffer increased risk of other physical and mental disorders through exposure to substantial trauma including torture, sexual violence, 
mutilation and machete wounds, loss of property and detention (Amanda et al., 2010; Bogic et al., 2012; Mitike and Deressa, 2009).

Natural disasters occurring between 1994 and 2000 were also associated with increases in all cause and disease specific DALYs in 2002 across sex-age subgroups of the populace. The longer-term consequences of disasters resulting from damage to water and sewer systems, channels of communication, schools, industries and health infrastructures have large impacts on communicable and noncommunicable diseases, especially respiratory conditions and perinatal and maternal conditions (Herbstman and Frank, 2005; WHO, 2008a). The severe nature of many natural disasters frequently leave victims feeling pain, distress and discomfort for years after the event has occurred (Johannesson et al., 2011). Further, the association between exposure to natural disasters and mental disorders including substance use disorders (McFarlane et al., 1994), depression (Green and Solomon, 1995), and anxiety disorders (Fan et al., 2011) is well established in the literature.

This study also found that the greater the urban growth experienced between 1990 and 1995, the greater number of DALYs lost in 2002 from all causes. However, this result was largely concentrated among children under the age of 15 years. That urban growth has a strong impact on the health of infants and children is predicted by the very nature of the urban environment. Urban infrastructures, especially water and sanitation systems, play a vital role in the transmission of infectious diseases as municipalities increasingly struggle to provide services for growing populations. Inadequate provision for solid waste collection also frequently lead to contamination of water bodies and have been shown to present substantial risk for spreading epidemics rapidly (Alexander and Ehrlich, 2000). Pollution and other characteristic of many urban environments play a critical role in the development of respiratory conditions, while noise 
exposure has been associated with hearing impairment, hypertension and ischemic heart disease (Cohen et al., 2003; Dockery et al., 1993).

Like urban growth, health expenditures in 1994 were independently but negatively associated with all cause DALYs in 2002, primarily among 0-to-14 year-olds. Nearly $80 \%$ of studies, conducted largely among developed countries, over the past 20 years have found that health expenditures are significantly associated with decreasing infant mortality (Nixon and Ulmann, 2006; Majnoni and Ulmann, 1999). However, there is considerable evidence to suggest that even small changes in health expenditures in developing or intermediate countries would have a larger impact on health outcomes than in developed countries. Developing countries are more sensitive to changes in health expenditures since the highest fraction of deaths are due to infectious and parasitic diseases (e.g. malaria, tuberculosis) (Jowett, 1999). Among the most deadly for children under the age of 14 are diarrheal diseases and acute respiratory infections, an observation consistent with the finding of the present study of the negative impact of health expenditures on DALYs lost among infants and children.

Life expectancy at birth was negatively associated with all cause DALYs among 0-to-4 year-olds, but positively associated with all cause DALYs among the older age groups. This result was not surprising as it would be expected that the greater pre-existing life expectancy at birth in 1994 would result in significantly fewer DALYs lost in 2002 among very young children. In contrast, the positive relationship between life expectancy at birth and all cause DALYs among the older age groups merely reflects the longer life necessary to die from diseases associated with older onsets or more chronic course.

This study was the first to combine deaths from terrorist actions, with deaths from civil war and one-sided violence to more fully characterize the nature of violence occurring during armed conflict, thereby highlighting terrorism and one-sided violence as substantial public 
health problems. The present study has also benefitted from three new databases designed to separately measure deaths from terrorism, civil war and one-sided violence more reliably than in the past and the use of appropriate data transformations to ensure the suitability of the data for statistical models employed. Limitations, however, are noted. Although there always exists a potential of omitting an important variable from the analyses presented herein, this potential was minimized in the current study by careful theorizing and attention to prior research. Although the results of this ecological comparative study cannot fully capture within country variability or support the individual level of inference, they can play an essential role in defining the impact of major public health problems such as terrorism, civil war and one-sided violence that operate at a population level to influence morbidity and mortality. The measures used in the present study were associated with various levels of reliability across WHO member states. However, the measures of interest in this research are the most reliable that have ever been available, permitting plausible systematic inferences of the longer-term influences of terrorism, war and one-sided violence on morbidity and mortality.

In summary, this study found that violence associated with terrorist actions, civil wars and one-sided violence had a significant and lingering impact on a broad range of noncommunicable and communicable diseases, independent of other economic and related factors whose relationship to mortality and morbidity have been well established in the literature. These results highlight the need to expand the traditional focus in the intervention literature on reducing morbidity and mortality from communicable diseases in conflict-affected populations (Banatvala and Zwi, 2000) to include those interventions targeting major noncommunicable diseases. The results of the present study can begin to help guide nongovernmental organizations (NGOs) and intergovernmental organizations (IGOs) to develop and strengthen interventions to reduce morbidity and mortality from a variety of 
noncommunicable as well as communicable diseases among vulnerable conflict-affected populations. Much more research is needed to fully understand the relationships between terrorism, civil war and one-sided violence and their deleterious longer-term impacts on public health for the purpose of highlighting the full health costs of war and related violence and ultimately providing a stronger rationale for promoting peace (Kerridge et al., 2012). 


\title{
Chapter IV: Paper 2. Terrorism, Civil War, One-Sided Violence and Global Burden of Diarrheal and Related Diseases
}

\author{
Bradley T. Kerridge ${ }^{a}$, Maria R. Khan ${ }^{b}$, Jürgen Rehm ${ }^{c}$, Amir Sapkota $^{d}$
}

\author{
${ }^{a}$ Bradley T. Kerridge \\ Department of Epidemiology and Biostatistics \\ School of Public Health \\ University of Maryland, College Park \\ College Park, Maryland, 20742 \\ ${ }^{\mathrm{b}}$ Department of Epidemiology \\ College of Public Health and Health Professions \\ School of Medicine \\ University of Florida Health Sciences Center \\ University of Florida \\ Gainesville, Florida, 32610 \\ ${ }^{\mathrm{c}}$ Centre for Addiction and Mental Health \\ 33 Russell Street \\ Toronto, Ontario \\ Canada, M5S 2S1 \\ ${ }^{\mathrm{d}}$ Maryland Institute for Applied Environmental Health \\ Department of Epidemiology and Biostatistics \\ School of Public Health \\ University of Maryland, College Park \\ College Park, Maryland, 20740
}




\begin{abstract}
The purpose of this study was to conduct a country-level analysis to determine the relationship between deaths due to terrorism, civil war and one-sided violence from 1994-2000 and disability-adjusted life years (DALYs) attributable to diarrheal and related diseases, including schistosomiasis, trachoma and the nematode infections (DSTN diseases), in 2002. Deaths resulting from terrorism, civil war and one-sided violence were significantly related to DSTN DALYs across the majority of sex-age subgroups of the populace, after controlling for baseline levels of improved water and sanitation and a variety of economic measures. Overall, a $1.0 \%$ increase in deaths due to terrorism and related violence from 1994-2000 was associated with an increase of $0.16 \%$ in DALYs lost to DSTN diseases in 2002. These associations were greatest among 0-to-4 year-olds. The results of the present study suggest that DSTN disease control efforts should target conflict-affected populations with particular attention to young children who suffer disproportionately from DSTN diseases in these settings. In view of the evidence that terrorism, civil war and one-sided violence may influence DTSN DALYs, control strategies should move beyond immediate responses to decrease incidence and severity of DSTN diseases to seek solutions through bolstering health systems infrastructure development in settings affected by terrorism and related violence. This study also highlights one of the hidden costs of terrorism and related violence, providing an additional rationale for promoting peace.
\end{abstract}

\title{
Introduction
}

Nearly one tenth of the global disease burden could be prevented by improving water supply, sanitation, hygiene and water resources management (World Health Organization [WHO], 2010b). The WHO recently estimated the disease burden attributable to the risk factor, water, sanitation and hygiene, for various disease outcomes (2008a). Among those outcomes 
were diarrhea (including cholera, salmonellosis, shigellosis, amoebiasis and other bacterial, protozoal and viral intestinal diseases), schistosomiasis, trachoma and the nematode infections (ascariasis, trichuriasis and hookworm disease). These specific infectious and parasitic diseases were uniquely determined to be $90 \%$ to $100 \%$ attributable to unsafe water and inadequate sanitation and hygiene (Prüss-Üstun et al., 2002; 2004).

Taken together, these diarrheal and related diseases account for approximately $5.0 \%$ of the global burden of disease, with diarrheal diseases (4.1\%) disproportionately contributing to this toll of death and disability. Diarrheal diseases are the second leading cause of death among children under five years-old, killing more than 1.5 million children annually (WHO, 2009). More than 200 million people worldwide are infected with schistosomiasis, and 700 million are at risk for this infection as a result of exposure to unsafe water and inadequate sanitation (Steinmann et al., 2006). Trachoma is responsible for approximately $3.0 \%$ of the world's blindness and visual impairments among approximately 5 million people worldwide (Resnikoff et al., 2008). There are 2 billion intestinal nematode infections affecting one third of the world's population, with the largest percentage attributable to ascariasis. Globally, ascariasis causes about 60,000 deaths each year, predominantly among children (WHO, 2008a; 2010b).

In recent years a growing body of research has recognized the importance of the longerterm impact of armed conflict and related violence in the development of infectious and parasitic diseases (Bieberson, 1999; Colombatti et al., 2009; Gayer et al., 2007; Guha-Sapir and van Panhuis, 2002a; Murray et al., 2002). This literature differentiates between the direct or immediate effects of armed conflict and related violence (e.g. battle deaths) from their indirect or longer-term effects on public health, many of which last for years after the fighting and bombing cease. Civil war and related violence influences the transmission of infectious and parasitic diseases in the longer-term largely through deterioration of health-related 
infrastructures including damage to water supplies, electricity, and sewage disposal systems necessary for health care services to operate (WHO, 2008a; 2010b). Other indirect effects of conflict and related violence on morbidity and mortality from infectious diseases include reduced public and private investment in health, economic recession, increased poverty, famine, departure or death of health care workers, lack of shelter and overcrowding (Perrin, 1996; WHO, 2006b). Indirect consequences of war on infectious and parasitic diseases are also demographic, that is, displacement and forced resettlement of large numbers of persons resulting in reduced access to health care resources, food, safe water and adequate sanitation (Asgary and Segar, 2011).

Despite the increasing recognition of the longer-term consequences of conflict and related violence on infectious and parasitic diseases, only two studies to our knowledge to date have quantitatively addressed the relationship (Ghobarah et al., 2003; 2004b). Both of these studies examined the relationship between civil war deaths from 1991-1997 and burden of disease, as measured by disability-adjusted life years (DALYs), attributable to specific communicable diseases in 1999. The DALY is a measure that combines information on morbidity and mortality for specific causes and is derived as the sum of years of life lost to premature mortality plus the years of life lost to disability in a population (Murray and Lopez, 1996). Controlling for an array of economic and related factors (e.g. health care expenditures, urban growth), civil war deaths were significantly related to DALYs attributable to human immunodeficiency virus/acquired immune deficiency syndrome (HIV/AIDS), malaria, tuberculosis, respiratory infections and other infections among the majority of sex-age subgroups of the populace (Ghobarah et al., 2003; 2004b). In sharp contrast, civil war deaths were not found to be associated with any infectious or parasitic diseases attributable to unsafe water and sanitation, including diarrheal diseases, schistosomiasis, trachoma, and the nematode 
infections. That infectious diseases most closely related to unsafe water and sanitation bore no relationship to armed conflict in these studies was surprising, since so many of the mechanisms through which conflict works to adversely impact infectious and parasitic disease incidence and severity strongly relate to unsafe water and inadequate sanitation (e.g. displacement and forced resettlement; deterioration of health and related infrastructures).

Although the work by Ghobarah et al. $(2003 ; 2004 b)$ has significantly increased our knowledge of the relationship between civil war and longer-term morbidity and mortality attributable to infectious disease, some limitations are noted. This research failed to directly control for major determinants of infectious disease morbidity and mortality, that is, the number of refugees/asylum seekers/displaced persons in host countries and the number of persons affected by natural disasters. The absence of associations between civil war deaths and DALYs due to DSTN diseases may have been, in part, the result of neglecting to transform DALY outcome measures that are skewed. Linear regression models used in these prior studies, and indeed in the present study, require such transformed data to satisfy the linearity assumption of the linear regression model. Foremost, these authors did not assess the impact of terrorist actions and one-sided violence on longer-term morbidity and mortality. One-sided violence is defined as the use of armed force by government or by a formally organized group against civilians and includes genocide and summary execution of prisoners (Kreutz and Eck, 2011). Between 1989 and 2004, the vast majority of fatalities from one-sided violence have taken take place in countries experiencing armed conflict and terrorism (Eck and Hultman, 2007; Ericksson et al., 2003; Lacina and Gleditsch, 2005) strongly suggesting that these three forms of intimately related violence be measured to better reflect the nature and intensity that has increasingly characterized civil conflict. 
The present study builds upon prior work on the relationship between civil war deaths and longer-term morbidity and mortality attributable to infectious diseases. Since the severity and scope of civil war has changed over the last three decades to increasingly include fatalities arising from terrorist actions and one-sided violence, the major exposure variable in this study was the sum of these three types of intimately related violence (Eck and Hultman, 2007; Ericksson et al., 2003). It is hypothesized that increasing numbers of deaths from terrorism, civil war and one-sided violence from 1994-2000 will be associated with increasing levels of morbidity and mortality (as measured by DALYs) in 2002 attributable to infectious diseases that are strongly related to unsafe water and inadequate sanitation (i.e. diarrheal diseases, schistosomiasis, trachoma, ascariasis, tricuriasis, and hookworm disease) among WHO Member States. This study will control for the effects of disease-specific vulnerability factors (i.e. percent of the population using improved water resources; percent of the population using improved sanitation facilities) and a number of economic factors (e.g. health expenditures, urban growth) measured at baseline in 1994. It is further predicted that the impact of terrorism, civil war and related violence on these infectious and parasitic diseases in the longer-term will be pervasive, adversely impacting the majority of age-sex subgroups of the populace.

\section{Methods}

\section{Outcome: Diarrheal and Related Disease DALYs}

The outcome variables were the number of DALYs (in thousands) due to diarrheal diseases, schistosomiasis, trachoma, and the nematode infections (ascariasis, trichuriasis and hookworm) (DSTN diseases) for 2002 for 183 of the 192 WHO Member States for the total sample and among sex and age subgroups of the populace (WHO, 2004a). DALYs are calculated as the sum of the years of life lost due to premature mortality and healthy years of life lost due to disability (Murray and Lopez, 1996). 


\section{Exposure: Deaths from Terrorism, Civil War and One-Sided Violence}

Data on the number of deaths among victims and perpetrators resulting from terrorist actions from 1994-2000 were derived from the 2010 update of the Global Terrorism Database (National Consortium for the Study of Terrorism and Responses to Terrorism (NCSTRT), 2010). Terrorist incidents include those that are intentional, achieve some level of violence or threat of violence and are perpetrated by sub-national, non-state actors. In addition, to qualify as a terrorist incident, at least two of the following three criteria must be met: (1) the act must be aimed at attaining a political, economic, religious or social goal; (2) there is evidence of an intention to coerce, intimidate, or convey some other message to a larger audience than the immediate victims; and (3) the action must be outside the context of legitimate warfare activities (NCSTRT, 2010).

Data for civil war deaths occurring between 1994 and 2000 were derived from the Battle Deaths Database (Lacina, 2009; Lacina and Gleditsch, 2005). Civil war is defined as armed conflict occurring between the government of a state and one or more internal opposition groups with or without intervention from other states. Civil war conflict is a contested incompatibility that concerns governments and/or territory where the use of armed force between two parties, of which at least one is the government of the state, results in at least 25 battle deaths. Battle deaths are defined as deaths resulting directly from violence inflicted through the use of armed force by a party to armed conflict.

Deaths resulting from one-sided violence for the years 1994-2000 were available from the One-sided Violence Database (Kreutz and Eck, 2011). One-sided violence is defined as the use of armed force by the government of the state or by a formally-organized group against civilians which results in at least 25 deaths and includes genocide and summary execution of prisoners. Only one-sided violence deaths perpetrated by government actors were included 
since those perpetrated by formally-organized groups overlapped with those included in the GTD.

\section{Pre-existing Vulnerability Control Variables}

The WHO defines two indicators to measure access to safe drinking water and basic sanitation: (1) the percentage of the population using improved drinking water sources; and (2) the percentage of the population using improved sanitation facilities (WHO, 2011c). An improved drinking water source is one that by nature of its construction adequately protects the source from contamination, in particular from fecal matter. An improved sanitation facility is one that hygienically separates human excreta from human contact (WHO, 2006a). For the purposes of this research, the percentages of the population using improved water sources and improved sanitation facilities were summed for the year 1994.

\section{Economic and Related Control Variables}

The number of refugees/asylum seekers/displaced persons (in thousands) residing in each host country at the end of the year 1994 served as an important control measure. These data were available from the United Nations High Commissioner for Refugee's Statistical Yearbook

(1995a). Similar to all control variables used in the present analyses, except the number of deaths/homeless/affected by natural disasters from 1994-2000, the number of refugees/asylum seekers/displaced persons was measured at baseline, that is, as close to the year 1994 as the available data would allow.

The natural disaster variable combined the number of deaths (persons confirmed as dead or missing), number of homeless (persons needing immediate shelter) and number affected (i.e. people requiring immediate assistance in basic survival needs such as food, water and sanitation), in thousands, occurring at the country level for the years 1994-2000. Data were available from the Emergency Events Database maintained by the WHO Collaborating Center 
for Research on Epidemiology and Disasters (Guha-Sapir et al., 2004). A disaster event is defined by CRED as one that meets one or more of the following criteria: (1) there were 10 or more people killed; (2) there were at least 100 people reportedly affected; or (3) the disaster led to the declaration of a state of emergency or calls for international assistance.

The urbanization variable in this study is the average percentage change in the urban population between 1990 and 1995, data collected routinely by the United Nations (UN) Department of Economic and Social Affairs and available on the UN Millennium Goals Database (UN, 2011b). General government health expenditures as a percentage of total government expenditure (GGHE as a percentage of TGE) was also included as a critical control measure of health financing systems. Data on GGHE as a percentage of TGE for 1994 were available from the WHO Global Health Observatory Database (2011a).

The measure of ethnic heterogeneity in this study is derived from Vanhanen (1999) that combines racial, linguistic and religious division, each measured as the percentage of the largest group of a country's population for the years 1994-1996. These three percentages are summed and its inverse measures the degree of ethnic heterogeneity.

Tropical climate is a critical determinant for the development of many infectious and parasitic diseases (WHO, 2010b). Tropical country status is operationalized as a dichotomous variable $(1=$ at least one-half of the land mass in the tropics, and $0=$ less than one-half of the land mass in the tropics). Data on tropical country status is collected by the International Union for the Conservation of Nature (2000).

\section{Statistical Analyses}

Using deaths from terrorism, civil war and one-sided violence in the years 1994-2000 produces a 2-year lag to DSTN DALYs in 2002. DALYs in 2002 reflect years of life lost due to deaths from DSTN diseases during 2002 plus the disability incurred by people experiencing 
these same conditions in 2002. Thus, these are not deaths or disabilities experienced in earlier years during which the terrorism and related violence was active.

Multivariable linear regression analyses were conducted to examine the relationships between deaths from terrorism, war and one-sided violence from 1994-to-2000 and DSTN DALYs in 2002, controlling for pre-existing vulnerability and economic factors at baseline. Analyses were conducted for the total sample and separately among sex and age $(0-4,5-14,15-$ 44, 45-59, and 60+ years old). Nine of the 192 WHO Member States did not have sufficient data on control variables and were excluded from the analyses. The majority $(n=8)$ of these countries were small islands or microstates. Rwanda was eliminated from the analyses because the country experienced 500,000 deaths due to genocide, rendering it an extreme outlier. The DALY outcome measures, the war and related violence exposure measure, and two control measures (number of deaths/homeless/affected by natural disasters and number of refugees/asylum seekers/displaced persons) were log transformed as the result of skew in order to satisfy the linearity assumption of the linear regression model.

\section{Results}

Table 11 shows the results from the multivariable linear regression analyses examining the relationships between deaths due to terrorism, war and one-sided violence from 1994-2000 and DALYs attributable to DSTN diseases in 2002 by sex. Regardless of sex, deaths due to terrorism, war and one-sided violence were significantly related to DSTN DALYs. On average, the beta coefficients associated with these relationships was 0.16 , indicating that a $1.0 \%$ increase in deaths due to terrorism, war and one-sided violence was associated with a $0.16 \%$ increase in DSTN DALYs.

Although not the focus in this study, the percentage of the population using improved water resources/sanitation facilities at baseline in 1994 was negatively associated with DSTN 
Table 11. Multivariable Linear Regression Analyses Between Terrorism, Civil War and One-Sided Violence Deaths From 1994-2000 and DALYs Attributable to Diarrheal and Related Diseases in 2002 by Sex

\begin{tabular}{|c|c|c|c|}
\hline Variables & $\begin{array}{l}\text { Male } \\
B(t)\end{array}$ & $\begin{array}{c}\text { Female } \\
\text { B (t) }\end{array}$ & $\begin{array}{l}\text { Total } \\
B(t) \\
\end{array}$ \\
\hline $\begin{array}{l}\text { Terrorism, war and one-sided } \\
\text { violence deaths, } 1994-200\end{array}$ & $0.15(4.91)$ & $0.15(4.82)$ & $0.16(4.83)$ \\
\hline $\begin{array}{l}\text { Percent improved water/sanitation, } \\
1994\end{array}$ & $-0.01(-6.40)$ & $-0.02(-6.27)$ & $-0.02(-6.31)$ \\
\hline $\begin{array}{l}\text { Number of refugees/asylum } \\
\text { seekers/displaced, } 1994\end{array}$ & $0.09(2.10)$ & $0.10(2.20)$ & $0.10(2.09)$ \\
\hline $\begin{array}{l}\text { Number affected by natural disasters, } \\
1994-2000\end{array}$ & $0.28(9.28)$ & $0.27(9.09)$ & $\mathbf{0 . 3 0}(9.45)$ \\
\hline Urban growth, 1990-1995 & $0.11(2.34)$ & $0.21(2.36)$ & $0.22(2.36)$ \\
\hline Health expenditures, 1994 & $-0.05(-2.52)$ & $-0.05(-2.57)$ & $-0.05(-2.64)$ \\
\hline Ethnic heterogeneity, 1994-1996 & $<0.01(1.43)$ & $<0.01(1.28)$ & $<0.01(1.06)$ \\
\hline Tropical country status & $0.22(1.19)$ & $0.24(1.23)$ & $0.22(1.06)$ \\
\hline Adjusted $R^{2}$ & 0.78 & 0.78 & 0.78 \\
\hline
\end{tabular}

Note: $\mathrm{N}=183$; Boldfaced beta coefficients significant at $\mathrm{p}<0.05$; figures in parentheses are t-values. 
DALYs in 2002 for each sex: a 1.0\% increase in improved water resources/sanitation facilities was associated with a $2 \%$ decrease in DSTN DALYs. A $1.0 \%$ increase in the number of refugees/asylum seekers/displaced persons residing in the host country at the end of 1994 was associated with a $0.10 \%$ increase in DALYs lost to DSTN diseases in 2002 while a $1.0 \%$ increase in the number of persons affected by natural disasters from 1994-2000 was associated with an increase of $0.30 \%$ in DSTN DALYs lost in 2002. A $1.0 \%$ increase in urban growth between 1990 and 1995 was associated with an increase of 24.6\% in DSTN DALYs and a $1.0 \%$ increase in GGHE of TGE was associated with a 5\% decrease in DSTN DALYs in 2002.

Tables 12 and 13 show the relationships between deaths due to terrorism, war and onesided violence from 1994-2000 and DSTN DALYs in 2002 by age among males and females, respectively. The results were generally consistent to the overall results. Terrorism, war and one-sided violence deaths were significantly related to DSTN DALYs among males and females in all age groups. However, this association was much greater among 0-to-4 year olds: a 1.0\% increase in deaths due to terrorism, war and one-sided violence was associated with, on average, an increase of $0.16 \%$ in DALYs lost to DSTN DALYs. The effect of deaths due to terrorism and related violence was less among the older age groups (5 years and older). A 1.0\% increase in deaths due to deaths due to terrorism, war and one-sided violence in 1994-2000 was associated with increases of between $0.04 \%$ to $0.08 \%$ in DSTN DALYs lost in 2002 among the older age groups.

\section{Discussion}

Deaths from terrorist actions, civil war and one-sided violence from 1994-2000 were positively related to DSTN DALYs occurring in 2002, even after controlling for baseline percentages of the population using improved water resources/sanitation facilities and a variety 
Table 12. Multivariable Linear Regression Analyses Between Terrorism, Civil War, and One-Sided Violence Deaths from 1994-2000 and DALYs Attributable to Diarrheal and Related Diseases in 2002 by Age among Males

\begin{tabular}{|c|c|c|c|c|c|}
\hline \multirow{2}{*}{ Variables } & \multicolumn{5}{|c|}{ Age (years) } \\
\hline & $\begin{array}{c}0-4 \\
B(t)\end{array}$ & $\begin{array}{l}5-14 \\
B(t)\end{array}$ & $\begin{array}{c}15-44 \\
B(t)\end{array}$ & $\begin{array}{l}45-59 \\
\mathrm{~B}(\mathrm{t})\end{array}$ & $\begin{array}{l}60+ \\
B(t)\end{array}$ \\
\hline $\begin{array}{l}\text { Terrorism, war and one-sided } \\
\text { violence deaths, 1994-2000 }\end{array}$ & $\mathbf{0 . 1 6}(5.16)$ & $0.08(3.72)$ & $0.08(3.31)$ & $0.05(2.53)$ & $0.04(2.46)$ \\
\hline $\begin{array}{l}\text { Percent improved water/sanitation, } \\
1994\end{array}$ & $-0.02(-8.01)$ & $-0.01(-2.90)$ & $<-0.01(-1.20)$ & $<-0.01(-0.85)$ & $<-0.01(-1.56)$ \\
\hline $\begin{array}{l}\text { Number of refugees/asylum } \\
\text { seekers/displaced, } 1994\end{array}$ & $0.08(1.85)$ & $0.06(1.84)$ & $0.09(2.66)$ & $0.07(2.72)$ & $0.08(2.97)$ \\
\hline $\begin{array}{l}\text { Number affected by natural disasters, } \\
1994-2000\end{array}$ & $0.25(8.45)$ & $0.17(7.87)$ & $0.18(7.96)$ & $0.12(6.25)$ & $0.11(6.17)$ \\
\hline Urban growth, 1990-1995 & $0.19(2.21)$ & $0.17(2.55)$ & $0.13(1.96)$ & $0.11(2.02)$ & $0.11(2.17)$ \\
\hline Health expenditures, 1994 & $-0.04(-2.31)$ & $-0.02(-1.44)$ & $-0.03(-1.95)$ & $-0.02(-1.49)$ & $-0.01(-1.28)$ \\
\hline Ethnic heterogeneity, 1994-1996 & $<0.01(1.69)$ & $<0.01(1.73)$ & $<0.01(1.29)$ & $<0.01(1.61)$ & $<0.01(1.75)$ \\
\hline Tropical country status & $0.19(0.98)$ & $\mathbf{0 . 5 0}(3.50)$ & $0.24(1.61)$ & $0.21(1.71)$ & $0.16(1.42)$ \\
\hline Adjusted $\mathrm{R}^{2}$ & 0.79 & 0.69 & 0.62 & 0.54 & 0.56 \\
\hline
\end{tabular}

Note: $\mathrm{N}=183$ countries; Boldfaced beta coefficients significant at $\mathrm{p}<0.05$; Figures in parentheses are $\mathrm{t}$-values. 
Table 13. Multivariable Linear Regression Analyses Between Terrorism, Civil War, and One-Sided Violence Deaths From 1994-2000 and DALYs Attributable to Diarrheal and Related Diseases in 2002 by Age Among Females

\begin{tabular}{|c|c|c|c|c|c|}
\hline \multirow[b]{2}{*}{ Variables } & \multicolumn{5}{|c|}{ Age (years) } \\
\hline & $\begin{array}{c}0-4 \\
B(t)\end{array}$ & $\begin{array}{l}5-14 \\
B(t)\end{array}$ & $\begin{array}{c}15-44 \\
B(t)\end{array}$ & $\begin{array}{l}45-59 \\
B(t)\end{array}$ & $\begin{array}{l}60+ \\
B(t)\end{array}$ \\
\hline $\begin{array}{l}\text { Terrorism, war and one-sided } \\
\text { violence deaths, } 1994-2000\end{array}$ & $\mathbf{0 . 1 5}(5.09)$ & $0.08(3.77)$ & $0.07(2.86)$ & $0.04(1.76)$ & $0.04(1.69)$ \\
\hline $\begin{array}{l}\text { Percent improved water/sanitation, } \\
1994\end{array}$ & $-0.02(-7.97)$ & $-0.01(-2.85)$ & $<-0.01(-0.85)$ & $<-0.01(-1.31)$ & $<-0.01(-2.01)$ \\
\hline $\begin{array}{l}\text { Number of refugees/asylum } \\
\text { seekers/displaced, } 1994\end{array}$ & $0.08(1.91)$ & $0.06(1.87)$ & $0.10(2.83)$ & $0.10(3.12)$ & $0.11(3.44)$ \\
\hline $\begin{array}{l}\text { Number affected by natural disasters, } \\
1994-2000\end{array}$ & $0.24(8.17)$ & $0.17(7.87)$ & $0.18(7.67)$ & $0.13(5.90)$ & $0.12(5.80)$ \\
\hline Urban growth, 1990-1995 & $0.20(2.24)$ & $0.16(2.56)$ & $0.13(1.87)$ & $0.12(1.88)$ & $0.13(2.07)$ \\
\hline Health expenditures, 1994 & $-0.05(-2.41)$ & $-0.02(-1.29)$ & $-0.03(-1.72)$ & $-0.02(-1.33)$ & $<-0.02(-1.24)$ \\
\hline Ethnic heterogeneity, 1994-1996 & $<0.01(1.50)$ & $<0.01(1.80)$ & $<0.01(1.29)$ & $<0.01(1.93)$ & $0.01(1.89)$ \\
\hline Tropical country status & $0.19(1.00)$ & $\mathbf{0 . 5 0}(3.58)$ & $0.26(1.74)$ & $0.23(1.70)$ & $0.19(1.40)$ \\
\hline Adjusted $R^{2}$ & 0.79 & 0.69 & 0.60 & 0.53 & 0.55 \\
\hline
\end{tabular}

Note: $\mathrm{N}=183$; Boldfaced coefficients significant at $\mathrm{p}<0.05$; Figures in parentheses are t-values. 
of economic measures empirically shown to affect public health. In contrast to prior studies (Ghobarah et al., 2003; 2004b), the adverse impact of terrorism, civil war and one-sided violence on DSTN DALYs was found across a majority of sex-age subgroups of the populace. This discrepancy may, in part, be due to broadening the major exposure variable, civil war deaths, to include deaths due to terrorist actions and one-sided violence and applying appropriate transformations to the DALY outcome measures to render the data suitable for linear regression analysis.

Associations between terrorism, war and one-sided violence and DSTN DALYs were also strongest among the very young (0-to-4 year olds), highlighting DSTN diseases as leading causes of child morbidity and mortality with their exacerbation often occurring in conflictaffected populations. This finding was not surprising as children are more vulnerable to DSTN diseases, especially among those with poor nutritional status and those exposed to poor environmental conditions (Gayer et al., 2007). Further, children are vulnerable to these diseases since they have a greater risk of life-threatening dehydration than adults because water constitutes a great proportion of a child's bodyweight (WHO, 2008a). Childhood malnutrition causes about $35 \%$ of all deaths among children and it is estimated that $50 \%$ of malnutrition is caused by repeated diarrhea or intestinal nematode infections as the result of unsafe water, and inadequate sanitation (WHO, 2010b). Consistent with this finding, health care expenditures were also related to DSTN DALYs in the 0-to-4 year old age group. Health care expenditures have repeatedly been shown to decrease infant mortality and increase life expectancy at birth (Majnoni and Ulman, 1999; Nixon and Ulman, 2006). This is particularly true in developing countries and conflict-affected populations where the highest fraction of deaths and disability are due to infectious and parasitic diseases, especially diarrheal diseases (Jowett, 1999). 
The prior literature on the public health consequences of terrorism, war and one-sided violence has not generally considered other contributing factors that may increase the risk of specific diseases such as pre-existing vulnerability factors (Levy and Sidel, 2003; 2007; 2009). Although not the focus of this study, the percentage of the population with improved water resources/sanitation facilities was included as the pre-existing control measure, consistent with the Global Burden of Disease (GBD) Study (WHO, 2008a) perspective that DSTN diseases are $90 \%$ to $100 \%$ attributable to unsafe water and inadequate sanitation. That the percentage of the population with improved water resources/sanitation facilities at baseline in 1994 was associated with DSTN DALYs in 2002 among 0-to-14 year-olds in the present study highlights the importance of inclusion of disease-specific vulnerability factors in future research examining the impact of terrorism and related violence on morbidity and mortality.

Although not the focus of this study, the number of refugees/asylum seekers/displaced persons in 1994 and the number of persons affected by natural disasters from 1994-2000 were also associated with DSTN DALYs in 2002 for the majority of sex-age subgroups of the populace. These results were expected since lack of safe water, adequate sanitation and hygiene and exposure to substantial loss and stress have often been observed among conflict-affected displaced populations (Stauffer and Weinberg, 2009; Toole, 1997) and those experiencing the aftermath of natural disasters (Joshi et al., 2011; Ligam, 2006; Waring and Brown, 2005). Moreover, large numbers of persons displaced by conflict and related violence and natural disasters, often migrating from rural poverty to urban slums, are exposed to severe overcrowding that substantially increases the risk of transmission of infectious diseases including DSTN diseases (Ahoua et al., 2006; Gayer et al., 2007; Toole and Waldman, 1997). The lack of access to safe water and adequate sanitation and other infrastructure also places slum dwellers at 
particular risk of several communicable diseases, especially diarrheal diseases (Utzinger and Keiser, 2006).

Although not all DSTN diseases are tropical (i.e. unique or more prevalent in the tropics) tropical country status was associated with DSTN DALYs in 2002, and its effect was strongest among 5-to-14 year-olds. DSTN diseases classified as tropical include schistosomiasis, ascariasis and trachoma. These tropical diseases contribute disproportionately to morbidity and mortality among school-aged children, many of whom will suffer chronic, irreversible diseases in later life, including cancer of the bladder, kidney failure and liver fibrosis (WHO, 2009; 2010b). Schistosomiasis, ascariasis and trachoma have also been identified by the WHO as neglected tropical diseases that, by definition, largely affect politically marginalized people and minorities (WHO, 2010b). Access to healthcare is a political process from which marginalized minorities are often excluded (Ghobarah et al., 2004b), a result consistent with the association found in this study between ethnic heterogeneity and DSTN DALYs. Dominant groups defined by ethnicity, language and/or religion shift resources away from minorities and the disadvantaged into government programs that would be of greater benefit to them (Fearon and Laitin, 2003; Ghobarah et al., 2004a), a situation that appears to apply equally to countries experiencing peace as well as conflict-affected populations.

This study combined deaths from terrorism, along with deaths due to civil war and onesided violence to more fully characterize the nature of violence occurring during armed conflict, thereby highlighting all three forms of conflict as substantial public health problems. The present study also benefited from consideration and inclusion of pre-existing vulnerability factors into the statistical models and the use of data transformations necessary to ensure the suitability of the data for linear regression analyses. Limitations, however, are noted. There always exists a potential for omitting an important control variable from the models presented 
herein, but the associated $\mathrm{R}^{2} \mathrm{~s}$ were very high, indicating a reasonably complete specification of the relevant influences. Although the results of the ecological comparative design used in this study cannot fully capture within-country variability, it can play an essential role in defining the impact of major public health problems such as terrorism, war and one-sided violence that operate at a population level to influence morbidity and mortality. The measures used in the present analyses were also associated with various levels of reliability across WHO Member States. However, these measures are the most reliable that have ever been available (Mathers et al., 2000), thereby permitting plausible, but tempered, systematic inferences of the longer-term influence of terrorism, civil war and one-sided violence on DSTN morbidity and mortality. In summary, terrorism, civil war and one-sided violence appears to influence DSTN infectious and parasitic diseases in the longer-term, independent of pre-existing vulnerability and economic factors whose relationship with DSTN diseases have been well established in the literature. The results of this study suggest that international governmental organizations (IGOs) and nongovernmental organizations (NGOs) should prioritize high risk populations for DSTN disease control to include conflict-affected populations with particular attention to young children who are most vulnerable to these diseases in these settings. In view of the indirect or longer-term impact of terrorism and related violence on DSTN diseases observed in this study, control strategies should move beyond short-term provisions for safe water and adequate sanitation facilities, hygiene education, drug therapy, case management and vector control (Batterman et al., 2009; Esrey et al., 1991; Fewtrell et al., 2005; WHO, 2010b) to seek longerterm solutions through health systems infrastructure development. Private-public partnerships concerned with the mass distribution of medicines can also play an important role in strengthening health care systems through the development of rapid, integrated control measures targeted at several related DSTN diseases in conflict-affected populations (Amazigo et al., 
2002). Such interventions should be pro-poor, safe and cost-effective, similar to current efforts to mass distribute mectizan, albendazole, and praziquantel for simultaneous treatment of ascariasis, trichuriasis, hookworm disease and schistosomiasis (Loukas and Hotez, 2006; Raso et al., 2004), diseases that are often comorbid and co-endemic in many countries (Molyneux, 2006; Molyneux et al., 2005). Beyond intervention, the results of this study help underscore one of the hidden costs of terrorism and related violence, providing an additional rationale for promoting peace. 


\section{Chapter V: Paper 3. Terrorism, Civil War, One-Sided Violence and Global Burden of Substance Use Disorders}

Bradley T. Kerridge ${ }^{\text {a }}$, Maria R. Khan ${ }^{\mathrm{b}}$, Jürgen Rehm ${ }^{\mathrm{c}}$, Amir Sapkota ${ }^{\mathrm{d}}$

${ }^{a}$ Department of Epidemiology and Biostatistics

School of Public Health

University of Maryland, College Park

College Park, Maryland 20740

${ }^{\mathrm{b}}$ Department of Epidemiology

College of Public Health Professions

School of Medicine

University of Florida Health Services Center

University of Florida

Gainesville, Florida, 32610

${ }^{c}$ Centre for Addiction and Mental Health

33 Russell Street

Toronto, Ontario

Canada, M5S 2S1

${ }^{d}$ Maryland Institute for Applied Environmental Health

Department of Epidemiology and Biostatistics

School of Public Health

University of Maryland, College Park

College Park, Maryland, 20742 


\begin{abstract}
Little is known about the longer-term impact of terrorism, civil war and one-sided violence (e.g. genocide) on substance use disorders. The purpose of this study was to examine associations between deaths due to terrorism and related violence from 1994-2000 and morbidity and mortality attributable to substance use disorders, measured as disability-adjusted life years (DALYs) among the World Health Organization Member States , controlling for adult per capita alcohol consumption, illicit drug use, and economic measures at baseline in 1994. Deaths due to terrorism, war and one-sided violence were significantly related to alcohol, drug and substance use disorder DALYs: a 1.0\% increase in deaths due to terrorism, war and one-sided violence from 1994-2000 was associated with increases of between $0.10 \%$ and $0.12 \%$ in alcohol and drug use DALYs in 2002. Associations were somewhat greater among males and among the 15-to-44 year-old age group. That terrorism, war and one-sided violence may influence morbidity and mortality attributable to substance use disorders in the longer-term suggests that more attention be given to rapid assessment and treatment of substance use disorders in conflictaffected populations with due consideration of gender and age differences that may impact treatment outcomes in these settings. Priorities should be established among agencies working with these populations to rebuild substance abuse treatment infrastructures and identify and treat the many physical and mental disorders often comorbid with substance use disorders.
\end{abstract}




\section{Introduction}

Historically, terrorism, civil war and one-sided violence (e.g. genocide) have not received the attention from substance abuse researchers as have other causes of substance use disorder morbidity and mortality. This is surprising in view of the increasing recognition of the indirect or longer-term consequences of terrorism and related violence on morbidity and mortality associated with substance use disorders in conflict-affected populations (DiMaggio and Galea, 2006; Murray et al., 2002; Strathdee et al., 2006; Weaver and Roberts, 2010) and the status of substance use disorders as major contributors to the global burden of disease (World Health Organization [WHO], 2002a; 2004b).

Terrorism, war and one-sided violence influence substance use disorder morbidity and mortality in the longer-term for many years after the fighting and bombings have ceased through several mechanisms. Terrorism and related violence damages health and economic infrastructures vital to prevention of morbidity and premature mortality (Colombatti et al., 2009; WHO, 2002a; 2006b). Substance abuse health care services are disrupted through damage to water supplies, electricity, and sewage disposal necessary for health services to operate, coupled with injury, death and disappearance of health care workers (Ezard et al., 2011; Hansch and Burkholder, 1996; Perrin, 1996). Agricultural systems are disrupted resulting in food rations, an important ingredient that has been implicated in facilitating home-brewed alcohol production in conflict-affected populations (Adelekan, 2006; Ezard et al., 2011).

Longer-term consequences of terrorism, war and one-sided violence on substance use disorders are also demographic, that is, displacement and forced resettlement of large numbers of persons resulting in reduced access to health resources, food, safe water and adequate sanitation (Asgary and Segar, 2011). Conflict-affected, including displaced populations, are exposed to extreme trauma including witnessing and experiencing physical and sexual violence, 
murder of family and friends, loss of livelihood, self-esteem, social roles, cultural and social support, overcrowding, and poor living conditions (Bonger, 2007; de Jong et al., 2007; Porter and Haslam, 2005; Strathdee et al., 2006). Exposure to severe stressors and experiences of such change and loss may result in excessive substance use as a coping strategy (Johnson, 1996; Weaver and Roberts, 2010).

Populations affected by terrorism, war and one-sided violence also suffer from high rates of a variety of physical diseases (Levy and Sidel, 2003; 2007; Schnurr and Green, 2004; WHO, 2006b) and mental illnesses including depressive disorders (de Jong et al., 2007; Levy and Sidel, 2007; Priebe et al., 2010) psychotic disorders (Jones et al., 2009), and anxiety disorders, especially post-traumatic stress disorder (DiMaggio and Galea, 2006; Murthy, 2007; Pederson, 2002), disorders that have been shown to be highly comorbid with substance use disorders (Compton et al., 2007; Hasin et al., 2007; Pietrzak et al., 2011; Schnurr and Green, 2004). Health problems associated with substance use disorders in conflict-affected populations have also been documented, including alcohol-related suicide (Bosnar et al., 2004), increased human immunodeficiency virus (HIV) and other blood-borne viruses (Strathdee et al., 2003), and gender-based violence (Ondeko and Purdin, 2004; WHO; 2006b).

Although research has found support for the longer-term impact of war on life expectancy and mortality (Guha-Sapir and van Panhuis, 2004; Li and Wen, 2005), these studies do not account for the burden of conflict associated with disability and non-fatal outcomes. To date, two studies to our knowledge have addressed the broader, longer-term health consequences of armed conflict using a summary measure of health that combined information on both morbidity and mortality for a variety of specific diseases (Ghoborah et al., 2003; 2004b). The measure was the disability-adjusted life year (DALY), that is derived as the sum of years of life lost to premature mortality and years of life lost due to disability in a population (Murray and 
Lopez, 1996a). Ghobarah et al. (2003; 2004b) examined the relationship between civil war deaths from 1991-1997 and DALYs in 1999 attributable to all causes and specific diseases, controlling for an array of economic factors (e.g. health expenditures, urban growth). Civil war deaths were significantly related to up to $30 \%$ of the 210 disease-specific DALYs examined but in these studies no associations were found between civil war deaths and neuropsychiatric disorders including substance use disorders.

Although the work by Ghobarah et al. $(2003 ; 2004 b)$ has significantly increased our knowledge of the relationship between civil war and longer-term morbidity and mortality, some limitations are noted. This research failed to control directly for two major determinants of global morbidity and mortality, that is, the number of refugees/asylum seekers/displaced persons in the host country, and the number of persons affected by natural disasters. Ghobarah et al. (2003; 2004b) also did not consider other contributing or pre-existing disease specific factors that relate differently to different diseases. Further, the absence of associations between civil war deaths and substance use disorder DALYs may have been, in part, the result of neglecting to transform the associated DALY measures that are skewed. Linear regression models used in these prior studies, and indeed in the present study, require such transformed data to satisfy underlying model assumptions.

Foremost, Ghoborah et al. $(2003 ; 2004 b)$ also did not assess the impact of terrorist actions and one-sided violence (e.g. genocide, summary execution of prisoners) on longer-term morbidity and mortality. Between 1989 and 2004, the vast majority of fatalities from one-sided violence has taken take place in countries experiencing armed conflict and terrorism (Eck and Hultmann, 2007; Eriksson et al., 2003). Less than 1\% of the total one-sided violence fatalities took place in countries that did not experience armed conflict and/or terrorism, suggesting that 
these three forms of intimately-related violence be counted to better reflect the nature and intensity that has increasingly characterized civil conflict.

The present study expands upon prior work on the relationship between civil war deaths and morbidity and mortality. Since the severity and scope of civil war has changed over the last three decades to increasingly include fatalities arising from terrorist actions and one-sided violence (Eck and Hultmann, 2007; Lacina and Gleditsch, 2005), the major exposure variable in this study will be the sum of these three types of intimately-related violence. This study also controlled for substance use disorder-specific vulnerability factors, that is, adult per capita alcohol consumption and/or illicit drug use depending on whether alcohol and drug use disorder DALYs were examined.

It is hypothesized that increasing numbers of deaths from terrorism, civil war and onesided violence from 1994-2000 will be associated with increasing levels of morbidity and mortality as measured by DALYs in 2002 attributable to alcohol, drug and combined substance use disorder DALYs, controlling for disease-specific vulnerability factors (i.e. per capita alcohol consumption, illicit drug use) and an array of economic factors (e.g. health expenditures, urban growth) measured at baseline in 1994. Given the numerous mechanisms through which terrorism and related violence impacts substance use disorders (i.e. displacement, destruction of health and related infrastructures, psychological stress), it is predicted that the impact of such violence on substance us disorders in the longer-term will be pervasive. That is, terrorism, war and one-sided violence will adversely impact on morbidity and mortality attributable to substance use disorders across the majority of age-sex subgroups of the populace at risk for these disorders.

\section{Methods}

\section{Outcome: Disability-Adjusted Life Year}


The outcome variables were the number of DALYs (in thousands) due to alcohol, drug and substance use disorders in 2002 among the 192 WHO Member States (Mathers et al., 2003; WHO, 2004a). DALYs are calculated as the sum of years of life lost due to premature mortality and healthy years of life lost to disability (Murray and Lopez, 1996a). Alcohol use disorder DALYs included those attributable to the harmful use of alcohol and alcohol dependence while drug use disorder DALYs included those attributable to harmful use of drugs and dependence. Alcohol and drug use disorder DALYs were examined separately and combined into substance use disorder DALYs across age-sex subgroups of the populace.

\section{Exposure: Deaths from Terrorism, War and One-sided Violence}

Data on the number of deaths among victims and perpetrators resulting from terrorist actions from 1994-2000 were derived from the 2010 update of the Global Terrorism Database (GTD: National Consortium for the Study of Terrorism and Response to Terrorism [NCSTR], 2010). The definition of a terrorist incident includes terrorist incidents that are intentional, achieve some level of violence or threat of violence and are perpetrated by sub-national, nonstate actors. In addition, to qualify as a terrorist incident, at least two of the following three criteria must be met: (1) the act must be aimed at attaining a political, economic, religious or social goal; (2) there is evidence of an intention to coerce, intimidate, or convey some other message to a larger audience than the immediate victims; and (3) the action must be outside the context of legitimate warfare activities (NCSTR, 2010).

Data for civil war deaths occurring from 1994 to 2000 were derived from the Battle Deaths Database (Lacina, 2009; Lacina and Gleditsch, 2005). Civil war is defined as armed conflict occurring between the government of a state and one or more internal opposition groups with or without intervention from other states. Armed conflict is defined as a contested incompatibility that concerns governments and/or territory where the use of armed force 
between two parties, of which at least one is the government of the state, results in at least 25 battle deaths (Lacina and Gleditsch 2005). Battle deaths result directly from violence inflicted through the use of armed force by a party to armed conflict.

Data on deaths resulting from one-sided violence for the years 1994-2000 were available from the One-sided Violence Database (Kreutz and Eck, 2011). One-sided violence is defined as the use of armed force by the government of the state or by a formally-organized group against civilians which results in at least 25 deaths. These deaths include genocide and summary execution of prisoners. Only one-sided violence deaths perpetrated by government actors were included in the analyses since those perpetrated by formally-organized groups were included in the GTD.

Using deaths from terrorism, civil war and one-sided violence in the years 1994-2000 produces a 2-year lag to substance use disorder DALYs in 2002. DALYs in 2002 reflect years of life lost due to deaths from a substance use disorders during 2002 plus the disability incurred by people suffering from the same conditions in 2002. Thus, these are not deaths or disabilities experienced in earlier years during which the terrorism and related violence was active.

\section{Control Variables: Preexisting Vulnerability Factors}

Per capita alcohol consumption was measured as total recorded consumption expressed as liters of pure alcohol, computed as the sum of alcohol production and imports, less alcohol exports, divided by the adult population (aged 15 years and older). Country level data for the year 1994, or at baseline, were available from the WHO Global Health Observatory Database (WHO, 2011a).

Illicit drug use is defined as the non-medical use of a variety of drugs that are prohibited by international law. The illicit drug use measure was the sum of the annual prevalences of illicit drug use related to cannabis, amphetamine-type stimulants, cocaine-type substances 
(including crack-cocaine), and opiates between 1993 and 1997 expressed as the percentages of the population above the age of 15 years. Data on illicit drug use were derived from the United Nations Global Illicit Drug Trends Report (1999) for the years 1993-1997.

\section{Control Variables: Economic Factors}

The number of refugees/asylum seekers/displaced persons (in thousands) residing in each host country at the end of the year 1994 served as an important control variable. These data were available from the UN High Commissioner for Refugees (UNHCR) Statistical Yearbook (1995a; 1995b). Similar to all control variables used in the present analyses, except the number of deaths/homeless/affected by natural disasters from 1994-2000, the number of refugees/asylum seekers/displaced persons were measured at baseline, that is, as close to the year 1994 as the available data would allow.

The natural disaster variable combined the number of deaths (persons confirmed as dead or missing), number of homeless (persons needing immediate shelter) and number affected (i.e. people requiring immediate assistance in basic survival needs such as food, water and sanitation), in thousands, occurring at the country level for the years 1994-2000. Data were available from the Emergency Events Database maintained by the WHO Collaborating Center for Research on Epidemiology and Disasters (Guha-Sapir et al., 2011). A disaster event is defined by CRED as one that meets one or more of the following criteria: (1) there were 10 or more people killed; (2) there were at least 100 people reportedly affected; or (3) the disaster led to the declaration of a state of emergency or calls for international assistance.

This study uses total general government health expenditures as a percentage of total government expenditure (GGHE as a percentage of TGE) as a critical economic control variable of health financing systems. Data on GGHE as a percentage of TGE for 1994 were available from the WHO Global Health Observatory Database (WHO, 2011a; 2011c). The measure of 
urbanization in this study is the average percentage change in the urban population between 1990 and 1995, data collected routinely by the UN Department of Economic and Social Affairs and available on the UN Millennium Goals Database (UN, 2011b).

Differences within a country in ethnic, linguistic and/or religious composition produces discrimination and unequal access to political power that translates into inequality in access to health care (Ghobarah et al., 2004a). The ethnic heterogeneity variable in this study is derived from Vanhanen (1999) that combines racial, linguistic and religious division, each measured as the percentage of the largest group of a country's population for the years 1994-1996. The inverse of these three percentages are summed to measure the degree of ethnic heterogeneity.

Life expectancy at birth is defined as the average number of years that a newborn is expected to live if current mortality rates continue to apply, data routinely collected by the WHO (2011a). In the present study, life expectancy at birth serves as a critical control variable, reflecting the effects of environmental degradation, exposure to harmful substances, access to health care and political power and living standards in 1994 or at baseline.

\section{Statistical Analyses}

As a preliminary to the multivariable analyses, descriptive statistics will be presented for all study variables, including total by age and sex and means as appropriate. Multivariable linear regression analyses will also be conducted to examine the relationships between deaths from terrorism, war and one-sided violence from 1994-2000 and DALYs due alcohol, drug and substance use disorders in 2002, controlling for preexisting vulnerability and economic factors. The number of countries excluded from the multivariable analyses due to insufficient data for control variables was small: $\mathrm{n}=10, \mathrm{n}=8$ and $\mathrm{n}=10$ when alcohol, drug and substance use DALYs served as outcome measures, respectively. The countries excluded were largely small islands and microstates. Rwanda was also eliminated from all analyses because this country 
experienced 500,000 deaths due to genocide in 1994, rendering it an extreme outlier. Examination of Cook's d, studentized residuals and leverage values detected no further problems with multivariate outliers. DALY outcome measures, the war and related violence exposure measure, and three control measures (number of deaths/homeless/affected by natural disasters, number of refugees/asylum seekers/displaced persons and annual prevalence of illicit drug use) were log transformed as the result of skew in order to satisfy the linearity assumption of the linear regression model.

\section{Results}

In 2002, there were approximately 20.3 million DALYs attributable to alcohol use disorders among WHO Member States. The majority of these DALYs lost were among males (17.2 million) compared with females (3.1 million) and among 15-to-29 year-olds (9.6 million) and 30-to-44 year-olds ( 7.3 million) relative to 45 -to-59 year-olds (2.7 milion), and those 60 years and older $(431,678)$. There were approximately 7.4 million DALYs attributable to drug use disorders in 2002, largely among males (5.8 million) compared with females (1.6 million). Similar to alcohol use disorders, the majority of drug use disorder DALYs were lost among 15to-29 year-olds and 30-to-44 year-old (4.3 and 2.3 million) relative to 45 -to-55 year-olds (651,071) 5-to-14 year-olds $(176,389)$ and those 60 years and older $(27,850)$.

Between 1994-2000 there were approximately 43,269, 632,851, and 27,895 deaths from terrorist actions, civil wars, and one-sided violence (excluding 500,000 deaths from genocide in Rwanda) deaths among the WHO Member States. With regard to pre-existing vulnerability factors, mean global per capita alcohol consumption in 1994 was approximately 4.9 liters and the mean annual prevalence of cannabis, cocaine-type substances, amphetamine-type substances and opiates between 1993 and 1997 was approximately 1.7\%. 
With regard to economic and related control variables, there were 24.2 million refugees/asylum seekers/displaced persons in 1994 and 1.1 billion dead/homeless/affected by natural disasters between 1994 and 2000 among the WHO Member States. Mean percentage change in urban population between 1990 and 1995 was $0.9 \%(\mathrm{SD}=1.01$; range: $-2.41 \%$ to 4.35\%) and GGH as a percentage of TGE in 1994 was $10.1 \%(\mathrm{SD}=4.51$; range: $0.00 \%-27.56 \%)$. The mean ethnic heterogeneity score between 1994 and 1996 was 43.9\% ( $\mathrm{SD}=35.19$; range: 0.00\%-147.00\%). Average life expectancy among WHO Member States in 1994 was 64.8 years $(\mathrm{SD}=9.94$, Range: $38.4-79.5$ years).

Table 14 shows the results from the linear regression analyses examining the relationships between deaths due to terrorism, war and one-sided violence from 1994-2000 and alcohol, drug and substance use disorder DALYs in 2002 by sex. Regardless of sex, deaths due to terrorism, war and one-sided violence were significantly related to alcohol, drug and substance use disorder DALYs. Overall, the coefficient for the association between deaths due to terrorism, civil war and one-sided violence and alcohol use disorder DALYs was 0.10, indicating that a $1.0 \%$ increase in deaths due to terrorism, war and one-sided violence from 1994-2000 was associated with a 0.10\% increase in alcohol use disorder DALYs in 2002. Further, a $1.0 \%$ increase in deaths due to terrorism, war and one-sided violence was associated with $0.12 \%$ and $0.14 \%$ increase in DALYs lost to drug use disorders and substance use disorders, respectively. The magnitudes of the associations were somewhat greater for males relative to females.

Tables 15 and 16 show the relationships between deaths due to terrorism, war and onesided violence from 1994-2000 and alcohol and drug use disorder DALYs in 2002 by sex and age subgroups of the world populace, respectively. The results were generally consistent to the overall results with the following exceptions. Terrorism, war and one-sided violence deaths 
Table 14. Multivariable Linear Regression Analyses Between Terrorism, Civil War, and One-Sided Violence Deaths from 1994-2000 and DALYs Attributable to Alcohol, Drug and Substance Use Disorders in 2002 by Sex

\begin{tabular}{|c|c|c|c|c|c|c|c|c|c|}
\hline \multirow[b]{2}{*}{ Variables } & \multicolumn{3}{|c|}{ Alcohol Use Disorder DALYs, 2002} & \multicolumn{3}{|c|}{ Drug Use Disorders DALYs, 2002} & \multicolumn{3}{|c|}{ Substance Use Disorders DALYs, 2002} \\
\hline & $\begin{array}{l}\text { Male } \\
\text { B (t) }\end{array}$ & $\begin{array}{c}\text { Female } \\
B(t)\end{array}$ & $\begin{array}{l}\text { Total } \\
\text { B (t) }\end{array}$ & $\begin{array}{l}\text { Male } \\
\text { B (t) }\end{array}$ & $\begin{array}{c}\text { Female } \\
\mathrm{B}(\mathrm{t})\end{array}$ & $\begin{array}{c}\text { Total } \\
\text { B }(t)\end{array}$ & $\begin{array}{c}\text { Male } \\
\text { B (t) }\end{array}$ & $\begin{array}{c}\text { Female } \\
\text { B ( } t)\end{array}$ & $\begin{array}{c}\text { Total } \\
\text { B }(t)\end{array}$ \\
\hline $\begin{array}{l}\text { Terrorism, war and one-sided } \\
\text { violence deaths, } 1994-2000\end{array}$ & $\begin{array}{c}0.10 \\
(3.02)\end{array}$ & $\begin{array}{c}0.06 \\
(2.49)\end{array}$ & $\begin{array}{c}0.10 \\
(3.06)\end{array}$ & $\begin{array}{c}0.12 \\
(3.77)\end{array}$ & $\begin{array}{c}0.08 \\
(3.33)\end{array}$ & $\begin{array}{c}0.12 \\
(3.81)\end{array}$ & $\begin{array}{c}0.14 \\
(4.19)\end{array}$ & $\begin{array}{c}0.10 \\
(3.71)\end{array}$ & $\begin{array}{c}0.14 \\
(4.23)\end{array}$ \\
\hline $\begin{array}{l}\text { Per capita alcohol consumption, } \\
1994\end{array}$ & $\begin{array}{c}\mathbf{0 . 1 5} \\
(6.59)\end{array}$ & $\begin{array}{c}0.12 \\
(6.64)\end{array}$ & $\begin{array}{c}0.16 \\
(6.76)\end{array}$ & - & - & - & $\begin{array}{c}0.10 \\
(4.20)\end{array}$ & $\begin{array}{c}0.08 \\
(4.03)\end{array}$ & $\begin{array}{c}0.10 \\
(4.25)\end{array}$ \\
\hline Prevalence of drug use, 1992-1997 & - & - & - & $\begin{array}{c}0.46 \\
(4.66)\end{array}$ & $\begin{array}{c}0.38 \\
(4.91)\end{array}$ & $\begin{array}{c}0.48 \\
(4.68)\end{array}$ & $\begin{array}{c}0.34 \\
(3.28)\end{array}$ & $\begin{array}{c}0.31 \\
(3.60)\end{array}$ & $\begin{array}{c}0.35 \\
(3.33)\end{array}$ \\
\hline $\begin{array}{l}\text { Number of refugees/asylum } \\
\text { seekers/displaced persons, } 1994\end{array}$ & $\begin{array}{c}0.10 \\
(2.20)\end{array}$ & $\begin{array}{c}\mathbf{0 . 0 6} \\
(1.70)\end{array}$ & $\begin{array}{c}0.10 \\
(2.19)\end{array}$ & $\begin{array}{c}0.15 \\
(3.54)\end{array}$ & $\begin{array}{c}0.11 \\
(3.21)\end{array}$ & $\begin{array}{c}0.16 \\
(3.56)\end{array}$ & $\begin{array}{c}0.12 \\
(2.64)\end{array}$ & $\begin{array}{c}0.10 \\
(2.52)\end{array}$ & $\begin{array}{c}0.12 \\
(2.62)\end{array}$ \\
\hline $\begin{array}{l}\text { Number of deaths/ } \\
\text { homeless/affected by natural } \\
\text { disasters, } 1994-2000\end{array}$ & $\begin{array}{c}0.35 \\
(11.46)\end{array}$ & $\begin{array}{c}0.24 \\
(10.38)\end{array}$ & $\begin{array}{c}\mathbf{0 . 3 6} \\
(11.46)\end{array}$ & $\begin{array}{c}0.23 \\
(8.02)\end{array}$ & $\begin{array}{c}\mathbf{0 . 1 7} \\
(7.62)\end{array}$ & $\begin{array}{c}0.24 \\
(8.03)\end{array}$ & $\begin{array}{c}\mathbf{0 . 3 5} \\
(11.86)\end{array}$ & $\begin{array}{c}0.28 \\
(11.06)\end{array}$ & $\begin{array}{c}\mathbf{0 . 3 6} \\
(11.77)\end{array}$ \\
\hline Urban growth, 1990-1995 & $\begin{array}{c}0.10 \\
(1.07)\end{array}$ & $\begin{array}{c}0.05 \\
(0.75)\end{array}$ & $\begin{array}{c}0.09 \\
(1.05)\end{array}$ & $\begin{array}{c}0.04 \\
(0.49)\end{array}$ & $\begin{array}{c}0.02 \\
(0.25)\end{array}$ & $\begin{array}{c}0.04 \\
(0.49)\end{array}$ & $\begin{array}{c}0.09 \\
(0.97)\end{array}$ & $\begin{array}{c}0.05 \\
(0.67)\end{array}$ & $\begin{array}{c}0.08 \\
(0.92)\end{array}$ \\
\hline Health expenditures, 1994 & $\begin{array}{c}0.02 \\
(1.16)\end{array}$ & $\begin{array}{c}\mathbf{0 . 0 3} \\
(1.86)\end{array}$ & $\begin{array}{c}-0.03 \\
(1.34)\end{array}$ & $\begin{array}{c}-0.03 \\
(-1.60)\end{array}$ & $\begin{array}{c}-0.02 \\
(-1.00)\end{array}$ & $\begin{array}{c}-0.03 \\
(-1.45)\end{array}$ & $\begin{array}{c}-0.01 \\
(-0.48)\end{array}$ & $\begin{array}{l}<-0.01 \\
(-0.13)\end{array}$ & $\begin{array}{c}-0.01 \\
(-0.37)\end{array}$ \\
\hline Ethnic heterogeneity, 1994-1996 & $\begin{array}{l}<0.01 \\
(1.07)\end{array}$ & $\begin{array}{l}<0.01 \\
(0.58)\end{array}$ & $\begin{array}{c}0.01 \\
(1.15)\end{array}$ & $\begin{array}{l}<0.01 \\
(0.29)\end{array}$ & $\begin{array}{l}<-0.01 \\
(0.48)\end{array}$ & $\begin{array}{l}<0.01 \\
(0.24)\end{array}$ & $\begin{array}{l}<0.01 \\
(0.62)\end{array}$ & $\begin{array}{l}<0.01 \\
(0.37)\end{array}$ & $\begin{array}{l}<0.01 \\
(0.67)\end{array}$ \\
\hline Life expectancy at birth, 1994 & $\begin{array}{c}\mathbf{0 . 0 7} \\
(5.84)\end{array}$ & $\begin{array}{c}0.06 \\
(6.49)\end{array}$ & $\begin{array}{c}\mathbf{0 . 0 7} \\
(5.95)\end{array}$ & $\begin{array}{c}\mathbf{0 . 0 4} \\
(3.42)\end{array}$ & $\begin{array}{c}\mathbf{0 . 0 3} \\
(3.11)\end{array}$ & $\begin{array}{c}\mathbf{0 . 0 4} \\
(3.32)\end{array}$ & $\begin{array}{c}\mathbf{0 . 0 6} \\
(5.42)\end{array}$ & $\begin{array}{c}\mathbf{0 . 0 5} \\
(5.48)\end{array}$ & $\begin{array}{c}\mathbf{0 . 0 7} \\
(5.36)\end{array}$ \\
\hline Adjusted $R^{2}$ & 0.64 & 0.62 & 0.65 & 0.58 & 0.55 & 0.58 & 0.68 & 0.65 & 0.67 \\
\hline
\end{tabular}

Note: $\mathrm{N}$ for alcohol use disorder DALYs $=182$ countries; $\mathrm{N}$ for drug use disorder DALYs $=184$ countries; $\mathrm{N}$ for substance use disorder DALYs $=182$ countries; Boldfaced beta-coefficients significant at $\mathrm{p}<0.05$; Figures in parentheses are t-values. 
Table 15. Multivariable Linear Regression Analyses Between Terrorism, Civil War, and One-Sided Violence Deaths from 1994-2000 and DALYs Attributable to Alcohol Use Disorders in 2002 by Sex and Age

\begin{tabular}{|c|c|c|c|c|c|c|c|c|}
\hline \multirow[b]{2}{*}{ Variables } & \multicolumn{4}{|c|}{ Male } & \multicolumn{4}{|c|}{ Female } \\
\hline & $\begin{array}{c}15-29 \\
B(t)\end{array}$ & $\begin{array}{c}30-44 \\
B(t)\end{array}$ & $\begin{array}{c}45-59 \\
B(t) \\
\end{array}$ & $\begin{array}{l}60+ \\
B(t)\end{array}$ & $\begin{array}{c}15-29 \\
B(t)\end{array}$ & $\begin{array}{l}30-44 \\
B(t) \\
\end{array}$ & $\begin{array}{c}45-59 \\
B(t)\end{array}$ & $\begin{array}{r}60+ \\
B(t) \\
\end{array}$ \\
\hline $\begin{array}{l}\text { Terrorism, war and one- } \\
\text { sided violence deaths, } 1994 \text { - } \\
2000\end{array}$ & $\begin{array}{c}\mathbf{0 . 0 8} \\
(2.63)\end{array}$ & $\begin{array}{c}\mathbf{0 . 0 8} \\
(2.69)\end{array}$ & $\begin{array}{c}\mathbf{0 . 0 6} \\
(2.70)\end{array}$ & $\begin{array}{c}\mathbf{0 . 0 4} \\
(2.30)\end{array}$ & $\begin{array}{c}\mathbf{0 . 0 6} \\
(2.39)\end{array}$ & $\begin{array}{c}\mathbf{0 . 0 4} \\
(1.88)\end{array}$ & $\begin{array}{c}\mathbf{0 . 0 3} \\
(1.86)\end{array}$ & $\begin{array}{c}0.01 \\
(1.57)\end{array}$ \\
\hline $\begin{array}{l}\text { Per capita alcohol } \\
\text { consumption, } 1994\end{array}$ & $\begin{array}{c}0.14 \\
(6.38)\end{array}$ & $\begin{array}{c}0.12 \\
(6.15)\end{array}$ & $\begin{array}{c}\mathbf{0 . 0 9} \\
(5.70)\end{array}$ & $\begin{array}{c}0.04 \\
(3.34)\end{array}$ & $\begin{array}{c}\mathbf{0 . 0 9} \\
(5.54)\end{array}$ & $\begin{array}{c}\mathbf{0 . 0 9} \\
(5.80)\end{array}$ & $\begin{array}{l}0.06 \\
(5.07)\end{array}$ & $\begin{array}{c}0.02 \\
(3.62)\end{array}$ \\
\hline $\begin{array}{l}\text { Number of Refugees/asylum } \\
\text { seekers/displaced, } 1994\end{array}$ & $\begin{array}{c}0.06 \\
(1.32)\end{array}$ & $\begin{array}{c}0.11 \\
(2.68)\end{array}$ & $\begin{array}{c}0.08 \\
(2.39)\end{array}$ & $\begin{array}{c}0.05 \\
(2.06)\end{array}$ & $\begin{array}{c}0.02 \\
(0.65)\end{array}$ & $\begin{array}{c}0.07 \\
(2.29)\end{array}$ & $\begin{array}{c}\mathbf{0 . 0 5} \\
(2.22)\end{array}$ & $\begin{array}{c}\mathbf{0 . 0 3} \\
(2.77)\end{array}$ \\
\hline $\begin{array}{l}\text { Number affected by natural } \\
\text { disasters, } 1994-2000\end{array}$ & $\begin{array}{c}\mathbf{0 . 3 3} \\
(11.26)\end{array}$ & $\begin{array}{c}0.29 \\
(10.97)\end{array}$ & $\begin{array}{c}\mathbf{0 . 2 3} \\
(10.47)\end{array}$ & $\begin{array}{l}0.13 \\
(8.51)\end{array}$ & $\begin{array}{c}0.22 \\
(9.94)\end{array}$ & $\begin{array}{c}0.17 \\
(8.78)\end{array}$ & $\begin{array}{c}\mathbf{0 . 1 2} \\
(7.83)\end{array}$ & $\begin{array}{c}\mathbf{0 . 0 5} \\
(5.76)\end{array}$ \\
\hline Urban growth, 1990-1995 & $\begin{array}{c}0.10 \\
(1.13)\end{array}$ & $\begin{array}{l}0.08 \\
(0.96)\end{array}$ & $\begin{array}{c}0.04 \\
(0.57)\end{array}$ & $\begin{array}{l}0.03 \\
(0.64)\end{array}$ & $\begin{array}{c}0.04 \\
(0.67)\end{array}$ & $\begin{array}{l}0.03 \\
(0.55)\end{array}$ & $\begin{array}{c}0.02 \\
(0.38)\end{array}$ & $\begin{array}{l}<0.01 \\
(0.19)\end{array}$ \\
\hline Health expenditures, 1994 & $\begin{array}{c}0.02 \\
(1.16)\end{array}$ & $\begin{array}{c}0.01 \\
(0.74)\end{array}$ & $\begin{array}{c}0.01 \\
(0.94)\end{array}$ & $\begin{array}{c}0.01 \\
(0.81)\end{array}$ & $\begin{array}{c}\mathbf{0 . 0 3} \\
(1.84)\end{array}$ & $\begin{array}{c}0.02 \\
(1.47)\end{array}$ & $\begin{array}{c}0.01 \\
(0.98)\end{array}$ & $\begin{array}{c}0.01 \\
(0.70)\end{array}$ \\
\hline $\begin{array}{l}\text { Ethnic heterogeneity, 1994- } \\
1996\end{array}$ & $\begin{array}{l}<0.01 \\
(0.93)\end{array}$ & $\begin{array}{l}<0.01 \\
(0.70)\end{array}$ & $\begin{array}{l}<0.01 \\
(0.10)\end{array}$ & $\begin{array}{l}<0.01 \\
(-0.30)\end{array}$ & $\begin{array}{l}<0.01 \\
(0.36)\end{array}$ & $\begin{array}{l}<0.01 \\
(0.28)\end{array}$ & $\begin{array}{l}<-0.01 \\
(-0.13)\end{array}$ & $\begin{array}{l}<0.01 \\
(0.29)\end{array}$ \\
\hline $\begin{array}{l}\text { Life expectancy at birth, } \\
1994\end{array}$ & $\begin{array}{c}\mathbf{0 . 0 6} \\
(5.40)\end{array}$ & $\begin{array}{c}0.06 \\
(6.10)\end{array}$ & $\begin{array}{c}\mathbf{0 . 0 5} \\
(6.19)\end{array}$ & $\begin{array}{c}\mathbf{0 . 0 3} \\
(5.73)\end{array}$ & $\begin{array}{c}\mathbf{0 . 0 5} \\
(6.49)\end{array}$ & $\begin{array}{c}0.05 \\
(6.10)\end{array}$ & $\begin{array}{c}\mathbf{0 . 0 3} \\
(5.31)\end{array}$ & $\begin{array}{c}0.01 \\
(3.96)\end{array}$ \\
\hline Adjusted $R^{2}$ & 0.61 & 0.62 & 0.61 & 0.50 & 0.58 & 0.57 & 0.51 & 0.38 \\
\hline
\end{tabular}

Note: $\mathrm{N}=182$ countries; Boldfaced beta-coefficients significant at $\mathrm{p}<0.05$; Figures in parentheses are t-values. 
Table 16. Multivariable Linear Regression Analyses Between Terrorism, Civil War, and One-Sided Violence Deaths from 1994-2000 and DALYs Attributable to Drug Use Disorders in 2002 by Sex and Age

\begin{tabular}{|c|c|c|c|c|c|c|c|c|}
\hline \multirow[b]{2}{*}{ Variables } & \multicolumn{4}{|c|}{ Male } & \multicolumn{4}{|c|}{ Female } \\
\hline & $\begin{array}{c}15-29 \\
B(t)\end{array}$ & $\begin{array}{c}30-44 \\
B(t)\end{array}$ & $\begin{array}{c}45-59 \\
B(t) \\
\end{array}$ & $\begin{array}{l}60+ \\
B(t) \\
\end{array}$ & $\begin{array}{c}15-29 \\
B(t)\end{array}$ & $\begin{array}{c}30-44 \\
B(t) \\
\end{array}$ & $\begin{array}{c}45-59 \\
B(t) \\
\end{array}$ & $\begin{array}{l}60+ \\
\mathrm{B}(\mathrm{t}) \\
\end{array}$ \\
\hline $\begin{array}{l}\text { Terrorism, war and one- } \\
\text { sided violence deaths, } 1994 \text { - } \\
2000\end{array}$ & $\begin{array}{c}0.09 \\
(3.34)\end{array}$ & $\begin{array}{c}0.09 \\
(3.53)\end{array}$ & $\begin{array}{c}0.06 \\
(3.02)\end{array}$ & $\begin{array}{l}<0.01 \\
(2.37)\end{array}$ & $\begin{array}{c}\mathbf{0 . 0 6} \\
(2.82)\end{array}$ & $\begin{array}{c}\mathbf{0 . 0 5} \\
(2.90)\end{array}$ & $\begin{array}{c}\mathbf{0 . 0 3} \\
(2.51)\end{array}$ & $\begin{array}{c}0.01 \\
(1.61)\end{array}$ \\
\hline $\begin{array}{l}\text { Prevalence of illicit drug } \\
\text { use, 1993-1997 }\end{array}$ & $\begin{array}{c}\mathbf{0 . 4 2} \\
(4.86)\end{array}$ & $\begin{array}{c}0.39 \\
(4.78)\end{array}$ & $\begin{array}{c}0.26 \\
(4.21)\end{array}$ & $\begin{array}{c}0.05 \\
(3.17)\end{array}$ & $\begin{array}{c}\mathbf{0 . 3 3} \\
(4.83)\end{array}$ & $\begin{array}{c}\mathbf{0 . 3 0} \\
(5.13)\end{array}$ & $\begin{array}{c}0.18 \\
(4.65)\end{array}$ & $\begin{array}{c}\mathbf{0 . 0 3} \\
(3.95)\end{array}$ \\
\hline $\begin{array}{l}\text { Refugees/asylum } \\
\text { seekers/displaced, } 1994\end{array}$ & $\begin{array}{c}0.12 \\
(3.23)\end{array}$ & $\begin{array}{c}0.12 \\
(3.37)\end{array}$ & $\begin{array}{c}\mathbf{0 . 0 8} \\
(2.90)\end{array}$ & $\begin{array}{c}0.01 \\
(1.00)\end{array}$ & $\begin{array}{c}\mathbf{0 . 0 8} \\
(2.84)\end{array}$ & $\begin{array}{c}\mathbf{0 . 0 8} \\
(3.04)\end{array}$ & $\begin{array}{c}\mathbf{0 . 0 4} \\
(2.67)\end{array}$ & $\begin{array}{c}\mathbf{0 . 0 1} \\
(1.71)\end{array}$ \\
\hline $\begin{array}{l}\text { Number affected by natural } \\
\text { disasters, } 1994-2000\end{array}$ & $\begin{array}{c}0.21 \\
(8.18)\end{array}$ & $\begin{array}{c}0.17 \\
(6.99)\end{array}$ & $\begin{array}{c}\mathbf{0 . 1 0} \\
(5.54)\end{array}$ & $\begin{array}{c}0.02 \\
(4.01)\end{array}$ & $\begin{array}{c}\mathbf{0 . 1 5} \\
(7.21)\end{array}$ & $\begin{array}{c}0.11 \\
(6.62)\end{array}$ & $\begin{array}{c}0.06 \\
(4.93)\end{array}$ & $\begin{array}{c}\mathbf{0 . 0 1} \\
(3.81)\end{array}$ \\
\hline Urban growth, 1990-1995 & $\begin{array}{c}0.03 \\
(0.41)\end{array}$ & $\begin{array}{c}0.03 \\
(0.44)\end{array}$ & $\begin{array}{l}<0.01 \\
(0.11)\end{array}$ & $\begin{array}{l}-0.01 \\
(-0.56)\end{array}$ & $\begin{array}{l}<-0.01 \\
(-0.04)\end{array}$ & $\begin{array}{l}<0.01 \\
(0.23)\end{array}$ & $\begin{array}{l}<-0.01 \\
(-0.07)\end{array}$ & $\begin{array}{c}-0.01 \\
(-0.74)\end{array}$ \\
\hline Health expenditures, 1994 & $\begin{array}{c}-0.02 \\
(-1.09)\end{array}$ & $\begin{array}{c}-0.03 \\
(-2.15)\end{array}$ & $\begin{array}{c}-0.04 \\
(-2.99)\end{array}$ & $\begin{array}{l}<-0.01 \\
(-2.36)\end{array}$ & $\begin{array}{l}<-0.01 \\
(-0.22)\end{array}$ & $\begin{array}{l}<-0.02 \\
(-1.49)\end{array}$ & $\begin{array}{c}-0.02 \\
(-2.60)\end{array}$ & $\begin{array}{c}-0.01 \\
(-1.73)\end{array}$ \\
\hline $\begin{array}{l}\text { Ethnic heterogeneity, 1994- } \\
1996\end{array}$ & $\begin{array}{l}<0.01 \\
(0.49)\end{array}$ & $\begin{array}{l}<0.01 \\
(0.43)\end{array}$ & $\begin{array}{l}<0.01 \\
(0.49)\end{array}$ & $\begin{array}{l}<0.01 \\
(1.28)\end{array}$ & $\begin{array}{l}<0.01 \\
(0.77)\end{array}$ & $\begin{array}{l}<0.01 \\
(0.68)\end{array}$ & $\begin{array}{l}<0.01 \\
(0.72)\end{array}$ & $\begin{array}{l}<0.01 \\
(1.21)\end{array}$ \\
\hline $\begin{array}{l}\text { Life expectancy at birth, } \\
1994\end{array}$ & $\begin{array}{c}\mathbf{0 . 0 3} \\
(2.74)\end{array}$ & $\begin{array}{c}\mathbf{0 . 0 4} \\
(4.27)\end{array}$ & $\begin{array}{c}\mathbf{0 . 0 3} \\
(3.93)\end{array}$ & $\begin{array}{c}\mathbf{0 . 0 1} \\
(2.29)\end{array}$ & $\begin{array}{c}\mathbf{0 . 0 2} \\
(2.43)\end{array}$ & $\begin{array}{c}0.02 \\
(3.47)\end{array}$ & $\begin{array}{c}\mathbf{0 . 0 1} \\
(3.31)\end{array}$ & $\begin{array}{c}\mathbf{0 . 0 1} \\
(2.64)\end{array}$ \\
\hline Adjusted $R^{2}$ & 0.57 & 0.54 & 0.45 & 0.30 & 0.51 & 0.50 & 0.41 & 0.27 \\
\hline
\end{tabular}

Note: $\mathrm{N}=184$ countries; Boldfaced beta-coefficients significant at $\mathrm{p}<0.05$; Figures in parentheses are t-values. 
were significantly related to alcohol and drug use disorder DALYs among males and females in the majority of age-sex subgroups of the populace, with the strongest associations observed among 15-to-44 year-olds. In general, associations were also greater among males than females across all age subgroups of the population.

\section{Discussion}

Deaths from terrorist actions, civil war and one-sided violence from 1994-2000 were positively related to alcohol, drug and substance use disorder DALYs occurring in 2002, after controlling for baseline alcohol consumption, illicit drug use and variety of economic measures empirically shown to affect public health. In contrast with prior studies (Ghobarah et al., 2003; 2004b), the adverse impact of terrorism, civil war and one-sided violence on DALYs attributable to substance use disorders was found across a majority of sex-age subgroups of the populace. This discrepancy may, in part, be due to broadening the major exposure variable, civil war deaths, to include deaths due to terrorist actions and one-sided violence and applying appropriate transformations to DALY outcome measures to render the data suitable for linear regression analysis.

Prior research on the longer-term public health consequences of terrorism, war and onesided violence has not focused exclusively on neuropsychiatric disorders, including substance use disorders, while the existing terrorism and war trauma literature has primarily focused on one longer-term mental outcome of trauma, that is, post-traumatic stress disorder (Levy and Sidel, 2009; Murthy, 2007; Pederson, 2002). However, psychological stresses associated with terrorism, war and one-sided violence arising from displacement, loss, grief and fear, social isolation, insecurity, loss of status and community, and witnessing and experiencing acts of violence such as summary execution, rape and assassinations can manifest in a variety of mental 
disorders. These disorders include a variety of depressive, anxiety and psychotic disorders (de Jong et al., 2007; DiMaggio and Galea, 2006; Levy and Sidel, 2009; Priebe et al., 2010), many of which are highly comorbid with substance use disorders (Compton et al., 2007; Hasin et al., 2007). Excessive substance use may also reflect self-medication for these psychiatric conditions, thereby increasing incidence and severity of substance use disorders in conflictaffected populations. From and epidemiological perspective, the magnitude and distribution of a variety of trauma-related disorders as collective experience in populations exposed to terrorism and related violence is far from being understood. The results of this study, however, clearly highlight substance use disorders as major longer-term trauma-related outcomes of terrorism, war and one-sided violence for which interventions must be developed and implemented in conflict-affected populations.

Prior research on the public health consequences of terrorism, war and one-sided violence has also generally not considered other contributing factors to specific disorders such as pre-existing vulnerability factors (Levy and Sidel, 2003; 2007). Per capita alcohol consumption and illicit drug use at baseline were included as control variables consistent with the GBD perspective that substance use disorder DALYs are largely attributable to substance use. Per capita alcohol consumption and illicit drug use in 1994 were significantly related to alcohol and drug use disorder DALYs in 2002, respectively, a result generalizing to the majority of sex-age subgroups of the populace. Unlike per capita alcohol consumption, illicit drug use may have also served as a proxy control measure in this study for the availability of illicit substances as lootable natural resources. With the end of the Cold War, state financing for terrorism and insurgent movements were dramatically reduced and the cultivation and sale of psychotropic substances became a lucrative source of alternative funding (Cornell, 2005). This was 
particularly true for coca, opium and cannabis that are easily appropriated, highly lucrative, and not easily obstructable due to their high value-to-size ratio.

The somewhat stronger associations between terrorism, war and one-sided violence and alcohol and drug use disorder DALYs among males than females may in large part be due to the greater prevalence and risk of alcohol and drug use disorders among males consistently observed in numerous nationally representative surveys (Demyttenaeree et al., 2004; Hasin et al., 2007; Kessler et al., 2007). Stronger associations between terrorism and related violence and alcohol and drug disorder DALYs among 15-to-44 year-olds relative to older age groups (45 years and older) likely reflects the distribution of ages of onset of these disorders that peak during early adolescence through early adulthood, declining sharply after the fourth decade of life (Compton et al., 2007; Degenhardt et al., 2004; Kessler et al., 2007). Understanding the sex and age differences observed in associations between terrorism and related violence and alcohol and drug use disorder DALYs will be critical in developing and implementing effective gender-andage-specific interventions for these disorders in conflict-affected populations.

Although not the focus of attention in this study, health expenditures as a percentage of total government expenditure were negatively related to drug use disorder DALYs, an association generally not observed for alcohol use disorders. These findings highlight the need for future research on conflict and health to include control measures on health financing specific to substance use disorders. However, data on alcohol and drug treatment services with respect to setting (e.g. mental health vs. specialized services) financing (e.g. tax revenue, social health insurance), efficiency, accessibility, service quality, cost-effectiveness and degree of cohesiveness are not yet available for the majority of WHO Member States (WHO, 2011a). Country-level information on health services for substance use disorders, and possible differentials in treatment financing characteristics for alcohol and drug use disorders, will be 
vital in the future to implementing national and international responses to burden of disease and disability resulting from substance use disorders in conflict-affected populations.

This study combined deaths from terrorist actions and one-sided violence with deaths from civil war to more fully characterize the nature of violence occurring during armed conflict. The present study has also benefitted from three new databases designed to separately measure deaths from terrorism, civil war and one-sided violence more reliably than in the past and the use of appropriate data transformations to ensure the suitability of the data for statistical models employed. This study uniquely focused on substance use disorders as major adverse longer-term consequences of terrorism and related violence and underscored the importance of including preexisting disease-specific covariates as explanatory variables in associated models. Limitations, however, are noted. Although there always exists a potential of omitting an important variable from the analyses presented herein, model $\mathrm{R}^{2} \mathrm{~s}$ were high, indicating a relatively complete specification of influences. The ecological comparative design used in this study cannot fully capture within-country variability. However, it can play an essential role in defining the impact of major public health problems such as terrorism, war and one-sided violence that operate at a population level to influence morbidity and mortality. Further, measures used in the present study are associated with various levels of reliability across WHO Member States. Accordingly, the results of this study and their interpretation should be tempered by the limits of the psychometric properties of the data. However, the measures of interest in this research are the most reliable that have ever been available (Lopez et al., 2006; Mathers, 2006; Mathers et al., 2003; 2005), permitting plausible inferences of the longer-term influences of terrorism, war and one-sided violence on DALYs attributable to substance use disorders that can begin to form the evidence base substance abuse interventions among conflict-affected populations. 
In summary, violence associated with terrorist actions, civil wars and one-sided violence appears to have a significant impact on longer-term substance use disorder morbidity and mortality independent of pre-existing alcohol and illicit drug use and economic factors whose relationship to mortality and morbidity attributable to a variety of diseases and conditions has been well established in the literature. The results of the present study suggest that greater attention be given to the prevention and treatment of substance use disorders in conflict-affected populations, including brief interventions targeted at high risk substance use, provisions for needles and syringes, and management of withdrawal and other acute conditions (UNHCR and WHO, 2008). It will also be critical for future intervention programs to identify phenomena that drive the observed gender and age differences in associations between terrorism and related violence and substance use disorder DALYs that may be unique to conflict-affected populations, with a view toward improving treatment effectiveness in these settings. This study also contributes to the evidence base necessary to establish priorities among agencies working with conflict-affected populations to rebuild substance abuse treatment systems and related healthcare infrastructures. Strengthening substance abuse treatment systems among conflict-affected populations will be critical to implementing more comprehensive treatment services for substance use disorders including cognitive, behavioral and drug therapies for substance dependence and identification and treatment of a variety of physical and psychiatric disorders that are often comorbid with substance use disorders (Ezard et al., 2011). 


\section{Chapter VI: Summary}

Armed conflict has been a major determinant of morbidity and mortality for most of human history (Krug et al., 2002). The nature and scope of armed contest taking place over the years has changed to increasingly include deaths inflicted through terrorist actions and one-sided violence (e.g. genocide) (Eck and Hultmann, 2007; Ericksson et al., 2003). The impact of terrorism, civil war and one-sided violence on population health arises from the immediate effects of combat (i.e., battle deaths) and from their indirect or longer-term consequences. These indirect consequences include the breakdown of water, sanitation, agricultural, transport, healthcare, safety and regulatory infrastructures that results in lack of shelter, safe water and adequate sanitation, food shortages, depressed economic performance, environmental degradation and heightened risk of disease and premature mortality (Dodge, 1990; Betsi et al., 2006; Guha-Sapir and van Panhuis, 2002a; Levy and Sidel, 2003; 2007). The ratio of the direct to longer term consequences of war and related violence has been estimated to be 9:1 (Krug et al., 2002). Despite this substantial impact on public health, little is known about the longer-term effects of terrorism, civil war and one-sided violence on public health and even less is known about their effects on many specific diseases.

Accordingly, this dissertation research is premised on the conceptualization that terrorism, civil war and one-sided violence adversely affect morbidity and mortality long after the fighting and bombings are over and that the health costs of such violence extend into the post-conflict period. The theoretical framework underlying this dissertation research is drawn from a general model used to study factors affecting public health. Several theoretically postulated mechanisms link terrorism, civil war and one-sided violence to increases in population exposure to morbidity and mortality: (1) damages to economic and health 
infrastructures (Colombatti et al., 2009; Guha-Sapir and van Panhuis, 2002a; 2002b; 2003; 2004; Levy and Sidel, 2003; 2007); (2) demographic impacts, that is, the displacement of large numbers of persons (Asgary and Segar, 2011; Atuyambe et al., 2011); (3) economic impacts, including depressed public expenditures on education, transportation, agriculture as well as other health sectors (Perrin, 1996; WHO, 2006b); and (4) psychological reactions, including stress, fear, depression, helplessness and impairment in daily functioning (Bonger et al., 2007;

DiMaggio and Galea, 2006; 2009; Dudley, 2005; Schnurr and Green, 2004).

The specific aims of this dissertation research were to examine the influence of one exposure variable, the combined number of deaths due to terrorism, civil war and one-sided violence from 1994-2000 on morbidity and mortality attributable to: (1) major communicable and noncommunicable diseases (Paper 1); (2) diarrheal and related diseases (Paper 2); and (3) substance use disorders (Paper 3) in 2002, as measured by disability-adjusted life years (DALYs) among WHO Member States (WHO, 2004a). Multivariable linear regression analyses examined the relationships between deaths due to terrorism, civil war and one-sided violence and DALYs attributable to major communicable and noncommunicable diseases, controlling for economic and related factors (i.e. number of refugees/asylum seekers/displaced persons in 1994, number of deaths/homeless/affected by natural disasters from 1994-2000, urban growth from 1990 to 1995, life expectancy at birth in 1994, general health expenditures as a percentage of total government expenditure in 1994, ethnic heterogeneity between 1994-1996 and tropical country status for communicable diseases (Papers 1-3)). Pre-existing vulnerability factors (i.e. percentage of the population using improved water resources/percentage of the population using improved sanitation facilities in 1994 (Paper 2) and adult per capita alcohol consumption in 1994 and annual prevalence of illicit drug use in 1994 (Paper 3) were also controlled. Analyses were conducted for the total sample and among relevant sex-age subgroups of the populace. 
The results of Paper 1 of this dissertation found that terrorism, civil war and one-sided violence had a significant impact on a broad range of communicable and noncommunicable diseases. Deaths from terrorist actions, civil war and one-sided violence from 1994-2000 were significantly related to all cause DALYs in 2002, even after controlling for a variety of economic and related factors empirically shown to affect public health. This result was generally consistent across sex-age subgroups and across a variety of major communicable and noncommunicable conditions and diseases: infectious and parasitic diseases, respiratory infections, maternal and perinatal conditions, nutritional deficiencies, malignant neoplasms, diabetes mellitus, endocrine disorders, neuro-psychiatric disorders, sense organ, cardiovascular, respiratory, digestive, genito-urinary, skin and musculoskeletal diseases, congenital anomalies and oral conditions. These results underscore the need to expand the traditional focus of interventions on communicable, maternal and perinatal, and nutritional diseases and conditions among conflict-affected populations to a variety of noncommunicable diseases shown in this study to be strongly associated with terrorism, civil war and one-sided violence in the longerterm.

Paper 2 found that deaths due to terrorism, civil war and one-sided violence were associated with diarrheal and related infectious and parasitic diseases (diarrheal diseases, schistosomiasis, trachoma, ascariasis, trichuriasis and hookworm), independent of economic and pre-existing vulnerability factors whose relationship with these diseases have been well established in the literature. These associations were greatest among 0 -to- 4 year-olds. The results of this study suggest that international governmental organizations (IGOs) and nongovernmental organizations (NGOs) should prioritize high risk areas for diarrheal and related disease control to include conflict-affected populations, with particular attention to young children who are most vulnerable to DSTN diseases in these settings. In view of the longer-term 
impact of terrorism and related violence on diarrheal and related diseases observed in this study, intervention and control strategies should move beyond existing provisions for safe water and adequate sanitation facilities, hygiene education, case management and vector control (Batterman et al., 2009; Esrey et al., 1991; Fewtrell, 2005; WHO, 2010b) to seek long-term solutions through health systems infrastructure development. Such interventions should be propoor, safe and cost-effective, similar to current efforts to mass distribute mectizan, albendazole and praziquantel for simultaneous treatment of ascariasis, trichuriasis, hookworm disease and schistosomiasis (Amazigo et al., 2002; Loukas and Hotez, 2006; Raso et al., 2004), diseases that are often comorbid and co-endemic in many countries (Molyneux, 2006; Molyneux et al., 2005).

In Paper 3, terrorist actions, civil wars and one-sided violence was found to have a significant and lingering effect on substance use disorders, independent of pre-exisiting alcohol consumption and illicit drug use and economic factors whose relationship to mortality and morbidity attributable to a variety of diseases and conditions has been well established in the literature. This result generalized to a majority of sex-age subgroups of the populace with stronger associations observed among males and among 15-to-44 year-olds. The results of the present study suggest that greater attention be given to prevention and treatment of substance use disorders in conflict-affected populations, including brief interventions targeted at high risk substance use, provisions for needles and syringes, and management of withdrawal and other acute conditions (UNHCR and WHO, 2008). It will be critical for future intervention programs to identify phenomena that drive the observed gender and age differences in associations between terrorism and related violence and substance use disorder DALYs that may be unique to conflict-affected populations with a view toward improving treatment effectiveness in these settings. This study also contributes to the evidence base necessary to establish priorities among agencies working with conflict-affected populations to rebuild substance abuse treatment 
systems, critical to implementing more comprehensive treatment services for substance use disorders including cognitive, behavioral and drug therapies for substance dependence and identification and treatment of comorbid physical and psychiatric disorders (Ezard et al., 2011).

Taken together, the results of Papers 1-3 of this dissertation research have substantially increased our understanding of the relationships between terrorism, civil war and one-sided violence and their deleterious longer-term impacts on public health. This research has also served to highlight the full health costs of terrorism, civil war and one-sided violence and will ultimately contribute to forging a stronger rationale for promoting peace. 


\section{Appendix A \\ Disability-Adjusted Life Years, 2002: Data Quality}

\section{Introduction}

The 2002 DALY measure is calculated as the sum of years of life lost (YLL) due to premature mortality and years of productive life lost due to disability (YLD). The YLL measure is the product of the number of deaths (mortality) multiplied by standard life expectancy at age of death in years. The YLD measure is the product of the number of incident cases times the average duration of a case until remission or death times a disability weight that reflects the severity of the disability or health state on a scale of 0 (equivalent to perfect health) and 1 (equivalent to death) (Murray and Lopez, 1994). One of the major advances of the Version 3.0 Global Burden of Disease (GBD) Study methodology used to calculate 2002 DALYs was an unprecedented effort to quantify uncertainty across the various primary components or inputs to the DALY calculation. In the 2002 GBD Study, uncertainty bounds around DALY component estimates were assessed across either countries or causes of diseases using standard numerical simulation methods (King et al., 2002; Vos, 2000). The 95\% uncertainty estimates and associated confidence intervals for those DALY components examined in the GBD study are summarized below.

\section{Life Expectancies}

For high income countries with complete registration data available, the uncertainty ranges for life expectancy were about \pm 0.07 years and \pm 0.16 years for males and females, respectively (Lopez et al., 2006). In regions such as Latin America and the Caribbean, where death registration data were incomplete, uncertainty ranges were typically about \pm 0.5 years. For regions with partial data on child mortality only where adult mortality was predicted by 
child mortality, the ranges were larger. For example, for Sub-Saharan Africa, uncertainty ranges are typically \pm 5.0 years.

\section{Mortality: All Cause and Specific Causes}

As can be seen in Table 17 uncertainty ranges for all-cause mortality varied widely across regions. In general, uncertainty for all-cause mortality ranged from $\pm 1.0 \%$ for high income countries and from $-15.0 \%$ to $+21.0 \%$ for Sub-Saharan Africa, with uncertainty ranges related to other regions, falling within these bounds (Lopez et al., 2006; Mathers et al., 2005).

Table 17. Total Deaths and 95\% Uncertainty Ranges for All-Cause Mortality by Region, 2000 (In Thousands)

\begin{tabular}{lcc}
\hline Region & Deaths & $\mathbf{9 5 \%}$ Uncertainty Range \\
\hline East Asia/Pacific & 13,070 & $12,379-13,866$ \\
Europe/Central Asia & 5,669 & $5,334-6,122$ \\
Latin American/Caribbean & 3,277 & $3,166-3,411$ \\
Middle East/North Africa & 1,914 & $1,790-2,088$ \\
South Asia & 13,557 & $13,053-14,240$ \\
Sub-Saharan Africa & 10,837 & $9,267-13,164$ \\
World & 56,216 & $53,387-60,173$ \\
\hline
\end{tabular}

For vital registration data coded using ICD-10, diagnostic and coding uncertainty together yielded relative $95 \%$ uncertainty ranges of $\pm 3 \%$ for Group I causes (communicable diseases, maternal and perinatal conditions and nutritional deficiencies) and $\pm 7 \%$ for Group II causes (noncommunicable diseases) (Mathers et al., 2005).

For specific causes of death, uncertainty ranges were generally greater than for all cause mortality because additional uncertainty introduced with attribution of underlying cause codes. 
Overall, estimates and uncertainty ranges around specific and selected causes of death of interest to this dissertation research include: ischemic heart disease, $7,061(6,328-7,844)$; cerebrovascular diseases, 5,388 (4,790-6,067); maternal conditions 508 (381-676); perinatal conditions, 2,521 (2,250-2,876); diarrheal diseases, 1,782 (1,557-2,065); schistosomiasis, 14 (13-16); lower respiratory infections, 3,751 (3,181-4,456); and drug use disorder, 85 (64-109) (Lopez et al., 2006). Distribution of uncertainty ranges for specific causes of death across regions mirrored those associated with all-cause mortality.

\section{Mortality: All Cause By Country}

Uncertainty in underlying cause of death attribution was assessed in terms of relative uncertainty. Relative uncertainty combined: (1) quantitative country-specific information on uncertainty levels in all-cause mortality (in some cases also uncertainty levels in major cause group distributions); (2) average relative uncertainty ranges for specific causes based on expert advice adjusted for specific causes; and (3) country-specific information on data sources, type of cause information and indicators of data quality (Mathers et al., 2005). Relative uncertainty estimates range between 0 and 100, with higher values indicating greater relative uncertainty. The majority of countries in the African Region had the greatest relative uncertainty associated with mortality ranging from 20 to 49, with the greatest uncertainty occurring in Timor-Leste (43) and Comoros (40). Other countries with high relative uncertainty in all cause mortality estimates included the Democratic Republic of Korea (49), Myanmar (40), Bosnia and Herzegovina (38), Bolivia (36), Afghanistan (36), Greece (36), Georgia (34), Yemen (31), Honduras (30), Cambodia (29), Pakistan (29), Chile (28), Saudi Arabia (28), Nepal (24), Spain (22) and Hungary (20). Large relative uncertainties among higher-income countries (e.g. Spain, Greece and Saudi Arabia) are largely attributable to a higher proportion of deaths coded to 
garbage codes or to the ICD-10 Chapter for Symptoms, Signs and Ill-Defined Conditions (Mathers et al., 2005).

\section{Uncertainty in Years of Life Lived With a Disability (YLD) - Number of Data Sets}

Estimates of YLD are by far the most complex component on burden of disease analysis, and require assessments of the available data on incidence, prevalence, duration and severity (as reflected in disability weights) for a wide variety of conditions. Reliability of YLD estimates was assessed in several ways in the 2002 GBD study including quantifying the number of data sources used for YLD estimates by region across causes. The total number of country data sources contributing to the estimation of YLD across Group I (communicable disease) and II (noncommunicable disease) causes was 8,096 distributed as follows by region: 1,955 for SubSarahan Africa; 1,735 for high income countries; 1,239 for Latin America and the Caribbean, 1,155 for East Asia and the Pacific; 914 for Europe and Central Asia; 590 for the Middle East and North Africa; and 522 for South Asia (Lopez et al., 2006).

Of the 8,096 data sets underlying estimates of 2002 YLD, 6,660 related to Group I causes and 1,475 related to Group II causes. Further, about one-quarter of the data sets related to populations in Sub-Saharan Africa and about one-fifth of the data related to populations in high income countries (Mathers et al., 2003). While the predominance of data for high income countries and Group I causes is not surprising, the large number of data sets contributing to YLD estimates in the Sub-Saharan Region and the paucity of data from some leading causes of noncommunicable diseases (e.g., ischemic heart disease) is surprising. Although the large number of data sets associated with Sub-Saharan Africa can be attributed to surveillance of major communicable disease, especially HIV/AIDS, the paucity of data sets for major noncommunicable diseases outside high-income countries is more difficult to explain.

\section{Uncertainty for Years of Life Lived with a Disability (YLD) and DALYs Arising from}




\section{Uncertainty in Disability Weights}

The estimated disability weights associated with the YLD calculation introduces the greatest amount of uncertainty in estimating YLD and DALYs by cause. In the 2002 GBD Study, uncertainty of YLD and DALY estimates arising from disability weight uncertainty was estimated only for low and middle income countries. No attempt was made by the WHO to combine this source of uncertainty with uncertainty related to mortality or the other sources to provide a comprehensive analysis for DALY estimates.

Table 18 summarizes estimates and the $95 \%$ uncertainty ranges for YLD and DALYs arising from uncertainty in disability weights for selected causes of interest to the dissertation research in low and middle income countries (Lopez et al., 2006). As can be seen in Table 18, it was expected that DALY uncertainty due to disability weight uncertainty would generally be greater for causes dominated by YLD (i.e. noncommunicable diseases) than causes dominated by YLL (i.e. communicable diseases). Further analyses conducted by the WHO also showed that uncertainty ranges for DALYs were also large for those YLD-dominated causes with high prevalences and low disability weights.

Taking into account uncertainty in disability weights did not result in significant uncertainty in the ranking of the top four causes of the burden of disease DALYs (i.e. perinatal conditions, lower respiratory infections, ischemic heart diseases and HIV/AIDS). Among the remaining top 10 causes of burden, disability weight uncertainty could change the rankings of individual causes up to two ranks, with the exceptions of major depressive disorder which could change up to four ranks due largely to uncertainty in the disability weight for mild depression. (Lopez et al., 2006; Mathers et al., 2003). For those conditions ranked 11th to 20th, uncertainty ranges associated with ranking were relatively narrow ( \pm 4 ranks) with the exception of hearing 
Table 18. Estimates and 95\% Uncertainty Ranges for YLD and DALYs Arising from Uncertainty in Disability Weights for Selected Causes in Low and Middle Income Countries, 2002 (in Thousands).

Cause

Diarrheal Disease

Trachoma

Trichuriasis

Lower Respiratory Infections

Upper Respiratory Infections

Perinatal Causes

Breast Cancer

Uterine Cancer

Diabetes Mellitus

Endocrine Disorders

Drug Use Disorders

Alcohol Use Disorders

Ischemic Heart Disease

Cardiovascular Disease

Chronic Obstructive

Pulmonary Disease

\section{YLD Uncertainty Range}

DALY

$58,685 \quad 55,100-63,800$

2,621

2,2025-3,195

$2,618 \quad 2,023-3,192$

$1,311 \quad 707-2,190$

1,413

$8,108-2,291$

4,430

$3,128-6,525$

83,579

$82,300-85,700$

181

$108-318$

1,680

$1,609-1,819$

$13,525 \quad 10,300-18,100$

$89,121 \quad 85,900-93,800$

308

226-318

$5,527 \quad 5,440-5,600$

276

200-416

908

831-1,046

5,661

4229-7736

15,806

14,400-17,900

$7,581 \quad 4,447-12,700$

$10,947 \quad 7,814-16,100$

9.808

$6,086-15,700$

11,009

$7,286-16,900$

$2,736 \quad 16,93-3,825$

4,406

$3,361-5,493$

$3,921 \quad 2525-5369$

$71,874 \quad 70,400-73,300$

$11,096 \quad 7,209-17,100$

$62,652 \quad 58,700-68,600$

$8,473 \quad 5,670-12,400$

33,457

$30,600-37,300$

loss ( \pm 11 ranks). For the majority of the remaining 20 causes, uncertainty in ranking attributable to disability weights were generally higher, ranging from \pm 4 to \pm 24 with a mean change in ranking of \pm 12 . 


\section{Summary}

The 2002 GBD Study represented the largest synthesis of population health data to date and efforts within this study to quantify uncertainty of the major components constituting the DALY calculation were unprecedented. Although there is much work to be done regarding improving the reliability of estimates of mortality, life expectancy, YLDs, and disability weights, a major advantage of the burden of disease approach to assessing reliability was to assess the completeness, reliability and consistency of routinely collected data with a view toward identifying critical gaps in health data collection. Extensive efforts to improve the reliability of data underlying DALY measure have been implemented since 2002 and include implementation of descriptive epidemiology surveillance programs in poor countries, greater availability of linked data sets on health outcomes, further longitudinal research into health state transitions, development of better methodology to derive disability weights due to various conditions, investments in death registration systems and expanding country-wide population surveys on health outcomes (Lopez et al., 2006).

The 2002 GBD Study represented the most extensive globally coordinated research and development effort in advancing knowledge and understanding of global descriptive epidemiology of morbidity and mortality to date. It also provided the framework for new data collection systems that ensured the continued relevance and reliability of global burden of disease statistics. Although it will take many years to realize the potential of these data collection efforts with respect to the reliability, the 2002 DALY statistics are the most reliable that have ever been available, permitting plausible and reasonable systematic inferences about the longer-term impact of terrorism, war and one-sided violence on DALYs attributable to communicable and noncommunicable diseases. 


\section{Appendix B \\ Global Burden of Disease Study 2002 Cause Categories}

\section{GBD Cause Name}

All Causes

I. Communicable, maternal, perinatal and nutritional conditions (a)

A. Infectious and parasitic diseases

1. Tuberculosis

2. Sexually transmitted diseases excluding HIV
a. Syphilis
b. Chlamydia
c. Gonorrhoea Other STDs

3. HIVIAIDS

4. Diarrhoeal diseases

5. Childhood-cluster diseases
a. Pertussis
b. Poliomyelitis
c. Diphtheria
d. Measles
e. Tetanus

6. Meningitis

7. Hepatitis B Hepatitis C

8. Malaria

9. Tropical-cluster diseases
a. Trypanosomiasis
b. Chagas disease
c. Schistosomiasis
d. Leishmaniasis
e. Lymphatic filariasis
f. Onchocerciasis

10. Leprosy

11. Dengue

12. Japanese encephalitis

13. Trachoma
ICD-9 Code

001-139, 243, 260269,279.5, 280-281, 285.9, 320-323, 381$382,460-465,466,480-$ 487, 614-616, 630-676, 760-779

001-139, 279.5, 320-323, $614-616,771.3$

010-018, 137

090-099, 614-616

090-097

$-$

098

099, 614-616

279.5 (=042-044)

001, 002, 004, 006-009

032, 033, 037, 045, 055, $138,771.3$

033

045, 138

032

055

$037,771.3$

036, 320-322

070.2-070.9

\section{$-$}

084

085, 086, 120, 125.0,

$125.1,125.3$

086.3, 086.4, 086.5,

$086.0,086.1,086.2,086.9$

120

085

125.0, 125.1

125.3

030

061

062.0

076

\section{ICD-10 Code}

A00-B99, G00-G04, N70-

N73, J00-J06, J10-J18, J20-J22, H65-H66, O00O99, P00-P96, E00-E02, E40-E46, E50, D50-D53, D64.9, E51-64

A00-B99, G00, G03-G04, N70-N73

A15-A19, B90

A50-A64, N70-N73

A50-A53

A55-A56

A54

A57-A64, N70-N73

B20-B24

$\mathrm{A} 00, \mathrm{~A} 01, \mathrm{~A} 03, \mathrm{A04}, \mathrm{A06}-$

A09

A33-A37, A80, B05, B91

A37

A80,B91

A36

B05

A33-A35

A39, G00, G03

B16-B19 (minus B17.1, B18.2)

B17.1, B18.2

B50-B54

B55-B57, B65, B73,

B74.0-B74.2

B56

B57

B65

B55

B74.0-B74.2

B73

A30

A90-A91

A83.0

A71 
14. Intestinal nematode infections

a. Ascariasis

b. Trichuriasis

c. Hookworm disease

(Ancylostomiasis and necatoriasis)

Other intestinal infections

B. Respiratory infections

1. Lower respiratory infections

2. Upper respiratory infections

3. Otitis media

C. Maternal conditions

1. Maternal haemorrhage

2. Maternal sepsis

3. Hypertensive disorders of pregnancy

4. Obstructed labour

5. Abortion

Other maternal conditions

D. Conditions arising during the perinatal period

1. Low birth weight

2. Birth asphyxia and birth trauma Other perinatal conditions

E. Nutritional deficiencies

1. Protein-energy malnutrition

2. lodine deficiency

3. Vitamin A deficiency

4. Iron-deficiency anaemia

Other nutritional disorders

II. Noncommunicable diseases (a)

A. Malignant neoplasms

1. Mouth and oropharynx cancers (b)

2. Oesophagus cancer (b)
126-129

B76-B81

127.0

B77

127.3

B7

$127.1,127.2,127.4-$ $003,005,020-027,031$, 034, 035, 038-041, 046049, 050-054, 056-057, 060, 062.1-066, 070.0070.1, 071-075, 077-079 080-083, 087-088, 100 $104,110-118,121-124$ 125.2, 125.4, 125.5, $125.6,125.7,125.9,130-$ $136,139,323$

$460-466,480-487,381$ 382

466, 480-487

460-465

381-382

630-676

$640,641,666$

670

642

660

630-639

643-659, 661-665, 667$669,671-676$

$760-779$ minus 771.3

\section{4-765}

767-770

760-763, 766, 771 (minus 771.3), 772-779

243, 260-269, 280-281, 285.9

260-263

243

264

280, 285.9

265-269, 281

140-242, 244-259, 270 279 (minus 279.5),282 285 (minus 285.9), 286$319,324-380,383-459$, 470-478, 490-611, 617$629,680-759$

140-208

140-149

150
A02,A05,A20-

A28,A31,A32,A38,A40-

A49,A65-A70,A74-

A79,A81,A82,A83.1-

A83.9,A84-A89,A92-

A99,B00-B04,B06-B15,B25-

B49,B58- B60,B64,B66-

B72,B74.3- B74.9,B75,B82-

B89,B92- B99, G04

J00-J06, J10-J18, J20-

J22, H65-H66

J10-J18, J20-J22

J00-J06

H65-H66

000-099

O44-O46, O67, O72

085-086

010-016

064-066

O00-007

O20-O43,047-063,068071,073-075,087-099

P00-P96

P05-P07

P03, P10-P15, P20-P29

$\mathrm{P} 00-\mathrm{P} 02, \mathrm{P} 04, \mathrm{P} 08, \mathrm{P} 35-$

$\mathrm{P} 96$

E00-E02, E40-E46, E50, D50-D53,D64.9, E51-E64

E40-E46

E00-E02

E50

D50, D64.9

D51-D53, E51-E64

C00-C97, D00-D48,D55-

D64 (minus D 64.9) D65-

D89, E03-E07, E10-E16,

E20-E34, E65-E88, F01-

F99, G06-G98, H0O-H61,

H68-H93, I00-I99, J30-

J98, K00-K92, N00-N64,

N75-N98, L00-L98, M00-

M99, Q00-Q99

$\mathrm{C} 00-\mathrm{C} 97$

$\mathrm{C} 00-\mathrm{C} 14$

C15 
3. Stomach cancer (b)

4. Colon and rectum cancers (b)

5. Liver cancer

6. Pancreas cancer

7. Trachea, bronchus and lung cancers

8. Melanoma and other skin cancers (b)

9. Breast cancer (b)

10. Cervix uteri cancer (b)

11. Corpus uteri cancer (b)

12. Ovary cancer (b)

13. Prostate cancer (b)

14. Bladder cancer (b)

15. Lymphomas and multiple myeloma (b)

16. Leukaemia (b)

Other malignant neoplasms (b)

B. Other neoplasms

C. Diabetes mellitus

D. Endocrine disorders

E. Neuro-psychiatric conditions

1. Unipolar depressive disorders

2. Bipolar affective disorder

3. Schizophrenia

4. Epilepsy

5. Alcohol use disorders

6. Alzheimer and other dementias

7. Parkinson disease

8. Multiple sclerosis

9. Drug use disorders

10. Post-traumatic stress disorder

11. Obsessive-compulsive disorder

12. Panic disorder

13. Insomnia (primary)

14. Migraine

Mental Retardation attributable to lead exposure

Other neuropsychiatric disorders

F. Sense organ diseases

1. Glaucoma

2. Cataracts

3. Vision disorders, age-related

4. Hearing loss, adult onset Other sense organ disorders
151

153, 154

155

157

162

172-173

174,175

180

179,182

183

185

188

200-203

204-208

$152,156,158-161,163-$ $171,181,184,186-187$, 189-199

210-239

\section{0}

240-242, 244-246, 251 259, 270-279 (minus 274, 279.5), 282-285 (minus 285.9), 286-289

290-319, 324-359

296.1, 311

296 (minus 296.1)

295

345

$291,303,305.0$

290, 330, 331

332

340

304, 305.2-305.9

308-309

300.3

300.2

307.4

346

317-319

292-294, 297-300.1, 300.4-302, 305.1, 306307 (minus 307.4), 310 312-316, 324-326, 333$337,341-344,347-349$, 350-359

360-380, 383-389

365

366

367.4

389

360-364, 367-380 (minus 367.4), 383-388
C16

C18-C21

$\mathrm{C} 22$

C25

C33-C34

C43-C44

C50

$\mathrm{C} 53$

C54-C55

C56

C61

C67

C81-C90, C96

C91-C95

$\mathrm{C} 17, \mathrm{C} 23, \mathrm{C} 24, \mathrm{C} 26-\mathrm{C} 32$, C37-C41,C45-C49,

C51,C52,C57-C60,C62C66,C68-C80,C97

D00-D48

E10-E14

D55-D64 (minus

D64.9),D65-D89, E03-

E07, E15-E16, E20-E34, E65-E88

F01-F99, G06-G98

F32-F33

F30-F31

F20-F29

G40-G41

F10

F01, F03, G30-G31

G20-G21

G35

F11-F16, F18-F19

F43.1

F42

F40.0, F41.0

F51

G43

F70-F79

F04-F09,F17,F34-

F39,F401-F409,F411-

F419, F43(minus F43.1),

F44-F50, F52-F69, F80-

F99,G06-G12,G23-

G25,G36, G37,G44-G98

H0O-H61, H68-H93

$\mathrm{H} 40$

$\mathrm{H} 25-\mathrm{H} 26$

H524

H90-H91

$\mathrm{H} 00-\mathrm{H} 21, \mathrm{H} 27-\mathrm{H} 35$, H43H61(minus H524), H68H83, H92-H93 
G. Cardiovascular diseases

1. Rheumatic heart disease

2. Hypertensive heart disease

3. Ischaemic heart disease (b)

4. Cerebrovascular disease

5. Inflammatory heart diseases

Other cardiovascular diseases (b)

H. Respiratory diseases

1. Chronic obstructive pulmonary disease

2. Asthma

Other respiratory diseases

I. Digestive diseases

1. Peptic ulcer disease

2. Cirrhosis of the liver

3. Appendicitis

Other digestive diseases

J. Genito-urinary diseases

1. Nephritis and nephrosis

2. Benign prostatic hypertrophy Other genitourinary system diseases

K. Skin diseases

L. Musculoskeletal diseases

1. Rheumatoid arthritis

2. Osteoarthritis

3. Gout

4. Low back pain

Other musculoskeletal disorders

M. Congenital anomalies

1. Abdominal wall defect

2. Anencephaly

3. Anorectal atresia

4. Cleft lip

5. Cleft palate

6. Oesophageal atresia

7. Renal agenesis

8. Down syndrome

9. Congenital heart anomalies

10. Spina bifida
390-459

390-398

401-405

410-414

430-438

$420,421,422,425$

415-417, 423-424, 426-

$429,440-448,451-459$

470-478, 490-519

J30-J98

490-492, 495-496

J40-J44

493

J45-J46

470-478, 494, 500-508, $510-519$

530-579

J30-J39,J47-J98

K20-K92

531-533

K25-K27

571

$\mathrm{K} 70, \mathrm{~K} 74$

540-543

K35-K37

530, 534-537, 550-553, 555-558, 560-570, 572-

579

K20-K22,K28-

K31,K38,K40-K66,K71-

K73,K75-K92

580-611, 617-629

580-589

N00-N64, N75-N98

N00-N19

600

$\mathrm{N} 40$

590-599, 601-611, 617629

680-709

N20-N39, N41-N64, N75$\mathrm{N} 98$

L00-L98

710-739, 274

M00-M99

714

M05-M06

715

M15-M19

274

M10

720-724 (minus 721.1, $722.0,722.4$ )

M45-M48, M54 (minus M54.2)

710-713, 716-719,721.1, $722.0,722.4,723,725$ 739

740-759

M00-M02, M08, M11-

M13, M20-M43, M50-

M53, M54.2, M55-M99

Q00-Q99

756.7

Q79.2-Q79.5

740.0

Q00

751.2

Q42

749.1

Q36

749.0

Q35, Q37

750.3

Q39.0-Q39.1

753.0

Q60

758.0

Q90

745-747

Q20-Q28

741

Q05 
Other Congenital anomalies

N. Oral conditions

1. Dental caries

2. Periodontal disease

3. Edentulism

Other oral diseases
$740.1,740.2,742-744$ $748,749.2,750.0,750.1$, 750.2, 750.4-751.1,

751.3-751.9, 752, 753.1$753.9,754,755,756.0-$

756.6, 756.8, 756.9, 757 758.1-758.9, 759

$\begin{array}{ll}520-529 & \mathrm{~K} 00-\mathrm{K} 14 \\ 521.0 & \mathrm{~K} 02 \\ 523 & \mathrm{~K} 05 \\ - & - \\ 520,521.1-521.9,522, & \mathrm{~K} 00, \mathrm{~K} 01, \mathrm{~K} 03, \mathrm{~K} 04, \mathrm{~K} 06-\end{array}$

Q01-Q04, Q06-Q18, Q30Q34, Q38, Q392-Q399, Q40-Q41, Q43-Q56, Q61Q78, Q790, Q791, Q796, Q798, Q799, Q80-Q89, Q $\mathrm{K} 14$ 


\section{Appendix C \\ Methodological Supplement}

This Appendix contains additional information on descriptive statistics of study variables used in this dissertation research that complements descriptive statistics presented in Chapter II of this dissertation (see Table 19). This Appendix also addresses several relevant methodological issues related to research focusing on the impact of conflict (i.e. terrorism, civil war and one-sided violence) on morbidity and mortality: (1) outlier diagnostics associated with linear regression analyses conducted in this dissertation; (2) use of stepwise linear regression analyses to determine the percentage of variance in the outcome DALY measures that is explained by the conflict exposure measure; and (3) the use of Poisson regression analysis to model DALY rates.

\section{Outlier Diagnostics in Linear Regression Analyses}

Thorough linear regression diagnostics were conducted for all models examined in this dissertation. The DALY outcome measures, exposure conflict measure and some control variables (i.e. number of refugees/asylum seekers/displaced, number affected by natural disasters, illicit drug use) were skewed and were natural log transformed. Rwanda experienced an inordinately high number of deaths from genocide in $1994(\mathrm{~N} \approx 500,000)$ and was removed from all linear regression analyses conducted in this dissertation. Once transformed, scatterplots between the outcome DALY measures and each covariate, including exposure and control variables were shown to be approximately linear. Leverage was also examined. Leverage occurs when there is an extreme value on a predictor variable indicating an outlier observation. There were no large leverage points in excess of 0.12 , the cut-off leverage value that would indicate undue influence of an observation. Leverage points were less than 0.09 in all models. In addition, Cook's distance (Cook's d), that detects influential observations by evaluating all 
Table 19. Additional Descriptive Statistics for Outcome, Exposure and Control Variables.

\begin{tabular}{|c|c|c|c|c|}
\hline Variable & Mean & Minimum & Maximum & Sum \\
\hline \multicolumn{5}{|l|}{ Outcome } \\
\hline All cause DALYs & $7,749,040$ & 379.7 & $299,408,030$ & $1,487,816,110$ \\
\hline Diarrheal and related disease DALYs & 358,446 & 2.84 & $15,684,460$ & $68,821,550$ \\
\hline Alcohol use disorder DALYs & 105,697 & 2.37 & $4,837,630$ & $20,293,890$ \\
\hline Drug use disorder DALYs & 38,385 & 2.24 & 734,610 & $7,369,850$ \\
\hline Substance use disorder DALYs & 144,082 & 4.61 & $4,918,200$ & $27,663,740$ \\
\hline \multicolumn{5}{|l|}{ Exposure } \\
\hline Civil war deaths & 3,296 & 0 & 112,750 & 632,851 \\
\hline Terrorism deaths & 224 & 0 & 7,112 & 43,269 \\
\hline One-sided violence deaths & 123 & 0 & 1,942 & 27,895 \\
\hline Combined violence deaths & 3,736 & 0 & 120,877 & 704,015 \\
\hline \multicolumn{5}{|l|}{ Pre-existing Vulnerability } \\
\hline $\begin{array}{l}\text { Percent using improved water } \\
\text { resources/sanitation }\end{array}$ & $147.7 \%$ & $27.0 \%$ & $200.0 \%$ & - \\
\hline Prevalence of illicit drug use & $1.7 \%$ & $0.0 \%$ & $16.5 \%$ & - \\
\hline Adult per capita alcohol consumption & 4.9 & 0 & 18.5 & - \\
\hline
\end{tabular}


Table 19. Continued..

\begin{tabular}{lllll} 
Variable & Mean & Minimum & Maximum & Sum \\
\hline Economic & & & & \\
Number of refugees/asylum seekers/displaced & 126,139 & 0 & $1,734,400$ & $24,218,700$ \\
Number affected by natural disasters & $5,448,080$ & 0 & 20 million & 1.046 billion \\
Health expenditures (\%) & $10.1 \%$ & $0.0 \%$ & $27.6 \%$ & - \\
Urban growth (\%) & $0.9 \%$ & $-2.4 \%$ & $4.4 \%$ & - \\
Ethnic heterogeneity & $43.9 \%$ & $0.0 \%$ & $147.0 \%$ & - \\
Life expectancy at birth (years) & 64.8 & 38.4 & 79.5 & - \\
\hline
\end{tabular}


variables simultaneously, was also calculated for each model. Generally, a Cook's d greater than 0.22 may be of concern. However, in no model did Cook's d exceed the 0.22 cut-off, but was in all cases $<0.12$. In summary, these linear regression diagnostics indicated the absence of outliers and observations with extreme values in linear regression models examined in this dissertation. Further, additional regression diagnostics demonstrated the absence of multicollinearity, homogeneity of variance of the residuals, and normality of residuals, that take together, demonstrates all assumptions underlying the linear regression models conducted in this dissertation research were satisfied.

\section{Stepwise Linear Regression Analyses}

Multivariable stepwise linear regression analysis might be used in future research on conflict and health to determine the proportions of variance in the outcome DALY variables that are explained by the conflict exposure variable. Stepwise linear regression analysis is a variant of forward linear regression analysis that operates by successive addition of significant or nonsignificant independent or predictor variables, but also checks a previously added variable to determine if it can be eliminated. The purpose of stepwise regression is to yield partial $\mathrm{R}^{2} \mathrm{~s}$ for variables remaining in the best model after the operation of the stepwise linear regression procedure. The best model is determined by specifying the significance levels for variables entering and staying in the model. Significance levels of $<0.01$ have been recommended when the purpose of model building is interpretation or explanatory rather than predictive (Hommer and Lemeshow, 2006). The partial $\mathrm{R}^{2}$ estimates the proportion of unexplained variation in the dependent variable that becomes explained with the addition of each predictor variable to the model. For the purpose of this demonstration, the contribution of the conflict variable to 
variation in DALY outcome measures was of central interest. To demonstrate stepwise linear regression modeling for future research on the relationship between conflict and morbidity and mortality, several full model multivariable linear regression analyses conducted in this dissertation research were re-examined using multivariable stepwise regression. The first stepwise regression analysis was conducted on the model having total diarrhea and related disease DALYs as the outcome variable. The results of this stepwise regression analysis are shown in Table 20. The best model identified in this stepwise procedure included the conflict exposure variable that accounted for $6.5 \%\left(\mathrm{R}^{2} * 100\right)$ of the variation in diarrheal and related disease DALYs. The associated F-test (48.5) was significant at the $<0.0001$ level, indicating that the conflict exposure variable contributes significantly to the model given the remaining control variables are in the model.

Table 20. Summary of Stepwise Linear Regression Analysis of Terrorism, Civil War and One-Sided Violence Deaths from 1994-2000 and Diarrheal and Related Disease DALYs in 2002.

\begin{tabular}{llllll} 
Variable & $\boldsymbol{\beta}$ & Partial R $^{2}$ & Model R $^{2}$ & F-Value & $\mathbf{P}>\mathbf{F}$ \\
\hline $\begin{array}{l}\text { Percent improved } \\
\text { water/sanitation }\end{array}$ & -0.02 & 0.489 & 0.489 & 174.5 & $<0.0001$ \\
$\begin{array}{l}\text { Number affected by } \\
\text { natural disasters }\end{array}$ & 0.32 & 0.206 & 0.695 & 122.8 & $<0.0001$ \\
$\begin{array}{l}\text { Terrorism, civil war } \\
\text { and one-sided violence } \\
\text { deaths }\end{array}$ & 0.18 & 0.065 & 0.760 & 48.5 & $<0.0001$ \\
$\begin{array}{l}\text { Health expenditures } \\
\text { Heaths }\end{array}$ & -0.06 & 0.012 & 0.773 & 10.09 & 0.0018 \\
\hline
\end{tabular}

Several additional stepwise regression analyses were conducted using full models examined in this dissertation. The outcome DALY variables associated with these models and 
the percentage of variation in the DALY variable explained by the conflict exposure variable in each of these models were: male diarrheal and related disease DALYs (partial $\mathrm{R}^{2}=0.066$ ); female diarrheal and related disease DALYs (partial $\mathrm{R}^{2}=0.067$ ); total all cause DALYs (partial $\left.\mathrm{R}^{2}=0.050\right)$; total communicable disease DALYs (partial $\left.\mathrm{R}^{2}=0.052\right)$; total noncommunicable disease DALYs (partial $\mathrm{R}^{2}=0.043$ ); total alcohol use disorder DALYs (partial $\mathrm{R}^{2}=0.041$ ); total drug use disorder DALYs (partial $\mathrm{R}^{2}=0.022$ ); total substance use disorder DALYs (partial $\mathrm{R}^{2}=$ 0.037). For these stepwise regression models, the percentage variation in the dependent variable that was explained by the conflict exposure variable ranged from $2.2 \%$ to $6.7 \%$.

Although multivariable stepwise regression analysis may be a useful in determining the contribution of a major exposure variable to variation in a dependent variable, it is not without criticism. Foremost, stepwise regression analysis can produce best models that may be difficult to interpret since it entails a large number of tests that can result in inflated Type 1 errors and model R² (Harrell 2001; Panik 2009). However, these problems are less likely when the associated full regression model satisfies all model assumptions as they do here. Perhaps the most widely recognized difficulty in stepwise regression is that the procedure, often referred as "data mining," should only be used with a large number of potential explanatory variables in situations where there is no underlying theory on which to base model selection (Burnham and Anderson, 2002; Cohen and Cohen, 1983).

Stepwise regression should not be used as a substitution for careful theorizing and substantive knowledge. With regard to this dissertation research that has been based on careful theorizing, the use of stepwise regression may not be as important as with exploratory applications. This is the case since the hypotheses in this dissertation research relate to determining whether conflict as the main exposure variable is significantly related to the 
outcome DALY variables, controlling for economic and pre-existing vulnerability variables. These hypotheses do not focus on the contribution of the conflict exposure variable to the variation in the DALY outcome measure given the control measures are included in the best model. The use of stepwise regression analysis in future research will depend on the specific application, especially consistency of the analysis with study hypotheses.

\section{Poisson Regression of DALY Rates}

This dissertation focused on modeling the number of DALYs in ordinary least squares regression analysis in order to determine whether conflict was related to morbidity and mortality controlling for economic and pre-existing vulnerability factors. In other applications, it may be of interest to model DALY rates, that is, the number of DALYs divided by the associated population figure by sex and age for each WHO Member State. Both DALY and DALY rate variables are skewed.

In the linear regression analysis conducted in this dissertation, the number of DALYs were natural $\log$ transformed to induce linearity with a secondary effect of ensuring homogeneity of residual variances. The appropriate regression analysis when the outcome measure is a DALY rate is Poisson regression, a modeling procedure that does not assume homogeneity of variance. Instead, in Poisson regression, residual variance is expected to be a function of the predicted number of DALYs, which in turn is a function of population size.

Poisson regression is used primarily for count data. When examining rates within Poisson regression analysis it is necessary to control for population size so that the Poisson regression will be a model of DALY rates rather than a model of number of DALYs (Dupont, 2009). This is accomplished in Poisson regression by entering the numerator of the DALY rate (i.e. the number of DALYs) as the dependent variable and the denominator of the DALY rate (i.e. population size) separately as a covariate. The population size covariate is included for 
control purposes only and is of no further interest. However, it is included to reduce bias in or increase precision of the estimate of the parameter of interest (the exposure conflict variable).

Poisson regression assumes the outcome variable has a Poisson distribution. With regard to rate data, the Poisson regression model expresses the log DALY rate as a linear function of a set of predictors (Hoffman, 2009; Kleinbaum et al., 2008). The idea is that the DALY rate is related to the conflict exposure variable through a link function. In Poisson regression, the link function is the natural $\log$ (Cameron and Trivedi, 1998). A strong assumption of the Poisson regression model is that its mean is equal to its variance, which is only plausible if all the assumptions underlying the Poisson distribution are fully met by the data. Typically, if the observed variance is greater or less than the mean then overdispersion is present, indicating poor model fit. [Note that there is no analogue in Poisson regression for $\mathrm{R}^{2}$ ].

Overdispersion in a Poisson model is assessed with the deviance value which has an approximate chi-square distribution with n-p degrees of freedom, where $n$ equals the number of observations and $\mathrm{p}$ is the number of predictor variables (including the intercept) and the expected value of a chi-square random variable is equal to the degrees of freedom (Cameron and Trivedi, 2011). Thus, if there is no overdispersion and the model fits the data well then the ratio of the deviance to its degrees of freedom should be about 1.0. In the presence of overdispersion, standard errors of the $\beta \mathrm{s}$ will be underestimated which in turn leads to misleading significance tests. However, the Poisson regression estimates ( $\beta$ s) remain unbiased in the presence of overdispersion. Since rate data is typically overdispersed to some degree, it is necessary to correct the standard errors of the estimates. This is usually accomplished by forcing the ratio of the deviance to its degrees of freedom to be 1.0. By forcing the deviance ratio to be 1.0 , the 
model becomes optimally dispersed and the standard errors are adjusted by a factor of the square root of the deviance ratio.

To demonstrate Poisson regression analysis using DALY rates as outcome variables, several linear regression analyses conducted in this dissertation using DALYs as outcome variables were re-examined. The first Poisson regression was conducted on a model having total all cause DALY rates as the outcome variable. The results of this Poisson regression model are shown in Table 21. Since the model was somewhat overdispersed (deviance ratio $=2.9$ ), standard errors of the $\beta$ s were corrected to account for the overdispersion. The $\beta$ coefficient associated with the conflict exposure variable was significant $(\mathrm{p}<0.0001)$ with a value of 0.09 , indicating that a $1.0 \%$ increase in deaths due to conflict was associated with a $9.0 \%\left(\exp ^{\beta}\right)$ increase in the all cause DALY rate (Liao, 1994).

Table 21. Summary of Poisson Regression Analysis of Terrorism, Civil War One-Sided Violence Deaths from 1994-2000 and All Cause DALY Rates in 2002

\begin{tabular}{lllll} 
Variable & $\boldsymbol{\beta}$ & \multicolumn{2}{l}{ Wald 95\% Confidence Limits } & F-Value \\
\hline $\begin{array}{l}\text { Terrorism, civil war, one-sided } \\
\text { violence deaths }\end{array}$ & 0.090 & 0.045 & 0.138 & 0.0001 \\
$\begin{array}{l}\text { Refugees/asylum } \\
\text { seekers/displaced }\end{array}$ & 0.071 & 0.008 & 0.135 & 0.0282 \\
$\begin{array}{l}\text { Number affected by natural } \\
\text { disasters }\end{array}$ & 0.230 & 0.174 & 0.286 & $<0.0001$ \\
$\begin{array}{l}\text { Health expenditures } \\
\text { Urban growth }\end{array}$ & -0.026 & -0.057 & 0.006 & 0.1072 \\
$\begin{array}{l}\text { Ethnic heterogeneity } \\
\text { Life expectancy }\end{array}$ & 0.017 & -0.105 & 0.138 & 0.7870 \\
& 0.001 & -0.003 & 0.005 & 0.5761 \\
& -0.009 & -0.027 & 0.008 & 0.2834
\end{tabular}

Note: Population size covariate significant at the $\mathrm{p}<0.001$ level. 
Several additional Poisson regression analyses were conducted. For each of these models, the $\beta$ coefficient of the conflict exposure variable was significant $(p<0.001)$ and the correction of the overdispersion was applied. The outcome DALY rate measure associated with each of these models and the percentage increase in the DALY rate associated with a $1.0 \%$ increase in conflict deaths for each of these models were: male all cause DALY rate (10.0\%); total diarrheal and related disease DALY rate $(8.8 \%)$; diarrheal and related disease DALY rate among 15-to-14 year-olds (7.2\%); total alcohol use disorder DALY rate (16.2\%); female alcohol use disorder DALY rate (7.6\%); male drug use disorder DALY rate (8.7\%); drug use disorder DALY rate among 15-to-44 year olds (12.0\%); total communicable disease DALY rate (11.3\%); total noncommunicable DALY rate $(11.9 \%)$.

In conclusion, when the outcome measure is a continuous DALY measure, the appropriate model is a linear regression analysis. When the outcome measure is a rate, the appropriate analysis is a Poisson regression analysis. These models are neither equivalent nor comparable owing to differences in the distributions underlying the models and nature of the outcome measures. 


\section{Bibliography}

Adams R.E. \& Boscarino J.A. (2011). A structural equation model of prevalent panic and posttraumatic stress disorder after a community disaster. Journal of Traumatic Stress, 24, 61-69.

Adelekan M. (2006). Rapid Assessment of Substance Use and HIV Vulnerability in Kakuma Refugee Camp and Surrounding Community; Kakuma, Kenya. Geneva Switzerland: United Nations High Commissioner for Refugees.

Aghababian R.V. \& Teuscher J. (1992). Infectious disease following major disasters. Annals of Emerging Medicine, 21, 362-367.

Agnew R. (1992). Foundations for a general strain theory of crime and delinquency. Criminology, 30, 47-87.

Ahoua L., Tamrat A., Duroch F., Grais R.F. \& Brown V. (2006). High mortality in an internally displaced population in Ituri, Democratic Republic of Congo, 2005: results of a rapid assessment under difficult conditions. Global Public Health, 1, 195-204.

Alesina A., Baqir R. \& Easterly W. (1999). Public goods and ethnic divisions. Quarterly Journal of Economics, 114, 1243-1284.

Alexander S.E. \& Ehrlich P.R. (2000). Population and the environment. In W.G. Ernst (ed.) Earth Systems: Processes and Issues. Cambridge, MA: Cambridge University Press.

Al Gasseer N., Desden E., Keeney G.B. \& Warren N. (2004). Status of women and infants in complex humanitarian emergencies. Journal of Midwifery and Women's Health, 49, 7-13.

Alirol E., Getaz L., Stoll G., Chappuis F. \& Loutan L. (2010). Urbanisation and infectious diseases in a globalized world. Lancet Infectious Disease, 10, 131-141.

Allender S., Foster C., Hutchinson L. \& Arambepola C. (2008). Quantification of urbanization to chronic diseases in developing countries: a systematic review. Journal of Urban Health, 85, 9381033.

Allodi F.A. (1991). Assessment and treatment of torture victims: a critical review. Journal of Nervous and Mental Disease, 179, 1004-1111.

Amanda C., Williams C., Pena C.R. \& Rice A.S.C. (2010). Persistent pain in survivors of torture: A cohort study. Journal of Pain and Symptom Management, 40, 715-722.

American College of Physicians. Inner-city health care. (1997). Annals of Internal Medicine,127, 485-490.

Amizago U., Brieger W.R., Katabarwa M., Akogoun O., Ntep M., Boetin B., N'Doyo J., Noma M. \& Seketeli A. (2002). The challenges of community directed treatment with ivermectin 
(CDMI) within the African Programme for Onchocerciasis Control (APOC). Annals of Tropical Medicine and Parasitology, 96(Supplement 1), 41-58.

Anand S. \& Hanson K. (1997). Disability-adjusted life years: a critical review. Journal of Health Economics, 16, 685-702.

Asgary R. \& Segar N. (2011). Barriers to health care access among refugee asylum seekers. Journal of Healthcare for the Poor and Underserved, 22, 506-522.

Atuyambe L.M., Ediau M., Orach C.G., Museneri M. \& Bazeyo W. (2011). Land slide disaster in eastern Uganda: rapid assessment of water, sanitation and hygiene in situation in Bulucheke camp, Bududa district. Environmental Health, 10, 38.

Azam J.P. \& Hoeffler A. (2002) Violence against civilians in civil wars: looting or terror? Journal of Peace Research, 39, 461-485.

Bailey R. (1999) The duration of human ocular chlamydia trachomatis infection is age dependent. Epidemiology and Infection, 123, 479-486.

Banatvala N. \& Zwi A.B. (2000). Public health and humanitarian interventions: developing the evidence base. British Medical Journal, 321, 101-105.

Batterman S., Eisenberg J., Hardin R., Kruk M., Lemos M.C., Michalak A.M., Mukherjee B., Renne E., Stein H., Watkins C. \& Wilson M.L. (2009). Sustainable control of water-related infectious diseases: a review and proposal for interdisciplinary health-based systems research. Environmental Health Perspectives, 117, 1023-1032.

Baxter P.J., Ing R., Falk H. \& Plikaytis B. (1983). Mount St. Helens eruptions: the acute respiratory effects of volcanic ash in a North American community. Archives of Environmental Health, 38, 138-143.

Beiser M. \& Hyman T. (1997). Refugees time perspective and mental health. American Journal of Psychiatry, 154, 996-1002.

Benner T., Schachinger U. \& Nerlich M. (2004). Telemedecine in trauma and disasters- from war to earthquake: are we ready? Studies in Health Technology and Informatics, 104, 106-115.

Bergh P.L. (1981). The Ethnic Phenomenon. Westerport: Prager.

Betsi N.A., Koudou B.G., Cisse G., Tschannen A.B., Pignol A.M., Ovattora Y., Madougou Z., Tanner M. \& Utzinger J. (2006). Effect of armed conflict on human resources and health systems in Cote d'Ivoire: Prevention and Care for People with HIV/AIDs. AIDs Care, 18, 356365 .

Bieberson, J. (1999). Epidemics in the wake of conflict. In Jean F. (ed.). Populations in Danger. London: John Libby Company. 
Bjornehed E. (2004). Narco-terrorism: the merger of the war on drugs and the war on terror. Global Crime, 6, 305-324.

Bogic M., Aidukovic D., Bremner S., Franciskovic T., Geleazzi G.M., Kucukalic A., LecicTosevski D., Morina N., Popovski M., Schutzwohl M., Wang D. \& Priebe S. (2012). Factors associated with mental health disorders in long-settled war refugees from the former Yugoslavia in Germany, Italy and the UK. British Journal of Psychiatry, 200, 216-223.

Bonger B., Brown L.M., Beutler L.E., Breckenridge J.N. \& Zimbardo P.G. (2007). Psychology of Terrorism. New York: Oxford University Press.

Bosnar A., Stemberg V., Cuculic D., Zambolo G., Stifter S. \& Cocklo M. (2004). Suicide rate after the 1991-1995 war in Southwestern Croatia. Archives of Medical Research, 35, 344-347.

Boyd M.A. \& Nihart M.A. (2007). Psychiatric Nursing: Contemporary Practice. Philadelphia: Lippincott.

Bradley D.J. (1998). The influence of local changes on the rise of infectious disease. In Greenwood B., de Cock K (eds.). New and Resurgent Infections: Prediction, Detection and Management of Tomorrow's Epidemics. Chicester, London: Wiley.

Bravo M., Rubio-Stipec M., Canino G.J., Woodbury M.A. \& Ribera J.C. (1990). The psychological sequelae of disaster stress prospectively and retrospectively evaluated. American Journal of Community Psychology, 18, 661-680.

Briere J. \& Elliott D. (2000). Prevalence, characteristics and long-term sequelae of natural disaster exposure in the general population. Journal of Traumatic Stress, 13, 661-678.

Buchwald D., Manson S., Dinges N., Keane E. \& Kinzie J.D. (1991). Prevalence of depressive symptoms among established Vietnamese refugees in the United states. Journal of General Internal Medicine, 8, 76-81.

Burnett A.C., Anderson P.J., Cheong J., Doyle L.W., Davey L.W. \& Wood S.J. (2011). Prevalence of psychiatric diagnoses in preterm and full-term children, adolescents and young adults: a meta-analysis. Psychological Medicine, 20;1-12

Burnham K.P. \& Anderson D.R. (2002). Model Selection and Multimodel Inference. Springer, New York.

Cameron A.C. \& Travedi P.K. (1998). Regression Analysis of Count Data. Cambridge University Press: Cambridge.

Cameron A.C. \& Travedi P.K. (2011). Regression-based tests for overdispersion in the Poisson model. Journal of Econometrics, 46, 347-364.

Caracci G. (2008). General concepts of the relationship between urban areas and mental health. Current Opinion on Psychiatry, 21, 385-390. 
Carballo M., Smajkic A., Zeric D., Dzidowska M., Gebre-Medhin J., \& Van Halem J. (2004). Mental health and coping in a war situation: the case of Bosnia and Herzegovina. Journal of Biosocial Science, 36, 463-477.

Carlson E.B. \& Rosser-Hogan R. (1991). Trauma experiences, posttraumatic stress, disassociation and depression in Cambodian refugees. American Journal of Psychiatry, 148, 1548-1551.

Carr C.J., Lewin T.J., Webster R.A., Kenardy J.A., Hazell P.L. \& Carter G.L. (1997). Psychosocial sequelae of the 1989 Newcastle earthquake. exposure and morbidity profiles during the first 2-years post disaster. Psychological Medicine, 27, 167-177.

Centers for Disease Control and Prevention. (2004). Physical health status of world trade center rescue and recovery workers \& volunteers- New York City, July 2002-August 2004. Morbidity and Mortality Weekly Report, 53, 807-812.

Chanda P., Hamainza B., Moonga H.B., Chalwe V., Banda P. \& Pagnoni F. (2011). Relative costs and effectiveness of treating uncomplicated malaria in two rural districts in Zambia: Implications for nationwide scale-up of home-based management. Malaria Journal, 10, 159.

Chanthikul S., Qasim S.R., Mukhopadhyay B. \& Chiang W.W. (2004). Computer simulation of leachate quality by recirculation in a sanitary landfill bioreactor. Environmental Science and Health and Toxicology, Part A, 39, 493-505.

Chia K.S., Jeyaratnam J., Chan T.B. \& Lim T.K. (1990). Airway responsiveness of firefighters after smoke exposure. British Journal of Medicine, 47, 524-527.

Cohen D.A., Farley T.A. \& Mason K. (2003). Why is poverty unhealthy? social and physical mediators. Social Science and Medicine, 57, 1631-1641.

Cohen J. \& Cohen P. (1983). Applied Multiple Regression Correlation Analysis for the Behavioral Sciences. Erlbaum: New Jersey.

Colombatti R., Vieria C.S., Bassani F., Cristofoli R, Coin A., Bertinato L. \& Riccardi F. (2009). Contamination of drinking water sources during the rainy season in an urban post-conflict community in Guinea Bissau: implications for a sanitation priority. African Journal of Medical Sciences, 38, 155-161.

Compton W.M., Thomas Y.F., Stinson F.S. \& Grant B.F. (2007). Prevalence, correlates, disability and comorbidity of DSM-IV drug abuse and dependence in the United States. Archives of General Psychiatry, 64, 566-576.

Conteh L., Engels T. \& Molyneux V. (2010). Socioeconomic aspects of neglected tropical diseases. Lancet, 375, 239-247.

Cornell S.E. (2005). The interaction of narcotics and conflict. Journal of Peace Research, 42, 751-760. 
De Jong K., van der Kam S., Ford N., Hargreaves S., van Oosten R., Cunningham D., Boots G., Adrault A. \& Kleber R. (2007). The trauma of ongoing conflict and displacement in Chechnya: quantitative assessment of living conditions, and psychosocial and general health status among war displaced in Chechnya and Ingushetia. Conflict and Health, 1, 1-13.

Deaton A. (2002). Policy implications of the gradient of health and wealth. Health Affairs, 21, 13-24.

Degenhardt L., Hall W., Werner-Smith M. \& Lynsky M. (2004). Illicit drug use. In Ezzati M, Lopez A.D., Rogers A., \& Murray C.J.L. (eds.). Comparative Quantification of Health Risks: Global and Regional Burden of Disease Attributable to Selected Major Risk Factors, Vol.1. Geneva, Switzerland: World Health Organization, 2004, 1109-1176.

Demyttenaere K., Bruffaerts R, Posada-Villa J., Gasquet I., Kovess V., Lepine J.P., Angermeyer M.C., Bernert S., de Girolamo G., Morosini P., Polidori G., Kikkawa T., Kawakami N., Ono G., Takeshima T., Uda H., Karam E.G., Fayyad J.A., Karam A.N., Mneimneh Z.N., Medina-Mora M.E., Borges G., Lara C., de Graaf R., Ormel J., Gureje O., Shen Y., Huang Y., Zhang M., Alonso J., Haro J.M., Vilagut G., Bromet E.J., Gluzman S., Webb C., Kessler R.C., Merikangas K.R., Anthony J.C., Von Koff M.R., Wang P.S., Brugha T.S., Aguilar-Gaxiola S., Lee S., Heeringa S., Pennell B.E., Zaslavsky A.M., Ustun T.B. \& Chatterji S. (2004). Prevalence, severity and unmet need for treatment of mental disorders in the World Health Organization Mental Health Surveys. Journal of the American Medical Association, 291, 2581-2590.

Di Maggio C. \& Galea S. (2006). The behavioral consequences of terrorism: a meta-analysis. Academic Emerging Medicine,13, 559-566.

Di Maggio C., Galea S. \& Li G. (2009). Substance use and misuse in the aftermath of terrorism, a Baynesian meta-analysis. Addiction, 104, 894-904.

Dockery D.W., Pope C.A., Xu X., Spengler J.D. \& Ware J.H. (1993). An association between air pollution and mortality in six U.S. cities. New England Journal of Medicine, 24, 1753-1759.

Dodge C.P. (1990). Health implications of war in Uganda and Sudan. Social Science and Medicine, 31, 691-698.

Doocy S. \& Burnham G. (2006). Point-of-use water treatment and diarrhea reduction in the emergency context: an effectiveness trial in Liberia. Tropical Medicine and International Health, $11,1542-1552$.

Dudley G. (2005). The ripple effects of terrorism. Journal of the American Osteopathic Society, 105, 533-534.

Dupont W.D. (2009). Statistical Modeling for Biomedical Researchers. Cambridge: Cambridge University Press.

Easterly W. \& Levine R. (1997). Africa's growth tragedy: policies and ethnic divisions. Quarterly Journal of Economics, 112, 1203-50. 
Ebata K. \& Miyaki Y. (1989). A mental health survey of the Vietnamese refugees in Japan. International Journal of Social Psychiatry, 35, 164-172.

Eck K. \& Hultmann L. (2007). One-sided violence against civilians in war: insights from new fatality data. Journal of Peace Research, 44, 233-246.

Elbadwi I. (1999). Civil wars and poverty: the role of external interventions, political rights and economic growth. Paper presented at the World Bank's Conference on "Civil Conflicts, Crime and Violence," February, Washington, DC.

Elo I.T., Martikainen P. \& Smith K.P. (2006). Socioeconomic differentials in mortality in Finland and the United States: the role of education and income. European Journal of Population, 22, 179-203.

Ericksson M., Wallenstein P. \& Sollenberg M. (2003). Armed Conflict 1989-2002. Journal of Peace Research, 40, 593-607.

Esrey S.A., Potash J.B., Roberts L. \& Shiff C. (1991). Effects of improved water supply and sanitation on ascariasis, diarrhoea, dracunculiasis, hookworm infection, schistosomiasis, and trachoma. Bulletin of the World Health Organization, 69, 609-621.

Ezard N., Oppenheimer E., Burton A., Schilperoord M., McDonald D., Adelekan M., Sakarati A. \& van Ommeren M. (2011). Six rapid assessments of alcohol and other substance use in populations displaced by conflict. Conflict and Health, 5, 1-15.

Fagan PW. (1990). World-wide refugees: problems of disruption, fear and poverty. In Holtzman W.H. \& Bornemann T.H. (eds.). Mental Health of Immigrants and Refugees. Austin: Hogg Foundation for Mental Health.

Fan F., Zhang Y., Yang Y., Mo L. \& Liu X. (2011). Symptoms of posttraumatic stress disorder, depression, and anxiety among adolescents following the 2008 Wenchuan earthquake in China. Journal of Traumatic Stress, 24, 44-53.

Fearon J. (2002). Ethnic structure and cultural diversity around the world: a cross-national data set on ethnic groups. Presented at the 2002 Annual Meeting of the American Political Science Association. Washington, DC.

Fearon J.D. \& Laitin D.D. (2003). Ethnicity, insurgency and civil war. American Political Science Review, 97, 75-90.

Fewtrell L., Kaufman R.B., Kay D., Enanoria W., Haller L. \& Colford J.M. (2005). Water, sanitation, and hygiene interventions to reduce diarrhoea in less developed countries: a systematic review and meta-analysis. Lancet Infectious Diseases, 5, 42-52.

Fireman E.M., Lerman Y. \& Ganor E. (2004). Induced sputum assessment in New York City firefighters exposed to World Trade Center dust. Environmental Health Perspectives, 112, 15641569. 
Flourney R. \& Yen I. (2004). The Influence of Community Factors on Health. Oakland, CA: Policy Link.

Fogarty International. (2007). Natural Disasters: Coping with the Health Impact. Washington DC, Disease Control Priorities Project.

Food and Agriculture Organization (FAO), United Nations. (2010). FAOSTAT Statistics Database - FAO. United Nations: New York.

Fussell E. \& Elliott J.R. (2009). Introduction: social organization of demographic responses of disaster: studying population-environment interactions in the case of Hurricane Katrina. Organization and Environment, 22, 379-394.

Gakidou E., Cowling K., Lozano R. \& Murray C.J.L. (2010). Increased educational attainment and its effect on child mortality in 175 countries between 1970 and 2009: a systematic analysis. Lancet, 376, 959-974.

Galea S., Ahern J., Vhalov D., Coffin P.O. \& Fuller C. (2002). Income distribution and risk of fatal drug overdose in New York City neighborhoods. Drug and Alcohol Dependence, 70, 139148.

Galea S. \& Vhalov D. (2005). Urban health: evidence, challenges and directions. Annual Review of Public Health, 26, 341-365.

Gardener W., Mulvey E.P. \& Shaw E.C. (1995). Regression analyses of counts and rates: poisson, overdispersed poisson, and negative binomial models. Psychological Bulletin, 118, 392404.

Gayer M., Legros D., Formenty P. \& Connolly M.A. (2007). Conflict and emerging infectious disease. Emerging Infectious Disease, 13, 1625-1631.

Ghobarah H.A., Huth P. \& Russett B. (2003). Civil wars kill and maim people- long after the shooting stops. American Political Science Review, 97, 189-202.

Ghobarah H.A., Huth P. \& Russett B. (2004a). Comparative public health: the political economy of human misery and well-being. International Studies Quarterly, 48, 73-94.

Ghobarah H.A., Huth P. \& Russett B. (2004b).The post-war public health effects of civil conflict. Social Science and Medicine, 59, 869-884.

Goyet C.V., Marti R.Z. \& Osorio C. (2006). Natural disasters mitigation and relief. In Jamison D.T., Breman J.G., Meashom A.R., Alleyne G., Claeson M., Evans D.B., Jha P., Mills A. \& Musgrove P (eds.). Diseases Control Priorities in Developing Countries, 2nd ed. New York: Oxford University Press.

Grafen A. \& Hails R. (2002). Modern Statistics for Life Sciences. Oxford: Oxford University Press. 
Green B.L. \& Solomon S.D. (1995). The mental health impact of natural disasters and technological disasters in traumatic stress. In Freedy J.R., \& Hobfoll S.E. (eds.), Traumatic Stress: Theory to Practice. New York: Plenum Press.

Greenbough G., McGeehin M., Bernard S.M., Trtanj J., Riad J. \& Engelberg D. (2001). The potential impacts of extreme weather events in the United States. Environmental Health Perspectives, 109,191-198.

Grimwood K. \& Forbes D.A. (2009). Acute and persistent diarrhea. Journal of the Pediatric Clinics of North America, 56, 1343-1361.

Guha-Sapir D. \& van Panhuis W. (2002a) Armed Conflict and Public Health: A Report of Knowledge and Knowledge Gaps. Brussels: WHO Collaborating Center for Research on the Epidemiology of Disasters.

Guha-Sapir D. \& van Panhuis W. (2002b). Mortality Risks in Recent Civil Conflicts: A Comparative Analysis. Brussells: Center for Research on Epidemiology of Disasters.

Guha-Sapir D. \& van Panhuis G. (2003). The importance of conflict-related mortality in civilian populations. Lancet, 361, 2126-2128.

Guha-Sapir D. \& van Panhuis W. (2004). Conflict-related mortality: an analysis of 37 datasets. Disasters, 28, 418-428.

Guha-Sapir D., Vos F., Below R. \& Ponserre S. (2011). Annual Disaster Review. Brussels: UCL Press.

Guha-Sapir D., Hargitt D. \& Hoyois P. (2004). Thirty Years of Natural Disasters, 1974-2000. The Numbers. Brussels: UCL Press.

Gwatkin D.R., Guillot M. \& Heuvaline P. (1999). The burden of disease among the global poor. Lancet, 354, 586-589.

HamiltonW.D. (1964). The genetic evolution of social behavior. In Arthur L.C. (ed.). The Sociobiology Debate. New York: Harper and Row.

Handy S.L., Boarnet M.G., Ewing R. \& Killingsworth R.E. (2002). How the built environment affects physical activity: views from urban planning. American Journal of Preventative Medicine, 23, 64-73.

Hansch S. \& Burkholder B. (1996). When chaos reigns: responding to complex emergencies. Harvard International Review, 18, 53-54.

Hanson B.W., Wodak A., Fiamma A. \& Coates T.J. (2010). Refocusing and prioritizing HIV programmes in conflict and post-conflict settings: funding recommendations. AIDS, 22,1-13. 
Harff B. (2003). No lessons learned from the holocaust? assessing risks of genocide and political mass murder since 1955. American Political Science Review, 97, 57-73.

Harpham T. \& Tanner M. (1995). Features and determinants of urban health status. In Harpham T. \&Tanner M. (eds.). Urban Health in Developing Countries. London: Earthscan Publications Limited.

Hasin D.S., Stinson F.S., Ogburn E. \& Grant B.F. (2007). Prevalence, correlates, disability and comorbidity of DSM-IV alcohol abuse and dependence in the United States. Archives of General Psychiatry, 64, 830-842.

Herbstmann J.B. \& Frank R. (2005). Respiratory effects of inhalation exposure among workers during the clean-up effort at the WTC disaster site. Environmental Research, 99, 85-92.

Hoddie M. \& Smith J.M. (2009). Forms of civil war violence and their consequences for future public health. International Studies Quarterly, 53, 175-202.

Hoeffler A. \& Azam, P. (2002). Violence against civilians in civil wars: looting or terror? Journal of Peace Research, 39, 461-485.

Hoffman J.P. (2009). Generalized Linear Models: An Applied Approach. Cambridge: Cambridge University Press.

Hoffman S.M. \& Oliver-Smith A. (2002). Culture and Catastrophe: The Anthropology of Disaster. Santa Fe: The School of American Research Press.

Holen A. (1993). The north sea oil rig disaster. In Wilson J.P. \& Raphael B. (eds.). International Handbook of Traumatic Stress Syndromes. New York: Plenum.

Hollifield M., Warner T.D., Lian N., Krakow B., Jenkins J., Kesler J., Stevenson J. \& Westermeyer J. (2002). Measuring trauma and health status in refugees. Journal of the American Medical Association, 288, 611-621.

Holman E.A., Silver R.C., Poulin M., Anderson J., Gil-Rivas V. \& McIntosh D.N. (2008). Terrorism, acute stress and cardiovascular health: a 3-year national study following the September $11^{\text {th }}$ attack. Archives of General Psychiatry, 65, 73-80.

Holt B.Y., Eiffler P. \& Brady W. (2003). Planning STI/HIV prevention among refugees and mobile populations: situation assessment of Sudanese refugees. Disasters, 27, 1-15.

Hommer D.W. \& Lemeshow S. (2006). Applied Regression Analyses. New York: John Wiley and Sons.

International Monetary Fund. (2011). Advanced Economies List. New York: International Monetary Fund. 
International Union for the Conservation of Nature (IUCN). (2000). Climate and Conservation. Geneva, Switzerland: IUCN.

Intergovernmental Panel on Climate Change. (2002). Climate Change 2001. Impacts, Adaptations, and Vulnerability. Contribution of Working Group II to the Third Assessment Report of the Intergovernmental Panel on Climate Change. New York: Cambridge University Press.

Iqbal Z. (2006). Health and human security. International Studies Quarterly, 50, 631-649.

Jamison D.T., Mosley W.H., Measham A.R. \& Bobadilla J. (1993). Disease Control Priorities in Developing Countries. New York: Oxford University Press.

Jernigan D.H., Monteiro M., Room R. \& Sexena S. (2000). Toward a global alcohol policy: alcohol, public health and the role of WHO. Bulletin of the World Health Organization, 78, 491499.

Johannesson K.B., Lundin T., Frojd T., Hultman C.M. \& Michel P.O. (2011). Tsunami-exposed tourist survivors: signs of recovery in a 3-year perspective. Journal of Nervous and Mental Disease, 199, 162-169.

Johnsen B.H., Eid J., Lovstad T. \& Michelsen L.T. (1997). Posttraumatic stress symptoms in nonexposed victims and spontaneous rescuers after an avalanche. Journal of Traumatic Stress, $10,133-140$.

Johnson T.P. (1996). Alcohol and drug use among displaced persons: a review. Substance Use and Misuse, 31, 1853-1889.

Jones L., Asare J.B., El Masri M., Moharaj A., Sherief H. \& von Ommeren M. (2009). Severe mental disorders in complex emergencies. Lancet, 374, 654-661.

Joshi P.C., Kaushal S., Aribam B.S., Khattri P., D'Aoust O., Singh M.M., Marx M. \& GuhaSapir D. (2011). Recurrent floods and prevalence of diarrhea among under five children: observations from Bahraich district, Uttar Pradesh, India. Global Health Action, 4, 6355-6362.

Jowett J. (1999). Bucking the trend? health care expenditures in low-income countries 19901995. International Journal of Health Planning and Management, 14, 269-285.

Kerridge B.T., Khan M.R. \& Sapkota A. (2012). Terrorism, civil war, one-sided violence and global burden of disease. Medicine, Conflict and Survival, 28, 199-218.

Kessler R.C., Angermeyer M., Anthony J.C., de Graaf R., Demyttenaere K., Gasquet I., de Graaf G., Guzman S., Gureje O., Haro J.M., Kawakami N., Karam A., Levinson D., Medina Mora M.E., Oakley Browne M.A., Posada-Villa J., Stein D.J., Adley Tsang C.H., Aguilar-Gaxiola S., Alonso J., Lee S., Heeringa S., Pennell B.E., Berglun P., Gruber M.J., Petukhova M., Chatterji S. \& Ustun T.B. (2007). Lifetime prevalence and age-of-onset distributions of mental disorders in 
the World Health Organization's World Mental Health Survey Initiative. World Psychiatry, 6, 168-176.

Keyes E. (2000). Mental health status in refugees: an integrative review of current research. Issues in Mental Health Nursing, 21, 397-410.

Khaw A.J., Salama P., Burkholder B. \& Dondero T.J. (2000). HIV risk and prevention in emergency-affected populations: a review. Disasters, 24, 181-197.

King G., Tomz M. \& Wittenberg J. (2000). Making the most of statistical analyses: improving interpretation and presentation. Journal of Political Science, 44, 341-355.

Kinsella J., Carter R. \& Reid W. (1991). Increased airways reactivity after smoke inhalation. Lancet, 337, 595-597.

Kleinbaum D.G., Kupper L.L., Nizam A. \& Miller K.E. (2008). Applied Regression Analysis and Other Multivariable Methods. Belmont, CA: Duxbury Press.

Kondo H., Seo N., Yasuda T., Hasizume M., Koido Y., Ninomiya N. \& Yamamoto Y. (2002). Post-flood epidemics and infectious disease in Mozambique. Prehospital and Disaster Medicine, 17, 126-133.

Kovats R.S., Campbell-Lendrum D., McMichael A.J., Woodward A. \& Cox J. (2001). Early effects of climate change: do they include changes in vector borne diseases? Philosophical Transactions of the Royal Society of London, 356, 1057-1068.

Kreutz J. \& Eck K. (2011). One-Sided Violence Codebook, Version 1.3. Uppsala, Sweden: Department of Peace and Conflict Research.

Krippner S. \& McIntyre T.M. (2003). The Psychological Impact of War Trauma on Civilians: An International Perspective. London: Prager.

Krug E.G., Dahlber L.L. \& Mercy J.A. (2002). World Report on Violence and Health. Geneva, Switzerland: World Health Organization.

Lacina B. (2009). Battle Deaths Dataset 1946-2005, Codebook for Version 3.0. Oslo, Norway: Center for the Study of Civil War, International Peace Research.

Lacina B. \& Gleditsch N.P. (2005). Monitoring trends in global combat: a new dataset of battle deaths. European Journal of Population, 21, 145-166.

LaFree G., Morris N.A. \& Dugan L. (2009). Cross-national patterns of terrorism. British Journal of Criminology, 52, 1-28.

Levett P.N. (2001). Leptospirosis. Clinical Microbiology, April, 296-326.

Levy B.S. \& Sidel VW (2003). Terrorism and Public Health. New York, NY: Oxford University Press. 
Levy B.S. \& Sidel V.W. (2007). War and Public Health. New York, NY: Oxford University Press.

Levy B.S. \& Sidel V.W. (2009). Health effects of combat: a life course perspective. Annual Review of Public Health, 30, 123-136.

Li Q. \& Wen M. (2005). The immediate and lingering effects of armed conflict on adult mortality: a time-series cross-national analysis. Journal of Peace Resolution, 42, 471-492.

Liao T.F. (1994). Interpreting Probability Models: Logit, Probit and Other Generalized Linear Models. Newbury Park, CA: Sage University Press.

Lieshout M., Kovats R.S., Livermore M.T.J. \& Martens P. (2004). Climate change and malaria: analysis of the SRES climate and socio-economic scenarios. Global Environmental Change, 14, 87-99.

Ligam B.L. (2006). Infectious diseases that pose specific challenges after natural disasters: a review. Pediatric Infectious Diseases, 17, 36-45.

Lockey J.E., Kapil V. \& Wiese N.K. (2007). Man-made vitreous fibers, vermiculate and zeolite. In Rom W.N., \& Markowitz S.B. (eds.). Environmental and Occupational Medicine. Philadelphia: Lippincott, Williams and Wilkins.

Lopez A.D. \& Mathers C.D. (2006a). Global and regional burden of disease and risk factors, 2001: systematic analysis of population health data. Lancet, 367-381.

Lopez A.D. \& Mathers C.D. (2006b). Measuring the global burden of disease and epidemiologic transitions. Annals of Tropical Medicine, 100, 481-499.

Lopez A.D., Mathers C.D., Ezzati M., Jamison D.T. \& Murray C.J.L. (2006). Global Burden of Disease and Risk Factors. Washington DC: World Bank.

Loukas A. \& Hotez P.J. (2006). Chemotherapy for helminth infections. In Bunton L.L., Lazo L. \& Parker K.P. (eds), Goodman and Gillman's the Pharmacological Basis of Therapuetics. New York: McGraw Hill.

Lyttkens C.H. (2003). Time to disable DALYs? on the use of disability-adjusted life years in health policy. European Journal of Health Economics, 4, 195-202.

Mackenbach J.P., Borst V. \& Schols J.M. (1997). Heat-related mortality among nursing home patients. Lancet, 349, 1297-1298.

Majnoni B. \& Ulmann P. (1999). The qualitative performance of the French health care systemevolutions compared to Europe since 1970. Health Science Systems, 3, 123-141.

Marsella A.J. (1998). Urbanization, mental health, and social deviancy. a review of issues and research. American Psychologist, 53, 624-634. 
Marshall G.N., Schell T.L., Elliott M.N., Bethold S.M. \& Chun C.A. (2005). Mental health of Cambodian refugees 2 decades after resettlement in the United States. Journal of the American Medical Association, 3, 571-579.

Masaki M. \& Koizumi A. (1987). Increase in life expectancy at birth in Japan- some implications for variable patterns of decrease in mortality. Health Policy, 7, 41-48.

Mathers C.D. (2006). Uncertainty and Data Availability for Global Burden of Disease Estimates, 2000-2002. Geneva, Switzerland: World Health Organization.

Mathers C.D., Bernard C., Iburg K.M., Inoue M., Fat D.M., Shibuya K., Stein C., Tomijima N. \& Xu H. (2003). Global Burden of Disease in 2002: Data Sources, Methods and Results. World Health Organization.

Mathers C.D., Ma F., Inove M., Rao C. \& Lopez A.D. (2005). Counting the dead and what they died from: an assessment of the global status of cause of death data. Bulletin of the World Health Organization. 83, 171-177.

Mathers C.D., Sadana R., Salomon J.A., Murray C.J.L, Lopez A.D. (2000). Estimates of DALE for 191 Countries: Methods and Results. Geneva, Switzerland: World Health Organization.

Mayberry R.M., Mili F. \& Ofili E. (2000). Racial and ethnic differences in access to medical care. Medical Care Research and Review, 50, 108-145.

McCoy J. (2008). Humanitarian response: improving logistics to save lives. American Journal of Disaster Medicine, 3, 283-293.

McFarlane A.C., Atchison M., Rafalowicz E. \& Papay P. (1994). Physical symptoms in posttraumatic stress disorder. Journal of Psychosomatic Research, 38, 715-726.

McMichael A.J., Ando M., Carcavalla R., Epstein P., Haines A. \& Jendritzitsky G. (1996). Human Population Health. In Watson R.T., Zinyowera M.C. \& Moss R.H. (eds.). Climate Change 1995- Impacts, Adaptations and Mitigation of Climate Change. New York: Cambridge University Press.

McMillen J.C., Smith E.M. \& Fisher R.H. (1997). Perceived benefit and mental health after three types of disaster. Journal of Consulting and Clinical Psychology, 65, 733-739.

Mendez M.A. \& Popkin B.M. (2004). Globalization, urbanization and nutritional change in the developing world. Electronic Journal of Agriculture and Development Econonomics, 1, 220-241.

Milton S. (1986). A sample size formula for multiple regression studies. Public Opinion Quarterly, 50, 112-118.

Mitike G. \& Deressa W. (2009). Prevalence and associated factors of female genital mutilation among Somali refugees in eastern Ethopia: a cross-sectional study. BMC Public Health, 9, 264. 
Mohan V., Mathur P. \& Deepa R. (2008). Urban rural differences in prevalence of self-reported diabetes in India- The WHO-ICMR Indian NCD risk factor surveillance. Diabetes Research and Clinical Practice, 80, 159-168.

Mollica R.M. (1987). The trauma story: the psychiatric care of refugee survivors of violence and torture. In Ochberg F.M. (ed.). Post-traumatic Therapy and the Victims of Violence. New York: Brunner/Mazel.

Molyneux D.H. (2006). Control of human parasitic diseases; context and overview. Advances in Parasitology, 61, 1-45.

Molyneux D.H., Hotez P.J. \& Fenwick A. (2005). Rapid interventions; how policy of integrated control for Africa's neglected tropical diseases could benefit the poor. PLoS Medicine, 2, e336.

Momson J.H. \& Kinnard V. (1993). Different Places, Different Voices. London: Routledge.

Montgomery M., Stren R., Cohen B. \& Reed H. (2003). Cities Transformed: Demographic Change and Its Implications in the Developing World. Washington DC: National Academy Press.

Montalvo J.G. \& Reynal-Querol M. (2005). Ethnic polarization, potential conflict, and civil wars. American Economic Review, 95, 796-816.

Montresor A., Gabrielli A.F., Diarra A. \& Engels D. (2010). Estimation of the cost of large-scale school deowrming programmes with benzimidazoles. Transactions of the Royal Society of Tropical Medicine and Hygiene, 104, 129-132.

Moore P.S., Marfin A.A., Quenemoen L.E., Gessner B.D., Ayub Y.S., Miller D.S., Sullivan K.M. \& Toole M.J. (1993). Mortality rates in displaced and resident populations of central Somalia during 1992 famine. Lancet, 341.

Mueller J. (2009). War has almost ceased to exist. Political Science Quarterly, 124, 297-321.

Murray C.J.L. \& Acharya A.K. (1997). Understanding DALYs. Journal of Health Economics, $16,703-730$.

Murray C.J.L. \& Lopez A.D. (1994). Quantifying disability: data, method and results. Bulletin of the World Health Organization, 72, 481-494.

Murray C.J.L. \& Lopez A.D. (1996a). The Global Burden of Disease. Geneva, Switzerland: World Health Organization.

Murray C.J.L. \& Lopez A.D. (1996b). The Global Burden of Diseases: A Comprehensive Assessment of Mortality and Disability from Diseases, Injuries and Risk Factors in 1990 Projected to 2020. Boston: Harvard School of Public Health.

Murray C.J.L., King G., Lopez A.D., Tomijima N. \& Krug E.G. (2002). Armed conflict as a public health problem. British Medical Journal, 324, 346-349. 
Murthy R.S. (2007). Mass violence and mental health. International Review of Psychiatry, 19, 183-192.

National Consortium for the Study of Terrorism and Response to Terrorism. (2010). Global Terrorism Database Codebook, 1970-2010. College Park, MD. National Consortium for the Study of Terrorism and Response to Terrorism.

Nel P. \& Righarts M. (2008). National disasters and the risk of violent civil conflict. International Studies Quarterly, 52, 159-185.

Nixon J. \& Ulmann P. (2006). The relationship between health care expenditure and health outcomes: evidence and caveats for a causal link. European Journal of Health Economics, 7, 718.

Nobles M. (2000). Shades of Citizenship. Stanford: Stanford University Press.

Norris F.H., Friedman M.J., Watson P.J., Byrne C.M., Diaz E. \& Kaniasty K. (2002). 60,000 disaster victims speak: part I. an empirical review of the empirical literature, 1981-2001. Psychiatry, 65, 207-239.

Norris F.H., Phifer J.F. \& Kaniasty K. (1994). Individual and community reactions to the Kentucky floods: findings from a longitudinal study of older adults. In Ursano R.J., Fullerton C.S. \& McCaughey B.G. (eds.) Individual and Community Response to Trauma and Disaster: The Structure of Human Chaos. Cambridge: Cambridge University Press.

Olson R.S. \& Drury AC. (1997). Untherapeutic communities: A cross-national analysis of postdisaster political unrest. International Journal of Mass Emergencies and Disasters, 15, 5-35.

Ondeko R. \& Purdin S. (2004). Understanding the causes of gender-based violence. Forced Migration Review, 19, 30.

Organization for Economic Co-Operation and Development/Centre de Recherche, d'Etude et de Documentation en Economie de la Santé (OECD/CREDES). (2000). OECD Health Data 2000. A Software Package for International Comparisons of Health Systems. Paris: OECD/CREDES.

Ostby G. \& Urdal H. (2011). Education and Civil Conflict: A Review of the Quantitative, Empirical Literature. Washington, DC: EFA Global Monitoring Report.

Panik M. (2009). Regression Modeling: Methods and Theory. Boca Raton: Taylor and Francis.

Passchier-Vermeer W. \& Passchier W.F. (2000). Noise exposure and public health. Environmental Health Perspectives, 108, 123-131.

Patel R. \& Burke T. (2009). Urbanization- an emerging humanitarian disaster. New England Journal of Medicine, 261, 741-743. 
Patz J.A., Epstein P.R., Burke T.A. \& Balbus J.M. (1996). Global climate change and emerging infectious diseases. Journal of the American Medical Association, 275, 217-223.

Payne L. (1998). Food shortages and gender relations in Ikafe settlement, Uganda. Gender and Development, 6, 30-36.

Pederson D. (2002). Political violence, ethnic conflict, and contemporary wars: broad implications for health and social wellbeing. Social Science and Medicine, 55, 175-190.

Perrin, P. (1996). War and Public Health. Geneva Switzerland: International Committee of the Red Cross.

Phifer J.F. \& Norris F.H. (1989). Psychological symptoms in older adults following natural disaster: nature, timing, duration and course. Journal of Gerontology, 44, 207-217.

Pick W.M. \& Obermeyer C.M. (1996). Urbanisation, household composition and the reproductive health of women in a South African city. Social Science and Medicine, 43, 14311441.

Pierre-Yves C., Pierre O. \& Caroline P. (1999). Health care spending as determinants of health outcomes. Economics of Health Care Systems, 8, 627-639.

Pietrzak R., Goldstein R.B., Southwick S.M. \& Grant B.F. (2011). Prevalence of Axis I comorbidity of full and partial posttraumatic stress disorder in the United States: results from Wave 2 of the National Epidemiologic Survey on Alcohol and Related Conditions. Journal of Anxiety Disorders, 25, 456-465.

Population Reference Bureau. (2002). Human Population: Fundamentals of Growth Patterns of World Globalization.www.prb.org/content/patterns_of_world_urbanization.com.

Porter M., \& Haslam N. (2005). Predisplacement and postdisplacement factors associated with mental health of refugees and internally displaced persons: a meta-analysis. Journal of the American Medical Association, 294, 602-612.

Prezant D.J., Levin S., Kelly K.J. \& Aldrich T.K. (2008). Upper and lower respiratory diseases after occupational and environmental disasters. Mount Sinai, 75, 89-100.

Priebe S., Bogic M., Adjukovic D., Franciskovic T., Galeazzi G.M., Kucukalic A., LecicTosevski D., Morina N., Popovski M., Wang D. \& Schüzwohl N. (2010). Mental disorders following war in the Balkans, a study in 5 countries. Archives of General Psychiatry, 67, 518528.

Produkschap voor Gedistill Dranken. (2006). World Drink Trends, 2006. Henley-on-Thames: NTC Publications Ltd. 
Prüss-üstun A., Kay D., Fewtrell L. \& Bartram J. (2002). Estimating the burden of disease from water, sanitation and hygiene at a global level. Environmental Health Perspectives, 11, 537-542.

Prüss-üstun A., Kay D., Fewtrell L. \& Bartrom J. (2004). Unsafe water, sanitation and hygiene. In Ezzati M., Lopez A.D., Rodgers A. \& Murray C.J.L. (eds.). Comparative Quantification of Health Risks. Geneva: World Health Organization.

Qureshi E.A., Merla V., Steinberg J. \& Rozanski A. (2003). Terrorism and the heart: implications for arrythmogenesis and coronary heart disease. Cardiac Electrophysiology Review, 7, 80-84.

Ramaiah K.D. (2000). The economic burden of lymphatic filariasis in India. Parasitology Today, $16,151-153$.

Ranger T. (1983). The invention of tradition in colonial Africa. In Hobbsbawn E. \& Ranger T. (eds.). The Invention of Tradition. Cambridge: Canto, Inc.

Rashid S.F. (2000). The urban poor in Dhaka City: their struggles and coping strategies during the floods of 1998. Disasters, 24, 240-253.

Raso G., Luginbhul A., Adjouna C.A., Tian-Bi N.T., Silue K.D., Mathys B., Vounatsou P., Wang Y., Dumas M.E., Holmes E., Singer B.H., Tanner M., N'goran E.K. \& Utzinger J. (2004). Multiple parasitic infections and their relationship to self reported morbidity in a community of rural Cote d'Ivoire. International Journal of Epidemiology, 33, 1092-1102.

Remme J.H., Blas F., Chitsulo L., Desjeux P.M., Engers H.D. \& Kanyok T.P. (2002). Strategic emphases for tropical diseases and research: A TDR perspective. Trends in Parasitology, 18, 421-426.

Rehm J., Rehn N., Room R., Monteiro M., Gmel G., Jernigan D. \& Frick U. (2003). Global distribution of average volume of alcohol consumption and patterns of drinking. European Addiction Research, 9, 147-156.

Rehm J., Room R., Monterio M., Graham K., Rehn N., Sempos C.T., Frick U. \& Jernigan D. (2004). Alcohol Use. In Ezzati M., Lopez A.D., Rogers A. \& Murray C.J.L. (eds.). Comparative Quantification of Health Risks: Global and Regional Burden of Disease Attributable to Selected Major Risk Factors, Vol.1. Geneva, Switzerland: World Health Organization, pp. 959-1108.

Reidpath D.D., Allotey P., Kouaume A. \& Cummins R.A. (2003). Measuring health in a vacuum: examining the disability weight of the DALY. Health, Policy and Planning, 18, 351356.

Resnikoff S., Pascolini D., Mariotti S.P. \& Pkharel G.P. (2008). Global magnitude of visual impairment caused by uncorrected refractive errors in 2004. Bulletin of the World Health Organization, 86, 63-70.

Reynal-Querol M. (2002). Ethnicity, Political Systems, and Civil Wars. Journal of Conflict Resolution, 46, 29-54. 
Roberts B., Ocaka K.F., Browne J., Oyok T. \& Sondorp E. (2011). Alcohol disorders among forcibly displaced persons in Northern Uganda. Addictive Behaviors, 36, 870-873.

Roberts J. (1999). Sensitivity of elasticity estimates for OECD health care spending: analysis of a dynamic heterogeneous data field. Health Economics and Econometrics, 8, 459-472.

Rogers D.J. \& Packer M.J. (1993). Vector-borne diseases, models and global climate change. Lancet, 342, 1282-1284.

Ross M.L. (2004a). How do natural resources influence civil war? evidence from 13 cases. International Organization, 58, 35-67.

Ross M.L. (2004b). What do we know about natural resources and civil war. Journal of Peace Research, 41, 337-356.

Sambanis N. (2001). Do ethnic and nonethnic civil wars have the same causes? Journal of Conflict Resolution, 45, 259-282.

Salzman S.H., Moosavy F.M. \& Miskoff J.A. (2004). Early respiratory abnormalities in emergency services police officers at the World Trade Center site. Journal of Occupational and Environmental Medicine, 46, 113-122.

Schnurr P.P. \& Green B.L. (2004). Trauma and Health: Physical Consequences to Extreme Stress. Washington, DC: American Psychological Association.

Schwartz B.S., Harris J.B., Khan A.I., Larocque R.C., Sack D.A., Malek M.A., Faruque A.S.G., Qadri F., Calderwood S.B., Luby S.P. \& Ryan ET. (2006). Diarrheal epidemics in Dhaka, Bangladesh, during three consecutive floods: 1988, 1998 and 2004. Tropical Medicine and Hygiene, 24, 1067-1073.

Shear K.M,, McLaughlin K.A., Ghesquiere A., Gruber M.J., Sampson N.A. \& Kessler RC. Complicated grief associated with Hurricane Katrina. Depression and Anxiety. 2011; 28: 648657.

Shultz A., Omollo J.O., Burke H., Qassim M., Ochieng J.B., Weinberg M., Feikin D.R. \& Breiman R.F. (2009). Cholera outbreak in Kenyan refugee camp: risk factors for illness and importance of sanitation. The American Journal of Tropical Medicine and Hygiene, 80: 640-645.

Sidel V.W. \& Levy BS. (2009). The health consequences of the diversion of resources to war and preparation of war. Social Medicine, 4, 133-135.

Sidel V.W. \& Levy B.S. (2003). War, terrorism and public health. Journal of Law, Medicine and Ethics, 31, 516-523.

Smith AD. (1964). The Ethnic Origins of Nations. New York: Blackwell. 
Spigel P.B., Hering H., Paik E. \& Schilperoord M. (2010). Conflict-affected displaced persons need to benefit from HIB and malaria national strategic plans and global fund grants. Conflict and Health, 4, 1-6.

Stauffer W.M. \& Weinberg M. (2009). Emerging clinical issues in refugees. Current Opinions in Infectious Diseases, 22, 436-442.

Steel Z., Silove D., Brooks R., Momartin S., Aluzairi B. \& Susljik I. (2006). Impact of immigration detention on temporary protection on the mental health of refugees. British Journal of Psychiatry, 188, 58-64.

Stein B. (1986). The experience of being a refugee: insights from the research literature. In Williams C.L. \& Westermeyer J. (eds.). Refugee Mental Health in Resettlement Countries. Washington DC: Hemisphere Publishing Corporation.

Steinmann P., Keiser J., Bos R., Tanner M. \& Utzinger J. (2006). Schistomiasis and water resources in development: systematic review, meta-analysis, and estimates of people at risk. Lancet Infectious Diseases, 6, 411-425.

Stewart F. (2002). Root causes of violent conflict in developing countries. British Medical Journal, 324, 342-345

Stewart F., Brown G. \& Langer A. (2007). Policies Towards Horizontal Inequalities. University of Oxford, Department of International Development: Centre for Research on Inequality, Human Security and Ethnicity.

Stout CE. (2002). The Psychology of Terrorism. London: Praeger.

Strathdee S.A., Zafar T., Brahmbhatt H., Baksh A. \& al Hassan S. (2003). High levels of needle sharing among injection drug users during Afghanistan War. Drug and Alcohol Dependence, 71, $17-24$.

Strathdee S.A., Stachowiak J.A., Toss C.S., al-Delaimy W.K., Wiebel W., Hankins C. \& Patterson T.L. (2006). Complex emergencies, HIB, and substance use: no "big easy" solution. Substance Use and Misuse, 14, 1637-1651.

Sutherst R.W. (1998). Implications of global change and climate variability for vector-borne diseases: generic approaches to impact assessments. International Journal of Parasitology, 14, 297-299.

Takano A., Takano T., Nakamura K. \& Takenuchi S. (1996). Health levels influenced by urban residential conditions-Tokyo. Urban Studies, 33, 879-894.

Theo H. \& Posnett J. (1992). The determinants and effects of health expenditure in developed countries. Journal of Health Economics, 11, 173-181.

Thoms O.N. \& Ron J. (2007). Public health, conflict and human rights: toward a collaborative research agenda. Conflict and Health, 1, 1-12. 
Thornton W.E. \& Voight L. (2007). Disaster rape: vulnerability of women to sexual assaults during Hurricane Katrina. Journal of Public Management and Social Policy, 13, 23-49.

Toole M.J. (1997). The public health aspects of complex emergencies and refugee situations. Annual Review of Public Health, 18, 283-312.

Toole M.J. \& Waldman R.J. (1993). Refugees and displaced persons. Journal of the American Medical Association, 270, 600-605.

Tracy M., Norris F.H. \& Galea S. (2011). Differences in the determinants of posttraumatic stress disorder and depression after a mass traumatic event. Depression and Anxiety, 28, 666-675.

Turnip S.S., Klungsoyr O. \& Hauff E. (2010). The mental health of populations directly and indirectly exposed to violent conflict in Indonesia. Conflict and Health, 30, 4-14.

United Nations. (2005). World Urbanization Prospects: the 2005 Revision. New York: United Nations.

United Nations. (2008). Food and Agricultural Statistics Database. New York: United Nations.

United Nations. (2010). Millennium Goals Report 2010. New York: United Nations.

United Nations. (2011a). Human Development Report. New York: United Nations.

United Nations. (2011b). United Nations Millennium Goals Database. New York: United Nations.

United Nations High Commissioner for Refugees. (1995a). Populations of Concern to UNHCR. A Statistical Overview. Geneva, Switzerland: United NationsHigh Commissioner for Refugees.

United Nations High Commissioner for Refugees. (1995b). The State of the World's Refugees: Fifty Years of Humanitarian Action. Geneva, Switzerland: United Nations High Commissioner for Refugees.

United Nations High Commissioner for Refugees/World Health Organization. (2008). Rapid Assessment of Alcohol and Other Substance Use in Conflict-affected and Displaced Populations: A Field Guide. Geneva, Switzerland: United Nations High Commissioner on Refugees.

United Nations Human Settlement Programmes (HABITAT). (2001). The State of the World's Cities 2001. Nairobi: UN-HABITAT.

United Nations International Drug Control Programme. (1997). World Drug Report. Vienna, Austria: United Nations.

United Nations Office of Drug Control and Crime Prevention. (1999). Global Illicit Drug Trends, 1999. New York:United Nations. 
Utzinger J. \& Keiser J. (2006). Urbanization and tropical health- then and now. Annals of Tropical Medicine and Parasitology, 100, 517-533.

Van der Kolk B.A., McFarlane A.C. \& Weisaeth L. (1996). Traumatic Stress: The Effects of Overwhelming Experience on Mind, Body and Society. New York: Guilford Press.

Van der Kolk B.A., McFarlane A.C. \& Weisaeth L. (1996). Traumatic Stress: The Effects of Overwhelming Experience on Mind, Body and Society. New York: Guilford Press.

Vanhanen T. (1999). Domestic ethnic conflict and ethnic nepotism: a comparative analysis. Journal of Peace Research, 36, 55-73.

Vlahov D. \& Galea S. (2002). Urbanization, urbanicity, and health. Journal of Urban Health, 79, S1-S12.

Vos D. (2000). Risk Analysis: A Quantitative Guide. New York: Wiley and Sons.

Vrijheid M. (2000). Health effects of residence near hazardous waste landfill sites: a review of the epidemiologic literature. Environmental Health Perspectives, 108, 101-112.

Wagner K.D., Brief D.J., Vielhauer M.J., Sussman S., Keane T.M. \& Malow R. (2009). The potential for PTSD, substance use, and HIV risk behavior among adolescents exposed to Hurricane Katrina. Substance Use and Misuse, 44, 1749-1767.

Wallenstein P. \& Sollenberg M. (2001). Armed conflict, 1989-2000. Journal of Peace Research, $38,629-644$.

Waring S.C. \& Brown B.J. (2005). The threat of communicable diseases following natural disasters: a public health response. Disaster Management and Response, 3, 41-45.

Weaver H. \& Roberts B. (2010). Drinking and displacement, a systematic review of the influence of forced displacement on harmful alcohol use. Substance Use and Misuse, 45, 23402355 .

Weine S.M., Vojvoda D., Becker D., McGlashan T., Hodzic E., Laub D., Hyman L., Sawyer M. \& Lazrove S. (1998). PTSD symptoms in Bosnian refugees 1 year after resettlement in the United States. American Journal of Psychiatry, 155, 562-564.

Whalley M.G. (2007). Mental health following terrorist attacks. British Journal of Psychiatry, 190, 94-96.

Williams A. (1999). Calculating the global burden of disease: time for a strategic reappraisal? Health Economics, 8, 1-8.

World Bank. (2009). The Impacts of Refugees on Neighboring Countries: A Development Challenge. Washington DC: World Bank. 
World Health Organization. (1977). International Statistical Classification of Diseases- Ninth Revision (ICD-9). Geneva, Switzerland: World Health Organization.

World Health Organization. (1992). International Statistical Classification of Diseases and Related Health Problems- Tenth Revision (ICD-10). Geneva, Switzerland: World Health Organization.

World Health Organization. (1994). Status Report on Alcohol. Geneva, Switzerland: World Health Organization.

World Health Organization. (1999a). Global Status Report on Alcohol. Geneva, Switzerland: World Health Organization.

World Health Organization. (1999b). World Health Report, 1999. Geneva, Switzerland: World Health Organization.

World Health Organization. (2000). Global Water Supply and Sanitation Assessment 2000 Report. Geneva, Switzerland: World Health Organization.

World Health Organization. (2002a). World Health Report, 2002. Geneva, Switzerland: World Health Organization.

World Health Organization. (2002b). World Report on Road Traffic Injury Prevention. Geneva, Switzerland: World Health Organization.

World Health Organization. (2002c). World Report on Violence and Health. Geneva, Switzerland: World Health Organization.

World Health Organization. (2004a). Disability-Adjusted Life Years by Country, Sex and Age. Geneva, Switzerland: World Health Organization.

World Health Organization. (2004b). Global Status Report on Alcohol, 2004. Geneva, Switzerland: World Health Organization.

World Health Organization. (2006a). Preventing Diseases Through Healthy Environments: Toward an Estimate of the Environmental Burden of Disease. Geneva, Switzerland: World Health Organization.

World Health Organization. (2006b). Violence - A Global Public Health Problem. Geneva, Switzerland: World Health Organization.

World Health Organization. (2007). Maternal Mortality in 2005: Estimates Developed by WHO,UNICEF, UNFPA, and the World Bank. Geneva, Switzerland: World Health Organization.

World Health Organization. (2008a). Safer Water, Better Health. Geneva, Switzerland: World Health Organization.

World Health Organization. (2008b). The Global Burden of Disease: 2004 Update. Geneva, 
Switzerland: World Health Organization.

World Health Organization. (2009). Diarrhea: Why Children Are Still Dying and What Can be Done. Geneva, Switzerland: World Health Organization.

World Health Organization. (2010a). The Atlas on Substance Abuse: Resources for the Prevention and Treatment of Substance Use Disorders. Geneva, Switzerland: World Health Organization.

World Health Organization. (2010b). Working to Overcome The Global Impact of Neglected Tropical Diseases: First Report on Neglected Tropical Diseases. Geneva, Switzerland: World Health Organization.

World Health Organization (2011a). Global Health Observatory Database. Geneva, Switzerland: World Health Organization.

World Health Organization. (2011b). Global Status Report on Alcohol and Health. Geneva, Switzerland: World Health Organization.

World Health Organization. (2011c). Indicator Code Book. World Health Statistics Indicators. Geneva, Switzerland: World Health Organization.

Xu J. \& Liao Q. (2011). Prevalence and predictors of posttraumatic growth among adult survivors one year following 2008 Sichuan earthquake. Journal of Affective Disorders. 133, 274280.

Yehuda R. (2005). Psychological Trauma. Washington, DC: American Psychiatric Press, Inc. 